\title{
Factors that influence the effectiveness of assessment plans in the improvement and sustainment phase in colleges and universities
}

Christopher A. McCullough

West Virginia University

Follow this and additional works at: https://researchrepository.wvu.edu/etd

\author{
Recommended Citation \\ McCullough, Christopher A., "Factors that influence the effectiveness of assessment plans in the \\ improvement and sustainment phase in colleges and universities" (2007). Graduate Theses, \\ Dissertations, and Problem Reports. 2780. \\ https://researchrepository.wvu.edu/etd/2780
}

This Dissertation is protected by copyright and/or related rights. It has been brought to you by the The Research Repository @ WVU with permission from the rights-holder(s). You are free to use this Dissertation in any way that is permitted by the copyright and related rights legislation that applies to your use. For other uses you must obtain permission from the rights-holder(s) directly, unless additional rights are indicated by a Creative Commons license in the record and/ or on the work itself. This Dissertation has been accepted for inclusion in WVU Graduate Theses, Dissertations, and Problem Reports collection by an authorized administrator of The Research Repository @ WVU.

For more information, please contact researchrepository@mail.wvu.edu. 
Factors that Influence

the Effectiveness of Assessment Plans in the

Improvement and Sustainment Phase in Colleges and Universities

\author{
By \\ Christopher A. McCullough
}

B.S. (Arizona State University) 2001

M.A. (Marshall University) 2002

A dissertation submitted to the College of Human Resources and Education

at West Virginia University in partial fulfillment of the requirements

for the degree of

\author{
Doctor of Education \\ in Higher Education Administration
}

Committee Members:

Elizabeth A. Jones, Ph. D., Chair

Ernest Goeres, Ph.D.

Jon Reed, J. D.

Van Dempsey, Ph. D.

Paul Rosier, Ed.D.

Educational Leadership Studies

\title{
Morgantown, West Virginia \\ 2007
}

Keywords: assessment of student learning, improving and sustaining assessment plans, student outcomes assessment 


\section{Abstract \\ Factors that Influence the Effectiveness of Assessment Plans in the Improvement and Sustainment Phase in Colleges and Universities}

\section{Christopher A. McCullough}

Assessment in higher education has become increasingly important throughout the

past 20 years. Institutions of higher education engage in student outcomes assessment for a plethora of purposes.

The researcher conducted this study to investigate current assessment practices at the undergraduate program level. The researcher determined the effectiveness of assessment plans within specific disciplines at institutions that have implemented and sustained their assessment plans. The researcher also identified the degree to which related institutional commitments and resources were provided to support assessment the assessment process. Faculty satisfaction with the assessment plan was also examined. 


\section{Table of Contents}

Chapter One: Introduction and Statement of Problem ......................................... 1

Research Questions .................................................................................. 6

Chapter Two: Review of Literature ............................................................. 9

Chapter Three: Research Design .................................................................. 38

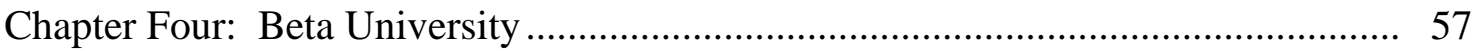

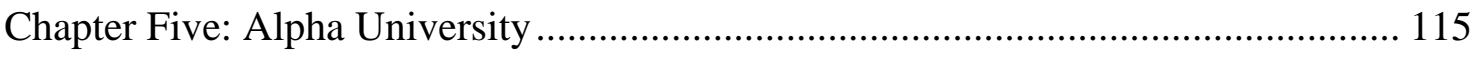

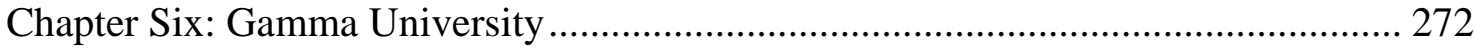

Chapter Seven: Cross Case Analysis ...................................................................... 379

Chapter Eight: Conclusions and Recommendations for Further Study ...................... 453

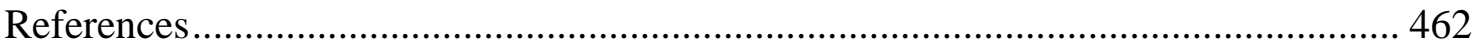

Appendices

Appendix A: Letter Requesting Nominations for Institutions that Have Assessment Plans Within the Sustainment and Improvement Phase........................................................................ 469

Appendix B: Nomination Form for National Assessment Leaders ................ 471

Appendix C: Letter to Request Institutional Site Approval............................ 472

Appendix D: Letter Granting Institutional Agreement to Participate............. 474

Appendix E: Letter Requesting Department Chair/Program

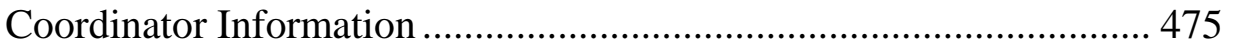

Appendix F: Institutional Assessment Leader Disclosure of Department Chairs/Program Coordinators Form ................................ 476

Appendix G: Department Chair/Program Coordinator Participation Letter Requesting Faculty Nominations....................... 477

Appendix H: Department Chair/Program Coordinator Form for Faculty Nominations 479 
Appendix I: Letter Requesting Faculty Participation ........................................480

Appendix J: Institutional Assessment Leaders/Department Chairs/ Program Coordinators Interview Protocol ...........................................481

Appendix K: Faculty Protocol .......................................................................485

Appendix L: Assessment Plan Effectiveness at the Sustainment and Improvement Phase Document Analysis Protocol ..............................488

Appendix M: Assessment Results Document Analysis Protocol .....................490

Appendix N: Assessment Meeting Minutes Document Analysis

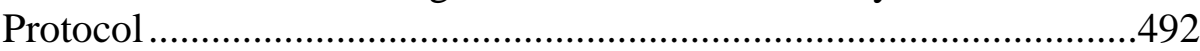

Appendix O: Letter to Request Institutional Site Approval..............................494

Appendix P: Pilot Study Interview Protocol....................................................496 


\section{Tables}

Table 1: Accreditation standards articulated by the Middle States

Commission on Higher Education ......................................................... 12

Table 2: Characteristics of assessment within the planning phase .......................... 20

Table 3: Characteristics of effective statement of intended learning

Outcomes

Table 4: Characteristics of assessment within the implementation phase

Table 5: Characteristics of assessment within the improving and sustaining phase.....

Table 6: Commitments and resources provided to assessment. 32

Table 7: Intended programmatic sample.....

Table 8: Linkage of interview questions and document analysis to the research questions 48

Table 9: Distribution of cognitive domains of intended learning outcomes............... 61

Table 10: Rubric criteria for the first-year writing assessment................................ 62

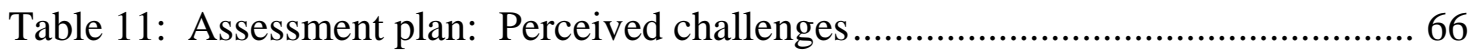

Table 12: Implementation of the current assessment plan: Perceived strengths

Table 13: Central leadership support for assessment: Perceived Strengths 74

Table 14: Frequency of theme emergence pertaining to strengths across items.......... 76

Table 15: Frequency of theme emergence pertaining to challenges across items ....... 77

Table 16: Distribution of cognitive domains of intended learning outcomes............. 81

Table 17: Assessment: Perceived challenges....................................................... 84

Table 18: Assessment plan: Perceived strengths ............................................... 85

Table 19: Implementation of the current assessment plan: Perceived strengths 
Table 20: Participation in assessment decisions: Perceived strengths...................... 91

Table 21: Central leadership support for assessment: Perceived strengths ............... 91

Table 22: Program faculty leadership support: Perceived strengths........................ 92

Table 23: Evaluations and rewards based on student assessment data or involvement: Perceived strengths ..................................................... 93

Table 24: Evaluations and rewards based on student assessment data or involvement: Perceived strengths ........................................................ 94

Table 25: Impact student assessment has had on the program: Perceived

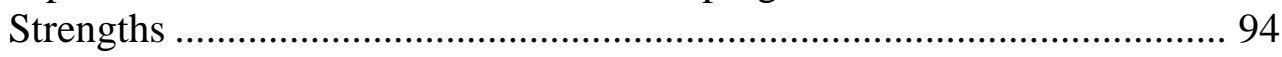

Table 26: Frequency of theme emergence pertaining to strengths across items......... 95

Table 27: Frequency of theme emergence pertaining to challenges across items ....... 96

Table 28: Assessment plan: Perceived strengths .................................................101

Table 29: Assessment plan: Perceived challenges................................................102

Table 30: Implementation of the current assessment plan: Perceived

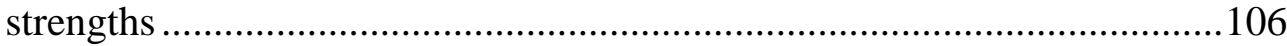

Table 31: Participation in assessment decisions: Perceived strengths.......................108

Table 32: Central leadership support for assessment: Perceived strengths 109

Table 33: Frequency of theme emergence pertaining to strengths across items..........111

Table 34: Frequency of theme emergence pertaining to challenges across items .......113

Table 35: Distribution of intended cognitive learning outcomes..............................120

Table 36: Assessment plan: Perceived strengths .................................................125

Table 37: Implementation of the current assessment plan: Perceived

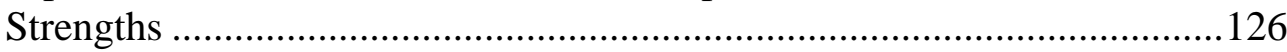

Table 38: Assessment plan: Perceived challenges..............................................127

Table 39: Participation in assessment decisions: Perceived strengths.......................128 
Table 40: Central leadership support for assessment: Perceived

Strengths

Table 41: Program faculty leadership support: Perceived strengths.............................130

Table 42: Professional development for student assessment: Perceived strengths

Table 43: Professional development for student assessment: Perceived challenges

Table 44: Evaluations and rewards based on student assessment data or involvement: Perceived strengths

Table 45: Use of assessment data in making academic decisions:

Perceived strengths 135

Table 46: Frequency of theme emergence pertaining to strengths across items..........136

Table 47: Frequency of theme emergence pertaining to challenges across items .......139

Table 48: Distribution of intended cognitive learning outcomes................................142

Table 49: Assessment plan: Perceived challenges........................................................148

Table 50: Assessment plan: Perceived strengths .........................................................149

Table 51: Implementation of the current assessment plan: Perceived strengths

Table 52: Implementation of the current assessment plan: Perceived Challenges 150

Table 53: Participation in assessment decisions: Perceived strengths .150

Table 54: Central leadership support for assessment: Perceived Strengths 152

Table 55: Program faculty leadership support: Perceived challenges .........................154

Table 56: Program faculty leadership support: Perceived strengths .155

Table 57: Professional development for student assessment: Perceived strengths 
Table 58: Evaluations and rewards based on student assessment data or involvement: Perceived strengths

Table 59: Evaluations and rewards based on student assessment data or involvement: Perceived challenges

Table 60: Use of assessment data in making academic decisions: Perceived challenges

Table 61: Impact student assessment had on the psychology program:

Perceived challenges

Table 62: Impact student assessment had on the psychology program:

Perceived strengths

Table 63: Frequency of theme emergence pertaining to strengths across items..........160

Table 64: Frequency of theme emergence pertaining to challenges across items .......163

Table 65: Distribution of intended cognitive learning outcomes..............................167

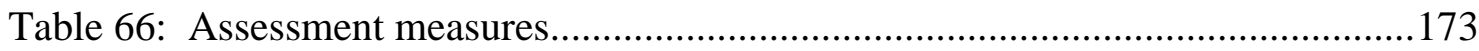

Table 67: Assessment plan: Perceived strengths ................................................178

Table 68: Assessment plan: Perceived challenges .................................................178

Table 69: Implementation of the current assessment plan: Perceived

Strengths

Table 70: Participation in assessment decisions: Perceived strengths.....

Table 71: Central leadership support for assessment: Perceived strengths 184

Table 72: Nursing faculty program leadership support: Perceived strengths 184

Table 73: Nursing faculty program leadership support: Perceived challenges...........185

Table 74: Professional development for student assessment: Perceived Strengths

Table 75: Evaluation and reward based on student assessment data or involvement: Perceived strengths

Table 76: Use of student assessment data in making academic decisions:

Perceived strengths 
Table 77: Impact student assessment had on the nursing program: Perceived Strengths 188

Table 78: Frequency of theme emergence pertaining to strengths across items.......... 189

Table 79: Frequency of theme emergence pertaining to challenges across items ........191

Table 80: Distribution of intended cognitive learning outcomes 194

Table 81: Assessment of the principles of undergraduate learning by biology department faculty. 196

Table 82: Assessment plan: Perceived strengths 197

Table 83: Assessment plan: Perceived challenges.................................................198

Table 84: Implementation of the current assessment plan: Perceived strengths ........202

Table 85: Participation in assessment decisions: Perceived strengths..........................203

Table 86: Participation in assessment decisions: Perceived challenges ......................203

Table 87: Central leadership support for assessment: Perceived strengths .................204

Table 88: Biology program faculty leadership support: Perceived strengths ..............205

Table 89: Biology program faculty leadership support: Perceived challenges............205

Table 90: Evaluations and rewards based on student assessment data or involvement: Perceived challenges................................................................206

Table 91: Use of student assessment data in making academic decisions: Perceived strengths 207

Table 92: Impact student assessment had on the biology program: Perceived Strengths .207

Table 93: Use of student assessment data in making academic decisions:

Perceived challenges 208

Table 94: Participation in assessment decisions: Perceived strengths...........................210

Table 95: Participation in assessment decisions: Perceived challenges ......................213

Table 96: Assessment plan: Perceived challenges.......................................................221 
Table 97: Assessment plan: Perceived strengths 222

Table 98: Implementation of the current assessment plan: Perceived strengths ........226

Table 99: Implementation of the current assessment plan: Perceived strengths ........226

Table 100: Participation in assessment decisions: Perceived strengths .....................227

Table 101: Central leadership support for assessment: Perceived strengths ..............229

Table 102: Central leadership support for assessment: Perceived challenges............229

Table 103: Professional development for student assessment: Perceived strengths...231

Table 104: Frequency of theme emergence pertaining to strengths across items........233

Table 105: Frequency of theme emergence pertaining to challenges across items .....236

Table 106: Distribution of intended cognitive learning outcomes............................241

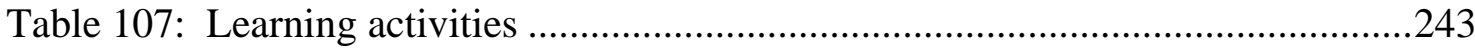

Table 108: Assessment plan: Perceived strengths ..............................................246

Table 109: Assessment plan: Perceived challenges..............................................247

Table 110: Implementation of the current assessment plan: Perceived strengths ......253

Table 111: Implementation of the current assessment plan: Perceived challenges ....254

Table 112: Participation in assessment decisions: Perceived strengths.....................255

Table 113: Central leadership support for assessment: Perceived strengths ..............256

Table 114: Central leadership support for assessment: Perceived challenges............258

Table 115: Secondary education program faculty leadership support:

Perceived strengths

Table 116: Secondary education program faculty leadership support:

Perceived challenges 261

Table 117: Evaluations and rewards based on student assessment data or involvement: Perceived strengths 
Table 118: Evaluations and rewards based on student assessment data or involvement: Perceived challenges 263

Table 119: Use of student assessment data in making academic decisions:

Perceived strengths 264

Table 120: Frequency of theme emergence pertaining to strengths across items........266

Table 121: Frequency of theme emergence pertaining to challenges across items .....268

Table 122: Distribution of intended cognitive learning outcomes............................279

Table 123: Assessment plan: Perceived strengths .................................................288

Table 124: Assessment plan: Perceived challenges..............................................290

Table 125: Implementation of the current assessment plan: Perceived strengths ......298

Table 126: Participation in assessment decisions: Perceived strengths .....................299

Table 127: Central leadership support for assessment: Perceived strengths ..............301

Table 128: Program faculty leadership support: Perceived strengths........................302

Table 129: Professional development for student assessment: Perceived Strengths

Table 130: Evaluation and rewards based on student assessment data or involvement: Perceived strengths 305

Table 131: Use of assessment data in making academic decisions: Perceived Strengths 306

Table 132: Impact student assessment has had on the program: Perceived challenges

Table 133: Frequency of theme emergence pertaining to strengths across items........310

Table 134: Frequency of theme emergence pertaining to challenges across items

Table 135: Distribution of intended cognitive learning outcomes............................316

Table 136: Assessment plan: Perceived challenges.................................................321 
Table 137: Implementation with the current assessment plan:

Perceived strengths 326

Table 138: Participation in assessment decisions: Perceived strengths........................327

Table 139: Central leadership support for assessment: Perceived strengths ...............328

Table 140: Program faculty leadership support for assessment: Perceived Challenges

Table 141: Professional development for student assessment: Perceived strengths

Table 142: Frequency of theme emergence pertaining to strengths across items..........332

Table 143: Frequency of theme emergence pertaining to challenges across items .....333

Table 144: Assessment plan: Perceived strengths ........................................................339

Table 145: Assessment plan: Perceived challenges.........................................................340

Table 146: Central leadership support for assessment: Perceived strengths ...............345

Table 147: Frequency of theme emergence pertaining to strengths across items.........348

Table 148: Frequency of theme emergence pertaining to challenges across items ......349

Table 149: Distribution of intended cognitive learning outcomes.................................352

Table 150: Assessment methods ................................................................................356

Table 151: Assessment plan: Perceived strengths .......................................................360

Table 152: Assessment plan: Perceived challenges......................................................361

Table 153: Implementation of the current assessment plan:

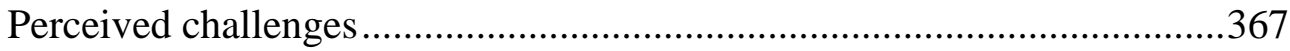

Table 154: Opportunities to participate in policy making:

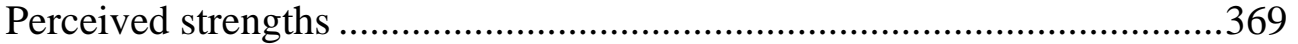

Table 155: Central leadership support for assessment:

Perceived strengths

Table 156: Program faculty leadership support for assessment: Perceived strengths 370 
Table 157: Professional development for student assessment:

Perceived strengths

Table 158: Evaluations and rewards based on student assessment:

Perceived strengths

Table 159: Use of student assessment data in making academic decisions:

Perceived strengths

Table 160: Evaluations and rewards based on student assessment:

Perceived strengths 374

Table 161: Frequency of theme emergence pertaining to strengths across items........375

Table 162: Frequency of theme emergence pertaining to challenges across items .376

Table 163: Program participation by institution .380

Table 164: Participants’ self-reported knowledge of assessment: Across institutions. .380

Table 165: Assessment related research activities: Across institutions. 381

Table 166: Distribution of intended learning outcomes:

Across institutions.

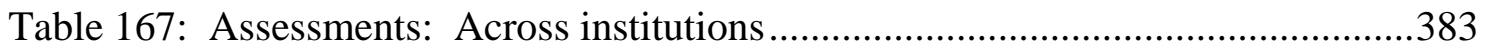

Table 168: Continuously improve programs and services: Across Institutions .........385

Table 169: Accountability to internal stakeholders: Across Institutions ....................388

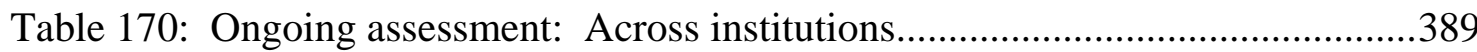

Table 171: Ongoing evaluation and improvement: Across institutions.....................390

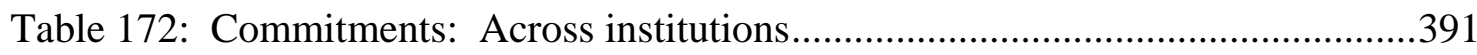

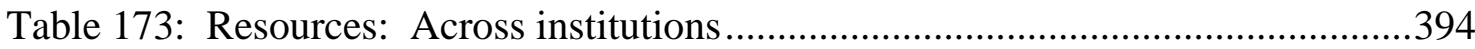

Table 174: Distribution of intended learning outcomes: Mathematics Department. 396

Table 175: Assessments: Mathematics department .396 
Table 176: Continuously improve programs and services: Mathematics

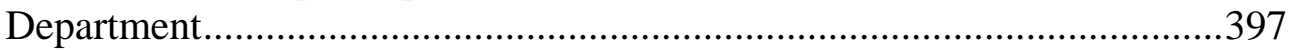

Table 177: Accountability to internal stakeholders: Mathematics department ..........398

Table 178: Ongoing assessment: Mathematics department...................................399

Table 179: Ongoing evaluation and improvement: Mathematics department............399

Table 180: Commitments: Mathematics department ............................................400

Table 181: Resources: Mathematics department ..................................................401

Table 182: Assessment methods: Strengths.....................................................402

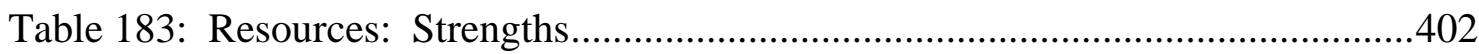

Table 184: Institutional assessment office: Strengths..........................................403

Table 185: Faculty participation: Strengths.......................................................404

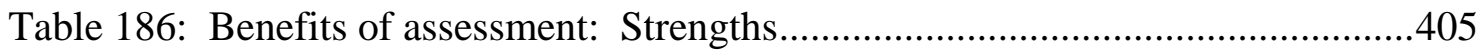

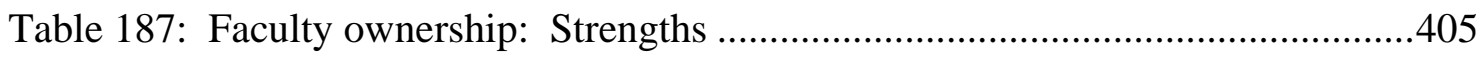

Table 188: Assessment plan: Challenges.............................................................406

Table 189: Assessments: English..................................................................407

Table 190: Continuously improve programs and services: English ........................407

Table 191: Accountability to internal stakeholders: English.................................408

Table 192: Ongoing assessment: English .....................................................408

Table 193: Ongoing evaluation and improvement: English ..................................409

Table 194: Commitments: English ...............................................................409

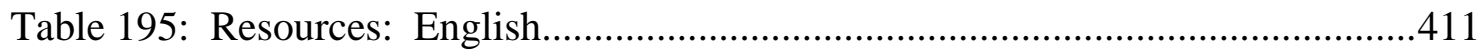

Table 196: Faculty participation: Strengths.....................................................412

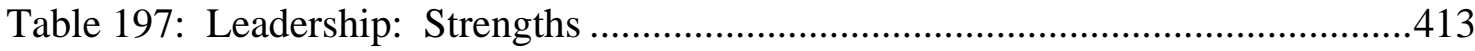


Table 198: Assessment discussions: Strengths ...................................................414

Table 199: Distribution of intended learning outcomes: Psychology ........................415

Table 200: Assessments: Psychology ................................................................416

Table 201: Continuously improve programs and services: Psychology ....................417

Table 202: Accountability to internal stakeholders: Psychology ..............................418

Table 203: Ongoing assessment: Psychology .....................................................418

Table 204: Faculty participation: Strengths .....................................................419

Table 205: Culture that valued assessment: Strengths...........................................420

Table 206: Institutional assessment office: Strengths.........................................421

Table 207: Assessment plan: Challenges..........................................................422

Table 208: Assessments: Secondary education ....................................................424

Table 209: Continuously improve programs and services:

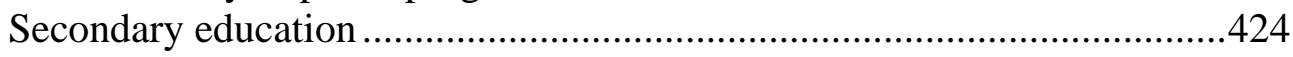

Table 210: Accountability to internal stakeholders: Secondary education.................425

Table 211: Ongoing assessment: Secondary education .........................................425

Table 212: Ongoing evaluation and improvement: Secondary education .................426

Table 213: Commitments: Secondary education ...............................................427

Table 214: Resources: Secondary education .................................................428

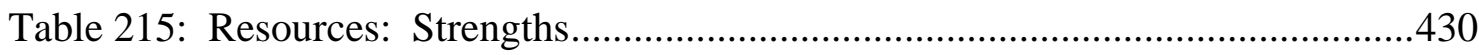

Table 216: Faculty participation: Strengths.....................................................430

Table 217: Benefits of assessment: Strengths.................................................431

Table 218: Assessment discussions: Strengths .................................................432

Table 219: Distribution of intended learning outcomes: Biology ............................433

Table 220: Assessments: Biology ...................................................................434 
Table 221: Accountability to internal stakeholders: Biology .................................435

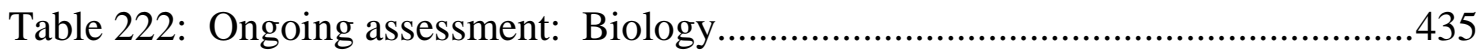

Table 223: Ongoing evaluation and improvement: Biology.................................436

Table 224: Commitments: Biology ...............................................................436

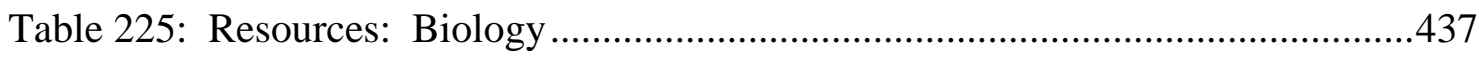

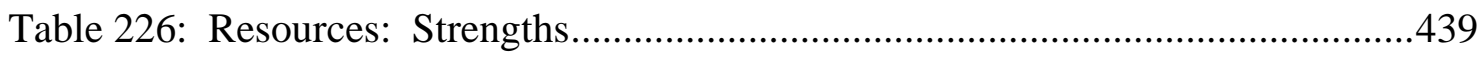

Table 227: Faculty participation: Strengths.....................................................440

Table 228: Assessment plan: Challenges...........................................................441

Table 229: Distribution of intended learning outcomes: Nursing .............................442

Table 230: Assessments: Nursing ................................................................442

Table 231: Continuously improve programs and services: Nursing........................444

Table 232: Ongoing assessment: Nursing......................................................444

Table 233: Ongoing evaluation and improvement: Nursing.................................445

Table 234: Commitments: Nursing...............................................................446

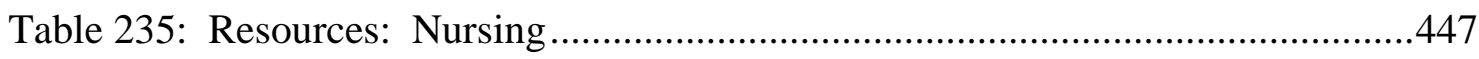

Table 236: Faculty participation: Strengths....................................................449

Table 237: Assessment plan: Strengths ..........................................................450

Table 238: Assessment methods: Strengths......................................................451

Table 239: Assessment plan: Challenges.........................................................451 


\section{Chapter 1}

\section{Problem Statement}

Assessment in higher education has become increasingly important over the past twenty years (Ewell, 2002). The assessment movement in higher education originated as a result of several national reports released in the 1980's pertaining to the state of education in the United States. Concerns pertaining to student learning in public K-12 schools led to the articulation of $A$ Nation at Risk by the National Commission on Excellence in Education in 1983. This report affected higher education and resulted in state legislation (passed in two-thirds of the states) which required public colleges and universities to establish plans to assess student learning (Burke, 2005a).

Recently, accreditation agencies have incorporated assessment measures into their accrediting standards. Huba and Freed (2000) explain the change in the locus of assessment requirements from state-level government bodies to accreditation agencies is an attempt to “...curtail the direct involvement of state legislatures in higher education...” (p. 17). While accreditation provides extrinsic motivation for institutions of higher education to pursue assessment endeavors, many additional external and internal purposes exist for institutions to develop and sustain assessment activities.

\section{External Uses of Assessment Data}

Externally, the importance of assessment manifested as a result of "state-based calls for greater accountability” (Ewell, 2002, p. 8) and accreditation requirements. The increase in state-based accountability is illustrated in a report by Lazerson, Wagenar, and Shumanius (2000). Lazerson, Wagenar, and Shumanius (2000) state: 
During the 1980s the number of states that required public colleges and universities to assess learning outcomes went from near zero to over 40; since 1988, all of the regional and programmatic accreditations have included assessment in their criteria for approval (p. 30).

Consideration of external stakeholders is critical due to the amount of fiscal resources distributed by state agencies. According to Ruppert (1996), 56\% of legislators utilize "reports of how colleges and universities perform on specific measures related to such areas as access, quality or efficiency” (p. 32) in determining higher education appropriations. The importance of legislative decision making is predicated on state funding allocations for institutions of higher education. The National Center for Higher Education Management Systems (NCHEMS, 2002a) reports that in 2005 the average state appropriation provided to each full-time equivalent student enrolled in public institutions of higher education was 6,241 dollars.

According to Ewell (2002), accreditation agencies are the primary motivation for institutions of higher education to engage in assessment activities. As a result of this involvement, accreditation agencies began to “...require member institutions to conduct outcomes assessment in order to maintain their status as accredited institutions” (Huba and Freed, 2000, p. 17). According to Ratcliff, Lubinescu, and Gaffney (2001) all of the major regional accrediting bodies have developed “....initiatives aimed at enhancing educational quality, promoting greater collaboration among accrediting bodies and institutions, and emphasizing the assessment of student learning outcomes” (p. 13). The importance of successful accreditation candidacy is predicated on institutional qualifications for student federal assistance. The United States Department of Education 
(n.d.), utilizes institutional accreditation as "one of several considerations used as a basis for determining eligibility for federal assistance.” NCHEMS states (2002b), "Federal Pell Grants are the largest source of aid [provided] to students who need assistance in financing higher education” (Federal Pell Grant Awards, para. 2). In 2001, over 3.7 million recipients of Federal Pell Grants were awarded a total of nearly 7.5 billion dollars in assistance (NCHEMS, 2002c). While assessment data is critical to securing state appropriations and federal assistance to students, studies indicate that assessment data is also utilized for internal purposes.

Internal Uses of Assessment Data

Internally, assessment data is utilized for continuous programmatic and institutional quality improvement through the measurement of student achievement, the promotion of learning, and program review (Huba \& Freed, 2000). Effective assessment practices of a plan within the improvement and sustainment phase necessitate the use of assessment data “...to continuously improve programs and services” (Banta, 2002, p. 276). A study conducted by Peterson, Einarson, Augustine, and Vaughn (1999) discovered that institutions reported assessment data influences the institutional decision making process pertinent to the student assessment plan, academic support services, academic program, general education curriculum, and pedagogy.

Assessment Defined

Huba and Freed (2000) define assessment as a:

process of gathering and discussing information from multiple and diverse sources in order to develop a deep understanding of what students know, understand, and can do with their knowledge as a result of their educational 
experiences; the process culminates when assessment results are used to improve subsequent learning (p. 19).

Measuring student achievement effectively necessitates the utilization of an assessment plan that includes statements of intended learning outcomes, assessment measures, experiences leading to intended learning outcomes, and a means by which assessment results will be utilized to improve learning (Huba and Freed, 2000). For the purpose of this study, the assessment framework must incorporate the institutional and programmatic levels.

Characteristics of an Effective Assessment Plan

Banta (2002) articulates a framework of effective assessment plans that accounts for three key stages of the assessment process. The three sequential stages of an effective assessment process include (1) planning, (2) implementing, and (3) improving and sustaining. This research study focuses on those institutions within the improving and sustaining assessment phase. According to Banta (2002), an effective assessment process will continuously improve and sustain when it:

- $\quad$ produces credible evidence of learning and maintains organizational effectiveness,

- ensures that assessment data are used continuously to improve programs and services,

- provides a vehicle for demonstrating accountability to stakeholders within and outside the institution,

- encompasses the expectation that outcomes assessment will be ongoing, not episodic, and 
- incorporates ongoing evaluation and improvement of the assessment process itself (p. 263).

\section{Relationship Between Assessment and Institutional Commitments/Resources}

Assessment is a critical practice on today’s college campus. The internal and external purposes for collecting assessment data directly affect programmatic and institutional quality improvement and fiscal survival. Development and maintenance of an effective assessment plan necessitates institutional commitment. Faculty development programs, time, and fiscal resources are required to sustain and improve the assessment plan. In a study conducted by March (In Gilbert, 1995) the researcher hypothesized that faculty involvement is dependent upon resources, perceived value of the innovation of assessment, and communication. Grunwald and Peterson (2003) found that fiscal resources, time, and administrative support are all critical to the success of large assessment endeavors.

Even though institutional budgets may be shrinking or cut each year, administrators should allocate sufficient resources to efficiently accomplish sustainment and improvement goals. Such resources typically include reducing faculty teaching loads so that faculty can address program or institutional assessment goals as well as hiring competent personnel to work on a regular basis to sustain assessment initiatives. Assessment leaders must understand the effect various assets have on the sustainment and improvement process of assessment. Therefore, understanding the relationship between various resources and the assessment process will ensure that the appropriate assets are being dispersed effectively. 
Purpose of the Study

The purpose of this study is to investigate current assessment practices at the undergraduate program level. This study will determine the effectiveness of assessment plans within specific disciplines at institutions that have implemented and sustained their assessment plans. The study will also identify the degree to which related institutional commitments and resources are provided to support assessment the assessment process. Faculty satisfaction with the assessment plan will examined.

\section{Research Questions}

1. Does the assessment plan and its implementation demonstrate characteristics of effective practice?

a. How does the assessment plan produce credible evidence of learning?

b. How is assessment data used to continuously improve programs and services?

c. How does the assessment plan provide a vehicle for demonstrating accountability to internal stakeholders?

d. How does the assessment plan encompass the expectation that outcomes assessment will be ongoing and not episodic?

e. How does the assessment plan incorporate ongoing evaluation and improvement of the assessment process itself?

2. What institutional resources are provided for the sustainment of the assessment process?

a. Are these resources sufficient to support the assessment process? 
b. What institutional resources are lacking or missing for the assessment endeavor?

3. How satisfied are faculty members with the student assessment process within their programs?

a. What factors are associated with faculty satisfaction regarding the assessment endeavor?

b. What factors reduce faculty satisfaction with the assessment endeavor?

Significance of the Study

This study will evaluate the assessment programs of institutions noted by assessment experts as maintaining exemplary assessment plans. Examination of program assessment plans within each participating institution will yield the state of the art assessment practices utilized to achieve student learning assessment within the sustainment and improvement phase. Identification of institutional commitments and funds required to improve assessment plans will assist administrators in the identification of appropriate resources to sustain the assessment process. An examination into faculty satisfaction with the assessment process within their academic programs will help administrators understand how to promote faculty ownership of assessment and their on-going commitment to this endeavor over time.

\section{Summary}

Recent developments pertinent to higher education have increased the importance of institutional and programmatic assessment. Assessment data is utilized by internal and external constituencies. Externally, assessment data is analyzed by agencies that appropriate funds and act as screening mechanisms for state funding and federal 
assistance (accreditation). Thus, legislative funding decisions may be predicated on assessment data (Ruppert, 1996). Additionally, institutions of higher education engage in assessment activities to satisfy the requirements of accrediting agencies (Banta, 2002).

Internally, institutions can utilize assessment data for a plethora of purposes. Internal purposes for maintaining an assessment plan include continuous quality improvement and more effective institutional planning and decision making. Maintaining an effective assessment plan, as defined by Banta (2002), requires institutional commitments and an organizational culture that values assessment. Thus, this study will evaluate the assessment plans and process in accordance to Banta’s characteristics of effective assessment during the improvement and sustainment phase, identify the institutional resources provided for assessment, and determine how satisfied faculty are with their program assessment endeavors. 


\section{Chapter 2}

\section{Literature Review}

\section{External Accountability: Required Assessments}

Accreditation. Externally, assessment data is utilized for a plethora of purposes. According to Kuh (2005), “...all [of] the regional accrediting associations and many field-specific organizations expect institutions to provide evidence of student learning and other measures of the quality of the student experience” (p. 149). Van Vught (1994) claims "accreditation may be the most fully developed institutionalization of the idea of accountability in higher education” (p. 6). The purposes of accreditation in the United States include:

- fostering excellence through the development of criteria and guidelines for assessing effectiveness,

- encouraging improvement through ongoing self-study and planning,

- ensuring external constituents that a program has clearly defined goals and appropriate objectives, maintains faculty and facilities to attain them, demonstrates it is accomplishing them, and has the prospect for continuing to do so,

- providing advice and counsel to new and established programs in the accrediting process, and

- ensuring that programs receive sufficient support and are free from external influence that may impede their effectiveness and their freedom of inquire (van Vught, 1994, p. 6). 
Two of the five above purposes of accreditation emphasize the importance of assessment activities in order for institutions of higher education to maintain or acquire accreditation. The desire of institutions of higher education to maintain accreditation is predicated on their eligibility for federal assistance. The Veterans Readjustment Act passed by Congress in 1952 utilized accrediting agencies as a mechanism to eradicate fraudulent activities that occurred as a result of the World War II veterans benefit program (Profit, 1979).

In 2002 the Middle States Commission on Higher Education increased its emphasis on assessment within its standards for accreditation (Middle States Commission on Higher Education, 2002). Three of the standards for accreditation as articulated by the Middle States Commission on Higher Education (2002) directly relate to assessment. These standards include

- institutional assessment,

- assessment of student learning, and

- institutional resources.

According to the Middle States Commission on Higher Education (2002), institutional assessment requires that:

The institution has developed and implemented an assessment plan and process that evaluates its overall effectiveness in:

- achieving its mission and goals;

- implementing planning, resource allocation, and institutional renewal processes;

- using institutional resources efficiently; 
- providing leadership and governance;

- providing administrative structures and services;

- demonstrating institutional integrity; and

- assuring that institutional processes and resources support appropriate learning and other outcomes for its students and graduates (Middle States, p. x).

The assessment of student learning requires demonstration "that the institution's students have knowledge, skills, and competencies consistent with institutional goals and that students at graduation have achieved appropriate higher education goals” (Middle States Commission on Higher Education, p. xi). Application of the standard of institutional resources requires outcomes assessment in order to effectively and efficiently allocate institutional resources (Middle States Commission on Higher Education, 2002). Additional standards indirectly relate to outcomes assessment via strategic planning. The standards for accreditation articulated by the Middle States Commission on Higher Education (2002) are illustrated in Table 1.

Performance reporting, performance funding, and performance budgeting each provide a means for state agencies to require accountability (Callan \& Finney, 2005). Burke (2005b) states "in spite of problems, performance funding, budgeting, and especially reporting remain the most used approaches in the states to the new accountability for results” (p. 239). At a minimum, one form of the aforementioned accountability mechanisms is employed in every State in the Union. 
Table 1

Accreditation standards articulated by the Middle States Commission on Higher Education

\begin{tabular}{|l|l|}
\hline \multicolumn{1}{|c|}{ Institutional Context } & \multicolumn{1}{c|}{ Educational Effectiveness } \\
\hline Standard 1: Mission, Goals, and Objectives & Standard 8: Student Admissions \\
\hline $\begin{array}{l}\text { Standard 2: Planning, Resource Allocation, } \\
\text { and Institutional Renewal }\end{array}$ & Standard 9: Student Support Services \\
\hline Standard 3: Intuitional Resources & Standard 10: Faculty \\
\hline Standard 4: Leadership and Governance & Standard 11: Educational Offerings \\
\hline Standard 5: Administration & Standard 12: General Education \\
\hline Standard 6: Integrity & $\begin{array}{l}\text { Standard 13: Related Educational } \\
\text { Activities }\end{array}$ \\
\hline Standard 7: Institutional Assessment & $\begin{array}{l}\text { Standard 14: Assessment of Student } \\
\text { Learning }\end{array}$ \\
\hline
\end{tabular}

Performance reporting. According to Burke (2005b), “performance reporting relies on publicity to push colleges and universities to pursue state priorities and improve institutional performance. It rests on the assumption that institutions and individuals perform better when they know their results will become public” (p. 218). Reports are typically disseminated to “...governors, legislators, and campus leaders, and they increasingly appear on the web sites of coordinating or system boards and individual institutions” (Burke, 2005b, p. 218). Performance reporting programs do not directly influence budget allocations; however, the information contained within the reports frequently influences budget allocations indirectly (Burke, 2005b). Burke and Minassians (2002) state, “although [performance reporting] has no official connection to budgeting, State Higher Education Finance Officers claimed [in 2002] that coordinating or system governing boards in $47 \%$ of the states with performance reports consider the results when making campus allocations” (p. 12). According to Burke and Minassians 
(2002), eighty-eight percent of the states maintained a performance reporting program in 2002.

Performance funding. Performance funding developed in Tennessee in 1979 (Banta, Rudolph, Van Dyke, \& Fisher, 1996). The performance based funding program established by the Tennessee Higher Education Commission:

...instituted a policy that gave public two- and four-year institutions an opportunity to earn a budget supplement of up to two percent of the instructional component of its education and general budget for carrying out the following activities:

- obtaining accreditation for accreditable academic programs;

- testing graduating students in their major fields and in general education using externally developed examinations, and - for additional credit - demonstrating that graduates score at or above national averages on these test;

- surveying enrolled students, recent graduates, and/or community members/employers to assess their satisfaction with the institution's academic program and student services; and

- conducting peer reviews of its academic programs (p. 23).

For individual public colleges and universities their own budgets are tied to state funding and specific indicators of institutional performance (Burke, 2005b). According to Burke (2005b):

it focuses on the distribution phase of the budget process. The relationship between funding and performance is tight, automatic, and formulaic. If a public college or university achieves a prescribed target or an improvement level on 
defined indicators, it receives a designated amount or percentage of state funding (p. 219).

According to Burke and Minassians (2002), thirty-six percent of the states maintained a performance funding program in 2002.

Performance budgeting. Performance budgeting is similar to performance funding; however, the distribution of assets is not as tightly connected. Performance budgeting utilizes performance indicators to assist governors, legislators, and higher education boards in the process of allocating assets, but it does not utilize performance indicators exclusively to distribute assets. According to Burke (2005b): performance budgeting allows governors, legislators, and higher education boards to consider campus achievement on performance indicators as one factor in determining allocations for public colleges and universities. Performance budgeting concentrates on budget preparation and presentation and often neglects, or even ignores, the distribution phase of budgeting. In performance budgeting the possibility of additional funding due to good or improved performance depends solely on the judgment and discretion of state, coordinating, or system officials (p. 219).

Research conducted by Burke and Minassians (2002) revealed that fifty-two percent of the states maintained a performance budgeting program in 2002.

\section{Internal Uses of Assessment Data}

Strategic planning. Internally, assessment data can be utilized “...in many areas of institutional planning and decision making” (Peterson \& Einerson, 2001, p. 634). Aloi (2004), emphasized the use of assessment data in decision making. Aloi identified 
several areas pertinent to strategic planning that utilized assessment data. Aloi found that assessment data is utilized in strategic plans in the following areas:

- academic curriculum,

- human resource decisions,

- facilities planning,

- student life programming,

- residence hall programming,

- religious life opportunities

- enhancement of service-learning experiences,

- electronic portfolio of student learning, and

- improvements to administrative processes.

A study conducted by Peterson, Einarson, Augustine, and Vaughn (1999) identified institutional variables that relate to the utilization of student assessment data for decision making. The researchers found that significant predictor variables to the use of assessment data for academic decision making for master's institutions were

- the extent of student assessment conducted by the institution;

- whether the institution conducts assessment for internal improvement;

- the number of people who have access to student assessment information;

- student enrollment;

- the total number of institutional studies linking students' performance to their interaction with the institution;

- the extent to which the academic budgeting process considers student assessment efforts and results; 
- the level of student [involvement in student assessment]; and

- the level of student affairs personnel involvement in student assessment (Peterson, et al., 1999, p. 29).

Predictor variables for doctoral and research intuitions were substantially different. The researchers found that significant predictor variables to the use of assessment data for academic decision making for doctoral and research institutions were

- the extent to which the institutions provide professional development on student assessment to faculty, administrators, and staff;

- the extent to which faculty are evaluated on participating in and using results of student assessment;

- the number of institutional studies relating students' performance to their interactions with the institutions;

- the importance of internal improvement as a purpose for conducting student assessment;

- the level of administrative and faculty support for student assessment;

- $\quad$ the level of student involvement in student assessment; and

- the extent to which the mission emphasizes undergraduate education and student assessment (Peterson, et al. 1999, p. 29).

However, Peterson, et al. (1999), state that many institutions of higher education “....are not aware of how influential [assessment] data is...” (p. 4).

Programmatic and institutional quality improvement. Additionally, assessment data should also be used for continuous programmatic and institutional quality improvement through the measurement of student achievement, the promotion of learning, and 
program review (Huba \& Freed, 2000). Literature synthesized by Shipman (2003) indicated that "numerous scholars and assessment practitioners note the importance of using assessment results for the purposes of continuous programmatic and institutional improvement” (p. 45). Angelo (1999) maintains that assessment “...should be first and foremost about improving student learning and secondarily about determining accountability for the quality of learning produced” (Angelo, para. 1). Peterson and Vaughn (2002) found that two of the three most common reasons institutions of higher education engage in student assessment is to improve student achievement and strengthen academic programs.

Levels of Assessment

Student level assessment. Student learning can be assessed for individual students at the course level (where results are aggregated), at the program level, and at the institutional level. Terenzini (1989) describes student assessment within courses as a process in which "students receive regular feedback on their knowledge and skill development, and teachers use the same information to shape their teaching strategies, activities and styles as well as to guide individual student learning” (p. 647). Student assessment directly effects student achievement within a course.

Course level assessment. Course level assessment examines the cumulative results of student performance within specific courses. Course outcomes are assessed at this level. In addition to data collected from projects, exams, or other assessment activities, classroom assessment techniques may be utilized determine what students are learning. The Middle States Commission on Higher Education (2003) illustrates typical course 
level assessments as “...writing samples, presentations, artistic performances, and exhibits...” (p. 30).

According to the Middle States Commission on Higher Education (2002):

The assessment of learning outcomes at the program or intuitional level is likely to be reflected in an aggregation or a synthesis of course-level assessments, including capstone courses, and may incorporate data from such additional measures as professional licensure examinations” (p. 51).

Program level assessment. Plomba and Banta (1999) define program assessment as a "comprehensive, systematic process that defines goals for student learning and then provides evidence or data indicating that a program has achieved these goals” (p. 53). According to Maki (2004), program assessment encompasses “department, divisions, schools, or services within an institution” (p. 2). Programmatic outcomes are assessed at this level.

Institutional level assessment. Institutional assessment is "based on a college's or university’s mission statement, educational philosophy, or educational objectives” (Maki, 2004, p. 2). Institutional assessment provides data that assists administrators in determining how effectively students are acquiring the skills identified within the mission and educational outcomes. According to the Middle States Commission on Higher Education (2003):

An institution may wish to demonstrate that certain goals expressed in its mission were achieved through exposure to the entirety of its curriculum and co-curricular experiences. For example, it may wish to show that regardless of program or major, which co-curricular activities students have participated in, and whether 
students were residents or commuters, they exhibit cultural sensitivity and global cultural and geographical awareness (p. 30).

\section{Characteristics of Effective Outcomes Assessment}

Banta (2002) defines three phases of assessment plans. Effective outcomes assessment necessitates a planning phase, an implementation phase, and an improving and sustaining phase. Each phase consists of four to six characteristics.

Planning phase. Assessment plan development begins in the planning phase (see Table 2). There are five major characteristics of effective practice that should be implemented. Input from pertinent stakeholders is necessary within this phase of assessment plan development in order to facilitate faculty buy-in, establish faculty ownership and to ascertain information from various members of the campus community (Banta, 2002). The need for faculty buy-in and ownership of the assessment plan is emphasized in the Hallmarks of Successful Programs to Assess Student Academic Achievement as articulated by the North Central Association (NCA) - Commission on Institutions of Higher Education (In Huba \& Freed, 2000). According to the Principles of Good Practice for Assessing Student Learning established by the American Association of Higher Education (AAHE) (In Huba \& Freed, 2000), assessment will promote greater improvement when “...representatives from across the campus community are involved” (p. 67). A major research study by Jones and Voorhees (2002) supports the need for stakeholder participation. Emergent themes from case studies illustrate that institutions engaged in strong practices of assessment enable "the appropriate stakeholders [to] fully participate in identifying, defining, and reaching a consensus about important competencies” (Jones \& Voorhees, p. 22). 
Table 2

Characteristics of assessment within the planning phase

\begin{tabular}{|l|r|}
\hline Stage & Characteristic \\
\hline Planning & $\bullet \begin{array}{l}\text { Effective assessment utilizes input from pertinent stakeholders in } \\
\text { order to facilitate faculty buy-in, establish faculty ownership and to } \\
\text { ascertain information from various members of the campus } \\
\text { community }\end{array}$ \\
\cline { 2 - 3 } & $\bullet \begin{array}{l}\text { Effective assessment is initiated when the need to ascertain } \\
\text { assessment data is recognized }\end{array}$ \\
\cline { 2 - 3 } & $\begin{array}{l}\text { Effective assessment has clear purposes that pertain to goals of } \\
\text { value }\end{array}$ \\
\cline { 2 - 3 } & $\begin{array}{l}\text { Effective assessment is predicated on “...clear, explicitly stated } \\
\text { program objectives” (Banta, 2002, p. 262) }\end{array}$ \\
\hline
\end{tabular}

Assessment should be initiated when the need to ascertain assessment data is recognized (Banta, 2002). Due to the time requirements of assessment plan development, “sufficient time for development” must be provided (Banta, 2002, p. 262). Recognition of the need of assessment may be predicated on accreditation requirements, budgeting/funding requirements, institutional planning and decision making data needs, and programmatic improvements.

The articulated plan itself should have clear purposes that pertain to goals of value to the educational community (Banta, 2002). According to AAHE’s Principles of Good Practice (In Huba \& Freed, 2000), “Assessment is most likely to lead to improvement when it is part of a larger set of conditions that promote change” (p. 67). The NCA's Commission on Institutions of Higher Education supports this characteristic by recognizing that "successful assessment leads to improvement” (In Huba \& Freed, 2000, p. 67). 
The final characteristic of assessment plans within the planning phase necessitates that assessment is predicated on “...clear, explicitly stated program objectives” (Banta, 2002, p. 262). The Principles of Good Practice advocated by the AAHE state "assessment works best when the programs it seeks to improve have clear, explicitly stated purposes” (In Huba \& Freed, 2000, p. 67). According to Maki (2004), "Helpful in developing outcome statements are taxonomies that classify the cognitive, behavioral, and affective domains of learning and identify levels of learning through verbs that capture that learning” (p. 63). Eight characteristics form the basis effective intended learning outcomes (see Table 3) (Huba \& Freed, 2000, p. 98).

Table 3

Characteristics of effective statement of intended learning outcomes

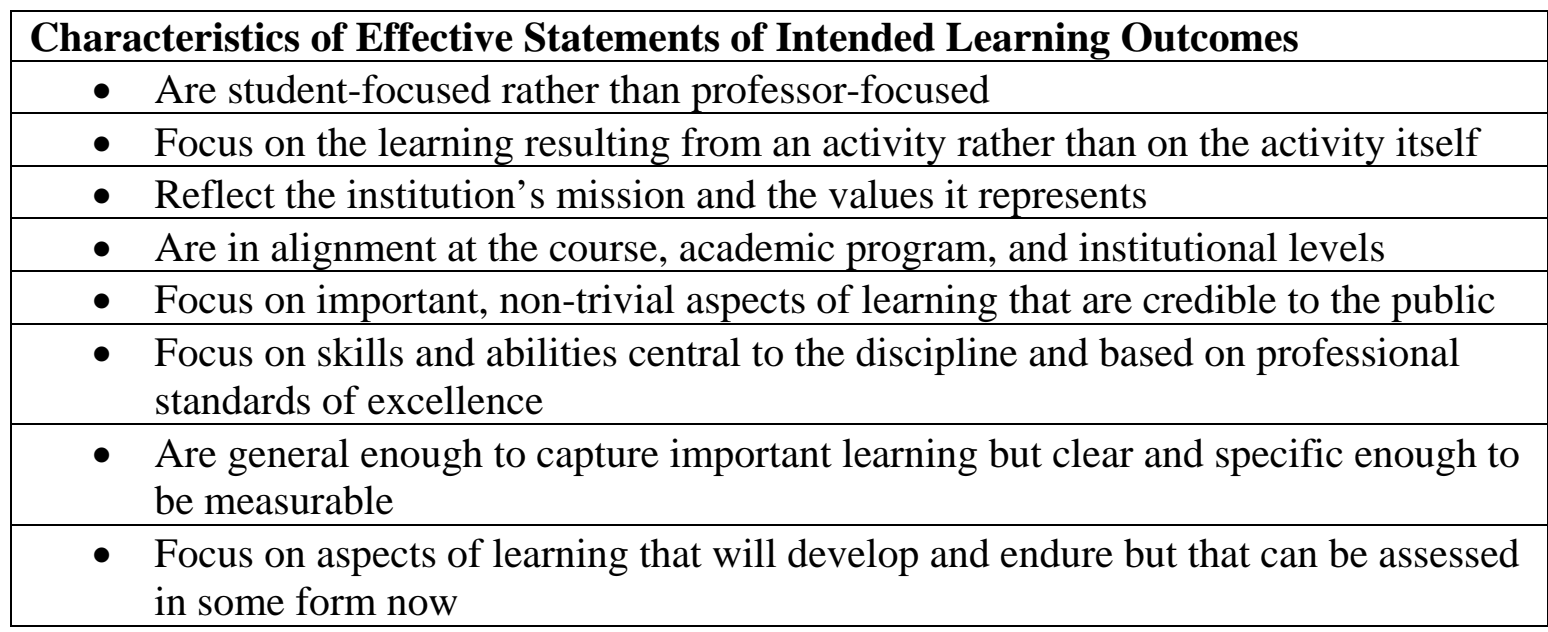

A major research study by Jones and Voorhees (2002) supports the need for clearly defined and understood competencies. Emergent themes from case studies illustrate that institutions engaged in strong practices of assessment articulate "competencies [that] are clearly defined, understood, and accepted by relevant stakeholders” (Jones \& Voorhees, 2002, p. 22). Additional principles articulated by Jones and Voorhees (2002) as an 
illustration of emergent themes indicate that institutions engaged in strong practice define competencies "at a sufficient level of specificity [so] that they can be assessed" and sufficiently clear to be accepted "by relevant stakeholders” (p. 22).

Implementation phase. After the assessment plan is established, it must be implemented. Banta (2002) has articulated eight characteristics that are representative of an assessment plan within the implementation phase (see Table 4).

Table 4

Characteristics of assessment within the implementation phase

\begin{tabular}{|c|c|}
\hline Stage & Characteristic \\
\hline \multirow[t]{8}{*}{ Implementation } & $\begin{array}{l}\text { - Effective assessment requires “knowledgeable and effective } \\
\text { leadership” (Banta, 2002, p. 262) }\end{array}$ \\
\hline & $\begin{array}{l}\text { - Effective assessment requires an appreciation for the need to } \\
\text { facilitate assessment endeavors as it is “essential to learning, } \\
\text { and therefore is everyone's responsibility” (Banta, 2002, p. 262) }\end{array}$ \\
\hline & $\begin{array}{l}\text { - Effective assessment must "include faculty and staff } \\
\text { development to prepare individuals to implement assessment } \\
\text { and prepare the findings" (Banta, 2002, p. 262) }\end{array}$ \\
\hline & $\begin{array}{l}\text { - Effective assessment requires the decentralization of } \\
\text { responsibility to empower unit level leaders }\end{array}$ \\
\hline & $\begin{array}{l}\text { Effective assessment incorporates multiple measures of } \\
\text { assessment to accommodate the multidimensional and } \\
\text { developmental properties of learning and to improve reliability } \\
\text { and validity }\end{array}$ \\
\hline & $\begin{array}{l}\text { - Effective assessment requires methods for evaluating the } \\
\text { assessment plan and student learning outcomes must be } \\
\text { articulated }\end{array}$ \\
\hline & $\begin{array}{l}\text { - Effective assessment requires "an environment that is receptive, } \\
\text { supportive, and enabling - on a continuous basis" (Banta, 2002, } \\
\text { p. 263) }\end{array}$ \\
\hline & $\begin{array}{l}\text { - Effective assessment enables “continuous communication with } \\
\text { constituents concerning activities and findings” (Banta, 2002, p. } \\
\text { 263) }\end{array}$ \\
\hline
\end{tabular}

Implementation of an assessment plan requires "knowledgeable and effective leadership” (Banta, 2002, p. 262). Banta (2002) states, “a truly supportive chief 
executive and/or provost can strengthen assessment immeasurably” (p. 269). Leadership must understand assessment in order to implement an assessment plan. A major research study by the Jones and Voorhees (2002) advocates for effective leadership in one of its key principles of effective assessment. Emergent themes from case studies illustrate that “a senior academic administrator becomes the public advocate, leader, and facilitator for creating an institutional culture that is open to change, willing to take risks, and fosters innovations by providing real incentives for participants” (Jones \& Voorhees, 2002, p. 20).

An appreciation for the need to facilitate assessment endeavors is "essential to learning, and therefore is everyone’s responsibility” (Banta, 2002, p. 262). This characteristic of assessment plan implementation extends the involvement of various stakeholders from the planning phase into the implementation phase. AAHE's Principles of Good Practice for Assessing Student Learning and the Hallmarks of Successful Programs to Assess Student Academic Achievement advocated by the NCA support this principle by stressing the need to involve various stakeholders from across the academic community (In Huba \& Freed, 2000).

Execution of the assessment plan should "include faculty and staff development to prepare individuals to implement assessment and prepare the findings” (Banta, 2002, p. 262). Faculty and staff must fully understand the process of assessing student learning so that the data collected will lead to improvement.

During the implementation phase, responsibility for assessment should be transferred to relevant units (Banta, 2002). Decentralization of assessment responsibilities will assist in the development of faculty ownership/responsibility. The NCA's Hallmarks of 
Successful Programs to Assess Student Academic Achievement states, “successful assessment has faculty ownership/responsibility” (In Huba \& Freed, 2000, p. 67).

The implementation of assessment should incorporate multiple measures of assessment to accommodate the multidimensional and developmental properties of learning and to improve reliability and validity (Banta, 2002). An assessment plan that includes multiple measures may require students to complete a commercially or locally developed exam, complete a commercially or locally developed survey, and create a portfolio. The same student learning outcomes should be assessed by each assessment activity. AAHE’s Principles of Good Practice for Assessing Student learning state, "assessment is most effective when it reflects an understanding of learning as multidimensional, integrated, and revealed in performance over time” (In Huba \& Freed, 2000, p. 67). The NCA’s Hallmarks of Successful Programs to Assess Student Academic Achievement further states, "successful assessment uses multiple measures” (In Huba \& Freed, 2000, p. 67). A major research study by Jones and Voorhees (2002) supports the need for multiple assessment methods. Emergent themes from case studies illustrate that institutions engaged in strong practices of assessment utilize "multiple assessments of competencies [to] provide useful and meaningful information that is relevant to decisionmaking or policy-development context” (Jones \& Voorhees, 2002, p. 25). Additionally, instrument evaluation should consider "the precision, reliability, validity, credibility, and costs [when] making selections about the best commercially developed assessments and/or locally developed approaches” (Jones \& Voorhees, 2002, p. 27).

According to Huba and Freed (2000) direct and indirect measures of student learning should be integrated into assessment. Direct assessment measures "directly measure the 
knowledge and skills that students have acquired in a course or program..." (Huba \& Freed, 2000, p. 79). "Direct measures of learning take the form of projects, products, papers/theses, exhibitions, performances, case studies, clinical evaluations, oral exams, interviews, locally developed tests, and licensure exams” (Huba \& Freed, 2000, p. 79). Indirect assessment measures such as "self-report surveys or interviews, alumni surveys, or employer surveys provide suggestions about student learning, but they do not measure learning itself” (Huba \& Freed, 2000, p. 82). Commercially developed assessments are often nationally normed and provide detailed analysis of reliability and validity data. However, locally developed assessments provide greater alignment to program or institutional outcomes.

At the implementation phase, methods for evaluating the assessment plan and student learning outcomes must be articulated (Banta, 2002). AAHE’s Principles of Good Practice for Assessing Student Learning state that "assessment requires attention to outcomes but also and equally to the experiences that lead to those outcomes” (In Huba \& Freed, 2000, p. 67). NCA’s Hallmarks of Successful Programs to Assess Student Academic Achievement support the need for assessment plan evaluation by stating "successful assessment includes a process for evaluating the assessment plan” (In Huba \& Freed, 2000, p. 67).

Assessment should occur "in an environment that is receptive, supportive, and enabling - on a continuous basis” (Banta, 2002, p. 263). The leadership and audience of assessment should be genuinely interested in assessment as a mechanism for improvement. A positive culture of assessment will assist in facilitating assessment implementation. 
The assessment plan must enable "continuous communication with constituents concerning activities and findings” (Banta, 2002, p. 263). Communication between various stakeholders is critical. Assessment data must be shared in order to utilize the data for a basis of improvement. A major research study by the Jones and Voorhees (2002) supports the need for communication with stakeholders. Emergent themes from case studies illustrate that institutions engaged in strong practices of assessment communicate the results of assessment clearly and "in a meaningful way so that all relevant stakeholders fully understand the results” (Jones \& Voorhees, 2002, p. 29).

Improving and Sustaining Phase. Once the assessment plan is implemented, it enters the improving and sustaining phase. There are eight characteristics of effective practice within the improving and sustaining phase (see Table 5). Within the improving and sustaining phase, assessment must "produce credible evidence of learning and organizational effectiveness” (Banta, 2002, p. 263). According to the Principles of Good Practice for Assessing Student Learning, assessment provides the vehicle for meeting “...responsibilities to students and to the public” (AAHE, In Huba \& Freed, 2000, p. 67). The Hallmarks of Successful Programs to Assess Student Academic Achievement supports this outcome of assessment by stating that "successful assessment provides feedback to students and the institution” (NCA, In Huba and Freed, 2000, p. 67). A major research study by Jones and Voorhees (2002) supports the need for credible evidence of learning. Emergent themes from case studies illustrate that institutions engaged in strong practices of assessment collect assessment data that is "directly linked with the goals of the learning experience” (Jones \& Voorhees, 2002, p. 28). The collection of formative assessment data will assist faculty in modifying the curriculum 
and/or pedagogy as the course is proceeding to improve student achievement.

Summative assessment data may be utilized to provide feedback to both the students and

the institution to illustrate how effectively students achieved programmatic and

institutional intended learning outcomes.

Table 5

Characteristics of assessment within the improving and sustaining phase

\begin{tabular}{|l|l|}
\hline Stage & Characteristic \\
\hline $\begin{array}{l}\text { Improving and } \\
\text { Sustaining }\end{array}$ & $\bullet \begin{array}{l}\text { Effective assessment must “produce credible evidence of } \\
\text { learning and organizational effectiveness" (Banta, 2002, p. 263) }\end{array}$ \\
\cline { 2 - 3 } & $\begin{array}{l}\text { Effective assessment must utilized data for continuous program } \\
\text { improvement and to improve services }\end{array}$ \\
\cline { 2 - 3 } & $\begin{array}{l}\text { Effective assessment must "provide a vehicle for demonstrating } \\
\text { accountability to stakeholders within and outside the } \\
\text { institution" (Banta, 2002, p. 263) }\end{array}$ \\
\cline { 2 - 3 } & $\begin{array}{l}\text { Effective assessment must be ongoing rather than episodic } \\
\text { Effective assessment must "incorporate on going evaluation and } \\
\text { improvement of the assessment process itself” (Banta, 2002, p. } \\
\text { 263) }\end{array}$ \\
\hline
\end{tabular}

Assessment data must be utilized for continuous program improvement and to improve services (Banta, 2002). The Hallmarks of Successful Programs to Assess Student Academic Achievement supports this outcome of assessment by stating that “successful assessment leads to improvement” (NCA, In Huba \& Freed, 2000, p. 67). Improvements should be considered for not only academic affairs but also student affairs and its services. A major research study by Jones and Voorhess (2002) supports the need for continuous program improvement. Emergent themes from case studies illustrate that institutions engaged in strong practices of assessment are utilizing results "in making critical decisions about strategies to improve student learning or allocation of resources” (Jones \& Voorhees, p. 25). 
Assessment should "provide a vehicle for demonstrating accountability to stakeholders within and outside the institution” (Banta, 2002, p. 263). This characteristic provides an additional means for educators to "meet responsibilities to students and to the public” (AAHE, In Huba \& Freed, 2000, p. 67). The data collected as a result of assessment illustrates student achievement and can be reported to various audiences.

Within the improving and sustaining phase, outcomes assessment must be ongoing rather than episodic (Banta, 2002). According to the Principles of Good Practice for Assessing Student Learning, "assessment works best when it is ongoing, not episodic” (AAHE, In Huba and Freed, 2000, p. 67). Assessment measures must be recorded at various times throughout a course or program rather than measuring student achievement at only specific points in time.

The final characteristic of effective outcomes assessment within the improving and sustaining phase requires assessment to "incorporate ongoing evaluation and improvement of the assessment process itself” (Banta, 2002, p. 263). As illustrated earlier, the Hallmarks of Successful Programs to Assess Student Academic Achievement state that assessment should include “a process for evaluating the assessment program” (In Huba and Freed, 2000, p. 67). Revisions to the assessment program should be made to continuously improve assessment activities. A major research study by Jones and Voorhees (2002) supports the need to engage in ongoing evaluation of the assessment plan and to involve pertinent stakeholders in the evaluation process. Emergent themes from case studies illustrate that institutions engaged in strong practices of assessment “experiment with new ways to document students’ mastery of competencies that supplement the traditional transcript" and to fully involve faculty and staff "in reviewing 
and making decisions about the strongest assessment instruments that will measure their specific competencies” (Jones \& Voorhees, 2002, p. 25).

The majority of characteristics identified by Banta directly relate to both the AAHE's Principles of Good Practice for Assessing Student Learning and the NCA's Hallmarks of Successful Programs to Assess Student Academic Achievement and emerge as themes in case studies.

Institutional Commitments and Resources

Research studies conducted by Peterson, et al. (1999), Shipman (2004), and Banta (2004) identified various institutional commitments and resources allocated to assessment endeavors. Commitments are mechanisms of support (such as assessment committees) provided to various units that are utilized to advance the assessment effort. Fiscal resources are required to maintain various degrees of commitment to the assessment endeavor. Resources are assets provided to the assessment endeavor that require budgeting in order to implement assessment. For example, if students were required to take a commercially-developed test there would be costs associated with the purchase of the tests.

According to Peterson, et al. (1999) “... administrators are urged to commit adequate fiscal, physical and staff resources to student assessment...” (p. 131). Peterson, et al. (1999) also express the need “...for institutions to:

- develop comprehensive student assessment information databases;

- to establish policies and practices facilitating the communication of student assessment purposes, activities and results with a broad range of internal and external constituents; and 
- to devise policies that promote the involvement of student affairs personnel and students in assessment efforts” (p. 131).

Peterson and Einerson (2001) state that “administrators and faculty have invested considerable time and effort in promoting, supporting, and implementing assessment efforts” (p. 629). Shipman (2004) conducted research to ascertain information pertaining to the “...types of institutional resources available to conduct assessment” (p. 6). The researcher distributed a survey to forty-four physician assistant program directors “...to elicit information regarding:

- $\quad$ executive level support,

- characteristics of assessment culture at their institutions,

- articulation of projected resource expenditures for assessment costs,

- allocation of resources for initial assessment costs,

- $\quad$ sustained assessment cost forecasting by line-item in successive budgeting cycles, and

- the programs guiding principles for assessment” (p.93).

The researcher (Shipman, 2004) found that 93\% of the program directors affirmed that “executive-level support is available to their program’s assessment efforts” (p. 93).

When asked to characterize the assessment culture of the directors respective institution: a majority (79\%) of directors believed that campus leaders view them as collaborators in the assessment process. Approximately, one-half of program directors reported effective communication, a trusting environment, and deliberate planning. Additional aspects of the assessment culture (i.e., being directly involved in assessment, integrating assessment costs in the budget, instituting 
authentic incentives for participation in assessment, and meeting regularly with faculty on assessment issues) were cited by 38 to $41 \%$ of program directors (Shipman, 2004, p. 93).

Fifty-five percent of the program directors revealed “...that they have articulated their projected expenditures for assessment activities at the senior leadership level” (Shipman, 2004, p. 94). Sixty percent of the program directors indicated that they “...had allocated resources for initial (or start-up) assessment costs...” (Shipman, 2004, p. 94). Thirty-four percent of the participants indicated that sustained costs for assessment are currently being forecasted. When queried about the implementation of guiding principles that pertain to their assessment process, "three-quarters of PA program directors responded in the affirmative” (Shipman, 2004, p. 95).

According to Banta (2004), "for outcomes assessment to succeed, the president or the provost or both must say it is important and provide essential support mechanisms” (p. 41). She further states:

The [essential support mechanisms include] opportunities for faculty and student affairs professionals to attend

- regional and national assessment conferences together;

- on-campus seminars on aspects of assessment, perhaps led by an external consultant from time to time;

- a campus wide assessment committee with broad representation;

- one or more offices charged with coordinating data-gathering initiatives such as surveys and standardized tests; 
- incorporation of outcomes assessment in the scholarship of teaching in promotion and tenure guidelines; and

- release time for faculty who assume major roles in the outcomes assessment initiative (Banta, 2004, p. 41).

Synthesis of this research yields seven items related to commitments to assessment and eight items related to resources provided to assessment (see Table 6).

Table 6

Commitments and resources provided to assessment

\begin{tabular}{|c|c|}
\hline Commitments & Resources \\
\hline $\begin{array}{l}\text { Policies and practices facilitating } \\
\text { the communication of student } \\
\text { assessment purposes, activities and } \\
\text { results with a broad range of } \\
\text { internal and external constituents }\end{array}$ & $\begin{array}{l}\text { - comprehensive student assessment } \\
\text { information databases }\end{array}$ \\
\hline $\begin{array}{l}\text { - Policies that promote the } \\
\text { involvement of student affairs } \\
\text { personnel and students in } \\
\text { assessment efforts }\end{array}$ & $\begin{array}{ll}\text { - } & \text { articulation of projected resource } \\
\text { expenditures for assessment costs }\end{array}$ \\
\hline - Executive level support & $\begin{array}{l}\text { - allocation of resources for initial } \\
\text { assessment costs }\end{array}$ \\
\hline $\begin{array}{l}\text { - Characteristics of assessment } \\
\text { culture at their institutions }\end{array}$ & $\begin{array}{l}\text { - } \text { sustained assessment cost } \\
\text { forecasting by line-item in } \\
\text { successive budgeting cycles }\end{array}$ \\
\hline - Guiding principles for assessment & $\begin{array}{l}\text { - regional and national assessment } \\
\text { conferences }\end{array}$ \\
\hline $\begin{array}{l}\text { - Campus wide assessment } \\
\text { committee with broad } \\
\text { representation }\end{array}$ & $\begin{array}{l}\text { on-campus seminars on aspects of } \\
\text { assessment, perhaps led by an } \\
\text { external consultant from time to } \\
\text { time }\end{array}$ \\
\hline \multirow[t]{2}{*}{$\begin{array}{l}\text { Incorporation of outcomes } \\
\text { assessment in the scholarship of } \\
\text { teaching in promotion and tenure } \\
\text { guidelines }\end{array}$} & $\begin{array}{l}\text { one or more offices charged with } \\
\text { coordinating data-gathering } \\
\text { initiatives such as surveys and } \\
\text { standardized tests } \\
\end{array}$ \\
\hline & $\begin{array}{l}\text { - release time for faculty who assume } \\
\text { major roles in the outcomes } \\
\text { assessment initiative }\end{array}$ \\
\hline
\end{tabular}




\section{Faculty Satisfaction and Assessment}

Palomba and Banta (1999) maintain that responsibility, resources, and rewards are required to overcome faculty resistance with assessment. A synthesis of literature by Grunwald and Peterson (2003) indicate "the importance of literature and value of the faculty's role in student assessment both to the student and to the institution as a whole are ubiquitous in the assessment literature” (p. 173).

A study conducted by Grunwald and Peterson (2003) examined the “...institutional factors that promote faculty satisfaction with their institution's approach to and support for student assessment and that are related to faculty involvement in their institution's support practices and their own engagement with student assessment in the classroom" (p. 173). The researchers discovered that:

the institution's student assessment purposes, its administrative support patterns, and its faculty instructional impacts are significant predictors of faculty satisfaction with their institution's approach to and support for student assessment. External influences on, faculty uses, and perceived benefits of professional development practices for student assessment are significant predictors of faculty involvement with student assessment in their institution and their classes (p. 173).

The researchers found that faculty satisfaction with an institutions assessment endeavor is promoted by instituting "institutional and managerial efforts that emphasize using student assessment for internal institutional academic improvement, establishing institution-wide mechanisms - plans, policies, and administrative offices” to facilitate assessment 
activities and to communicate benefits and influences (Grunwald \& Peterson, 2003, p. 202).

\section{Summary}

The importance of assessment in higher education is predicated on external and internal constituencies. Externally, the most significant influences on student assessment are the federal and state government and regional accreditation associations (Peterson \& Vaughn, 2002, p. 27). Performance budgeting, funding, and reporting also emphasize the need for effective assessment. Internally, institutions conduct assessment activities in order to improve student achievement and improve academic programs (Peterson \& Vaughn, p. 33). Huba and Freed (2000) define assessment as a process of gathering and discussing information from multiple and diverse sources in order to develop a deep understanding of what students know, understand, and can do with their knowledge as a result of their educational experiences; the process culminates when assessment results are used to improve subsequent learning (p. 19).

Analyzing the assessment process within an institution of higher education necessitates exploration of the effectiveness of the assessment process, the resources provided to the assessment endeavor, and faculty satisfaction with assessment.

Key Terms

\section{Assessment:}

Assessment is the process of gathering and discussing information from multiple and diverse sources in order to develop a deep understanding of what students know, understand, and can do with their knowledge as a result of their educational 
experiences; the process culminates when assessment results are used to improve subsequent learning (Huba \& Freed, 2000, p. 8).

Assessment Methods:

Direct Assessments:

Students are required to demonstrate their abilities and knowledge. Direct assessments may take a variety of forms - projects, products, papers/these, exhibitions, performances, case studies, clinical evaluations, portfolios, interviews, and oral exams (Huba \& Freed, 2000, p. 11).

Indirect Assessments:

Indirect assessments of learning include self-report measures such as surveys distributed to students which can be used both in courses and at the program and institutional levels. Other indirect measures used in program or institutional assessment include surveys of graduates or employers in which respondents share their perceptions about what graduates know or can do with their knowledge (Huba \& Freed, 2000, p. $11)$.

Classroom Assessment Techniques:

Small-scale assessments conducted continually in college classrooms by disciplinebased teachers to determine what students are learning in that class (Cross \& Steadman, 1996, p. 8).

Commercially Developed Tests and Surveys:

Commercially developed tests and surveys are often nationally normed and provide detailed analysis of reliability and validity data. 
Course-Embedded Assessment:

Assessment techniques included within a course that should include program and course outcomes (Huba \& Freed, 2000).

Evaluation:

Using assessment information to make an informed judgment on such things as:

- whether students have achieved the learning goals we've established for them;

- the relative strengths and weaknesses of our teaching/learning strategies;

or

- what changes in our goals and teaching/learning strategies might be appropriate (Suskie, 2004, p. 5).

Formative Assessment:

Ascertains evidence of learning along the progression of students' studies. Results of formative assessment provide useful information about program- and institution-level learning that can stimulate immediate change in pedagogy, design of instruction, curriculum, co-curriculum, and services that support learning (Maki, 2004, p. 89). Locally-Developed Tests and Surveys:

Locally developed tests and surveys provide greater alignment to program or institutional outcomes than commercially developed tests and surveys. However, reliability and validity data is more difficult to ascertain.

Performance Budgeting:

Performance budgeting allows governors, legislators, and higher education boards to consider campus achievement on performance indicators as one factor in determining 
allocations for public colleges and universities (Burke, 2005a, p. 219).

Performance Funding:

Performance funding focuses on the distribution phase of the budget process. The relationship between funding and performance is tight, automatic, and formulaic. If a public college or university achieves a prescribed target or an improvement level on defined indicators, it receives a designated amount or percentage of state funding (Burke, 2005a, p. 219).

Performance Reporting:

Performance reporting relies on publicity to push colleges and universities to pursue state priorities and improve institutional performance. It rests on the assumption that institutions and individuals perform better when they know their results will become public” (Burke, 2005a, p. 218).

Student Learning Outcomes:

Intended learning outcomes describe the kinds of things that students know or can do after instruction that they didn't know or couldn't do before (Huba \& Freed, 2000, p. 93). Helpful in developing outcome statements are taxonomies that classify the cognitive, behavioral, and affective domains of learning and identify levels of learning Summative Assessment:

Summative assessment methods provide evidence of students' final mastery levels. They prompt students to represent the cumulative learning of their education and answer the question: How well do our students actually achieve our institution- and programlevel expectations (Maki, 2004, p. 90)? 


\section{Chapter 3}

\section{Methodology}

The methodology section of the dissertation contains information pertaining to the research design, population and sample, sampling procedures, instrumentation, data collection procedures, data analysis, and limitations of the study. The purpose of this study was to investigate the current assessment practices at the undergraduate program level. The researcher determined the effectiveness of assessment within specific disciplines at institutions that implemented and sustained their plans; identified the degree to which related institutional commitments and resources were provided to support the assessment process; and examined faculty satisfaction with the assessment. The researcher investigated the following research questions:

1. Does the assessment plan and its implementation demonstrate characteristics of effective practice?

a. How does the assessment plan produce credible evidence of learning?

b. How is assessment data used to continuously improve programs and services?

c. How does the assessment plan provide a vehicle for demonstrating accountability to internal stakeholders?

d. How does the assessment plan encompass the expectation that outcomes assessment will be ongoing and not episodic?

e. How does the assessment plan incorporate ongoing evaluation and improvement of the assessment process itself? 
2. What institutional resources and commitments are provided for the sustainment of the assessment process?

a. Are sufficient institutional resources provided to support the assessment process?

b. What institutional resources are lacking or missing for the assessment endeavor?

3. How satisfied are faculty members with the student assessment process within their programs?

a. What factors are associated with faculty satisfaction regarding the assessment endeavor?

b. What factors reduce faculty satisfaction with the assessment endeavor?

Grunwald and Peterson (2003) discovered that fiscal resources, time, and administrative support were all critical to the success of comprehensive assessment endeavors. Therefore, the results of this study may assist assessment leaders in making decisions pertaining to the allocation of necessary resources to effectively and efficiently support assessment activities when the assessment plan is in the improvement and sustainment phase.

\section{Research Design}

The researcher investigated current assessment practices at the undergraduate program levels, determined the effectiveness of assessment plans, and identified the degree to which related institutional commitments and resources were provided to support the assessment process. The researcher employed a qualitative research design. 
According to Merriam (2001),

[Qualitative research] is an effort to understand situations in their uniqueness as part of a particular context and the interactions there. This understanding is an end in itself, so that it is not attempting to predict what may happen in the future necessarily, but to understand the nature of that setting... and in the analysis to be able to communicate that faithfully to others who are interested in that setting (p. $6)$.

Glesne and Peshkin (1992) stated “qualitative researchers seek to make sense of personal stories and the ways in which they intersect” (p. 1).

The researcher selected this design on the basis of several characteristics pertinent to qualitative research. Through a synthesis of literature, Aloi (2004) identified seven “characteristics of qualitative research that were influential in selecting the design for [a] study” (p. 80). These characteristics included:

1. qualitative researchers are primarily concerned with process, in addition to outcomes or products; they are interested in how things occur;

2. qualitative researchers are interested in understanding what the participants in the study are thinking and why they think what they do;

3. the process of qualitative research is inductive; the research builds abstractions, concepts, hypotheses, or theories rather than testing existing theories;

4. the product of qualitative research is richly descriptive; words and pictures rather than numbers are used to convey what the researcher has learned;

5. the qualitative researcher is the primary instrument for data collection and analysis; 
6. the natural setting is the direct source of data, usually necessitating fieldwork; and

7. the design of a qualitative study is emergent and flexible, responsive to the changing conditions of the study in progress (Aloi, 2004, p. 80).

The researcher utilized multiple case studies (Merriam, 2001) to gather and analyze data from interviews and documents gathered from three institutions of higher education. These case studies enabled the researcher to:

- determine if program assessments demonstrate characteristics of effective practice,

- identify the commitments/resources allocated to the assessment endeavor, and

- examine faculty satisfaction with the assessment endeavor.

Glesne and Peshkin (1992) identified three data gathering methods that were prominent in qualitative research. These included participant observation, interviewing, and document collection. The researcher performed three case studies consisting of interviews and document analyses. The research techniques utilized in this study

- elicited data needed to gain understanding of the phenomenon in question,

- contributed different perspectives on the issue, and

- made effective use of the time available for data collection (Glesne and Peshkin, 1992, p. 24).

The utilization of multiple data sources assisted in making the findings more believable (Glesne \& Peshkin, 1992).

\section{Population and Sample}

The population for this study consisted of all colleges and universities in the United States except for community colleges as identified by the Carnegie Foundation for the 
Advancement of Teaching and Learning (2006). The sample was based on the recommendations of three nationally respected assessment leaders. The assessment leaders included:

- Dr. Trudy Banta, Professor of Higher Education, Vice Chancellor, Planning and Institutional Improvement, Indiana University Purdue University Indianapolis;

- Dr. Elizabeth Jones, Associate Professor, Educational Leadership Studies, West Virginia University; and

- Dr. Barbara Wright, Associate Director, Western Associateion of Schools and Colleges.

The researcher contacted nationally respected assessment leaders in August of 2006 via e-mail messages (see Appendix A) and requested that they identify ten institutions (excluding community colleges) from the population that they asserted upheld the characteristics of effective assessment practices within the sustainment and improvement phase as described by Banta. Banta (2002) described an assessment plan within the improvement and sustainment phase as maintaining characteristics of effective practice if it:

- produces credible evidence of learning,

- ensures that assessment data are used continuously to improve programs and services,

- provides a vehicle for demonstrating accountability to stakeholders within and outside the institution,

- encompasses the expectation that outcomes assessment will be ongoing, not 
episodic, and

- incorporates ongoing evaluation and improvement of the assessment process itself (p. 263).

\section{Sampling Procedures}

The researcher utilized purposeful sampling to examine "information rich cases" (Patton, 2002, p. 46) and to illuminate "issues of central importance to the purpose of the research” (Patton, 2002, p. 46). The nationally respected assessment leaders nominated (through e-mail) ten institutions that they perceived to adhere to Banta's principles of effective assessment plans in the sustainment and improvement phase (see Appendix B). The researcher invited five of the common institutions identified by two or three of the assessment leaders to participate in this study. The final selection of three institutions with assessment plans in the improvement and sustainment phase helped the researcher to evaluate exemplary assessment plans.

The researcher utilized Biglan's (1973) model to gain a representative sample of programs for study within the participating institutions. "Biglan suggested that academic disciplines differed along three dimensions: hard (disciplines that work from an agreedupon paradigm) versus soft, pure (basic research) versus applied, and non-life (disciplines that study inanimate objects) versus life” (Cashin \& Downey, 1995, p. 82). According to Smart and Elton (1987, p. 225), “the Biglan Model would appear to have particular value in the quest to develop systematic knowledge about the internal diversity of institutions of higher learning” (p. 50). Thus, the researcher identified eight different academic undergraduate programs representing each dimension and extremity along the continuum and each program coordinator/department chair was invited to participate in the study 
(see Table 7). However, at least two programs from each institution declined to participate within this study.

Table 7

Intended programmatic sample

\begin{tabular}{|c|c|c|c|c|}
\hline \multirow{2}{*}{ Task Area } & \multicolumn{2}{|c|}{ Hard } & \multicolumn{2}{c|}{ Soft } \\
\cline { 2 - 5 } & $\begin{array}{c}\text { Nonlife } \\
\text { System }\end{array}$ & $\begin{array}{c}\text { Life } \\
\text { System }\end{array}$ & $\begin{array}{c}\text { Nonlife } \\
\text { System }\end{array}$ & $\begin{array}{c}\text { Life } \\
\text { System }\end{array}$ \\
\hline Pure & Mathematics & Biology & English & Psychology \\
\hline \multirow{2}{*}{ Applied } & $\begin{array}{c}\text { Engineering } \\
\text { (Civil) }\end{array}$ & Nursing & Accounting & $\begin{array}{c}\text { Secondary } \\
\text { Education }\end{array}$ \\
\hline
\end{tabular}

The researcher utilized "network" techniques to identify subjects for this study (Glesne \& Peshkin, 1992, p. 27). The assessment director at the selected university acted as the institutional representative and identified additional subjects. Individuals requested to participate in interviews included the:

- Assessment Director,

- program administrators (typically department chairs) of each program identified in Table 7, and

- faculty members from the programs identified in Table 7 (three faculty members per program).

The researcher requested a higher number of participants because some faculty declined to participate. If certain majors were not offered at a particular university, then the researcher conducted interviews with faculty from the programs that were available. Thus, multiple perspectives at each site enabled the validation of data at each institution. 


\section{Institutional Approval}

After the national assessment scholars identified five institutions, the researcher invited the institutional assessment leader from each university to participate in the study by mail (see Appendix C). The researcher provided a sample approval letter that the assessment leaders completed and returned (see Appendix D). Once the researcher obtained the letters of agreement or approval from each institutional assessment leader, the entire study's materials were submitted to the West Virginia University Institutional Review Board for the Protection of Human Subjects (IRB) for approval.

The researcher requested the names of the administrators representing the programs under study from the institutional assessment leaders after all IRB approval documents were acquired (see Appendix E). A form for the institutional assessment leader to provide the names of program administrators accompanied the letters containing the request (see Appendix F). Once the institutional assessment leader identified the program administrators, the researcher asked each program administrator to nominate three faculty members from their particular program (see Appendices $G$ and $H$ ). The researcher invited nominated faculty to participate in the study (see Appendix I) and conducted follow-up phone calls with non-respondents. When an adequate number of subjects representing at least three academic programs agreed to participate, the researcher visited each site to interview participants and collect documents. The first site was Alpha University and the researcher visited this site in November of 2006. The second site was Gamma University and the researcher visited this site in November of 2006. The third site was Beta University and the researcher visited this site in February of 2007. 


\section{Data Collection}

The researcher examined information gathered from interviews and document analysis. Interviews and documents are two of the three most prominent means of data collection within a qualitative research design (Glesne \& Peshkin, 1992). The researcher conducted interviews to illuminate information that could not be directly observed (Patton, 2002). According to Miller (In Patton, 2002), "texts are one aspect of the sensemaking activities through which we reconstruct, sustain, contest and change our sense of social reality. They are socially constructed realities that warrant study in their own right” (p. 498). The researcher utilized two interview protocols and a document analysis protocol to collect data during the months of November 2006 and February 2007. Interview protocols. The researcher employed an Institutional Assessment Leader/Program Administrator Interview Protocol and a Faculty Satisfaction Interview Protocol in this study. Each interview protocol required 60 minutes to complete.

The subjects of the Institutional Assessment Leader/Program Administrator Interview Protocol included the institutional assessment leaders and program administrators of each undergraduate program under study (as identified in Table 7) as well as the institutional

assessment leader (see Appendix J). The interview protocol contained items pertinent to demographic information, assessment plan effectiveness, resources and commitments, and satisfaction. Demographic information items illuminated the context in which the administrator views assessment. Assessment plan effectiveness items required the identification of evidence of each of the characteristics of effective practice as defined by Banta (2002) and discussed in greater detail in the literature review. Resource and commitment items provided insight into the types and quantities of support the institution 
provided to assessment. These items were derived from previous literature (Peterson, et al. 1999, Shipman, 2004, and Banta, 2004). Satisfaction items elicited a broad overview of the subjects' experience with the assessment plan. The researcher adapted satisfaction items from the Institutional Climate for Student Assessment (ICSA) survey developed by the research program on Institutional Support for Student Assessment for the National Center for Postsecondary Improvement (2000). A sample of Likert scale response items from the ICSA were modified and included within the interview protocol. The researcher utilized yes/no response items and open-ended questions to gather data. Open-ended interview questions enabled the examination of responses that "capture[d] the points of view of other people...” (Patton, 2002, p. 21) and yielded detailed information regarding the ability of the assessment plan to fulfill the characteristics of effective practice of assessment within the sustainment and improvement phase as described by Banta (2002). Analysis of this qualitative data illustrated the means by which assessment plans fulfilled characteristics of effectiveness.

The researcher invited a sample of three full-time faculty members representing the programs under study to participate in an interview to determine their satisfaction with assessment. However, some faculty members declined to participate in this study. The Faculty Satisfaction Interview Protocol elicited demographic and satisfaction data. The researcher asked the same satisfaction items included within the Institutional Assessment Leader/Program Administrator Interview Protocol. However, the researcher asked this sample several additional satisfaction items, adapted from the (ICSA Survey), to elicit a more extensive view of faculty satisfaction with assessment. 
Document collection. Document analysis provided methodological triangulation and strengthened the results of the study. The researcher analyzed academic program assessment plans, reports of assessment results, and minutes from assessment meetings to identify characteristics of effective practice and to determine consistency between interview responses and the actual documents. However, the availability of documents varied based on the institution and type of program. Table 8 illustrates the relationship between all of the interview questions and the document analysis protocol to the major research questions. The researcher based the Assessment Plan Effectiveness Document Analysis Protocol on the characteristics of assessment plans in the improvement and sustainment phase as identified by Banta (2002) (see Appendix L). The researcher based the Assessment Results Document Analysis Protocol (see Appendix M) and the Assessment Meeting Minutes Document Analysis Protocol (see Appendix N) on an assessment checklist developed by Jones (2005). Jones (2005) developed the assessment plan checklist to evaluate the degree to which assessment plans adhered to best practices.

Table 8

Linkage of interview questions and document analysis to the research questions

\begin{tabular}{|r|l|l|l|l|l|}
\hline & $\begin{array}{l}\text { Interview Protocol - } \\
\text { Institutional } \\
\text { Assessment } \\
\text { Leader/Department } \\
\text { Chair/ Programmatic } \\
\text { Assessment Leader }\end{array}$ & $\begin{array}{l}\text { Interview } \\
\text { Protocol - } \\
\text { Faculty } \\
\text { Satisfaction }\end{array}$ & $\begin{array}{l}\text { Document } \\
\text { Analysis } \\
\text { Protocol - } \\
\text { Assessment } \\
\text { Plan } \\
\text { Effectiveness }\end{array}$ & $\begin{array}{l}\text { Document } \\
\text { Analysis } \\
\text { Protocol - } \\
\text { Assessment } \\
\text { Results }\end{array}$ & $\begin{array}{l}\text { Document } \\
\text { Analysis } \\
\text { Protocol - } \\
\text { Assessment } \\
\text { Meeting } \\
\text { Minutes }\end{array}$ \\
\hline $\begin{aligned} \text { RQ } \\
1\end{aligned}$ & $14-21$ & & $1-7$ & $1-11$ & $1-9$ \\
\hline a & $14,15,16$ & & 1,2 & 3,5 & 1,2 \\
\hline b & 17,18 & & 3 & $6,8,9,10$ & 3,9 \\
\hline c & 19 & & 4 & $1,2,4$ & 4,8 \\
\hline d & 20 & & 5 & 11 & 5 \\
\hline e & 21 & & 6 & 7,12 & 6 \\
\hline
\end{tabular}


Table 8

Linkage of interview questions and document analysis to the research questions:

Continued

\begin{tabular}{|l|l|l|l|l|l|}
\hline & $\begin{array}{l}\text { Interview Protocol - } \\
\text { Institutional } \\
\text { Assessment } \\
\text { Leader/Department } \\
\text { Chair/ Programmatic } \\
\text { Assessment Leader }\end{array}$ & $\begin{array}{l}\text { Interview } \\
\text { Protocol - } \\
\text { Faculty } \\
\text { Satisfaction }\end{array}$ & $\begin{array}{l}\text { Document } \\
\text { Analysis } \\
\text { Protocol - } \\
\text { Assessment } \\
\text { Plan } \\
\text { Effectiveness }\end{array}$ & $\begin{array}{l}\text { Document } \\
\text { Analysis } \\
\text { Protocol - } \\
\text { Assessment } \\
\text { Results }\end{array}$ & $\begin{array}{l}\text { Document } \\
\text { Analysis } \\
\text { Protocol - } \\
\text { Assessment } \\
\text { Meeting } \\
\text { Minutes }\end{array}$ \\
\hline $\begin{array}{l}\text { RQ } \\
2\end{array}$ & $22-42$ & 7 & & 7 \\
\hline $\begin{array}{l}\text { RQ } \\
3\end{array}$ & $43-47$ & $12-21$ & & & \\
\hline
\end{tabular}

In accordance with West Virginia University’s Institutional Review Board requirements, the researcher discussed the confidentiality of data, anonymous reporting of data, and appropriate uses of research with each participant. The researcher included this information in the script for each interview protocol. The researcher tape recorded interviews that were fully transcribed.

\section{Data Management and Analysis}

The researcher analyzed data from the case sites during and immediately following site visits. Merriam (1998) maintained that data collection and analysis should occur simultaneously within qualitative research. The researcher utilized a unique case orientation in order to maintain "the richness, depth, meaning, and contribution of [this] research” (Patton, 2002, p. 55). The researcher utilized coding procedures to improve “standardization and rigor” (Patton, 2002, p. 127) and to “expand, transform, and reconceptualize [the] data” (Coffey \& Atkinson, 1996, p. 29). The researcher identified emergent themes within each case that "manifest[ed] the phenomenon of interest 
intensely” (Patton, 2002, p. 234). Following the analyses of individual cases, the researcher conducted a comparative analysis (Patton, 2002) that is reported in Chapter 7. Interview protocols. The researcher utilized a field log to record details of the site visit and relevant notes pertinent to the study. The researcher coded and examined interview data to identify emergent themes. Effective coding and analysis of the data required:

- transcription,

- an analysis to ascertain a "general sense" of the data,

- the organization of data into categories labeled by terms based on the language of the participant, the development of "a description of the setting or people as well as categories or themes for analysis,”

- a narrative to discuss the findings, and

- $\quad$ interpretation of the data (Creswell, 2003, p. 193).

The researcher separated data based on the position of the participant. Document Analysis Protocols. The researcher employed document analysis protocols to analyze information from assessment plans, assessment meeting minutes, and assessment results. Data gathered from the documents analyzed were used to reinforce or dispute the findings from the two aforementioned interview protocols.

\section{Validating the Findings}

The researcher utilized “multiple-data-collection methods...” (Glesne \& Peshkin, 1992, p. 24) to establish triangulation. The assessment plan effectiveness interview protocol and the document analysis protocol yielded data triangulation through the use of multiple data sources in the examination of assessment activities (Patton, 2002). Thus, the researcher compared the results of the assessment plan characteristics interview to the 
assessment plan document, assessment meeting minutes, and assessment results data to “...provide cross-data validity checks” (Patton, p. 248).

The researcher achieved data triangulation in the evaluation of commitments and resources. Two data sources, the Institutional Assessment Leaders/Department Chairs/Program Coordinators Interview Protocol and the assessment plan documents, yielded data triangulation (Patton, 2002). The researcher examined the data gathered from the two data sources to measure consistency.

The researcher established data triangulation within the faculty satisfaction interview protocol. The utilization of multiple subjects within this interview protocol yielded data triangulation (Patton, 2002). The researcher interviewed multiple faculty members from the majority of programs included within the scope of this study.

\section{Background of the Researcher}

Due to the interpretative nature of qualitative research, it is crucial to disclose biases and past experiences held and acquired by the researcher (Creswell, 1994). The researcher earned a baccalaureate degree in business administration from a research university with very high research activity as described by the basic institutional classifications as articulated by the Carnegie Foundation for the Advancement of Teaching institution of higher education (2006). The researcher also earned a Master of Arts degree in secondary education from a master's college with larger programs (Carnegie Foundation for the Advancement of Teaching, 2006). Currently, the researcher is a doctoral candidate in higher education leadership studies at West Virginia University, a research institution with high research activity and works as a graduate research assistant within the same department (Carnegie Foundation for the Advancement of 
Teaching, 2006). The researcher’s experience in higher education began as an adjunct faculty member in the social sciences department of a community college. Courses taught at this institution included pre-service teacher education, economics, and orientation to college. The researcher has also facilitated instruction for University 101 courses.

The researcher conducts assessment research. He provided consulting services to a First-Year Experience Program and facilitated faculty development workshops. Additionally, he reported research findings and participated in several regional, national, and international professional conferences related to assessment.

The researcher's interest in assessment is predicated on the current biotechnological revolution. As society moves from a technological revolution into a biotechnological revolution increasing demands are placed on the human mind. Increasing effectiveness and efficiency in the classroom raises the standard of collegiate education. Educators must provide students with a curriculum that encourages critical thinking, working in diverse teams, and critiquing real-world issues and that achieves its intended outcomes. Administrators' tasks are to provide the guidance necessary to move educational institutions in this direction. Thus, administration must encourage educators to explore the means in which their students are achieving course, program, and institutional outcomes.

\section{Pilot Study}

The researcher conducted a pilot study during August of 2006 (see Appendix O) “...to learn about [the] research process, interview schedule, observation techniques, and yourself” (Glesne \& Peshkin, 1992, p. 30). The researcher strictly followed the study 
design. The purpose of the pilot study was to examine the interview protocols and document analyses to ensure that relevant data was collected. At the end of the interview, each participant reflected upon the clarity and order of questions (see Appendix P). Participants also critiqued the cover letter. The researcher examined the protocol analyses to ensure that relevant data was extracted from the documents.

\section{Institutional Background}

The pilot study was conducted during the Fall semester of 2006 at a small, historically black college in the mid-Atlantic region of the United States. The institution had a history of effective assessment practice that provided an appropriate venue to test the interview and document analyses protocols. The institution is a "four-year state supported commuter college” classified as a baccalaureate/associates college by the Carnegie Foundation for the Advancement of Teaching (2006). As of the Fall 2006 semester enrollment totaled 3,506 students. The institution is accredited by The Higher Learning Commission and maintains membership in the North Central Association (2005b).

The institution was without an institutional assessment leader in 2005. A new institutional assessment leader was hired in September of 2006 and as a result the assessment endeavor has recently been reinvigorated.

\section{Participants}

The researcher contacted the institutional assessment leader who formally served as the Director of Institutional Research and Effectiveness (IRE) and she requested the department head of the English program and a faculty member within the English program to participate in this study. Therefore, these three individuals were interviewed 
by the researcher. The Director of IRE also provided copies of the institutional assessment plan, English program assessment plan, assessment meeting minutes from assessment committee meetings, and assessment results from the 2004-2005 academic year.

The Director of IRE was employed by the institution for two months and did not hold tenure. She served strictly as a full-time administrator and also served on the institutional assessment committee.

The department chairperson was employed by the institution for three and a half years. She did not hold tenure and served as a faculty member as well as the assistant dean in the School of Humanities. She attended assessment committee meetings.

The full-professor within the English program was employed by the institution for 10 years and held tenure. He served on the institutional assessment committee and chaired the committee.

\section{Process}

The researcher interviewed the institutional assessment leader and the department chair by utilizing the Institutional Assessment Leaders/Department Chairs/Program Coordinators Interview Protocol (Appendix J). The researcher also interviewed the English faculty member by utilizing the Faculty Satisfaction Interview Protocol (Appendix K). At the conclusion of each interview, each participant was asked a series of questions using the same Pilot Study Interview Protocol (Appendix P). This protocol enabled participants to critique the appropriate questions given the interviewees' role at the institution and the corresponding cover letter. The researcher discovered that both interview protocols required approximately 45 minutes to complete. 
The process of document analysis was carefully critiqued by the researcher. Requests of assessment plans, assessment meetings minutes, and assessment reports enabled the researcher to determine if these documents could be gathered at other institutions. The researcher applied the document analyses protocols to the appropriate materials to ensure that the proper data could be extracted.

\section{Data Analysis}

Data analysis required the examination and comparison of interview data, field notes, and document contents. Responses to interview questions were consistent among all participants. Thus, both the Institutional Assessment Leaders/Department Chairs/Program Coordinators Interview Protocol and the Faculty Satisfaction Interview Protocol yielded relevant data.

Results

The Director of IRE, the department chair, and the faculty member believed the questions in the interview protocol were easy to understand and well organized. They shared no significant suggestions to improve the study. The faculty member stated, "I think overall [the questions] were fairly succinct and clear.” The administrators and faculty member also indicated that the cover letter was clear, concise, and effectively explained the purpose of the study. Therefore, no changes were made to the interview protocols.

The researcher applied the Assessment Plan Effectiveness in the Sustainment and Improvement Phase Document Analysis Protocol (Appendix L), Assessment Results Document Analysis Protocol (Appendix M), and the Assessment Meeting Minutes Document Analysis Protocol (Appendix N) to extract necessary information. The design 
of the document analysis protocols enabled the researcher to highlight the data that was critical to this study. The researcher found that each protocol effectively gathered pertinent data, but also provided a means to organize data efficiently.

\section{Conclusion}

This pilot study provided an opportunity for the researcher to practice using the interview protocols and document analysis protocols. The interview and document analysis protocols yielded relevant data. The rich quality of data gathered by the researcher through interviews and document analyses supported the implementation of a qualitative research design for this study. 


\section{Chapter 4}

\section{Beta University}

\section{Institutional Background}

Beta University (BU) is identified by the Carnegie Foundation for the Advancement of Teaching (2006) as a master’s college and university with larger programs (basic classification). BU is located in the mid-Western region of the United States. During the 2006-2007 academic year, 13,449 students were enrolled in approximately 89 programs. BU employs 578 full-time faculty. According to the BU website (2007),

$\mathrm{BU}$ is a public comprehensive university dedicated to the communication, expansion, and integration of knowledge through excellent undergraduate education as its first priority and complementary excellent graduate and professional academic programs; through the scholarly, creative, and research activity of its faculty, staff, and students; and through public service and cultural and arts programming in its region.

University Assessment Council. The University Assessment Council (UAC) was composed of a liaison from the curriculum council, two undergraduate students, the Director of Assessment (representing the Provost's Office), one representative from the Office of Institutional Research, a staff member from the Office of Admissions and Retention, student affairs staff, and the academic deans. The Director of Assessment holds tenure and a full-time appointment in the Office of the Provost. According to the university assessment plan document the responsibilities of the Director of Assessment included the direction and coordination of:

- all undergraduate assessment activities under the assessment plan, 
- $\quad$ undergraduate program review, and

- the provision of appropriate technical support to the committee.

The UAC monitored and assisted with the implementation of assessment activities within the university. The UAC reports to the faculty senate and the provost. According to the university assessment plan, the UAC was charged with implementing the BU Assessment Plan as finally approved by the President of BU; making any further policy recommendations that may arise in the implementation process to the Curriculum Council; maintaining the assessment program; and making recommendations to the Curriculum Council as warranted by the findings of assessment activities.

According to the university assessment plan document, faculty and administrators utilized assessment data at BU in order to:

- make improvements in program structure, in course content, and in pedagogy,

- provide individual students with periodic indications of their performance relative to program objectives and facilitate placement and advisement, and

- $\quad$ evaluate the competence of its graduates, "competence" being understood to include not only expertise within a discipline, but also attainment of the objectives of the University's general education program.

Senior Assignment. Nearly every academic program required a senior assignment where students demonstrated their achievement related to specific program outcomes. The institutional assessment leader reported that $\$ 75,000$ was distributed to the academic programs to support this assessment. She also reported that faculty could be awarded a $\$ 1,500$ mini-grant to conduct assessment activities. Participating BU programs in this 
research study included English, mathematics and statistics, and secondary education. Undergraduate English Program

The Department of English awarded a Bachelor of Arts Degree in English and a Bachelor of Science Degree in English Education in conjunction with the School of Education. Program faculty also awarded minors in English, creative writing, and linguistics.

The English program faculty consisted of 11 professors, five associate professors, and 10 assistant professors. Interview data revealed that approximately 10 part-time faculty taught courses in the department. Undergraduate English students were primarily enrolled full-time. Class sizes ranged between 12 to 36 students.

\section{Study Participants}

The researcher conducted interviews with the assistant department chair and an assistant professor. The assistant department chair was serving his sixth year as a program administrator. He had worked in higher education for about 30 years. The assistant department chair reported that he no longer investigated research related to assessment. However, he directed the writing program for eight years and was involved with assessment at that time. He had not attended any conferences that focused on student outcomes assessment nor had he attended any conferences that included assessment sessions on the program in the past two years. He had not published any papers pertaining to student outcomes assessment in the past two years; however, he had authored assessment related publications in the past.

The second participant, an assistant professor, was serving his second year at BU. He had worked in higher education for 13 years. The assistant professor purported to be 
quite knowledgeable about student outcomes assessment. He noted that writing assessment was one of his areas of study as a graduate student. The assistant professor had not attended any conferences that focused on student outcomes assessment; however, he had attended three conferences that included assessment sessions on the program in the past two years. He presented assessment results at two of the conferences he attended. The assistant professor published two papers pertaining to student outcomes assessment in the past two years.

\section{Characteristics of Effective Assessment Practice}

The researcher analyzed interview data and information posted on the website of the Office of Undergraduate Assessment and Program Review to identify characteristics of effective practice. Additionally, the researcher evaluated the assessment plan to determine the degree to which its implementation demonstrated characteristics of effective practice.

Credible evidence of learning. Documents and interview respondents illustrated various components of the assessment plan that ensured that learning was relevant and assessment measures were reliable. English faculty assessed 15 student learning

outcomes. However, five of the learning statements were not learner-centered, measurable, nor clear. Thus, the researcher analyzed ten outcomes.

The outcomes for the English major spanned two of the six domains contained within Bloom’s Taxonomy (Anderson, et al., 2001). Thirty percent of the outcomes represented the understand domain and $70 \%$ of the outcomes represented the apply domain (see Table 9). No outcomes were representative of the remember, analyze, evaluate, or create domains. Additionally, the researcher did not identify any outcomes representative 
of the affective domain. The researcher found that intended learning outcomes were learner-centered, clear, and measurable. The program's mission statement was not available for analysis.

\section{Table 9}

Distribution of cognitive domains of intended learning outcomes

\begin{tabular}{|c|c|c|}
\hline Cognitive Domain & $\mathrm{N}$ & $\%$ \\
\hline Create & 0 & 0 \\
\hline Evaluate & 0 & 0 \\
\hline Analyze & 0 & 0 \\
\hline Apply & 7 & 70 \\
\hline Understand & 3 & 30 \\
\hline Remember & 0 & 0 \\
\hline
\end{tabular}

Examples of intended learning outcomes within the understand domain included:

- $\quad$ understand the history of the English language and

- understand American literacy.

Examples of intended learning outcomes within the apply domain included:

- demonstrate good oral communication skills and

- write coherently.

All English majors are required to participate in a small senior seminar (enrolling 15 students or less) that serves as a capstone experience. For this capstone course, the assistant department chair revealed that all seniors completed a research paper. He noted that student assessment data gathered from the research paper was not aggregated across sections nor correlated with other data. The assistant department chair further noted that the capstone course faculty independently assessed the research paper. Therefore, no common rubric was utilized in the assessment of research papers. 
Information pertaining to assessment results posted on the Office of Undergraduate Assessment and Program Review website revealed that the assessment results did not link directly to the intended learning outcomes of the program. According to this website, the senior research paper “covered discipline-specific traits only and did not cover the department's published goals, the [College of Arts and Sciences] Desired Characteristics, nor the University General Education expectations.

All undergraduate students were required to enroll in a first-year writing course sequence (ENGL 101 and ENGL 102). According to the assistant department chair, portfolio assessments were piloted in several English 101 and English 102 sections in 2005. Assessment documents posted on the English 101 and English 102 website indicated that faculty utilized rubrics to critique a sample of student work with regard to the course outcomes. Faculty utilized the rubrics to assess student learning across six different dimensions (see Table 10).

Table 10

Rubric criteria for the first-year writing assessment

\begin{tabular}{|c|c|c|}
\hline \multirow[t]{2}{*}{ Dimensions } & \multicolumn{2}{|c|}{ Criteria } \\
\hline & English 101 & English 102 \\
\hline Invention & $\begin{array}{l}\text { - Purpose of the essay is clear and } \\
\text { appropriate to the assignment. } \\
\text { - Introduction engages the reader and } \\
\text { creates interest. } \\
\text { - Essay maintains interest by the } \\
\text { creative choices made in content } \\
\text { selection. }\end{array}$ & \\
\hline
\end{tabular}


Table 10

Rubric criteria for the first-year writing assessment: Continued

\begin{tabular}{|c|c|c|}
\hline \multirow[t]{2}{*}{ Dimensions } & \multicolumn{2}{|c|}{ Criteria } \\
\hline & English 101 & English 102 \\
\hline Arrangement & $\begin{array}{l}\text { - Organization is effective in } \\
\text { developing and supporting a thesis. } \\
\text { - Introduction includes an "essay } \\
\text { map" (forecasting statement) and/or } \\
\text { a clearly stated thesis. } \\
\text { - Discussion paragraphs present a } \\
\text { coherent, logical case in support of } \\
\text { the thesis, with appropriate } \\
\text { rhetorical strategies, examples, } \\
\text { definitions, and explanations. } \\
\text { Essay concludes smoothly and } \\
\text { powerfully. }\end{array}$ & \\
\hline Development & - $\quad \mathrm{N} / \mathrm{A}$ & $\begin{array}{l}\text { Discussion paragraphs present a } \\
\text { coherent, logical case in support of } \\
\text { the claim, using appropriate } \\
\text { rhetorical strategies, examples, } \\
\text { definitions, explanations, and other } \\
\text { credible evidence from outside } \\
\text { sources. } \\
\text { - Discussion paragraphs avoid } \\
\text { logical fallacies and errors in } \\
\text { reasoning. } \\
\text { As appropriate, discussion } \\
\text { paragraphs critically respond to, } \\
\text { analyze, and synthesize other } \\
\text { written texts. }\end{array}$ \\
\hline $\begin{array}{l}\text { Research } \\
\text { Methods }\end{array}$ & - $\mathrm{N} / \mathrm{A}$ & 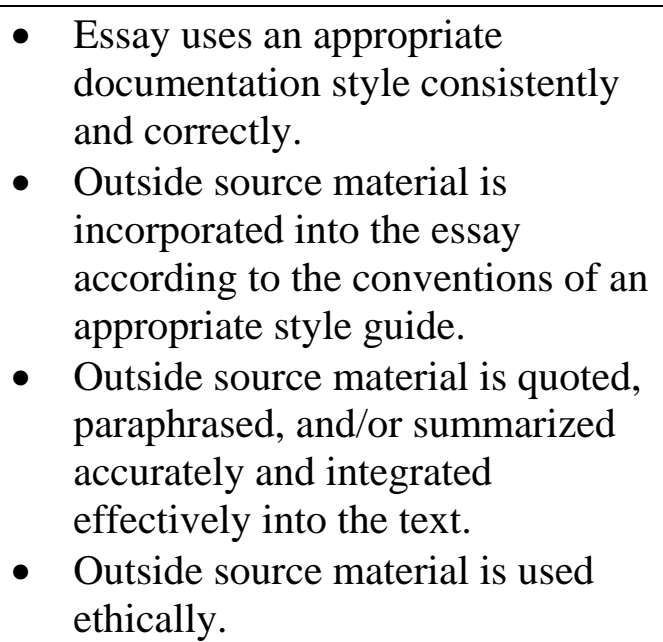 \\
\hline
\end{tabular}


Table 10

Rubric criteria for the first-year writing assessment: Continued

\begin{tabular}{|c|c|c|}
\hline \multirow[t]{2}{*}{ Dimensions } & \multicolumn{2}{|c|}{ Criteria } \\
\hline & English 101 & English 102 \\
\hline Style & $\begin{array}{l}\text { Language, content, and persona are } \\
\text { appropriate to subject, audience, and } \\
\text { purpose. } \\
\text { - Essay exhibits sophisticated control } \\
\text { of language and syntactic structures. }\end{array}$ & $\begin{array}{l}\text { - Language, content, and persona } \\
\text { are appropriate to subject, } \\
\text { audience, and purpose. } \\
\text { - Essay exhibits sophisticated } \\
\text { control of language and syntactic } \\
\text { structures. }\end{array}$ \\
\hline Conventions & $\begin{array}{l}\text { Essay uses Edited American English } \\
\text { and includes features of other } \\
\text { dialects only when they serve } \\
\text { particular rhetorical purposes. }\end{array}$ & $\begin{array}{l}\text { Essay uses Edited American } \\
\text { English and includes features of } \\
\text { other dialects only when they } \\
\text { serve particular rhetorical } \\
\text { purposes. }\end{array}$ \\
\hline
\end{tabular}

Ultimately, a first-year writing assessment plan will allow faculty to "analyze how the first-year writing program is helping students meet the [course] outcomes.” The English 101 website further states,

In addition to making the results known to the English Department and others in the university community, we will use this data to review our need for further faculty development, realignment of goals and objectives, or a revised assessment tool. In addition, we anticipate that the results will show strengths of the first year writing program in terms of helping students develop as stronger writers and readers, critical thinkers, and life-long learners.

Continuous Improvement. The assistant department chair revealed that many informal discussions about student assessment occurred. He further stated, there is a curriculum committee that oversees any sorts of changes in courses or new courses within the department and there is always anecdotal or informal 
discussions when you are in that committee, but as far as it being a formal thing, I just don’t think we have anything like that.

The assistant department chair provided an example of how the results from assessment activities could be used to make targeted changes. He reported that a new required undergraduate course was developed to strengthen students’ vocabulary and basic backgrounds of English before they enrolled in courses that required a more sophisticated understanding of the English language. The assistant department chair noted that the assessment data utilized to support this programmatic change was purely anecdotal. He further noted that decisions based on assessment data were made "in an informal way and within the confines of the curriculum committee.”

Accountability to internal stakeholders. The assistant department chair maintained that accountability to internal stakeholders was "anecdotal.” He noted that the English 101 faculty have developed formal assessment methodologies. However, the assistant department chair emphasized that formal mechanisms to maintain accountability to internal stakeholders did not exist at the program level.

Ongoing assessment. Interview respondents and documents supported that assessment occurred on a predictable schedule within the English Department. The assistant department chair and data from the website of the Office of Undergraduate Assessment and Program Review each indicated that the senior research paper was an important ongoing assessment tool. The assistant department chair also identified the portfolio assessment activities that occurred within several sections of English 101. He continued, "[assessment] is always ongoing because everybody is always teaching and everybody is 
always discussing their experiences in the classes and that eventually finds its way into course proposals, course changes, or curriculum committee discussions.”

Ongoing Evaluation and Improvement. Interview data revealed that the assessment plan within the Department of English did not contain a formal method to evaluate and improve the plan itself. When asked about the ability of the assessment plan to facilitate ongoing evaluation and improvement, the assistant department chair reported that it occurred "utterly anecdotally.”

The assistant department chair and the assistant professor purported to be dissatisfied with the program's assessment plan. They noted that revisions to the assessment plan were needed (see Table 11). The assistant department chair stated, "I think we are a little confused right now on the senior project." However, he did feel some satisfaction in "the fact that the university has set up a mechanism to try to make assessment plans cohere.” The assistant department chair maintained that little communication between the department and institutional assessment leaders had occurred.

\section{Table 11}

Assessment plan: Perceived challenges

\begin{tabular}{|l|l|c|}
\hline Factors & $\begin{array}{l}\text { Assistant } \\
\text { Department } \\
\text { Chair }\end{array}$ & $\begin{array}{l}\text { Assistant } \\
\text { Professor }\end{array}$ \\
\hline $\begin{array}{l}\text { Assessment } \\
\text { Plan Needs } \\
\text { Revision }\end{array}$ & $\mathrm{X}$ & $\mathrm{X}$ \\
\hline $\begin{array}{l}\text { Inconsistency } \\
\text { of Senior } \\
\text { Project }\end{array}$ & $\mathrm{X}$ & \\
\hline
\end{tabular}


Table 11

Assessment plan: Perceived challenges: Continued

\begin{tabular}{|l|l|c|}
\hline Factors & $\begin{array}{l}\text { Assistant } \\
\text { Department } \\
\text { Chair }\end{array}$ & $\begin{array}{l}\text { Assistant } \\
\text { Professor }\end{array}$ \\
\hline $\begin{array}{l}\text { Communication } \\
\text { Between } \\
\text { Department and } \\
\text { Institutional } \\
\text { Assessment } \\
\text { Leaders }\end{array}$ & \multicolumn{1}{|c|}{$\mathrm{X}$} & \\
\hline $\begin{array}{l}\text { Lack of } \\
\text { Program } \\
\text { Faculty Support }\end{array}$ & & \\
\hline $\begin{array}{l}\text { Lack of } \\
\text { Resources }\end{array}$ & & $\mathrm{X}$ \\
\hline
\end{tabular}

The assistant professor maintained that support for assessment was “sporadic.” He noted that program faculty view assessment as important; however, he claimed that central administration shared no desire to provide resources to assessment endeavors. The assistant professor further maintained that the assessment plan "need[s] serious attention and resources.” He noted a desire to incorporate portfolio assessments within the English program.

\section{Institutional Commitments and Resources}

Commitments. When asked if the utilization of student assessment data was considered in the evaluating and rewarding of faculty the assistant department chair stated, “if you [participated in assessment activities] it would be considered part of what you are supposed to do.” However, he noted that research publications pertaining to student assessment would be considered a research activity. Additionally, the assistant department chair reported that student assessment expertise would not typically be 
considered in the hiring process for new faculty. However, he noted that a recent faculty search included student assessment expertise as a desired qualification.

When queried about the policies and practices that facilitated the communication of student assessment purposes, the assistant department chair identified the University Assessment Committee (UAC). He stated that communication regarding assessment originates from the UAC.

When asked about policies to promote the involvement of student affairs personnel and students in assessment efforts, the assistant department chair stated that there may be such polices but “I wouldn’t know.” He stated that executive-level support for student assessment was evident through the UAC and financial resources provided to faculty who worked on assessment projects.

When asked to describe the culture of assessment within the English program, the assistant department chair felt as though assessment was primarily considered in the two freshman writing courses. He stated, “once you get beyond [the first-year, assessment] becomes fairly anecdotal.” The assistant department chair further noted that if a formal assessment mechanism existed then variables would cause faculty to go "batty trying to create something that had both reliability and was really testing what it was supposed to test.” He reported that a document contained guiding principles for assessment related to the first-year composition courses and the senior seminar. An on-line search of BU's website revealed the following goals for the assessment activities related to the first-year composition program:

- to clarify and explain the mission, goals, content, and evaluation procedures of the first-year expository writing curriculum to current and prospective BU students; 
- to describe the first-year expository writing curriculum and offer curricular guidelines for the range of faculty teaching English 101 and 102:

o new teaching assistants and new lecturers who may also be teaching for the first time or come from other programs with different curricula and goals, and

o experienced faculty already possessing a valuable mix of pedagogical objectives and teaching philosophies;

- to refocus the purpose and means of assessing the teaching of expository writing in our department and across the BU campus;

- $\quad$ to provide a transparent means for comparing the BU expository writing program to benchmarks set by:

o local administration,

o regional accrediting agencies, and

o the Council of Writing Program Administrators and the National Council of Teachers of English; and

- to reflect our program's focus on students, on their understanding of expository writing process, and on their knowledge of the results they can expect to see in their writing after taking their first-year writing classes.

When queried about the incorporation of outcomes assessment into the scholarship of teaching in promotion and tenure guidelines, the assistant department chair stated that it was considered incidentally. However, he noted that a component of the annual evaluation for faculty assigned to assessment activities included assessment criteria.

In summary, the significant commitments for assessment included: 
- publications count towards research,

- communication about assessment from the University Assessment Council,

- executive-level support,

- assessment committee with broad representation,

- guiding principles for portions of the assessment plan, and

- incorporation of outcomes assessment into the scholarship of teaching in promotion and tenure guidelines for relevant faculty.

Resources. Resources associated with the on-campus assessment activities included financial support for testing or professional development opportunities and access to consulting services. When asked to identify resources that were allocated to the Department of English from the institution, the assistant department chair identified the availability of financial assistance from the UAC. According to the assistant department chair, “... at least twice a semester [the UAC] will send out notices saying that there is money to be had for people in departments who need the money for various assessment projects.” He further noted that the English Department had not needed that type of support.

While a comprehensive student assessment database was not directly available to program faculty, the assistant department chair was able to access information typically available in such a database through the UAC. He noted that the UAC had a lot of data that would be relevant to such a database.

The assistant department chair stated that professional development assessment workshops were offered at BU. He noted, “just this week two of our English faculty members gave a workshop [intended for the campus community].” The assistant 
department chair also noted that external consultants facilitated some developmental workshops.

Support for faculty to attend professional conferences on student assessment was available. The assistant department chair reported that "fairly often...you'll have groups of faculty and administrators who are going off either to different campuses or conferences that deal with assessment.” He noted that adequate assistance was available to send each faculty member to one or two assessment based conferences per year.

According to the assistant department chair, internal consulting services for faculty on the use of student assessment in course design and instruction were available informally. He claimed that "there are people in the English Department and in the School of Education who are well informed [about assessment].” However, the assistant department chair provided a comparison of his assessment related experiences at BU with the same type of experiences at another institution where he had previously been employed. He stated,

[at my previous institution] there was an assessment office with a statistician so that if I were going to [implement] some sort of a[n] [assessment] program with five or six of our courses, this person would design something for us. We don't seem to have something like that set up here.

The assistant department chair reported that there were very limited types of assistance (in the form of paid leaves, stipends, mini-grants, or course reductions) for faculty to work on assessment activities. However, he noted additional financial assistance, in the form of mini-grants, from an on-campus committee charged with improving undergraduate education. The assistant department chair stated that mini 
grants were awarded on a competitive basis. Furthermore, the assistant department chair reported to be unaware of assessment workshops for deans, department chairs, and other academic administrators or student affairs staff and student affairs administrators. However, he claimed that some workshops were available for academic administrators “years ago.” The assistant department chair also noted that there was no annual budget allocated to academic units to support student assessment. He maintained that such a budget line was not necessary as financial resources were available from the UAC. According to the assistant department chair, "the person who was overseeing [the committee] has just left and there is a sheet out now for people to apply for the position.” He noted that the person who will oversee the committee will be an internal faculty member.

The assistant department chair did not identify a specific office as being helpful with coordinating data-gathering initiatives such as surveys and standardized tests. He noted that "there have been people who every now and then will give us reports.” Additionally, the assistant department chair noted that a program-level assessment office did not exist.

In summary, the significant resources available from the institution included:

- financial assistance,

- availability of assessment database with relevant data,

- professional development workshops,

- internal and external consulting services,

- $\quad$ support to attend assessment related conferences,

- University Assessment Committee, and

- helpful "people” with data gathering initiatives. 
Faculty Satisfaction with Assessment and the Assessment Plan

The researcher examined faculty satisfaction with program assessment by analyzing interview data from two individuals: (1) the assistant department chair who was also a professor and (2) an assistant professor. The assistant department chair was asked a sample of the items included on the Faculty Satisfaction Interview Protocol. These items were intended to elicit information regarding their satisfaction with implementation of the current assessment plan, opportunities to participate in policy making, and central leadership support for assessment. Only the assistant professor was invited to respond to the items pertaining to faculty leadership support, professional development, evaluations and rewards, academic decision making, and the impact of student assessment on the program.

Satisfaction with the Implementation of the Current Assessment Plan. Both participants purported to be neutral in their satisfaction with the implementation of the current assessment plan. The assistant department chair stated, "I’m glad there is interest and there is an [assessment] structure, but I'm not convinced that we have something implemented that is really effective” (see Table 12). He noted that first-year writing faculty had made significant progress implementing their assessment plan.

The assistant professor identified the lack of program-level assessment. He stated, "the implementation for the official stuff was designing the website, agreeing on the goals and outcomes, and that's it. That's as far as they got.” The assistant professor continued, "[faculty] got money to do [assessment] then they ran out of time and money so they stopped." 
Table 12

Implementation of the current assessment plan:

Perceived strengths

\begin{tabular}{|l|l|l|}
\hline Factors & $\begin{array}{l}\text { Assistant } \\
\text { Department } \\
\text { Chair }\end{array}$ & $\begin{array}{l}\text { Assistant } \\
\text { Professor }\end{array}$ \\
\hline Faculty Interest & $\mathrm{X}$ & \\
\hline $\begin{array}{l}\text { Institutional } \\
\text { Assessment } \\
\text { Plan }\end{array}$ & $\mathrm{X}$ & \\
\hline
\end{tabular}

Faculty Satisfaction with Participation in Assessment Decisions. The assistant department chair purported to be satisfied with the opportunities he had to participate in assessment decision-making. He stated, "when I wanted to do a lot of it, I had whatever access I wanted.” The assistant professor did not provide a response to this query.

Faculty Satisfaction with Central Leadership Support for Assessment. The assistant department chair reported to be satisfied while the assistant professor was very satisfied with the central leadership support for student assessment. They discussed key attributes that supported their satisfaction (see Table 13).

Table 13

Central leadership support for assessment:

Perceived strengths

\begin{tabular}{|l|l|c|}
\hline Factors & $\begin{array}{l}\text { Assistant } \\
\text { Department } \\
\text { Chair }\end{array}$ & $\begin{array}{l}\text { Assistant } \\
\text { Professor }\end{array}$ \\
\hline $\begin{array}{l}\text { Central } \\
\text { Leadership } \\
\text { Support }\end{array}$ & X & \\
\hline $\begin{array}{l}\text { Director of } \\
\text { Assessment }\end{array}$ & & X \\
\hline
\end{tabular}


The assistant department chair stated, "I think [central leadership] is there and I think [central leadership] is good on this campus...” The assistant professor identified the assistance of the director of assessment as the most important factor in his satisfaction. He stated, "She has given me a little bit of money to help pay for some things. She has been helpful in all kinds of ways."

Faculty Satisfaction with Psychology Program Faculty Leadership Support. The assistant professor reported to be highly satisfied with program faculty leadership support for assessment. The assistant professor noted that he has "a great set of colleagues.” He stated, “[my colleagues] have given me the chance to develop [assessment tools]...and work with me to make sure that I'm supported.” He also noted that other faculty implemented a scoring rubric he developed.

Faculty Satisfaction with Professional Development for Student Assessment. The assistant professor purported to be neutral in his satisfaction with professional development opportunities for student assessment. He stated, “I’m not sure how to answer that.” He noted that the institution's teaching and learning center frequently facilitated developmental workshops pertaining to student assessment.

\section{Faculty Satisfaction with Evaluations and Rewards Based on Student Assessment}

Data or Involvement. The assistant professor did not purport to be satisfied or dissatisfied with evaluations and rewards based on student assessment data or involvement. The assistant professor indicated that he has received positive feedback during his annual reviews. When prompted to describe his satisfaction with evaluations and rewards based on assessment activities, the assistant professor stated that such evaluations "remain to be seen." 
Faculty Satisfaction with the Use of Student Assessment Data in Making Academic

Decisions. The assistant professor did not indicate his satisfaction with the use of student assessment data in making academic decisions. He stated, "we have yet to do that." He continued, "this semester we are just in the process of collecting the hard data from the students.”

Faculty Satisfaction with the Impact Student Assessment had on Their Program. The assistant professor purported to be satisfied with the impact student assessment had on his program. He noted that as a result of a pilot assessment activity, the "level of instruction has improved.”

Faculty Satisfaction Summary. Table 14 illustrates the frequency of theme emergence across items related to strengths.

Table 14

Frequency of theme emergence pertaining to strengths across items

\begin{tabular}{|l|c|c|}
\hline Factors & $\begin{array}{l}\text { Assistant } \\
\text { Department } \\
\text { Chair }\end{array}$ & $\begin{array}{c}\text { Assistant } \\
\text { Professor }\end{array}$ \\
\hline $\begin{array}{l}\text { Institutional } \\
\text { Assessment Plan }\end{array}$ & 2 & 0 \\
\hline Faculty Interest & 1 & 0 \\
\hline $\begin{array}{l}\text { Avenues to Participate } \\
\text { in Assessment } \\
\text { Decisions }\end{array}$ & 1 & 0 \\
\hline $\begin{array}{l}\text { Central Leadership } \\
\text { Support }\end{array}$ & 0 & 1 \\
\hline $\begin{array}{l}\text { Director of } \\
\text { Assessment }\end{array}$ & 0 & 1 \\
\hline $\begin{array}{l}\text { Teaching and Learning } \\
\text { Center }\end{array}$ & 1 & 0 \\
\hline
\end{tabular}


Table 14

Frequency of theme emergence pertaining to strengths

across items: Continued

\begin{tabular}{|l|c|c|}
\hline Factors & $\begin{array}{l}\text { Assistant } \\
\text { Department } \\
\text { Chair }\end{array}$ & $\begin{array}{l}\text { Assistant } \\
\text { Professor }\end{array}$ \\
\hline $\begin{array}{l}\text { Positive Feedback } \\
\text { During Annual } \\
\text { Reviews }\end{array}$ & 0 & 1 \\
\hline $\begin{array}{l}\text { Increased Academic } \\
\text { Rigor }\end{array}$ & 0 & 1 \\
\hline
\end{tabular}

Program faculty identified the institutional assessment plan as a strength of assessment.

The assistant department chair noted that the institutional assessment plan provided a structure of reporting that was helpful in maintaining and implementing the program's assessment plan.

Program faculty identified assessment plan revisions as a challenge pertaining to assessment (see Table 15). The assistant department chair and the assistant professor both noted that the constant state of revision of the assessment plan impeded their satisfaction.

\section{Table 15}

Frequency of theme emergence pertaining to challenges across items

\begin{tabular}{|l|c|c|}
\hline Factors & $\begin{array}{l}\text { Assistant } \\
\text { Department } \\
\text { Chair }\end{array}$ & $\begin{array}{l}\text { Assistant } \\
\text { Professor }\end{array}$ \\
\hline $\begin{array}{l}\text { Assessment Plan } \\
\text { Needs Revision }\end{array}$ & 1 & 1 \\
\hline $\begin{array}{l}\text { Inconsistency of } \\
\text { Senior Project }\end{array}$ & 1 & 0 \\
\hline
\end{tabular}




\section{Table 15}

Frequency of theme emergence pertaining to challenges

across items: Continued

\begin{tabular}{|l|c|c|}
\hline Factors & $\begin{array}{l}\text { Assistant } \\
\text { Department } \\
\text { Chair }\end{array}$ & $\begin{array}{l}\text { Assistant } \\
\text { Professor }\end{array}$ \\
\hline $\begin{array}{l}\text { Communication } \\
\text { Between } \\
\text { Department and } \\
\text { Institutional } \\
\text { Assessment } \\
\text { Leaders }\end{array}$ & 1 & 0 \\
\hline $\begin{array}{l}\text { Lack of Program } \\
\text { Faculty Support }\end{array}$ & 0 & \\
\hline Lack of Resources & 0 & 1 \\
\hline $\begin{array}{l}\text { Undefined } \\
\text { Evaluation and } \\
\text { Reward Process } \\
\text { Based on Student } \\
\text { Assessment Data or } \\
\text { Involvement }\end{array}$ & & 1 \\
\hline $\begin{array}{l}\text { Assessment Data } \\
\text { Not Used to Make } \\
\text { Academic } \\
\text { Decisions }\end{array}$ & 0 & \\
\hline
\end{tabular}

Undergraduate Mathematics and Statistics Program

The Department of Mathematics and Statistics awarded Bachelor of Arts and Bachelor of Science Degrees in Mathematic Studies with specializations in mathematical sciences, applied mathematics, statistics, and actuarial science. A Bachelor of Science in Mathematics was also available for secondary education teacher certification. Program faculty awarded minors in mathematics, statistics, and mathematics education.

The mathematics and statistics program faculty consisted of 10 professors, five associate professors, and four assistant professors. Interview data revealed that approximately 10 part-time faculty taught courses in the department. Undergraduate 
mathematics and statistics students were primarily enrolled full-time. Class sizes ranged between 10 to 60 students.

\section{Study Participants}

The researcher conducted interviews with the department chair, a professor, and an associate professor. The department chair was serving his first year as a program administrator. He had worked in higher education for about 30 years. The department chair reported that he had some knowledge of assessment that developed as a result of formal and informal discussions within the department and the university community. He had not attended any conferences that focused on student outcomes assessment nor had he attended any conferences that included assessment sessions on the program in the past two years. He had not published any papers pertaining to student outcomes assessment in the past two years.

The second participant, a professor, was serving his first year at BU. He had worked in higher education for 13 years. The professor claimed that he was not very knowledgeable about assessment. However, he stated, “I'm comfortable in seeing a student give a final report and assessing how well they’ve done.” The professor had not attended any conferences that focused on student outcomes assessment nor had he attended any conferences that included assessment sessions on the program in the past two years. He had not published any papers pertaining to student outcomes assessment in the past two years.

The third participant, an associate professor, was serving his third year at BU. He had worked in higher education for 10 years. The associate professor purported to be fairly knowledgeable about student outcomes assessment. He noted that teaching and directing 
senior projects helped him develop his assessment knowledge. The associate professor had not attended any conferences that focused on student outcomes assessment nor had he attended any conferences that included assessment sessions on the program in the past two years. He had not published any papers pertaining to student outcomes assessment in the past two years.

\section{Characteristics of Effective Assessment Practice}

The researcher analyzed interview data and various documents from the Department of Mathematics and Statistics to identify characteristics of effective practice. Additionally, the researcher evaluated the assessment plan to determine the degree to which its implementation demonstrated characteristics of effective practice.

Credible evidence of learning. The researcher gathered information from documents and interviews that illustrated various components of the assessment plan. Faculty assessed seven learning outcomes that were relevant to the discipline. The outcomes for the mathematics and statistics major spanned four of six domains contained within Bloom's Taxonomy (Anderson, et al., 2001). Twenty-nine percent of the outcomes represented the understand domain, fourteen percent of the outcomes represented the apply domain, fourteen percent of the outcomes represented the analyze domain, and forty-three percent of the outcomes represented the create domain (see Table 16). Program faculty did not assess any outcomes that were representative of the affective domain. These outcomes were learner-centered and were clear, measurable, and spanned multiple learning domains. The program's mission statement was not available for analysis. 
Table 16

Distribution of cognitive domains of intended learning outcomes

\begin{tabular}{|c|c|c|}
\hline Cognitive Domain & N & $\%$ \\
\hline Create & 3 & 43 \\
\hline Evaluate & 0 & 0 \\
\hline Analyze & 1 & 14 \\
\hline Apply & 1 & 14 \\
\hline Understand & 2 & 29 \\
\hline Remember & 0 & 0 \\
\hline
\end{tabular}

Examples of intended learning outcomes within the understand domain included:

- determine the validity of theorems of a moderate level of complexity and

- determine the validity of proofs of a moderate level of complexity.

An example of an intended learning outcome within the apply domain included:

- $\quad$ solve real-world problems by applying mathematic reasoning.

An example of an intended learning outcome within the analyze domain included:

- $\quad$ analyze a topic from the mathematical sciences.

Examples of intended learning outcomes within the create domain included:

- construct a written report deemed satisfactory by experts in the field and

- construct theorems of an elementary level of complexity.

Program faculty in the Department of Mathematics and Statistics utilized two major indicators of student achievement: (1) final exams and (2) the senior project to assess student learning. The department chair revealed that faculty distributed common final examinations to daytime sections of college algebra, pre-calculus, and calculus I. The senior project required students to create a product to demonstrate their abilities pertinent to program learning outcomes. According to the 2003 - 2005 BU undergraduate catalog, 
all seniors are required to take MATH 498 and 499 (Senior Seminar and Senior Project), which carry two credits each. MATH 499 is graded Satisfactory or Unsatisfactory. Passing this course is required for graduation. The student is required to consult with a member of the Mathematics/Statistics faculty to prepare a proposal for a culminating project. The Senior Assignment Committee, established for this purpose, must approve all proposals. The completed project is evaluated by a Project Evaluation Committee and includes both the documentation and an oral presentation by the student. Members of the faculty are invited to attend the oral presentation.

The analysis of data from the aforementioned assessment activities was appropriate. Faculty utilized descriptive statistics to analyze student achievement pertaining to the senior project. The assessment results linked directly to the intended learning outcomes of the program.

Continuous Improvement. Interview respondents and data posted on the Undergraduate Assessment and Program Review Office website provided evidence of program changes or improvements based on assessment data. The department chair revealed that discussions about assessment data occurred during yearly faculty meetings. He further stated, we also have a senior assignment committee consisting of several faculty members who supervise [the senior project] during the year. The committee would discuss [assessment results] within the committee and with all senior project directors...this is a continuing exchange of ideas throughout the year. 
The department chair indicated that faculty utilized assessment data to identify weaknesses within student achievement. He noted that student assessment data could be compared on a yearly basis. According to the information on the Undergraduate Assessment and Program Review website, results from the 2003 - 2004 academic year senior project revealed that all of the students completing the senior project satisfied minimum expectations. However, faculty noted that the learning outcomes pertaining to the construction of theorems and proofs of an elementary level were not assessed in the senior project. Thus, faculty revised the senior project to require students to demonstrate their ability to perform these tasks.

Furthermore, a three year summary of assessment results from 2003 - 2005 revealed that students were lacking in their writing and presentation skills. As a result of weaknesses in writing skills, faculty developed Math 498 - Senior Seminar and required all mathematics majors to complete the course. Within Math 498, faculty required students to solve a real-world problem and to author a report that presented their solutions. As a result of weaknesses in presentation skills, faculty submitted a request to the faculty senate to add one credit hour to Math 223 and Math 350. Program faculty utilized the additional class time to “...give students the opportunity to work out problems on the board and to improve their presentation skills.”

Accountability to internal stakeholders. The department chair maintained that accountability to internal stakeholders occurred as a result of the senior project. He compared the senior project to a "mini-masters thesis." The department chair continued, "the fact that [students] were able to write something like [the senior project that ensures]that they are sufficiently prepared.” He concluded that the student's ability to 
complete the senior project illustrated successful teaching and learning within the department.

Ongoing assessment. Interview respondents and documents supported that assessment occurred on a predictable schedule within the Department of Mathematics and Statistics. The department chair and data posted on the website of the Office of Undergraduate Assessment and Program Review each identified the senior project as an important activity that facilitated ongoing assessment. The department chair noted that faculty reviewed intended learning outcomes after they reviewed assessment results. He also noted, "if we see that there is a particular weakness that is in several [senior projects] then the first thing [we do] is discuss this, the second is think about changing how we do things.”

Ongoing Evaluation and Improvement. Interview data revealed that the assessment plan within the Department of Mathematics and Statistics did not contain a formal method to evaluate and improve the assessment plan itself.

The department chair, professor, and associate professor purported to be satisfied with the program's assessment plan. The department chair noted that he would like to see assessment data on "a much bigger scale together with other universities.” However, he confirmed that his desire was "beyond what we can achieve [at BU]" (see Table 17).

Table 17

Assessment plan: Perceived challenges

\begin{tabular}{|l|l|l|l|}
\hline Factors & $\begin{array}{l}\text { Department } \\
\text { Chair }\end{array}$ & Professor & $\begin{array}{l}\text { Associate } \\
\text { Professor }\end{array}$ \\
\hline $\begin{array}{l}\text { Nationally } \\
\text { Comparable Data }\end{array}$ & $\mathrm{X}$ & & \\
\hline
\end{tabular}




\section{Table 17}

Assessment plan: Perceived challenges: Continued

\begin{tabular}{|l|l|c|l|}
\hline Factors & $\begin{array}{l}\text { Department } \\
\text { Chair }\end{array}$ & Professor & $\begin{array}{l}\text { Associate } \\
\text { Professor }\end{array}$ \\
\hline $\begin{array}{l}\text { Lack of Student } \\
\text { Motivation }\end{array}$ & & $\mathrm{X}$ & \\
\hline $\begin{array}{l}\text { Increased } \\
\text { Workload for } \\
\text { Faculty }\end{array}$ & & $\mathrm{X}$ & \\
\hline $\begin{array}{l}\text { Increased } \\
\text { Workload for } \\
\text { Students }\end{array}$ & & $\mathrm{X}$ & \\
\hline
\end{tabular}

The professor stated, “we’ve got a very difficult senior assignment and I think that's good” (see Table 18). He noted that the senior project created a challenging workload for faculty and students. Additionally, the professor reported that “some [students] just don’t have the motivation to finish [the senior project].”

Table 18

Assessment plan: Perceived strengths

\begin{tabular}{|l|l|c|c|}
\hline Factors & $\begin{array}{l}\text { Department } \\
\text { Chair }\end{array}$ & Professor & $\begin{array}{l}\text { Associate } \\
\text { Professor }\end{array}$ \\
\hline $\begin{array}{l}\text { Challenging } \\
\text { Assessments }\end{array}$ & & $\mathrm{X}$ & \\
\hline $\begin{array}{l}\text { Multiple } \\
\text { Methods of } \\
\text { Assessment }\end{array}$ & & & $\mathrm{X}$ \\
\hline
\end{tabular}

The associate professor noted that the assessment plan was [working well]. He reported that faculty were able to evaluate student achievement through written and oral activities. 


\section{Institutional Commitments and Resources}

Commitments. University and program leaders demonstrated their commitment to assessment. When asked if the utilization of student assessment data was considered in the evaluating and rewarding faculty, the department chair stated, "this would be considered part of one’s teaching accomplishment.” He explained, “each faculty [member] submits an annual report. This report is crucial as far as your merit salary increase [for the following year]. You have to provide evidence of your achievements in teaching and research.” Additionally, the department chair reported that student assessment expertise might be considered in the hiring process for new faculty. He noted that consideration of assessment expertise would be dependent upon the needs of the program faculty.

When queried about the policies and practices that facilitated the communication of student assessment purposes, the department chair noted that the process was "wellknown to more senior faculty.” He noted that a committee disseminated information during the academic year that "remind[ed] faculty members about the procedure, about the deadlines, and so on.”

When asked about policies to promote the involvement of student affairs personnel and students in assessment efforts, the department chair indicated that no relationship between the Department of Mathematics and Statistics and any student affairs personnel existed. He illustrated executive level support for student assessment through the distribution of financial resources and availability of developmental workshops for junior faculty. When asked to describe the culture of assessment within the Department of Mathematics and Statistics, the department chair stated, "many people value this 
experience a lot. Some are a little bit skeptical of it because of the [internal comparison] limitation. I think for the most part, faculty participate and are willing and interested in assessment.” He reported that guiding principles for assessment were known to program faculty to "some extent." He further noted that while some faculty may not be fully aware of the guiding principles for assessment, "most faculty know the basics.” Additionally, the department chair reported that a campus-wide assessment committee with broad representation did not exist. However, he noted the availability of the Office for Undergraduate Assessment and Program Review for assistance with assessment.

When queried about the incorporation of outcomes assessment into the scholarship of teaching in promotion and tenure guidelines, the department chair stated that outcomes assessment had been incorporated.

In summary, the significant commitments included:

- assessment data considered in the evaluation and rewarding of faculty (teaching),

- $\quad$ student assessment expertise considered in the hiring process for new faculty (if needed),

- committee that communicated assessment procedures and deadlines,

- executive-level support,

- culture that valued assessment,

- articulated guiding principles of assessment were known by faculty,

- assistance from the Office for Undergraduate Assessment and Program Review, and

- incorporated of outcomes assessment into the scholarship of teaching in promotion and tenure guidelines. 
Resources. Resources associated with the assessment activities on campus included financial support for testing or professional development opportunities and access to consulting services. When asked to identify resources allocated to the faculty of the Department of Mathematics and Statistics from the institution, the department chair stated that resources were limited and no annual budget was allocated to academic units to support assessment. He further noted that program faculty did not request funding for the senior project although it was available. The department chair continued, "the support here is minimal, but this is in part because we didn't request any major support.”

According to the department chair, program faculty did not have access to a comprehensive student assessment database. He stated that professional development assessment workshops were offered at BU and that support for faculty to attend professional conferences on student assessment was available. The department chair reported, "I believe there is an avenue to apply for funding specifically though [the Office of Undergraduate Assessment and Program Review].” He noted that program faculty could attend two assessment conferences annually.

According to the department chair, internal consulting services for faculty on the use of student assessment in course design and instruction were available from the Office of Undergraduate Assessment and Program Review. He claimed that "we get e-mails from them inviting us to ask questions or to consult with them if we have problems.”

The department chair reported that there were no types of assistance (in the form of paid leaves, stipends, mini-grants, or course reductions) for faculty to work on assessment activities. Furthermore, he reported to be unaware of assessment workshops for deans, department chairs, and other academic administrators or student affairs staff 
and student affairs administrators. However, he claimed that assessment "was discussed a few times during various chairs meetings.” The department chair did not identify a specific office as helpful with coordinating data-gathering initiatives such as surveys and standardized tests. Additionally, he noted that a program-level assessment office did not exist.

In summary, the significant resources available from the institution included:

- professional development workshops,

- conference support, and

- internal consulting services.

Faculty Satisfaction with Assessment and the Assessment Plan

Faculty satisfaction with program assessment was determined by analyzing interview data from three individuals: (1) the department chair who was also a professor, (2) a professor, and (3) an associate professor. The department chair was asked a sample of the items included on the Faculty Satisfaction Interview Protocol. These items were intended to elicit information regarding their satisfaction with implementation of the current assessment plan, opportunities to participate in policy making, and central leadership support for assessment. Only the professor and associate professor were invited to respond to the items pertaining to faculty leadership support, professional development, evaluations and rewards, academic decision making, and the impact of student assessment on the program.

Satisfaction with the Implementation of the Current Assessment Plan. All of participants purported to be satisfied with the implementation of the current assessment 
plan. All participants discussed strong levels of faculty participation in assessment (see

Table 19). The associate professor also noted the desire of program administrators to include all of the faculty members on committees that support assessment.

The professor discussed the value of the senior project and how faculty earned four units of course credit. However, the professor claimed that the paperwork and service required to facilitate a senior project was extensive.

Table 19

Implementation of the current assessment plan: Perceived strengths

\begin{tabular}{|l|c|c|c|}
\hline Factors & $\begin{array}{l}\text { Department } \\
\text { Chair }\end{array}$ & Professor & $\begin{array}{l}\text { Associate } \\
\text { Professor }\end{array}$ \\
\hline $\begin{array}{l}\text { Faculty } \\
\text { Participation }\end{array}$ & $\mathrm{X}$ & $\mathrm{X}$ & $\mathrm{X}$ \\
\hline $\begin{array}{l}\text { Course load } \\
\text { Received }\end{array}$ & & $\mathrm{X}$ & \\
\hline
\end{tabular}

Faculty Satisfaction with Participation in Assessment Decisions. All of the participants purported to be neutral to very satisfied with their opportunities to participate in assessment decisions. The department chair was neutral and reported that most of his involvement with assessment occurred within the department. The department chair reported that assessment data collected within the department could not be compared nationally (see Table 20).

The professor reported to be very satisfied with his opportunities to participate in assessment decisions. He had chaired the senior assignment committee and served as a regular member. The associate professor reported that he was very satisfied with his opportunities to participate in assessment decisions. He noted that all of the faculty collectively discuss assessment at an annual faculty meeting. 
Table 20

Participation in assessment decisions: Perceived strengths

\begin{tabular}{|l|l|c|c|}
\hline Attributes & $\begin{array}{l}\text { Department } \\
\text { Chair }\end{array}$ & Professor & $\begin{array}{l}\text { Associate } \\
\text { Professor }\end{array}$ \\
\hline $\begin{array}{l}\text { Committee } \\
\text { Participation }\end{array}$ & & $\mathrm{X}$ & \\
\hline $\begin{array}{l}\text { Annual Faculty } \\
\text { Meeting }\end{array}$ & & & $\mathrm{X}$ \\
\hline
\end{tabular}

Faculty Satisfaction with Central Leadership Support for Assessment. All of the participants reported to be satisfied with central leadership support for assessment. The department chair stated, "I think the university is providing adequate support" (see Table 21). The professor claimed that central leadership communicates their desires; however, they did not interfere with the daily activities of the program faculty. He reported that central leadership wanted the ownership of assessment to remain with the program faculty. The professor noted that financial support was available; however, the program faculty had not yet "figured out” how to use it.

\section{Table 21}

Central leadership support for assessment: Perceived strengths

\begin{tabular}{|l|l|c|c|}
\hline Factors & $\begin{array}{l}\text { Department } \\
\text { Chair }\end{array}$ & Professor & $\begin{array}{l}\text { Associate } \\
\text { Professor }\end{array}$ \\
\hline $\begin{array}{l}\text { Ownership of } \\
\text { Assessment } \\
\text { with the } \\
\text { Department }\end{array}$ & $\mathrm{X}$ & \\
\hline $\begin{array}{l}\text { Financial } \\
\text { Support }\end{array}$ & & $\mathrm{X}$ & $\mathrm{X}$ \\
\hline $\begin{array}{l}\text { Expertise of } \\
\text { Faculty and } \\
\text { Administrators }\end{array}$ & & & $\mathrm{X}$ \\
\hline
\end{tabular}


The associate professor identified the expertise of the faculty and administrators within the university. He stated, "I think they have a good system. I think we have good people in the university who are doing this.” He also noted that program faculty had access to resources if they desired to utilize them. The associate professor illustrated the use of financial resources from the university to purchase mathematical software to assist students in writing their senior assignment.

Faculty Satisfaction with Mathematics and Statistics Program Faculty Leadership Support. The professor reported to be satisfied while the associate professor reported to be very satisfied with program faculty leadership. The professor noted, "I think we distribute the workload well.” The associate professor stated, “I am very satisfied with our chair." He noted that the level of academic rigor within courses had increased throughout the past few years (see Table 22).

Table 22

Program faculty leadership support: Perceived strengths

\begin{tabular}{|l|c|c|}
\hline Factors & Professor & $\begin{array}{l}\text { Associate } \\
\text { Professor }\end{array}$ \\
\hline $\begin{array}{l}\text { Evenly } \\
\text { Distributed } \\
\text { Workload }\end{array}$ & $\mathrm{X}$ & \\
\hline $\begin{array}{l}\text { Support from } \\
\text { Chair }\end{array}$ & & $\mathrm{X}$ \\
\hline $\begin{array}{l}\text { Increased } \\
\text { Academic } \\
\text { Rigor Within } \\
\text { Courses }\end{array}$ & & \\
\hline
\end{tabular}

Faculty Satisfaction with Professional Development for Student Assessment. The professor and the associate professor reported to be satisfied with professional 
development for student assessment. The professor reported that program faculty could attend developmental workshops once a month. The associate professor noted that support for professional development was available upon request. He also indicated that program faculty could attend developmental workshops frequently throughout the academic year.

\section{Faculty Satisfaction with Evaluations and Rewards Based on Student Assessment}

Data or Involvement. The professor reported to be somewhat satisfied while the associate professor reported to be very satisfied with evaluations and rewards based on student assessment data or involvement. The professor noted that a large degree of the success of his promotion packet was predicated on assessment activities (see Table 23). Specifically, he cited his work in facilitating senior assignments.

The associate professor emphasized his work facilitating senior assignments. He stated, “we are being recognized or at least the department really recognizes those who have been active [with senior projects].”

Table 23

Evaluations and rewards based on student assessment data or involvement: Perceived strengths

\begin{tabular}{|l|c|c|}
\hline Factors & Professor & $\begin{array}{l}\text { Associate } \\
\text { Professor }\end{array}$ \\
\hline $\begin{array}{l}\text { Promotion } \\
\text { Packet }\end{array}$ & $\mathrm{X}$ & \\
\hline $\begin{array}{l}\text { Senior } \\
\text { Assignment }\end{array}$ & $\mathrm{X}$ & $\mathrm{X}$ \\
\hline
\end{tabular}

Faculty Satisfaction with the Use of Student Assessment Data in Making Academic Decisions. The professor purported to be very satisfied while the associate professor 
purported to be neutral with the use of student assessment data in making academic decisions. The professor reported that course changes had been implemented to better support the senior project and to satisfy Illinois Board of Higher Education Accreditation. The associate professor noted that the development of the senior seminar course enhanced student learning in the senior project (see Table 24).

Table 24

Evaluations and rewards based on student assessment data or involvement: Perceived strengths

\begin{tabular}{|l|c|c|}
\hline Factors & Professor & $\begin{array}{l}\text { Associate } \\
\text { Professor }\end{array}$ \\
\hline $\begin{array}{l}\text { Course } \\
\text { Changes }\end{array}$ & $\mathrm{X}$ & \\
\hline Senior Seminar & & $\mathrm{X}$ \\
\hline
\end{tabular}

Faculty Satisfaction with the Impact Student Assessment had on Their Program. The professor and the associate professor reported to be very satisfied with the impact student assessment had on the Department of Mathematics and Statistics. The professor stated, “I'd say that just the fact that [students] have to write a senior project has strengthened [the program] (see Table 25).”

Table 25

Impact student assessment has had on the program:

Perceived strengths

\begin{tabular}{|l|c|c|}
\hline Factors & Professor & $\begin{array}{l}\text { Associate } \\
\text { Professor }\end{array}$ \\
\hline Senior Project & $\mathrm{X}$ & \\
\hline $\begin{array}{l}\text { Mathematical } \\
\text { Maturity }\end{array}$ & & $\mathrm{X}$ \\
\hline
\end{tabular}


The associate professor noted the need for assessment to ensure that students were "really mathematically mature.”

Faculty Satisfaction Summary. Table 26 illustrates the frequency of theme emergence across items related to strengths. Program faculty identified the senior assignment, faculty participation, and financial support as assessment strengths. The professor and the associate professor identified data from the senior assignment as useful in evaluations and rewards for faculty based on student assessment data or involvement. The professor also noted the senior assignment provided useful data to make decisions within the Department of Mathematics and Statistics. The department chair and the associate professor identified faculty participation as an important reason for their satisfaction with the implementation of the current assessment plan. The professor and the associate professor identified financial support as an important factor influencing their satisfaction with central leadership support for assessment. The professor and the associate professor identified the frequency of developmental workshops as another factor positively influencing their satisfaction.

Table 26

Frequency of theme emergence pertaining to strengths across items

\begin{tabular}{|c|c|c|c|}
\hline Factors & $\begin{array}{l}\text { Department } \\
\text { Chair }\end{array}$ & Professor & $\begin{array}{l}\text { Associate } \\
\text { Professor }\end{array}$ \\
\hline Senior Assignment & 0 & 2 & 1 \\
\hline $\begin{array}{l}\text { Faculty } \\
\text { Participation }\end{array}$ & 1 & 0 & 1 \\
\hline Financial Support & 0 & 1 & 1 \\
\hline $\begin{array}{l}\text { Challenging } \\
\text { Assessments }\end{array}$ & 0 & 1 & 0 \\
\hline $\begin{array}{l}\text { Multiple Methods } \\
\text { of Assessment }\end{array}$ & 0 & 0 & 1 \\
\hline $\begin{array}{l}\text { Course Load } \\
\text { Received }\end{array}$ & 0 & 1 & 0 \\
\hline
\end{tabular}


Table 26

Frequency of theme emergence pertaining to strengths across items:

Continued

\begin{tabular}{|l|c|c|c|}
\hline Factors & $\begin{array}{l}\text { Department } \\
\text { Chair }\end{array}$ & Professor & $\begin{array}{l}\text { Associate } \\
\text { Professor }\end{array}$ \\
\hline $\begin{array}{l}\text { Committee } \\
\text { Participation }\end{array}$ & 0 & 1 & 0 \\
\hline $\begin{array}{l}\text { Annual Faculty } \\
\text { Meeting }\end{array}$ & 0 & 0 & 1 \\
\hline $\begin{array}{l}\text { Ownership of } \\
\text { Assessment with } \\
\text { the Department }\end{array}$ & 0 & 1 & 0 \\
\hline Assessment Plan & 0 & 0 & 1 \\
\hline Quality of Faculty & 0 & 0 & 1 \\
\hline $\begin{array}{l}\text { Evenly Distributed } \\
\text { Workload }\end{array}$ & 0 & 1 & 0 \\
\hline Support from Chair & 0 & 0 & 1 \\
\hline $\begin{array}{l}\text { Increased } \\
\text { Academic Rigor }\end{array}$ & 0 & 0 & 1 \\
\hline $\begin{array}{l}\text { Frequency of } \\
\text { Developmental } \\
\text { Workshops }\end{array}$ & 0 & 1 & 1 \\
\hline Promotion Packet & 0 & 1 & 0 \\
\hline Course Changes & 0 & 1 & 0 \\
\hline Senior Seminar & 0 & 0 & 1 \\
\hline $\begin{array}{l}\text { Mathematical } \\
\text { Maturity of } \\
\text { Students }\end{array}$ & 0 & 0 & 1 \\
\hline
\end{tabular}

Program faculty identified increased faculty workloads as an assessment challenge as they developed and implemented the assessment plan (see Table 27). 
Table 27

Frequency of theme emergence pertaining to challenges across items

\begin{tabular}{|l|c|c|c|}
\hline Factors & $\begin{array}{l}\text { Department } \\
\text { Chair }\end{array}$ & Professor & $\begin{array}{l}\text { Associate } \\
\text { Professor }\end{array}$ \\
\hline $\begin{array}{l}\text { Increased } \\
\text { Workload for } \\
\text { Faculty }\end{array}$ & 0 & 1 & 1 \\
\hline $\begin{array}{l}\text { Nationally } \\
\text { Comparable Data }\end{array}$ & 1 & 0 & 0 \\
\hline $\begin{array}{l}\text { Lack of Student } \\
\text { Motivation to } \\
\text { Complete the } \\
\text { Senior Project }\end{array}$ & 0 & 1 & 0 \\
\hline $\begin{array}{l}\text { Increased } \\
\text { Workload for } \\
\text { Students }\end{array}$ & 0 & 1 & 0 \\
\hline $\begin{array}{l}\text { Unable to Utilize } \\
\text { Financial } \\
\text { Resources }\end{array}$ & 0 & 1 & 0 \\
\hline
\end{tabular}

\section{Undergraduate Secondary Education Program}

The secondary education program awarded state teaching certificates. According to the 2006 - 2007 university catalog, students pursued degrees in the academic disciplines they desired to teach. Students earned secondary education teacher certification in addition to the disciplinary degree.

The secondary education program consisted of four faculty members. Interview data revealed that no part-time faculty taught courses in the program. Undergraduate secondary education students were primarily enrolled full-time. Class sizes ranged between 20 to 40 students.

\section{Study Participants}

The researcher conducted interviews with the program coordinator and an assistant professor. The program coordinator was serving his fifth year at BU. He worked in 
higher education for five years. The program coordinator reported that he was fairly knowledgeable about outcomes assessment. He noted that student and program evaluations occurred regularly within the program. The program coordinator also identified the importance of maintaining NCATE accreditation requirements. This administrator and faculty member had attended four conferences that focused on student outcomes assessment in the past two years and he presented assessment results at one of the conferences he attended. The program coordinator authored or co-authored two articles pertaining to student outcomes assessment in the past two years.

The second participant, an assistant professor, was serving his fourth year at BU. He has worked in higher education for four years. The assistant professor claimed that he was fairly familiar with student outcomes assessment. He had attended three conferences that focused on student outcomes assessment in the past two years. The assistant professor did not present assessment results at any of the conferences he attended nor had he published any papers pertaining to student outcomes assessment in the past two years.

\section{Characteristics of Effective Assessment Practice}

The researcher analyzed interview data to identify characteristics of effective assessment practice. Additionally, the researcher evaluated the assessment plan to determine the degree to which its implementation demonstrates characteristics of effective practice.

Credible evidence of learning. The researcher was not given access to the intended learning outcomes for the program. Therefore, no learning outcomes could be analyzed. Secondary education program faculty utilized seven major assessments to measure student achievement. The program coordinator revealed that faculty utilized the Illinois 
State Basic Skills Test, a content area examination, the Assessment of Professional Teaching Test, an exit survey, an alumni survey, a teaching portfolio critiqued with a rubric, and clinical observations to assess student learning. He noted that state teacher certification required the Illinois State Basic Skills Test, a content area examination, and the Assessment of Professional Teaching Test.

According to the program coordinator, faculty utilized the Illinois State Basic Skills Test to assess student achievement in writing, reading comprehension, basic mathematics, and algebra. Program faculty utilized the content area examination to assess student achievement within the academic discipline. The Assessment of Professional Teaching Test assessed students’ professional teaching, technology, language arts, and special education standards. The exit survey and the alumni survey both required participants to report the degree to which the program had prepared them for their teaching careers. The program coordinator stated that the teaching portfolio contained students’ philosophy of education statement, classroom management plan, lesson and unit plans, evidence of their student's work, and resumes.

Furthermore, the program coordinator reported that faculty relied on the aforementioned assessment methods to produce credible evidence of learning. He noted that when students passed the state content test, the State of Illinois Department of Education viewed the student as a "highly qualified teacher." The program coordinator noted that assessment data from clinical experiences and student portfolios were important in maintaining credible evidence of student learning. He reported that faculty from the School of Education and the College of Arts and Sciences examined the teaching portfolios. He also noted that program faculty used a data warehouse to track 
graduates. The researcher was not given access to any of the assessment methods nor results.

Continuous Improvement. Interview respondents provided evidence of program changes or improvements that were implemented as a result of assessment data. The program coordinator revealed that discussions about assessment data occurred periodically. He stated, “I don't think it's a regular thing. At the end of each semester we certainly have informal conversations about student progress or lack thereof. We're always monitoring more in a formative fashion than we are in a summative fashion.” The program coordinator further revealed that informal assessment discussions occurred between faculty who served on the joint committee on teacher preparation.

Accountability to internal stakeholders. The program coordinator maintained that accountability to internal stakeholders occurred as a result of faculty participation across departments. He noted that "the assessment plan certainly is looked at closely by the School of Education as well as the College of Arts and Sciences, so it does provide evidence of the programs or areas that need improvement.” He again noted that the joint committee on teacher preparation was important in maintaining accountability to internal stakeholders.

Ongoing assessment. Interview respondents reported that assessment occurred on a predictable schedule within the secondary education program. The program coordinator noted that faculty aggregated assessment data at the conclusion of each semester. Additionally, the licensure examinations occurred sequentially throughout the curriculum. 
Ongoing Evaluation and Improvement. Interview respondents revealed that program faculty shared assessment data with faculty from other units within the School of Education. When asked about the ability of the assessment plan to facilitate ongoing evaluation and improvement, the program coordinator noted that faculty constantly collected and reviewed data.

The program coordinator and the assistant professor purported to be satisfied with the program's assessment plan. The program coordinator wanted better coordination of assessment measures between the College of Arts and Sciences and the School of Education because it would be more effective in providing qualitative assessment data. The program coordinator also noted that teacher education candidates "are pleased" to discover areas in which they can improve their teaching methods (see Table 28).

Table 28

Assessment plan: Perceived strengths

\begin{tabular}{|l|c|c|}
\hline Factors & $\begin{array}{l}\text { Program } \\
\text { Coordinator }\end{array}$ & $\begin{array}{l}\text { Assistant } \\
\text { Professor }\end{array}$ \\
\hline $\begin{array}{l}\text { Identification of } \\
\text { Areas for } \\
\text { Teacher } \\
\text { Candidates to } \\
\text { Improve }\end{array}$ & 1 & 0 \\
\hline $\begin{array}{l}\text { Flexible } \\
\text { Formula for } \\
\text { Assessment }\end{array}$ & 0 & 1 \\
\hline
\end{tabular}

The assistant professor stated, “we don’t have a rigid formula for assessment of [students], which to me is positive." He noted that the he "would like to see an assessment that is based on learning [across the country]" (see Table 29). The assistant professor concluded, "I know there is always room for improvement.” 
Table 29

Assessment plan: Perceived challenges

\begin{tabular}{|l|c|c|}
\hline Factors & $\begin{array}{l}\text { Program } \\
\text { Coordinator }\end{array}$ & $\begin{array}{l}\text { Assistant } \\
\text { Professor }\end{array}$ \\
\hline $\begin{array}{l}\text { Alignment of } \\
\text { Assessment } \\
\text { Methods with } \\
\text { Other Schools } \\
\text { on Campus }\end{array}$ & 1 & 0 \\
\hline $\begin{array}{l}\text { Nationally } \\
\text { Comparable } \\
\text { Data }\end{array}$ & 0 & 1 \\
\hline
\end{tabular}

\section{Institutional Commitments and Resources}

Commitments. University and program leaders demonstrated their commitment to assessment. When asked if the utilization of student assessment data was considered in evaluating and rewarding faculty, the program coordinator noted the importance of effective teaching. He explained, every faculty member who teaches a course has to have a course evaluation which primarily focuses on the content of the course, the quality of the instruction, and other things like that. That information is reviewed by the department chair and may or may not impact the annual merit pay that is ascribed to that candidate.

Additionally, the program coordinator reported that student assessment expertise might be considered in the hiring process for new faculty. He stated,

I wouldn't say that it's solely a focus, nor would I necessarily say that it would be part of the job description for a particular job opening. If there was a need expressed by one program for someone whose expertise was in assessment, then certainly that would be one of the criteria used for making the hiring decision. 
When queried about the policies and practices that facilitated the communication of student assessment purposes, the program coordinator noted that such information originated from program administrators. When asked about policies to promote the involvement of student affairs personnel and students in assessment efforts, the program coordinator indicated that no relationship between the secondary education program and any student affairs personnel existed. He stated that executive-level support for student assessment was evident due to the permanent structure of the Office of Undergraduate Assessment and Program Review. This office regularly conducts program reviews.

When asked to describe the culture of assessment within the secondary education program, the coordinator stated, "I think because of the nature of the secondary education program [assessment] is working as well as it possibly could given the fact that we [interact] with 11 different departments in the College of Arts and Sciences [and instructional faculty within the School of Education].” He further noted that a more effective alignment of programmatic outcomes would improve the culture of assessment. Additionally, the program coordinator reported that a campus-wide assessment committee with broad representation existed. He noted that the committee acted under the auspice of the Office of Undergraduate Assessment and Program Review.

According to the program coordinator, guiding principles for assessment for the secondary education program were not formally articulated. When queried about the incorporation of outcomes assessment into the scholarship of teaching in promotion and tenure guidelines, the program coordinator stated that "course evaluations produced by students and other evidence of teachers' advocacy in the classroom certainly would be part of the promotion and tenure process.” 
In summary, the significant commitments included:

- assessment data considered in evaluating and rewarding of faculty teaching,

- consideration of student assessment expertise in the hiring process for new faculty (if needed),

- campus-wide assessment committee with broad representation,

- executive-level support through a permanent assessment office,

- culture that values assessment,

- service offered by the Office for Undergraduate Assessment and Program Review, and

- incorporation of outcomes assessment into the scholarship of teaching in promotion and tenure guidelines.

Resources. Resources associated with the assessment activities on campus included financial support for testing, professional development opportunities, and access to consulting services. When asked to identify resources that were allocated to program faculty from the institution, the program coordinator noted only conference support.

According to the program coordinator, program faculty had access to a comprehensive student assessment database. He stated that professional development assessment workshops were offered at BU. Support for faculty to attend professional conferences on student assessment was available. The program coordinator noted that the university offered "a variety of different kinds of workshops."

According to the program coordinator, faculty did not have access to internal consulting services for course design and instruction. However, he noted that the Office 
of Undergraduate Assessment and Program Review evaluated academic programs every seven years.

The program coordinator reported that assistance (in the form of paid leaves, stipends, mini-grants, or course reductions) for faculty to work on assessment activities was available. He stated, I would imagine that if a faculty member wanted to [work on assessment related activities] and went through the approval process, that if it was valid the university would grant sabbatical and/or release. The releases would be primarily governed by grants.

Furthermore, he reported to be unaware of assessment workshops for deans, department chairs, and other academic administrators or student affairs staff and student affairs administrators. The program coordinator also noted that central administrators did not allocate an annual budget to units to support student assessment activities. He identified a specific office as being helpful with coordinating data-gathering initiatives such as surveys and standardized tests. Additionally, he noted that a program-level assessment office did not exist.

In summary, the significant resources available from the institution included:

- professional development workshops,

- conference support,

- comprehensive student assessment database,

- course release, and

- an office charged with coordinating data-gathering initiatives such as surveys and standardized tests. 
Faculty Satisfaction with Assessment and the Assessment Plan

Faculty satisfaction with program assessment was determined by analyzing interview data from two individuals: (1) the program coordinator who was also an assistant professor, and (2) an assistant professor. The researcher asked the program coordinator a sample of the items included on the Faculty Satisfaction Interview Protocol. These items were intended to elicit information regarding their satisfaction with implementation of the current assessment plan, opportunities to participate in policy making, and central leadership support for assessment. Only the assistant professor was invited to respond to the items pertaining to faculty leadership support, professional development, evaluations and rewards, academic decision making, and the impact of student assessment on the program.

Satisfaction with the Implementation of the Current Assessment Plan. Both of participants purported to be very satisfied with the implementation of the current assessment plan. He noted, "we are getting sufficient data so that we can begin to make some decisions" (see Table 30). The program coordinator further explained that units that supported teacher education within the College of Arts and Sciences had been active in developing new assessment activities.

Table 30

Implementation of the current assessment plan: Perceived strengths

\begin{tabular}{|l|c|c|}
\hline Factors & $\begin{array}{l}\text { Assistant } \\
\text { Department } \\
\text { Chair }\end{array}$ & $\begin{array}{l}\text { Assistant } \\
\text { Professor }\end{array}$ \\
\hline $\begin{array}{l}\text { Generation of } \\
\text { Data }\end{array}$ & 1 & 0 \\
\hline
\end{tabular}


Table 30

Implementation of the current assessment plan:

Perceived strengths continued

\begin{tabular}{|l|c|c|}
\hline Factors & $\begin{array}{l}\text { Assistant } \\
\text { Department } \\
\text { Chair }\end{array}$ & $\begin{array}{l}\text { Assistant } \\
\text { Professor }\end{array}$ \\
\hline $\begin{array}{l}\text { Assessment } \\
\text { Support from } \\
\text { Supporting } \\
\text { Programs }\end{array}$ & 1 & 0 \\
\hline $\begin{array}{l}\text { Faculty } \\
\text { Participation }\end{array}$ & 0 & 1 \\
\hline $\begin{array}{l}\text { Autonomy of } \\
\text { the Program } \\
\text { Faculty }\end{array}$ & 0 & 1 \\
\hline $\begin{array}{l}\text { Non-Rigid } \\
\text { Assessment } \\
\text { Plan }\end{array}$ & 0 & 1 \\
\hline
\end{tabular}

The assistant professor noted that faculty participated in the assessment endeavor. He also noted the autonomy of the faculty within the secondary education program as an important factor with his satisfaction. The assistant professor stated, "we are not too rigid on assessment.”

Faculty Satisfaction with Participation in Assessment Decisions. Both of the participants were satisfied with their opportunities to participate in assessment decisions. The program coordinator reported that he participated "in part of the dialogue that takes place in this department and also in the joint committee on teacher preparation.” He also noted that he participated in meetings that included assessment discussions in the School of Education and the College of Arts and Sciences once a semester (see Table 31). The program coordinator cautioned that "shaping policy [was] still under the [jurisdiction] of the dean's office.” He concluded, “we are responsible for following the policies of the 
university and the School of Education. How those are translated into our program is pretty much completely up to [the faculty].”

Table 31

Participation in assessment decisions:

Perceived strengths

\begin{tabular}{|l|c|c|}
\hline Factors & $\begin{array}{l}\text { Program } \\
\text { Coordinator }\end{array}$ & $\begin{array}{l}\text { Assistant } \\
\text { Professor }\end{array}$ \\
\hline $\begin{array}{l}\text { Program } \\
\text { Faculty } \\
\text { Meetings }\end{array}$ & 1 & 1 \\
\hline $\begin{array}{l}\text { Joint } \\
\text { Committee on } \\
\text { Teacher } \\
\text { Preparation }\end{array}$ & 1 & 0 \\
\hline $\begin{array}{l}\text { Informal } \\
\text { Discussions }\end{array}$ & 0 & 1 \\
\hline
\end{tabular}

The assistant professor reported that program faculty meetings included discussions about assessment. He also noted that faculty discussed assessment results informally.

Faculty Satisfaction with Central Leadership Support for Assessment. The program coordinator purported to be very satisfied while the assistant professor purported to be unsatisfied with central leadership support for assessment. The program coordinator identified the availability of resources for assessment and the utilization of assessment data at the university level for accreditation and program review purposes as important factors in his satisfaction. He stated, “[central leadership support for assessment] promotes a healthy dialogue in regards to [the] program, program delivery, and the outcomes of the program” (see Table 32).

The assistant professor stated that he did not appreciate discussions concerning the rigidity of assessment. He noted, "there was a time when too much [of a] rigid formula 
was being suggested in terms of evaluating students.” The assistant professor stated that he did not want to be directed on the way to assess his students.

Table 32

Central leadership support for assessment:

Perceived strengths

\begin{tabular}{|l|c|c|}
\hline Factors & $\begin{array}{l}\text { Program } \\
\text { Coordinator }\end{array}$ & $\begin{array}{l}\text { Assistant } \\
\text { Professor }\end{array}$ \\
\hline Resources & 1 & 0 \\
\hline $\begin{array}{l}\text { Utilization of } \\
\text { Assessment } \\
\text { Data }\end{array}$ & 1 & 0 \\
\hline $\begin{array}{l}\text { Promotion of } \\
\text { Healthy } \\
\begin{array}{l}\text { Assessment } \\
\text { Discussions } \\
\text { within the } \\
\text { University } \\
\text { Community }\end{array}\end{array} \quad 1$ & \\
\hline
\end{tabular}

Faculty Satisfaction with Secondary Education Program Faculty Leadership Support. The assistant professor reported to be satisfied with program faculty leadership. He stated, "we are autonomous in the way we assess our students." The assistant professor noted that faculty follow their “own different mechanics for assessing [students].”

Faculty Satisfaction with Professional Development for Student Assessment. The assistant professor purported to be satisfied with professional development for student assessment. He identified access to professional development opportunities as an important factor with his satisfaction.

Faculty Satisfaction with Evaluations and Rewards Based on Student Assessment Data or Involvement. The assistant professor reported to be unsatisfied with evaluations and rewards based on student assessment data or involvement. He stated, "not just for 
me, but for all of us, we are not rewarded on the basis of student assessment.” However, his response was more pertinent to student's satisfaction with the instructor's pedagogy than assessment activities. When prompted to describe the way in which activities with assessment may be viewed within the scope of evaluations and rewards, the assistant professor reported that such activities would be viewed in a "favorable way" by administrators in his program.

Faculty Satisfaction with the Use of Student Assessment Data in Making Academic Decisions. The assistant professor reported to be somewhat satisfied with the use of student assessment data in making academic decisions. He stated, “if we are making decisions on the basis of outcomes of student assessment, we're assuming that student assessments are perfect or that they are real.” The assistant professor further noted, "we are assuming that students actually understood [the content].”

Faculty Satisfaction with the Impact Student Assessment had on Their Program. The assistant professor purported to be somewhat satisfied with the impact student assessment had on the secondary education program. He noted that he had utilized assessment data to make academic decisions. However, the assistant professor cautioned that he was unaware of the ways in which other faculty utilize assessment results. He concluded that assessment data supported the addition of required clinical experience hours within the secondary education program.

Faculty Satisfaction Summary. Table 33 illustrates the strengths of assessment identified by faculty. The most frequently identified themes pertaining to assessment strengths included:

- flexible formula for assessment, 
- autonomy of program faculty,

- discussion of assessment results in program faculty meetings, and

- utilization of assessment data in making key decisions about program changes.

Table 33

Frequency of theme emergence pertaining to

strengths across items

\begin{tabular}{|l|c|c|}
\hline Factors & $\begin{array}{l}\text { Program } \\
\text { Coordinator }\end{array}$ & $\begin{array}{l}\text { Assistant } \\
\text { Professor }\end{array}$ \\
\hline $\begin{array}{l}\text { Flexible } \\
\text { Formula for } \\
\text { Assessment }\end{array}$ & 0 & 2 \\
\hline $\begin{array}{l}\text { Autonomy of } \\
\text { Program } \\
\text { Faculty }\end{array}$ & 0 & 2 \\
\hline $\begin{array}{l}\text { Program } \\
\text { Faculty } \\
\text { Meetings }\end{array}$ & 1 & 1 \\
\hline $\begin{array}{l}\text { Utilization of } \\
\text { Assessment } \\
\text { Data }\end{array}$ & 1 & 1 \\
\hline $\begin{array}{l}\text { Identification of } \\
\text { Areas for } \\
\text { Teacher }\end{array}$ & 1 & 0 \\
$\begin{array}{l}\text { Candidates to } \\
\text { Improve }\end{array}$ & 1 & 0 \\
\hline $\begin{array}{l}\text { Generation of } \\
\text { Data }\end{array}$ & 1 & 0 \\
\hline $\begin{array}{l}\text { Assessment } \\
\text { Support from } \\
\text { Supporting } \\
\text { Programs }\end{array}$ & 0 & 1 \\
\hline $\begin{array}{l}\text { Faculty } \\
\text { Participation }\end{array}$ & 1 & \\
\hline $\begin{array}{l}\text { Joint } \\
\text { Committee on } \\
\text { Teacher } \\
\text { Preparation }\end{array}$ & $\begin{array}{l}\text { Informal } \\
\text { Discussions }\end{array}$ & \\
\hline
\end{tabular}


Table 33

Frequency of theme emergence pertaining to strengths across items: Continued

\begin{tabular}{|l|c|c|}
\hline Factors & $\begin{array}{l}\text { Program } \\
\text { Coordinator }\end{array}$ & $\begin{array}{c}\text { Assistant } \\
\text { Professor }\end{array}$ \\
\hline Resources & 1 & 0 \\
\hline $\begin{array}{l}\text { Promotion of } \\
\text { Healthy } \\
\text { Assessment } \\
\text { Discussion } \\
\text { within the } \\
\begin{array}{l}\text { University } \\
\text { Committee }\end{array}\end{array}$ & 1 & \\
\hline $\begin{array}{l}\text { Access to } \\
\text { Professional } \\
\text { Development } \\
\text { Opportunities }\end{array}$ & & 0 \\
\hline $\begin{array}{l}\text { Favorable View } \\
\text { of Assessment }\end{array}$ & & \\
$\begin{array}{l}\text { Work in } \\
\text { Faculty } \\
\text { Evaluations }\end{array}$ & & \\
\hline
\end{tabular}

Each of the participants identified program faculty meetings and the utilization of assessment data as important factors influencing their satisfaction with their participation in assessment decisions. Each of the participants also identified the utilization of assessment data in making key decisions about program changes as important factors of their satisfaction.

The assistant professor noted the non-rigid formula for assessment and the autonomy of program faculty was beneficial to the assessment plan and its implementation. He also reported that the autonomy of program faculty was helpful to the implementation of the current assessment plan and to program faculty leadership. 
Program faculty did not identify any perceived challenges to assessment on multiple occasions (see Table 34).

Table 34

Frequency of theme emergence pertaining to challenges across items

\begin{tabular}{|l|c|c|}
\hline Factors & $\begin{array}{l}\text { Program } \\
\text { Coordinator }\end{array}$ & $\begin{array}{l}\text { Assistant } \\
\text { Professor }\end{array}$ \\
\hline $\begin{array}{l}\text { Alignment of } \\
\text { Assessment } \\
\text { Methods with } \\
\text { Other Schools } \\
\text { on Campus }\end{array}$ & 1 & 0 \\
\hline $\begin{array}{l}\text { Nationally } \\
\text { Comparable } \\
\text { Data }\end{array}$ & 0 & 1 \\
\hline $\begin{array}{l}\text { Confining } \\
\text { Assessment } \\
\text { Discussions }\end{array}$ & 0 & 1 \\
\hline $\begin{array}{l}\text { Assumption } \\
\text { that Assessment } \\
\text { Activities are } \\
\text { Perfect }\end{array}$ & 0 & 1 \\
\hline
\end{tabular}

In this case study, the researcher presented the institutional background as it pertains to assessment and described the programs and participants. Participants in this BU case study included the institutional assessment leader, program administrators (two department chairs and one program coordinator), and faculty from the Departments of English, Mathematics and Statistics, and the Secondary Education.

The researcher fully analyzed data gathered from the interviews and documents. The major results pertaining to each research question are highlighted and presented by each academic program. In addition, the frequency of themes pertaining to participants' satisfaction with assessment is discussed including strengths and challenges. In Chapter 
7, the researcher presents the major results from the cross-site analysis which includes participants’ demographic information, comparison of assessment practices across participating programs at the three universities pertinent to the sustainment and improvement phase (Banta, 2002). Commitments and resources provided to assessment and faculty satisfaction data are also discussed in Chapter 7. 


\section{Chapter 5}

\section{Alpha University}

\section{Institutional Background}

Alpha University (AU) is identified by the Carnegie Foundation for the Advancement of Teaching (2006) as a research university with high research activity (basic classification). AU is located in the mid-west region of the United States. During the 2006-2007 academic year, over 29,000 students were enrolled in over 200 programs. AU employed 2,359 full-time faculty and 1800 part-time faculty. According to the AU website (2007), the mission of the institution is to:

advance the state and the intellectual growth of its citizens to the highest levels nationally and internationally through research and creative activity, teaching and learning, and civic engagement. By offering a distinctive range of bachelor's, master's, professional, and Ph.D. degrees, AU promotes the educational, cultural, and economic development of central Indiana and beyond through innovative collaborations, external partnerships, and a strong commitment to diversity.

Participating AU programs in this research study included Mathematics and Statistics, Psychology, Biology, Secondary Education, English and Nursing.

General education outcomes. Faculty at Alpha University implemented general education outcomes that were assessed within the general education curriculum as well as within the student's discipline of study. According to the institutional assessment leader, "we have six Principles of Undergraduate Learning (PULs) and those are stated in such a way that they become student learning outcomes." She continued, "we have said that 
general education persists throughout the curriculum and that these generic skills, these principles, are really enacted in the disciplines.” According to the institution's website, the Principles of Undergraduate Learning, developed over several years of discussion involving hundreds of faculty, students, and staff, were adopted by the Faculty Council in May 1998. These principles describe the fundamental intellectual competence and cultural and ethical awareness that we believe every graduate of a baccalaureate degree program should attain.

The institutional assessment leader reported that "everyone of the programs is supposed to have learning outcomes in the major that take into account the Principles of Undergraduate Learning.” These outcomes were based on six goals that included:

- core communication and quantitative skills,

- critical thinking,

- integration and application of knowledge,

- intellectual depth, breadth, and adaptiveness,

- understanding society and culture, and

- values and ethics.

Program review and assessment committee. The institutional assessment leader reported that each academic program was required to submit an annual report to the Program Review and Assessment Committee (PRAC). She noted that assessment data was contained within the annual program review report. Program review and assessment plan documents were submitted to a campus-wide program review and assessment committee. According to the institutions’ website, 
The Program Review and Assessment Committee (PRAC) is composed of representatives of a broad range of academic units and support units. The committee establishes guidelines for comprehensive program review for academic and administrative units and provides guidance for student outcomes assessment throughout the institution. It also provides a forum for the exchange of program review and assessment information and strategies among graduate and undergraduate programs and administrative units. The committee, which has faculty leadership, funds, grants that promise innovative approaches or improved practice in assessment. It also has the responsibility for preparing campus assessment plans and reports that may be required by the North Central Association. The activities of the committee are supported by the Office of the Vice Chancellor for Planning and Institutional Improvement.

According to the institutional assessment leader, the PRAC was composed of "two members from each discipline plus representatives from the library, student affairs, and all of the other administrative offices that have assessment specialists. She noted, “internal people are very much impressed by the PRAC reports.”

Office of the Senior Advisor to the Chancellor. The Senior Advisor to the Chancellor coordinated program review and assessment activities at the institutional level and served on the PRAC. The institutional assessment leader worked with assessment specialists within administrative offices, student support services, academic support services and in academic areas. Additionally, she reported that some schools had associate or assistant deans that coordinate school- and program- level assessment activities. In addition to coordinating institutional level assessment activities, the institutional assessment leader 
participated in national- and state-level higher education policy setting pertaining to accreditation and assessment.

\section{Undergraduate Mathematics Program}

The Department of Science awarded a Bachelor of Science Degree in Mathematics. Faculty offered specializations in pure mathematics, applied mathematics, actuarial science, and mathematics education. Additionally, students could pursue a minor in mathematics.

The mathematics program faculty consisted of 12 professors, 11 associate professors, and five assistant professors. Interview data revealed that between 20 to 40 part-time faculty taught courses in the department. Undergraduate mathematics students were primarily enrolled full-time. Class sizes ranged between 30 to 45 students.

\section{Study Participants}

The researcher conducted interviews with two associate professors and a senior lecturer. The senior associate professor was in his 26th year as a professor at the institution and was serving his 20th year as the associate chairperson. He had worked in higher education for 31 years. He claimed that he was not very knowledge about student outcomes assessment. The senior associate professor acted in the capacity of the "point person” for assessment within the department. This faculty member attended one conference that focused on student outcomes assessment in the past two years. He had not published any papers pertaining to student outcomes assessment in the past two years nor had he presented assessment results at any conferences.

The second participant, the junior associate professor, was serving his 23rd year at AU. This associate professor purported to be “somewhat” knowledgeable about student 
outcomes assessment since he was responsible for developing a remedial program in mathematics. The associate professor did not attend any conferences that focused on student outcomes; however, he had attended one conference that included outcomes assessment sessions on the program in the past two years. He had published one paper pertaining to student outcomes assessment in the past two years and presented assessment results at one conference within the past two years.

The third participant, a senior lecturer, was serving his 12th year at AU. He had worked in higher education for approximately 11 years. The senior lecturer had not attended any conferences that focused on student outcomes assessment nor had he attended any conferences that included assessment sessions on the program in the past two years. He had not published any papers pertaining to student outcomes assessment in the past two years.

\section{Characteristics of Effective Assessment Practice}

The researcher analyzed interview data and the 2006 Department of Mathematical Sciences Assessment of Student Learning Annual Report to identify characteristics of effective practice. Additionally, the researcher evaluated the assessment plan to determine the degree to which its implementation demonstrated characteristics of effective practice. However, the researcher was unable to interview the mathematics department chair. Thus, the researcher utilized limited data to evaluate the assessment plan. Additionally, the researcher did not collect any data that illustrated the commitments and resources provided to the assessment endeavor of the program since the department chair was unavailable. 
Credible evidence of learning. Documents and interview respondents illustrated various components of the assessment plan that demonstrated that learning was relevant to the major and assessment measures were reliable. Mathematics program faculty assessed 23 student learning outcomes. However, 14 of the learning statements were not learner-centered, measurable, nor clear. Thus, the researcher analyzed nine outcomes.

The outcomes for the mathematics major spanned three of six cognitive domains contained within Bloom’s Taxonomy (Anderson, et al., 2001). The outcomes were skewed to the mid-level cognitive domains. None of the cognitive outcomes were representative of the remember, evaluate, or create domains. Fifty-five percent of the outcomes represented the understand domain, $11 \%$ of the outcomes represented the apply domain, 22\% of the outcomes represented the analyze domain (see Table 35). One outcome was representative of the affective domain. These outcomes were learnercentered and were clear, measurable, and spanned multiple learning domains. A departmental mission statement was not available.

Table 35

Distribution of intended cognitive learning outcomes

\begin{tabular}{|c|c|c|}
\hline Cognitive Domain & N & $\%$ \\
\hline Create & 0 & 0 \\
\hline Evaluate & 0 & 0 \\
\hline Analyze & 2 & 22.2 \\
\hline Apply & 1 & 11.1 \\
\hline Understand & 5 & 55.5 \\
\hline Remember & 0 & 0 \\
\hline
\end{tabular}

Examples of the intended learning outcomes within the understand domain included:

- understand mathematical arguments and

- understand the principal modes of discovery in mathematics. 
Examples of intended learning outcomes within the apply domain included:

- demonstrate information competence and

- apply psychological principles to critical issues within the area of specialization for the specific course.

Examples of intended learning outcomes within the analyze domain included:

- critically analyze mathematical arguments and

- analyze mathematical data.

The Department of Mathematics utilized two assessment methods to measure student achievement. The department's Assessment of Student Learning Annual Report revealed that common examinations and a capstone product were the main assessment methods. Mathematics department faculty implemented common examinations across multiple sections of three courses: MATH 118 (Finite Mathematics), MATH 111 (Algebra), and MATH 163 (Integrated Calculus and Analytic Geometry). According to the department's annual assessment report,

the assessment process that was adopted [by faculty] entails dividing the material for a particular course into topics (which correspond to course outcome objectives). Exam scores for individual students are broken down into subscores on each topic. The variation in scores from student to student, from section to section, and from year to year can then be analyzed.

Program faculty also examined "section averages on each topic, standard deviations on each topic for each section, and the standard deviation of the section averages on each topic." According to the assessment report, they determined the "topics that give students the most trouble.” In this way, "the department can better identify particular 
weaknesses and strengths of students, instructors, and books. Also, instructors and course coordinators can try to develop more consistent ways of presenting topics that prove to be more problematic for students and instructors."

Additionally, mathematics faculty designed a capstone assessment activity that assessed student achievement related to the general education objectives. The capstone experience project required students to display:

- an ability to formulate problems, solve them, and interpret their solution,

- an understanding of the nature of proof,

- a mastery of diverse mathematical ideas,

- an ability to communicate mathematical ideas orally and in writing,

- an ability in applying knowledge from one branch of mathematics to another from mathematics to other disciplines,

- an efficient use of technological tools and scientific resources (e.g. journals),

- a knowledge of contemporary and ethical issues in science and their relations to society, and

- an appreciation of the historical development of an area of mathematics.

The above items were then incorporated into a rubric. According to the annual assessment report, faculty are using [the capstone rubric] to assess how well the capstone experience is serving its intended purpose (requiring the student to show growth in all of the PUL's, and in discipline specific outcome goals) and as an assessment tool to assess how well our programs are achieving their goals.

Faculty critiqued capstone projects utilizing a five-point Likert scale. 
The analysis of data from the aforementioned assessment activities was appropriate. Descriptive statistics were provided for examination data. According to the faculty, the assessment results linked directly to the intended learning outcomes of the program.

Continuous Improvement. The 2006 annual assessment report provided no evidence to document program changes or improvements that had been implemented based on assessment data. However, the report revealed that a high percentage of [AU] students are skillful problem solvers, show mastery of diverse mathematical ideas, show ability to communicate ideas of their discipline orally and in writing, show ability to apply knowledge from one area [of mathematics] to another, [and] show ability to apply knowledge from mathematics to other disciplines.

Accountability to internal stakeholders. The 2006 annual departmental assessment report revealed that the common examinations and the capstone experience were the only assessments implemented by faculty. Thus, faculty utilized data from these assessment activities to demonstrate accountability to internal stakeholders. Additionally, program faculty submit an annual assessment report to the School of Science administrators.

Ongoing assessment. The annual departmental assessment report revealed that faculty embedded common examinations into specific courses that included items pertinent to specific intended learning outcomes. Thus, assessment occurred on a predictable schedule within the Department of Mathematics.

Ongoing Evaluation and Improvement. The annual departmental assessment report provided no evidence to suggest that faculty conducted an ongoing evaluation and improvement of the assessment plan. 


\section{Faculty Satisfaction with Assessment}

Faculty satisfaction with program assessment was determined by analyzing interview data from three individuals: two associate professors and a senior lecturer. The researcher elicited information regarding their satisfaction with the implementation of the current assessment plan, opportunities to participate in policy making, central leadership support for assessment, faculty leadership support, professional development, evaluations and rewards, academic decision making, and the impact of student assessment on the program.

Satisfaction with the Assessment Plan. The senior associate professor purported to be very satisfied with the assessment plan while the junior associate professor and senior lecturer reported to be satisfied. The senior associate professor emphasized the leadership of the department assessment leader and the ability of faculty to track student performance (see Table 36). He noted, “I’m probably more responsible for [the assessment plan] than anyone else.” The senior associate professor also valued the interest of departmental faculty to track student achievement over time.

The junior associate professor claimed, "[the assessment plan] gets at what the students really need to learn.” He continued by noting the usefulness of assessment data to “increase student's learning to the objectives [set by faculty] as opposed to the other way around.”

Satisfaction with the Implementation of the Current Assessment Plan. All three participants purported to be satisfied with the implementation of the current assessment plan. The junior associate professor claimed that assessment improved student retention 
Table 36

Assessment plan: Perceived strengths

\begin{tabular}{|l|c|l|l|}
\hline Factors & $\begin{array}{l}\text { Senior } \\
\text { Associate } \\
\text { Professor }\end{array}$ & $\begin{array}{l}\text { Junior } \\
\text { Associate } \\
\text { Professor }\end{array}$ & $\begin{array}{l}\text { Senior } \\
\text { Lecturer }\end{array}$ \\
\hline $\begin{array}{l}\text { Department } \\
\text { Assessment Leader }\end{array}$ & $\mathrm{X}$ & & \\
\hline $\begin{array}{l}\text { Tracking of Student } \\
\text { Performance }\end{array}$ & $\mathrm{X}$ & $\mathrm{X}$ & \\
\hline $\begin{array}{l}\text { Learning is } \\
\text { Relevant to } \\
\text { Objectives }\end{array}$ & & & \\
\hline
\end{tabular}

within the program and achievement (see Table 37). He noted that student assessment generated student achievement data that program faculty found useful to inform academic decisions. Specifically, the junior associate professor reported that faculty offered some mathematics courses in shopping malls rather than a more traditional academic setting. He stated that assessment data revealed that students attending off-campus AU mathematics courses in a high school building performed better than the students enrolled in off-campus courses facilitated in a shopping mall. The junior associate professor discussed how the variety of assessment methods (such as common examinations) provided evidence regarding the quality of teaching. However, the junior associate professor noted challenges monitoring adjunct faculty members who had lower teaching evaluation scores compared to other on-campus departments. He stated that the department "had no control over [adjunct] instructors after we hired them.” The junior associate professor continued, “[program administrators] gave [adjunct faculty members] the [course] book, the syllabus... and we never saw them again.” When teaching 
evaluation scores were low, he claimed that direct student achievement data should be examined to evaluate teaching.

Table 37

Implementation of the current assessment plan: Perceived strengths

\begin{tabular}{|l|l|c|c|}
\hline Factors & $\begin{array}{l}\text { Senior } \\
\text { Associate } \\
\text { Professor }\end{array}$ & $\begin{array}{l}\text { Junior } \\
\text { Associate } \\
\text { Professor }\end{array}$ & Senior Lecturer \\
\hline $\begin{array}{l}\text { Improves } \\
\text { Retention in the } \\
\text { Program }\end{array}$ & & $\mathrm{X}$ & \\
\hline $\begin{array}{l}\text { Improves } \\
\text { Student } \\
\text { Achievement }\end{array}$ & & $\mathrm{X}$ & \\
\hline $\begin{array}{l}\text { Generates Data } \\
\text { Useful to } \\
\text { Academic } \\
\begin{array}{l}\text { Decision } \\
\text { Making }\end{array}\end{array}$ & & $\mathrm{X}$ & \\
\hline $\begin{array}{l}\text { Common } \\
\text { Examinations }\end{array}$ & & $\mathrm{X}$ & \\
\hline $\begin{array}{l}\text { Evidences of } \\
\text { Learning to } \\
\text { Support Faculty } \\
\text { Teaching }\end{array}$ & & & \\
Quality & & $\mathrm{X}$ & \\
\hline
\end{tabular}

Even though the senior associate professor and the senior lecturer reported to be satisfied with the implementation of the current assessment plan, they both identified challenges. The senior associate professor noted that the assessment plan was still under revision (see Table 38). He noted, “there’s still more to do, but I basically think the department’s doing what it can.” The senior lecturer expressed concerns with physical restrictions. He stated, "when you have 2000 students trying to get into a single room or a few rooms to take a departmental exam, well that presents problems.” 
Table 38

Assessment plan: Perceived challenges

\begin{tabular}{|l|l|l|c|}
\hline Factors & $\begin{array}{l}\text { Senior } \\
\text { Associate } \\
\text { Professor }\end{array}$ & $\begin{array}{l}\text { Junior } \\
\text { Associate } \\
\text { Professor }\end{array}$ & $\begin{array}{l}\text { Senior } \\
\text { Lecturer }\end{array}$ \\
\hline $\begin{array}{l}\text { Assessment Plan } \\
\text { Under Revision }\end{array}$ & $\mathrm{X}$ & & \\
\hline $\begin{array}{l}\text { Physical Plant } \\
\text { Restrictions }\end{array}$ & & & $\mathrm{X}$ \\
\hline
\end{tabular}

Faculty Satisfaction with Participation in Assessment Decisions. The senior and junior associate professor purported to be very satisfied with their opportunities to participate in assessment decisions while the senior lecturer reported to be satisfied (see Table 39). The senior associate professor reported that his contribution to the assessment plan was an important factor in his satisfaction. He stated, "I am in charge of many of the aspects of departmental assessment...so I guess you'd say I have all of the access I'd ever wish for." He also identified his service to the departmental assessment committee. He noted, “I'm the departmental representative on the assessment committee.”

The junior associate professor stated, "we created our own [assessment plan]. I was the one doing the work, so in a sense I was creating the policy up to a certain point. I've kind of gotten out of that in the last six to 10 years.” The senior lecturer illustrated faculty participation as an important factor to his satisfaction. He stated, "the writing of exams, the objectives, what's going to be on those exams, [the faculty] have been working on [that] for a long time.” Additionally, the senior lecturer noted informal faculty discussions about assessment data. 
Table 39

Participation in assessment decisions: Perceived strengths

\begin{tabular}{|l|l|l|c|}
\hline Factors & $\begin{array}{l}\text { Senior } \\
\text { Associate } \\
\text { Professor }\end{array}$ & $\begin{array}{l}\text { Junior } \\
\text { Associate } \\
\text { Professor }\end{array}$ & Senior Lecturer \\
\hline $\begin{array}{l}\text { Personal } \\
\text { Contribution to } \\
\text { the Assessment } \\
\text { Plan }\end{array}$ & $\mathrm{X}$ & $\mathrm{X}$ & \\
\hline $\begin{array}{l}\text { Service to } \\
\text { Departmental } \\
\text { Assessment } \\
\text { Committee }\end{array}$ & & $\mathrm{X}$ & \\
\hline $\begin{array}{l}\text { Faculty } \\
\text { Participation }\end{array}$ & & & \\
\hline $\begin{array}{l}\text { Informal } \\
\text { Faculty } \\
\text { Discussions }\end{array}$ & & & $\mathrm{X}$ \\
\hline
\end{tabular}

Faculty Satisfaction with Central Leadership Support for Assessment. The senior associate professor purported to be satisfied with the central leadership support for assessment while the junior associate professor purported to be very satisfied and the senior lecturer purported to be neutral. The senior associate professor reported that the program assessment plan required few resources (see Table 40). He stated, "I think the sort of assessment that the department does doesn't really require an outside investment.” The senior associate professor also noted that faculty participated in assessment endeavors.

The junior associate professor identified the institutional assessment leader as an important factor in his satisfaction with central leadership support. He stated, "hiring a vice chancellor whose responsibility is assessment sends a clear marker to the entire 
Table 40

Central leadership support for assessment: Perceived strengths

\begin{tabular}{|l|c|l|l|}
\hline Factors & $\begin{array}{l}\text { Senior Associate } \\
\text { Professor }\end{array}$ & $\begin{array}{l}\text { Junior Associate } \\
\text { Professor }\end{array}$ & Senior Lecturer \\
\hline $\begin{array}{l}\text { Program } \\
\begin{array}{l}\text { Assessment Plan } \\
\text { Requires Few } \\
\text { Resources }\end{array}\end{array}$ & $\mathrm{X}$ & & \\
\hline $\begin{array}{l}\text { Faculty } \\
\text { Participation }\end{array}$ & $\mathrm{X}$ & & \\
\hline $\begin{array}{l}\text { Institutional } \\
\text { Assessment Leader }\end{array}$ & & $\mathrm{X}$ & \\
\hline $\begin{array}{l}\text { Availability of } \\
\text { Resources for } \\
\text { Assessment } \\
\text { Activities }\end{array}$ & & $\mathrm{X}$ & \\
\hline
\end{tabular}

institution of expectations, priorities, and resources for that activity.” Additionally, the junior associate professor noted the resources made available by the institution to support assessment activities.

The senior lecturer remained neutral in his response as he claimed he had "no contact" with central leadership. He further noted that he had "no expectations" concerning central leadership and assessment.

Faculty Satisfaction with Mathematics Program Faculty Leadership Support. The senior associate professor reported to be very satisfied with program faculty leadership support for assessment while the junior associate professor reported to be neutral and the senior lecturer reported to be satisfied. The senior associate professor noted that faculty “have always been willing to do what we’ve asked them to.” He also noted he had access to assessment data. The senior lecturer identified the leadership of the department chair 
as an important factor of his satisfaction (see Table 41). He noted, "our department chair is very responsive to what's happening... he is very easy to work with.”

Table 41

Program faculty leadership support: Perceived strengths

\begin{tabular}{|l|c|l|c|}
\hline Factors & $\begin{array}{l}\text { Senior } \\
\text { Associate } \\
\text { Professor }\end{array}$ & $\begin{array}{l}\text { Junior } \\
\text { Associate } \\
\text { Professor }\end{array}$ & Senior Lecturer \\
\hline $\begin{array}{l}\text { Faculty } \\
\text { Participation }\end{array}$ & $\mathrm{X}$ & & \\
\hline $\begin{array}{l}\text { Access to } \\
\text { Assessment } \\
\text { Data }\end{array}$ & $\mathrm{X}$ & & \\
\hline $\begin{array}{l}\text { Department } \\
\text { Chair } \\
\text { Leadership }\end{array}$ & & & $\mathrm{X}$ \\
\hline
\end{tabular}

However, the junior associate professor identified the lack of faculty participation in assessment policy making as an assessment challenge. He stated, “faculty don’t know what's actually going on behind the sense [with assessment policy making].”

Faculty Satisfaction with Professional Development for Student Assessment. The senior associate professor purported to be satisfied with professional development for student assessment while the junior associate professor and the senior lecturer purported to be neutral. The senior associate professor identified the leadership of the School of Science Assessment Committee as an important factor with his satisfaction (see Table 42). He stated, "under [the current leadership] I think the committee is doing a pretty good job of helping the departments in dealing with assessment.” The senior associate professor also noted the importance of faculty discussions. He reported that the assessment committee was "getting us all together and having us talk about what each individual department is going." 
Table 42

Professional development for student assessment: Perceived strengths

\begin{tabular}{|l|c|l|c|}
\hline Factors & $\begin{array}{l}\text { Senior } \\
\text { Associate } \\
\text { Professor }\end{array}$ & $\begin{array}{l}\text { Junior } \\
\text { Associate } \\
\text { Professor }\end{array}$ & Senior Lecturer \\
\hline $\begin{array}{l}\text { Leadership of } \\
\text { the School } \\
\text { Assessment } \\
\text { Committee }\end{array}$ & $\mathrm{X}$ & & \\
\hline $\begin{array}{l}\text { Faculty } \\
\text { Discussion }\end{array}$ & $\mathrm{X}$ & & \\
\hline $\begin{array}{l}\text { Utilization of } \\
\text { Exemplary } \\
\text { Faculty to } \\
\text { Facilitate } \\
\text { Developmental } \\
\text { Workshops }\end{array}$ & & & \\
\hline $\begin{array}{l}\text { National } \\
\text { Assessment } \\
\text { Institute }\end{array}$ & & $\mathrm{X}$ & \\
\hline $\begin{array}{l}\text { Developmental } \\
\text { Workshops } \\
\text { Available for } \\
\text { Adjunct Faculty }\end{array}$ & & & \\
\hline
\end{tabular}

Even though the junior associate professor and the senior lecturer reported to be neutral in their satisfaction with professional development for student assessment, they each identified some strengths. The junior associate professor noted that exemplary faculty facilitated developmental workshops pertaining to assessment. He also noted that many of the program faculty participated in the National Assessment Institute facilitated by AU. The senior lecturer noted that developmental workshops were available to adjunct faculty.

The junior associate professor and the senior lecturer also noted challenges with professional development. The junior associate professor reported that infrequent 
assessment workshops were only utilized by faculty whose position responsibilities included assessment (see Table 43). The senior lecturer reported that resources available to facilitate developmental workshops were limited.

Table 43

Professional development for student assessment: Perceived challenges

\begin{tabular}{|l|l|l|c|}
\hline Factors & $\begin{array}{l}\text { Senior } \\
\text { Associate } \\
\text { Professor }\end{array}$ & $\begin{array}{l}\text { Junior } \\
\text { Associate } \\
\text { Professor }\end{array}$ & Senior Lecturer \\
\hline $\begin{array}{l}\text { Developmental } \\
\text { Workshops } \\
\text { Utilized by } \\
\text { Faculty with a } \\
\text { Professional } \\
\text { Obligation } \\
\text { Related to } \\
\text { Assessment }\end{array}$ & \multicolumn{1}{|c|}{$\mathrm{X}$} & \\
\hline $\begin{array}{l}\text { Lack of } \\
\text { Availability of } \\
\text { Developmental }\end{array}$ & & & \\
Workshops & & & \\
Pertaining to & & & \\
Assessment & & & \\
\hline Limited & & & \\
Resources to & & & \\
Facilitate & & & \\
Additional & & & \\
Professional & & & \\
Development & & & \\
Workshops & & & \\
\hline
\end{tabular}

Faculty Satisfaction with Evaluations and Rewards Based on Student Assessment

Data or Involvement. Each of the associate professors responded differently when queried about their satisfaction with evaluations and rewards based on student assessment data or involvement. The senior associate professor purported to be satisfied with evaluations and rewards based on student assessment data or involvement while the 
junior associate professor purported to be unsatisfied and the senior lecturer purported to be neutral.

The senior associate professor reported that the department chair considered the assessment activities of faculty when he evaluated them (see Table 44). He stated, "I think [the chair] takes account of all the efforts the faculty do. I think faculty members don’t have to worry about not being given appropriate credit.” The junior associate professor reported that assessment work was required for promotion. He stated, “for anyone on this campus to get promoted on teaching, they need to do the assessment themselves and they need to get it published.” The junior associate professor also identified teaching awards for assessment activities and the availability of stipends to support assessment activities. The senior lecturer reported that the intrinsic value of assessment to improve pedagogy was an important factor in his satisfaction.

The junior associate professor identified the institutional assessment leader as an important factor in his satisfaction with central leadership support. He stated, "hiring a vice chancellor whose responsibility is assessment sends a clear marker to the entire Table 44

Evaluations and rewards based on student assessment data or involvement: Perceived strengths

\begin{tabular}{|l|l|l|l|}
\hline Factors & $\begin{array}{l}\text { Senior } \\
\text { Associate } \\
\text { Professor }\end{array}$ & $\begin{array}{l}\text { Junior } \\
\text { Associate } \\
\text { Professor }\end{array}$ & Senior Lecturer \\
\hline $\begin{array}{l}\text { Department } \\
\text { Chair Considers }\end{array}$ & & & \\
$\begin{array}{l}\text { Assessment } \\
\text { Efforts of } \\
\text { Faculty }\end{array}$ & $\mathrm{X}$ & & \\
\hline
\end{tabular}


Table 44

Evaluations and rewards based on student assessment data or involvement: Perceived strengths continued

\begin{tabular}{|l|l|l|c|}
\hline Factors & $\begin{array}{l}\text { Senior } \\
\text { Associate } \\
\text { Professor }\end{array}$ & $\begin{array}{l}\text { Junior } \\
\text { Associate } \\
\text { Professor }\end{array}$ & Senior Lecturer \\
\hline $\begin{array}{l}\text { Publication of } \\
\text { Assessment } \\
\text { Work is } \\
\text { Required for } \\
\text { Promotion }\end{array}$ & & X & \\
\hline $\begin{array}{l}\text { Teaching } \\
\text { Awards for } \\
\text { Assessment } \\
\text { Work }\end{array}$ & & X & \\
\hline $\begin{array}{l}\text { Stipends } \\
\text { Available for } \\
\text { Assessment }\end{array}$ & & & \\
Work & & & \\
\hline Intrinsic Value & & & \\
\hline
\end{tabular}

However, the junior associate professor reported that the process of evaluating and rewarding faculty based on assessment data needs to be improved. He noted that administrators talk about rewarding faculty for assessment; however, “you don’t see any action on it.”

Faculty Satisfaction with the Use of Student Assessment Data in Making Academic Decisions. Both of the associate professors purported to be satisfied with the use of student assessment data in academic decision making. However, the senior lecturer remained neutral in his response.

The senior associate professor reported that the use of assessment data in making academic decisions ensured that teaching practices were effective (see Table 45). He stated, “[faculty use assessment data] to track to see that teaching isn’t getting sidetracked 
or that the students are sort of consistently performing at the same level, hopefully maybe improving a little bit over time...but at least not falling back.” However, the senior associate professor noted a challenge in the use of assessment data to inform programmatic changes. He stated, “[assessment data] really hasn’t driven departmental changes.” The junior associate professor reported that assessment data had been used for student advising purposes. He stated, "I have looked at the performance in courses holistic to the capstone experience and decided whether they should actually apply for [a teaching license].” The senior lecturer reported that he did not know how faculty or administrators utilized assessment data in academic decision making.

Table 45

Use of assessment data in making academic decisions: Perceived strengths

\begin{tabular}{|l|c|l|l|}
\hline Factors & $\begin{array}{l}\text { Senior Associate } \\
\text { Professor }\end{array}$ & $\begin{array}{l}\text { Junior Associate } \\
\text { Professor }\end{array}$ & Senior Lecturer \\
\hline $\begin{array}{l}\text { Ensures } \\
\text { Effective } \\
\text { Teaching } \\
\text { Practices }\end{array}$ & $\mathrm{X}$ & & \\
\hline $\begin{array}{l}\text { Use of } \\
\text { Assessment } \\
\text { Data for Student } \\
\text { Advising }\end{array}$ & & & \\
\hline
\end{tabular}

Faculty Satisfaction with the Impact Student Assessment had on the Mathematics

Program. Both of the associate professors reported to be satisfied with the impact student assessment had on the mathematics program. However, the senior lecturer remained neutral in his response. The senior associate professor claimed that program faculty utilized assessment data. He stated, "the department pays attention and learns 
from the data we collect.” The junior associate professor and the senior lecture did not provide any factors associated with their satisfaction.

Faculty Satisfaction Summary. Table 46 illustrates the frequency of themes across items related to strengths in assessment. The most frequently identified themes pertaining to assessment strengths were:

- faculty participation and

- personal contributions to the assessment plan.

The senior associate professor revealed that strong central leadership support for assessment and program faculty leadership encouraged faculty participation.

Additionally, the senior lecturer noted that faculty participated in assessment decisions.

Both of the associate professors made one reference to their personal contributions to the assessment plan through their participation in assessment decisions.

Table 46

Frequency of theme emergence pertaining to strengths across items

\begin{tabular}{|l|c|c|c|}
\hline Factors & $\begin{array}{l}\text { Senior } \\
\text { Associate } \\
\text { Professor }\end{array}$ & $\begin{array}{l}\text { Junior } \\
\text { Associate } \\
\text { Professor }\end{array}$ & $\begin{array}{l}\text { Senior } \\
\text { Lecturer }\end{array}$ \\
\hline $\begin{array}{l}\text { Faculty } \\
\text { Participation }\end{array}$ & 2 & 0 & 0 \\
\hline $\begin{array}{l}\text { Personal } \\
\text { Contribution to the } \\
\text { Assessment Plan }\end{array}$ & 1 & 1 & 0 \\
\hline $\begin{array}{l}\text { Department } \\
\text { Assessment Leader }\end{array}$ & 1 & 0 & 0 \\
\hline $\begin{array}{l}\text { Tracking of Student } \\
\text { Performance }\end{array}$ & 1 & 1 & 0 \\
\hline $\begin{array}{l}\text { Learning is } \\
\text { Relevant }\end{array}$ & 0 & 1 & 0 \\
\hline Improves Retention & 0 & 1 & 0 \\
\hline $\begin{array}{l}\text { Improves Student } \\
\text { Achievement }\end{array}$ & 0 & 0 & 0 \\
\hline
\end{tabular}


Table 46

Frequency of theme emergence pertaining to strengths across items:

Continued

\begin{tabular}{|l|c|c|c|}
\hline Factors & $\begin{array}{l}\text { Senior } \\
\text { Associate } \\
\text { Professor }\end{array}$ & $\begin{array}{l}\text { Junior } \\
\text { Associate } \\
\text { Professor }\end{array}$ & $\begin{array}{l}\text { Senior } \\
\text { Lecturer }\end{array}$ \\
\hline $\begin{array}{l}\text { Generated Data } \\
\text { Useful to Academic } \\
\text { Decision Making }\end{array}$ & 0 & 1 & 0 \\
\hline $\begin{array}{l}\text { Common } \\
\text { Examinations }\end{array}$ & 0 & 1 & 0 \\
\hline $\begin{array}{l}\text { Evidences of } \\
\text { Learning to } \\
\text { Support Faculty } \\
\text { Teaching Quality }\end{array}$ & 0 & 1 & 0 \\
\hline $\begin{array}{l}\text { Informal Faculty } \\
\text { Discussions }\end{array}$ & 0 & 0 & 0 \\
\hline $\begin{array}{l}\text { Program } \\
\text { Assessment Plan } \\
\text { Requires Few } \\
\text { Resources }\end{array}$ & 1 & 1 & 0 \\
\hline $\begin{array}{l}\text { Institutional } \\
\text { Assessment Leader }\end{array}$ & 0 & 0 & 0 \\
\hline $\begin{array}{l}\text { Availability of } \\
\text { Resources for } \\
\text { Assessment } \\
\text { Activities }\end{array}$ & 0 & 0 & 0 \\
\hline $\begin{array}{l}\text { Access to } \\
\text { Assessment Data }\end{array}$ & 1 & 0 & 0 \\
\hline $\begin{array}{l}\text { Department Chair } \\
\text { Leadership }\end{array}$ & 0 & 0 & 0 \\
\hline $\begin{array}{l}\text { Leadership of } \\
\text { School Assessment } \\
\text { Committee }\end{array}$ & 0 & 0 & 0 \\
\hline $\begin{array}{l}\text { Faculty } \\
\text { Discussions }\end{array}$ & 0 & 0 & 0 \\
\hline $\begin{array}{l}\text { Utilization of } \\
\text { Exemplary Faculty } \\
\text { to Facilitate } \\
\text { Developmental } \\
\text { Workshops }\end{array}$ & 0 & 0 & 0 \\
\hline
\end{tabular}


Table 46

Frequency of theme emergence pertaining to strengths across items:

Continued

\begin{tabular}{|l|c|c|c|}
\hline Factors & $\begin{array}{l}\text { Senior } \\
\text { Associate } \\
\text { Professor }\end{array}$ & $\begin{array}{l}\text { Junior } \\
\text { Associate } \\
\text { Professor }\end{array}$ & $\begin{array}{l}\text { Senior } \\
\text { Lecturer }\end{array}$ \\
\hline $\begin{array}{l}\text { National } \\
\text { Assessment } \\
\text { Institute }\end{array}$ & 0 & 1 & 0 \\
\hline $\begin{array}{l}\text { Developmental } \\
\text { Workshops } \\
\text { Available for } \\
\text { Adjunct Faculty }\end{array}$ & 0 & 0 & 1 \\
\hline $\begin{array}{l}\text { Department Chair } \\
\text { Considers } \\
\text { Assessment }\end{array}$ & 1 & 0 & 0 \\
\hline $\begin{array}{l}\text { Assessment Efforts } \\
\text { of Faculty }\end{array}$ & 1 & 1 & 0 \\
\hline $\begin{array}{l}\text { Publication of } \\
\text { Assessment Work } \\
\text { is Required for } \\
\text { Promotion }\end{array}$ & 0 & 1 & 0 \\
\hline $\begin{array}{l}\text { Teaching Awards } \\
\text { for Assessment } \\
\text { Work }\end{array}$ & 0 & 0 & 0 \\
\hline $\begin{array}{l}\text { Stipends Available } \\
\text { for Assessment } \\
\text { Work }\end{array}$ & 0 & 1 & 0 \\
\hline Intrinsic Value & 0 & 0 & 1 \\
\hline $\begin{array}{l}\text { Ensures Effective } \\
\text { Teaching Practices }\end{array}$ & 1 & 0 & 0 \\
\hline $\begin{array}{l}\text { Use of Assessment } \\
\text { Data for Student } \\
\text { Advising }\end{array}$ & 0 & 0 & 0 \\
\hline
\end{tabular}

No common themes pertaining to challenges with assessment emerged among participants (see Table 47). 
Table 47

Frequency of theme emergence pertaining to challenges across items

\begin{tabular}{|c|c|c|c|}
\hline Factors & $\begin{array}{l}\text { Senior } \\
\text { Associate } \\
\text { Professor }\end{array}$ & $\begin{array}{l}\text { Junior } \\
\text { Associate } \\
\text { Professor }\end{array}$ & $\begin{array}{l}\text { Senior } \\
\text { Lecturer }\end{array}$ \\
\hline $\begin{array}{l}\text { Assessment Plan } \\
\text { Under Revision }\end{array}$ & 1 & 0 & 0 \\
\hline $\begin{array}{l}\text { Physical Plant } \\
\text { Restrictions }\end{array}$ & 0 & 0 & 1 \\
\hline $\begin{array}{l}\text { Developmental } \\
\text { Workshops } \\
\text { Utilized by Specific } \\
\text { Faculty Involved } \\
\text { with Assessment }\end{array}$ & 1 & 0 & 0 \\
\hline $\begin{array}{l}\text { Limited Resources } \\
\text { to Facilitate } \\
\text { Additional } \\
\text { Professional } \\
\text { Development } \\
\text { Workshops }\end{array}$ & 0 & 0 & 1 \\
\hline $\begin{array}{l}\text { Lack of Rewards } \\
\text { for Assessment } \\
\text { Work }\end{array}$ & 0 & 1 & 0 \\
\hline
\end{tabular}

\section{Undergraduate Psychology Program}

The Department of Science awarded Bachelor of Science and Bachelor of Arts degrees in Psychology. Students could pursue specializations in clinical rehabilitation, industrial/organizational psychology, and the psychology of addictions within the curriculum of either degree. However, students could only pursue a specialization in behavioral neuroscience within the Bachelor of Science degree. Additionally, students could pursue a minor in psychology.

The psychology program faculty consisted of eight professors, 12 associate professors, and four assistant professors. The university catalog revealed that 14 part-time faculty 
taught courses in the department. Undergraduate psychology students were primarily enrolled full-time. Class sizes ranged between 30 and 130 students.

\section{Study Participants}

The researcher conducted interviews with a professor and three associate professors. The professor was in his seventh year at AU. He had worked in higher education for 35 years. He claimed that he was fairly knowledgeable about student outcomes assessment and reported that he was "one of the pioneers in actually writing one of the first coherent [documents] that went into an American Psychological Association book that set the stage for assessment in psychology.” The professor attended one conference that focused on student outcomes assessment and five conferences that included assessment sessions on the program in the past two years. He presented assessment results at three conferences. He had not published any papers pertaining to student outcomes assessment in the past two years.

The second participant, associate professor A, was serving his tenth year at AU. He had worked in higher education for ten years. Associate professor A purported to be fairly knowledgeable about student outcomes assessment. He noted that as an industrial/organizational psychologist he had "been exposed to methods for assessing different things in an organizational setting, so I think we get exposure to research methods and quantitative techniques used to analyze that data.” Associate professor A had not attended any conferences that focused on student outcomes; however, he had attended two conferences that included outcomes assessment sessions on the program in the past two years. He had presented assessment results at three conferences; however, 
he had not published any papers pertaining to student outcomes assessment in the past two years.

The third participant, associate professor B, was serving his thirteenth year at AU. He had worked in higher education for approximately 18 years. Associate professor B reported to be fairly knowledgeable about student outcomes assessment. He had attended one conference that focused on student outcomes assessment; however, he had not presented assessment results at any conferences in the past two years. Associate professor B had not authored any publications about student outcomes assessment.

The fourth participant, associate professor C, was serving his tenth year at AU. He had worked in higher education for 10 years. Associate professor $\mathrm{C}$ reported to be fairly knowledgeable about student outcomes assessment. He had not attended any conferences that focused on student outcome assessment nor any conferences that included assessment on the program in the past two years. Associate professor $\mathrm{C}$ had not authored any publications on student outcomes assessment nor presented assessment results at a conference in the past two years.

\section{Characteristics of Effective Assessment Practice}

The researcher analyzed interview data and the Psychology Department 2005 Assessment Report to identify characteristics of effective practice. However, the researcher was unable to interview the psychology department chair. As a result, the researcher did not collect any data that illustrated the commitments and resources provided to program assessment. 
Credible evidence of learning. Psychology program faculty assessed 23 student learning outcomes. However, three of the learning statements were not learner-centered, measurable, nor clear. Thus, the researcher analyzed 20 outcomes.

The outcomes for the psychology major spanned two of the six cognitive domains contained within Bloom's Taxonomy (Anderson, et al., 2001). The cognitive outcomes were skewed to the lower-level. Seventy percent of the outcomes represented the understand domain and 30\% of the outcomes represented the apply domain (see Table 48). None of the outcomes were representative of the affective domain. These outcomes were learner-centered, clear, and measurable. A departmental mission statement was not available.

Table 48

Distribution of intended cognitive learning outcomes

\begin{tabular}{|c|c|c|}
\hline Cognitive Domain & N & $\%$ \\
\hline Create & 0 & 0 \\
\hline Evaluate & 0 & 0 \\
\hline Analyze & 0 & 0 \\
\hline Apply & 6 & 30 \\
\hline Understand & 14 & 70 \\
\hline Remember & 0 & 0 \\
\hline
\end{tabular}

Examples of the intended learning outcomes within the understand domain included:

- understand psychological research methods and

- understand the ethics of psychology.

Examples of intended learning outcomes within the apply domain included:

- demonstrate information competence and

- use critical thinking in the scientific approach to problem solving. 
The Assessment Progress Table for School of Science Departments indicated that psychology program faculty had identified student learning outcomes and "link[ed] the student learning outcomes to specific curricular components." According to the psychology professor, these outcomes were derived from "what the American Psychological Association indicated were good outcomes.” However, program faculty were in the process of identifying or creating direct assessment methods to measure student achievement associated with the student learning outcomes. The Department of Psychology 2005 Assessment Report revealed that mainly indirect measures of student learning and satisfaction data had been collected through the senior reflection paper, a graduating student survey, a mentoring faculty survey, and an academic advisor survey. This report revealed that "data from the written senior reflections on the PULs and the graduating student survey are collected to provide School of Science and the Psychology Department with information that can be used to increase the effectiveness of their programs.”

According to the assessment report, "the mentoring and advising surveys are used to give feedback to faculty who serve as mentors and advisors to School of Science students.” The researcher was not able to analyze results from these surveys "due to their confidential nature.”

The analysis of data from the graduating student survey and the alumni survey were appropriate. Descriptive statistics were provided for each measure. However, the assessment results were more closely related to the PULs (general education outcomes) than the intended program learning outcomes. 
Continuous Improvement. Interview data revealed that faculty rarely utilized assessment data to inform academic decisions. However, faculty and students offered many suggestions based on assessment and satisfaction data to improve the program. Data from the graduating student survey revealed that "more students were not accepted into [graduate] programs than those who were accepted.” Thus, it was recommended that faculty become more proactive in the graduate school admissions process. The alumni survey revealed that students had "successfully retained a high level of subject knowledge and skill after graduation.” Therefore, faculty offered no suggestions for improving the curriculum based on this data. However, satisfaction data collected from alumni revealed that weaknesses existed in advising, research opportunities, program curriculum, oral communication, and the "lack of continuity between a statistics course and introduction to laboratory in psychology.”

According to the assessment report, "it was not possible to determine if [advising] weaknesses were due to actual problems in the advising system, alumni unawareness of the advising resources available to them, alumni underutilization of [advising] resources, or a combination of these four variables.” Faculty suggested disseminating information during the first day of classes each semester to inform students of the services and availability of advising resources.

Alumni and capstone course students expressed concerns about the few opportunities they had to conduct research with faculty. According to the report, "both groups believe the department should make faculty research more accessible to psychology students.”

Alumni and capstone course students revealed that psychology courses lacked coherence and information regarding ethics in the discipline. With regard to the 
coherence of the program curriculum, capstone course students noted that formatting requirements for documents varied by faculty. Thus, a recommendation was made for faculty to require the same document formatting requirements across the curriculum. Additionally, alumni believed that they "did not learn ethical standards at [the institution].” Thus, a recommendation was made to test all psychology students "to ensure that they know the ethics involved in psychological research.”

Alumni and capstone course students reported that they "did not excel” in oral communication. According to the report, “...students felt they were not given enough opportunities to improve [their communication skills] by giving oral presentations.” Thus, a recommendation was made for faculty to require additional oral presentations within the program curriculum.

Students enrolled in the capstone course reported that there was a "lack of continuity between Statistics (B305) and Introduction to Laboratory in Psychology (B311).” According to the report, many students indicated that B305 did not prepare them for B311. They reported learning in the mathematical basis of statistics in B305, but were then expected to be proficient in software programs such as SPSS and other data analysis programs when they entered B311.

Thus, suggestions were made "to incorporate the use of data analysis programs in B305" and to "have a computer science data analysis class specifically designed for psychology students.”

Accountability to internal stakeholders. Program faculty shared assessment data, held discussions based on assessment results, and implemented program changes to maintain 
accountability to internal stakeholders. As a result of these activities, all program faculty contributed to assessment endeavors.

Ongoing assessment. Interview data revealed that faculty utilized graduate and alumni surveys on a regular basis to collect assessment data.

Ongoing Evaluation and Improvement. Interview data and documents did not reveal any methods utilized by faculty to conduct ongoing evaluation and improvement of the assessment plan itself. However, some individual faculty were aware of changes that should occur within their assessment approaches.

Faculty Satisfaction with Assessment and the Assessment Plan

Faculty satisfaction with program assessment was determined by analyzing interview data from four individuals: a professor and three associate professors. The researcher elicited information regarding their satisfaction with implementation of the current assessment plan, opportunities to participate in policy making, central leadership support for assessment, faculty leadership support, professional development, evaluations and rewards, academic decision making, and the impact of student assessment on the program.

Satisfaction with the Assessment Plan. The professor and associate professor A purported to be dissatisfied with the assessment plan while associate professor B purported to be satisfied and associate professor $\mathrm{C}$ was neutral in his response. The professor reported that program assessment was “discouraging.” With regard to assessment activities, associate professor A reported that 
there has been an ongoing debate about what assessment is and how much needs to be done and I think a fundamental issue is that some people think that assigning fair course grades is all of the assessment that you need.

The professor reinforced this theme and reported that faculty perceived course grades to be assessment measures. He stated that faculty “don’t quite understand that a grade is global...that's made up of a variety of different [characteristics].”

The professor noted that faculty valued research; however, since teaching was perceived to be less important it was not valued as highly. Associate professor A stated, most people are just too busy [to pursue assessment activities]. [Faculty] are doing everything they can to get tenure, to publish their research, teach, and find time to spend with their family. They have to make choices about what they are going to do and I think that there aren't a lot of incentives.

He further reported that assessment initiatives had been undertaken by individual faculty. However both associate professors A and B revealed that a comprehensive plan had never been developed. Associate professor A claimed that the assessment plan was under revision and that there were challenges analyzing the quantity of data collected (see Table 49). The professor stated,

[the assessment plan] is fairly comprehensive and put together fairly well except for the fact that it takes a tremendous amount of time to go through and content analyze and qualitatively take apart answers to open-ended questions. So, nobody ever did anything with that. 
Table 49

Assessment plan: Perceived challenges

\begin{tabular}{|l|c|c|c|c|}
\hline Factors & Professor & $\begin{array}{l}\text { Associate } \\
\text { Professor A }\end{array}$ & $\begin{array}{l}\text { Associate } \\
\text { Professor B }\end{array}$ & $\begin{array}{l}\text { Associate } \\
\text { Professor C }\end{array}$ \\
\hline $\begin{array}{l}\text { Lack of } \\
\text { Understanding of } \\
\text { Assessment } \\
\text { (Equating } \\
\begin{array}{l}\text { Assessment as } \\
\text { Grades Only) }\end{array}\end{array}$ & $\mathrm{X}$ & $\mathrm{X}$ & \\
\hline Faculty Resistance & $\mathrm{X}$ & & $\mathrm{X}$ & \\
\hline $\begin{array}{l}\text { Assessment Plan } \\
\text { Has Not Been } \\
\text { Implemented }\end{array}$ & $\mathrm{X}$ & & $\mathrm{X}$ & \\
\hline $\begin{array}{l}\text { Assessment Plan is } \\
\text { Under Revision }\end{array}$ & & $\mathrm{X}$ & & \\
\hline $\begin{array}{l}\text { Tremendous Time } \\
\text { Investment for Data } \\
\text { Analysis }\end{array}$ & $\mathrm{X}$ & $\mathrm{X}$ & & \\
\hline Lack Incentives & & $\mathrm{X}$ & & \\
\hline $\begin{array}{l}\text { Determining } \\
\text { Priorities }\end{array}$ & & & & \\
\hline
\end{tabular}

Even though associate professor B reported that he was satisfied with the assessment plan, he identified several challenges. This associate professor and the full professor noted that faculty were resistant to assessment. Associate professor $\mathrm{C}$ reported that "the plan is evolving.” He noted that the department had collected “considerable data.” Associate professor $\mathrm{C}$ reported that faculty examined correlations of student characteristics and academic performance (see Table 50). Additionally, he claimed that faculty were developing interventions to assist students that were considered at risk.

Satisfaction with the Implementation of the Current Assessment Plan. All four participants reported to maintain different degrees of satisfaction with the implementation of the current assessment plan. Associate professor $\mathrm{C}$ reported to be very satisfied with 
Table 50

Assessment plan: Perceived strengths

\begin{tabular}{|l|l|l|l|c|}
\hline Factors & Professor & $\begin{array}{l}\text { Associate } \\
\text { Professor A }\end{array}$ & $\begin{array}{l}\text { Associate } \\
\text { Professor B }\end{array}$ & $\begin{array}{l}\text { Associate } \\
\text { Professor C }\end{array}$ \\
\hline Data was Analyzed & & & & X \\
\hline $\begin{array}{l}\text { Development of } \\
\text { Academic } \\
\text { Intervention Plans }\end{array}$ & & & & $\mathrm{X}$ \\
\hline
\end{tabular}

the implementation of the current plan. He identified alumni surveys as an important factor with his satisfaction (see Table 51). However, associate professor C noted that the plan lacked systematic assessment.

Table 51

Implementation of the current assessment plan: Perceived strengths

\begin{tabular}{|l|l|l|l|c|}
\hline Factors & Professor & $\begin{array}{l}\text { Associate } \\
\text { Professor A }\end{array}$ & $\begin{array}{l}\text { Associate } \\
\text { Professor B }\end{array}$ & $\begin{array}{l}\text { Associate } \\
\text { Professor C }\end{array}$ \\
\hline Alumni Surveys & & & & $\mathrm{X}$ \\
\hline $\begin{array}{l}\text { Improving Faculty } \\
\text { Participation }\end{array}$ & & $\mathrm{X}$ & & \\
\hline
\end{tabular}

Associate professor A was neutral in his response. He reported that faculty participation with assessment activities was improving; however, keeping up with the data was challenging. He stated, "the most challenging thing to our whole evaluation or assessment is that once people have a little information, there's tons more than they want” (see Table 52). The professor reported to be dissatisfied with the implementation of the plan. He noted that an assessment plan had not been implemented. Associate professor B offered no response to this item. 
Table 52

Implementation of the current assessment plan: Perceived challenges

\begin{tabular}{|l|c|l|l|l|}
\hline Factors & Professor & $\begin{array}{l}\text { Associate } \\
\text { Professor A }\end{array}$ & $\begin{array}{l}\text { Associate } \\
\text { Professor B }\end{array}$ & $\begin{array}{l}\text { Associate } \\
\text { Professor C }\end{array}$ \\
\hline $\begin{array}{l}\text { Tremendous Time } \\
\text { Investment for Data } \\
\text { Analysis }\end{array}$ & & $\mathrm{X}$ & & \\
\hline $\begin{array}{l}\text { Assessment Plan } \\
\text { Not Implemented }\end{array}$ & $\mathrm{X}$ & & & \\
\hline
\end{tabular}

Faculty Satisfaction with Participation in Assessment Decisions. All of the participants reported to be satisfied with their participation in assessment decisions. The professor identified the Program Review and Assessment Committee (PRAC), a competitive grant program for assessment activities, and assessment templates as important factors with his satisfaction (see Table 53). He noted that the PRAC was "the committee that sets [assessment] policy.” The professor further noted that the PRAC had developed “a small grant program for people to do assessment projects.” He also reported that the assessment templates provided a "skeletal structure for departments and school to look at [assessment].”

Table 53

Participation in assessment decisions: Perceived strengths

\begin{tabular}{|l|c|c|l|l|}
\hline Factors & Professor & $\begin{array}{l}\text { Associate } \\
\text { Professor A }\end{array}$ & $\begin{array}{l}\text { Associate } \\
\text { Professor B }\end{array}$ & $\begin{array}{l}\text { Associate } \\
\text { Professor C }\end{array}$ \\
\hline $\begin{array}{l}\text { Program Review } \\
\text { and Assessment } \\
\text { Committee }\end{array}$ & $\mathrm{X}$ & $\mathrm{X}$ & & \\
\hline Assessment Grants & $\mathrm{X}$ & & & \\
\hline $\begin{array}{l}\text { Assessment } \\
\text { Templates }\end{array}$ & $\mathrm{X}$ & & & \\
\hline $\begin{array}{l}\text { Personal } \\
\text { Contribution to the } \\
\text { Assessment Plan }\end{array}$ & & $\mathrm{X}$ & & \\
\hline
\end{tabular}


Table 53

Participation in assessment decisions: Perceived strengths continued

\begin{tabular}{|l|l|l|l|c|}
\hline Factors & Professor & $\begin{array}{l}\text { Associate } \\
\text { Professor A }\end{array}$ & $\begin{array}{l}\text { Associate } \\
\text { Professor B }\end{array}$ & $\begin{array}{l}\text { Associate } \\
\text { Professor C }\end{array}$ \\
\hline $\begin{array}{l}\text { Service to } \\
\text { Undergraduate } \\
\text { Committee }\end{array}$ & & & $\mathrm{X}$ & $\mathrm{X}$ \\
\hline $\begin{array}{l}\text { Holds } \\
\text { Administrative } \\
\text { Position }\end{array}$ & & & $\mathrm{X}$ & \\
\hline $\begin{array}{l}\text { Department } \\
\text { Meetings }\end{array}$ & & & & $\mathrm{X}$ \\
\hline Faculty Retreat & & & & $\mathrm{X}$ \\
\hline $\begin{array}{l}\text { E-Mail } \\
\text { Communication }\end{array}$ & & & & $\mathrm{X}$ \\
\hline
\end{tabular}

Associate professor A identified his personal contributions to the assessment plan and the PRAC as key factors influencing his satisfaction with assessment decisions. He stated, "I was one of the players in [the development] of the principles of undergraduate learning.”

Associate professor B identified his service to the undergraduate science committee and his position as a course coordinator as his venues to participate in assessment decisions. He noted that the undergraduate committee had "the freedom to make decisions about what we'd like...to concentrate on.” Additionally, he reported that as the course coordinator he "would have the opportunity if [he] wished to be involved in assessment policy making for the introductory level courses.” Associate professor C identified monthly undergraduate committee meetings, department meetings, a faculty retreat, and e-mail communication as important factors related to his satisfaction.

Faculty Satisfaction with Central Leadership Support for Assessment. All four participants reported to be very satisfied with central leadership support for assessment. 
Associate professor A reported that the university leaders were very knowledgeable about student outcomes assessment. He stated, "I really respect the people that run this campus and I don’t hesitate to pick their brains when I need to” (see Table 54).

Associate professor B reported that the Center for Teaching and Learning "provides expertise in [assessment].” He also identified grants awarded by the institution to support assessment activities.

Associate professor C identified clear communication from central leadership, a culture that values assessment, the availability of resources and developmental workshops, and data services from the Office of Information Management and Institutional Research as important factors of his satisfaction. With regard to clear communication, he stated, “we are constantly getting a very clear message from [central leadership].” Associate professor C noted that monetary resources were available to support assessment activities and that developmental workshops were available "a couple of times each semester.” He also reported that the Office of Information Management and Institutional Research provided data to program faculty.

Table 54

Central leadership support for assessment: Perceived strengths

\begin{tabular}{|l|c|c|c|c|}
\hline Factors & Professor & $\begin{array}{l}\text { Associate } \\
\text { Professor A }\end{array}$ & $\begin{array}{l}\text { Associate } \\
\text { Professor B }\end{array}$ & $\begin{array}{l}\text { Associate } \\
\text { Professor C }\end{array}$ \\
\hline $\begin{array}{l}\text { Expertise of } \\
\text { Administrators }\end{array}$ & $\mathrm{X}$ & $\mathrm{X}$ & & \\
\hline $\begin{array}{l}\text { Center for } \\
\text { Teaching and } \\
\text { Learning }\end{array}$ & & & $\mathrm{X}$ & \\
\hline Assessment Grants & & & $\mathrm{X}$ & \\
\hline $\begin{array}{l}\text { Clear } \\
\text { Communication } \\
\text { from Central } \\
\text { Leadership }\end{array}$ & & & & $\mathrm{X}$ \\
\hline
\end{tabular}


Table 54

Central leadership support for assessment: Perceived strengths continued

\begin{tabular}{|l|l|l|l|c|}
\hline Factors & Professor & $\begin{array}{l}\text { Associate } \\
\text { Professor A }\end{array}$ & $\begin{array}{l}\text { Associate } \\
\text { Professor B }\end{array}$ & $\begin{array}{l}\text { Associate } \\
\text { Professor C }\end{array}$ \\
\hline $\begin{array}{l}\text { Culture that Values } \\
\text { Assessment }\end{array}$ & & & & $\mathrm{X}$ \\
\hline $\begin{array}{l}\text { Availability of } \\
\text { Resources }\end{array}$ & & & & $\mathrm{X}$ \\
\hline $\begin{array}{l}\text { Availability of } \\
\text { Developmental } \\
\text { Workshops }\end{array}$ & & & & $\mathrm{X}$ \\
\hline $\begin{array}{l}\text { Institutional } \\
\text { Research Office }\end{array}$ & & & & $\mathrm{X}$ \\
\hline
\end{tabular}

Even though the professor reported to be very satisfied with central leadership support, he noted that there needed to be more contact between faculty and administrators. He stated, central leadership just doesn’t dribble down as much as it should. [The institutional assessment leader] is a strong force and is really perceived as a competent person so that helps drive some of the credibility. That's not to say that everybody buys what [the institutional assessment leader] says.

Faculty Satisfaction with Psychology Program Faculty Leadership Support. The professor, associate professor A, and associate professor B reported to be dissatisfied with program faculty leadership support while associate professor $\mathrm{C}$ reported to be very satisfied. The professor identified faculty resistance as an important factor with his dissatisfaction (see Table 55). He reported that he was awarded a \$3000 grant to develop a student exit knowledge content examination. However, at a program faculty meeting the professor was informed "in no uncertain terms" that he was not to develop such an 
examination. He noted that it was problematic for his colleagues to "get in the way of grant money.”

Associate professor A reported that faculty were conducting a minimal number of assessments. Associate professor B reported that the department chair was "not very helpful in terms of getting the rest of the faculty to see the advantages of [assessment].” He noted that the resistance of program administrators and faculty impeded the implementation of an assessment plan.

Table 55

Program faculty leadership support: Perceived challenges

\begin{tabular}{|l|c|c|c|c|}
\hline Factors & Professor & $\begin{array}{l}\text { Associate } \\
\text { Professor A }\end{array}$ & $\begin{array}{l}\text { Associate } \\
\text { Professor B }\end{array}$ & $\begin{array}{l}\text { Associate } \\
\text { Professor C }\end{array}$ \\
\hline Faculty Resistance & $\mathrm{X}$ & & & \\
\hline $\begin{array}{l}\text { Minimal Quantity } \\
\text { of Assessments } \\
\text { Implemented }\end{array}$ & & $\mathrm{X}$ & & \\
\hline $\begin{array}{l}\text { Program } \\
\text { Administrator } \\
\text { Resistance }\end{array}$ & & & $\mathrm{X}$ & \\
\hline
\end{tabular}

Associate professor $\mathrm{C}$ had different perceptions. He reported that program faculty were committed to assessment (see Table 56). He stated,

we've got a core of, probably about a fourth of our faculty, that are represented on the undergraduate committee and to some degree all of them have been involved in some aspect of conceptualizing different ways of assessing outcomes or actually just doing it on their own imitative.

He also identified the implemented assessment methods as an important factor of his satisfaction. 
Table 56

Program faculty leadership support: Perceived strengths

\begin{tabular}{|l|l|l|l|c|}
\hline Factors & Professor & $\begin{array}{l}\text { Associate } \\
\text { Professor A }\end{array}$ & $\begin{array}{l}\text { Associate } \\
\text { Professor B }\end{array}$ & $\begin{array}{l}\text { Associate } \\
\text { Professor C }\end{array}$ \\
\hline $\begin{array}{l}\text { Commitment of } \\
\text { Program Faculty }\end{array}$ & & & & $\mathrm{X}$ \\
\hline $\begin{array}{l}\text { Assessment } \\
\text { Methods }\end{array}$ & & & & $\mathrm{X}$ \\
\hline
\end{tabular}

Faculty Satisfaction with Professional Development for Student Assessment. All of the participants purported to be satisfied with professional development for student assessment. The professor noted that there were many assessment experts on campus and that resources were available to support faculty attending conferences (see Table 57). All three associate professors reported the availability of developmental workshops through the Center for Teaching and Learning. Associate professor B stated that the Center for Teaching and Learning "has some very good opportunities in terms of workshops, conferences, on-line materials, and help at the center.” Associate professor C also stated the availability of grants to support assessment activities was another factor related to his satisfaction.

Associate professor A purported to be dissatisfied with professional development for student assessment. He reported that faculty lacked incentives to participate in developmental sessions.

Table 57

Professional development for student assessment: Perceived strengths

\begin{tabular}{|l|c|l|l|l|}
\hline Factors & Professor & $\begin{array}{l}\text { Associate } \\
\text { Professor A }\end{array}$ & $\begin{array}{l}\text { Associate } \\
\text { Professor B }\end{array}$ & $\begin{array}{l}\text { Associate } \\
\text { Professor C }\end{array}$ \\
\hline $\begin{array}{l}\text { Assessment } \\
\text { Experts on Campus }\end{array}$ & $\mathrm{X}$ & & & \\
\hline
\end{tabular}


Table 57

Professional development for student assessment: Perceived strengths continued

\begin{tabular}{|l|c|l|l|c|}
\hline Factors & Professor & $\begin{array}{l}\text { Associate } \\
\text { Professor A }\end{array}$ & $\begin{array}{l}\text { Associate } \\
\text { Professor B }\end{array}$ & $\begin{array}{l}\text { Associate } \\
\text { Professor C }\end{array}$ \\
\hline $\begin{array}{l}\text { Financial Support } \\
\text { to Attend } \\
\text { Conferences }\end{array}$ & $\mathrm{X}$ & & & \\
\hline $\begin{array}{l}\text { Availability of } \\
\text { Developmental } \\
\text { Workshops }\end{array}$ & & & & $\mathrm{X}$ \\
\hline $\begin{array}{l}\text { Availability of } \\
\text { Grants to Support } \\
\text { Assessment } \\
\text { Activities }\end{array}$ & & & & $\mathrm{X}$ \\
\hline $\begin{array}{l}\text { Center for } \\
\text { Teaching and } \\
\text { Learning }\end{array}$ & & & & $\mathrm{X}$ \\
\hline Lack Incentives & & & $\mathrm{X}$ & $\mathrm{X}$ \\
\hline
\end{tabular}

Faculty Satisfaction with Evaluations and Rewards Based on Student Assessment

Data or Involvement. Associate professor C purported to be very satisfied with

evaluations and rewards based on student assessment data or involvement while associate professor B purported to be dissatisfied. The professor and associate professor A remained neutral in their responses.

Associate professor $\mathrm{C}$ identified merit based pay raises and peer reviews to evaluate teaching as important factors related to his satisfaction (see Table 58). However, he did not relate either the merit point system or the peer reviews to assessment activities. He supported associate professor $\mathrm{C}$ by reporting that the merit system did not include assessment criteria to evaluate faculty activities related to assessment. 
Table 58

Evaluations and rewards based on student assessment data or involvement: Perceived strengths

\begin{tabular}{|l|l|l|l|c|}
\hline Factors & Professor & $\begin{array}{l}\text { Associate } \\
\text { Professor A }\end{array}$ & $\begin{array}{l}\text { Associate } \\
\text { Professor B }\end{array}$ & $\begin{array}{l}\text { Associate } \\
\text { Professor C }\end{array}$ \\
\hline $\begin{array}{l}\text { Merit Based Pay } \\
\text { Raises }\end{array}$ & & & & $\mathrm{X}$ \\
\hline $\begin{array}{l}\text { Peer Reviews to } \\
\text { Evaluate Teaching }\end{array}$ & & & & $\mathrm{X}$ \\
\hline
\end{tabular}

Associate professor B reported that faculty were not rewarded for their work with assessment. Even though he purported to be dissatisfied with evaluations and rewards based on student assessment data or involvement, he noted that faculty received acknowledgement for their assessment activities. The professor also reported that faculty received few rewards for assessment activities. Associate professor A also claimed that assessment related activities did not count towards merit (see Table 59).

Table 59

Evaluations and rewards based on student assessment data or involvement: Perceived challenges

\begin{tabular}{|l|l|l|l|c|}
\hline Factors & Professor & $\begin{array}{l}\text { Associate } \\
\text { Professor A }\end{array}$ & $\begin{array}{l}\text { Associate } \\
\text { Professor B }\end{array}$ & $\begin{array}{l}\text { Associate } \\
\text { Professor C }\end{array}$ \\
\hline Lack of Rewards & $\mathrm{X}$ & & $\mathrm{X}$ & \\
\hline Factors & Professor & $\begin{array}{l}\text { Associate } \\
\text { Professor A }\end{array}$ & $\begin{array}{l}\text { Associate } \\
\text { Professor B }\end{array}$ & $\begin{array}{l}\text { Associate } \\
\text { Professor C }\end{array}$ \\
\hline $\begin{array}{l}\text { No Merit Points for } \\
\text { Assessment } \\
\text { Related Activities }\end{array}$ & $\mathrm{X}$ & $\mathrm{X}$ & $\mathrm{X}$ \\
\hline
\end{tabular}

Faculty Satisfaction with the Use of Student Assessment Data in Making Academic Decisions. The professor and associate professor B purported to be dissatisfied with the use of student assessment data in making academic decisions while associate professor A 
purported to be neutral and associate professor $C$ purported to be very satisfied. The professor reported that program faculty “do not take [assessment] seriously” (see Table 60). Associate professor B reported that some assessment data was collected; however, it was not used to inform academic decisions. Associate professor A stated, "there is no one instance I can point to and say I think this is where some assessment data was used to change something...” However, associate professor C reported that faculty utilized assessment data to review teaching techniques and improve student advising.

Table 60

Use of assessment data in making academic decisions: Perceived challenges

\begin{tabular}{|l|c|c|c|c|}
\hline Factors & Professor & $\begin{array}{l}\text { Associate } \\
\text { Professor A }\end{array}$ & $\begin{array}{l}\text { Associate } \\
\text { Professor B }\end{array}$ & $\begin{array}{l}\text { Associate } \\
\text { Professor C }\end{array}$ \\
\hline Faculty Resistance & $\mathrm{X}$ & & & \\
\hline $\begin{array}{l}\text { Assessment Data } \\
\text { Was Not Used for } \\
\text { Decision Making }\end{array}$ & & $\mathrm{X}$ & $\mathrm{X}$ & \\
\hline $\begin{array}{l}\text { Use of Assessment } \\
\text { Data to Review } \\
\text { Teaching } \\
\text { Techniques }\end{array}$ & & & & $\mathrm{X}$ \\
\hline $\begin{array}{l}\text { Use of Assessment } \\
\text { Data to Improve } \\
\text { Student Advising }\end{array}$ & & & & \\
Services & & & & $\mathrm{X}$ \\
\hline
\end{tabular}

Faculty Satisfaction with the Impact Student Assessment had on the Psychology

Program. Associate professors A and B reported to be dissatisfied with the impact student assessment had on the psychology program while the professor reported to be neutral and associate professor $\mathrm{C}$ reported to be very satisfied. Associate professor A identified the lack of quality assessment data as an important factor with his dissatisfaction (see Table 61). He stated, "I would like to see [assessment data] collected 
on a regular basis through a variety of means including but not limited to an

examination.”

Table 61

Impact student assessment had on the psychology program: Perceived challenges

\begin{tabular}{|l|l|c|c|c|}
\hline Factors & Professor & $\begin{array}{l}\text { Associate } \\
\text { Professor A }\end{array}$ & $\begin{array}{l}\text { Associate } \\
\text { Professor B }\end{array}$ & $\begin{array}{l}\text { Associate } \\
\text { Professor C }\end{array}$ \\
\hline $\begin{array}{l}\text { Lack of Quality } \\
\text { Assessment Data }\end{array}$ & & X & & \\
\hline $\begin{array}{l}\text { Assessment Data } \\
\text { Was Not Used for } \\
\text { Decision Making }\end{array}$ & & & X & \\
\hline
\end{tabular}

Associate professor B reported that faculty had not utilized assessment data to inform programmatic changes. However, he maintained that assessment improved teaching within the program and facilitated the incorporation of multiple assessment methods (see Table 62). Associate professor C stated, “we’ve probably made more progress [utilizing assessment data] than we have with developing formal assessments of the skills and knowledge that our students acquire.”

Table 62

Impact student assessment had on the psychology program: Perceived strengths

\begin{tabular}{|l|l|l|c|c|}
\hline Factors & Professor & $\begin{array}{l}\text { Associate } \\
\text { Professor A }\end{array}$ & $\begin{array}{l}\text { Associate } \\
\text { Professor B }\end{array}$ & $\begin{array}{l}\text { Associate } \\
\text { Professor C }\end{array}$ \\
\hline Improved Teaching & & & $\mathrm{X}$ & \\
\hline $\begin{array}{l}\text { Facilitated the } \\
\begin{array}{l}\text { Incorporation of } \\
\text { Multiple Methods } \\
\text { of Assessment }\end{array}\end{array}$ & & $\mathrm{X}$ & \\
\hline
\end{tabular}


Faculty Satisfaction Summary. Table 63 illustrates the frequency of themes across items related to strengths in assessment. The most frequently identified themes pertaining to assessment strengths were:

- the Center for Teaching and Learning,

- assessment expertise of administrators,

- program review and assessment committee, and

- service to the undergraduate committee.

Two of the associate professors reported that the Center for Teaching and Learning was helpful in promoting professional development for student assessment.

The professor and associate professor A reported that the expertise of central administration was an important factor of their satisfaction with institutional leadership. Associate professor B also identified the Center for Teaching and Learning as an important factor of his satisfaction with central leadership support.

The professor and associate professor A both reported that the PRAC was an important venue for participating in assessment decisions. Associate professors B and C identified undergraduate committees as important venues for participating in assessment decisions.

Table 63

Frequency of theme emergence pertaining to strengths across items

\begin{tabular}{|l|c|c|c|c|}
\hline Factors & Professor & $\begin{array}{l}\text { Associate } \\
\text { Professor A }\end{array}$ & $\begin{array}{l}\text { Associate } \\
\text { Professor B }\end{array}$ & $\begin{array}{l}\text { Associate } \\
\text { Professor C }\end{array}$ \\
\hline $\begin{array}{l}\text { Center for } \\
\text { Teaching and } \\
\text { Learning }\end{array}$ & 0 & 1 & 2 & 1 \\
\hline
\end{tabular}


Table 63

Frequency of theme emergence pertaining to strengths across items: Continued

\begin{tabular}{|c|c|c|c|c|}
\hline Factors & Professor & $\begin{array}{l}\text { Associate } \\
\text { Professor A }\end{array}$ & $\begin{array}{l}\text { Associate } \\
\text { Professor B }\end{array}$ & $\begin{array}{l}\text { Associate } \\
\text { Professor C }\end{array}$ \\
\hline $\begin{array}{l}\text { Expertise of } \\
\text { Administrators }\end{array}$ & 1 & 1 & 0 & 0 \\
\hline $\begin{array}{l}\text { Program Review } \\
\text { and Assessment } \\
\text { Committee }\end{array}$ & 1 & 1 & 0 & 0 \\
\hline $\begin{array}{l}\text { Service to the } \\
\text { Undergraduate } \\
\text { Committee }\end{array}$ & 0 & 0 & 1 & 1 \\
\hline Alumni Surveys & 0 & 0 & 0 & 1 \\
\hline $\begin{array}{l}\text { Improving Faculty } \\
\text { Participation }\end{array}$ & 0 & 1 & 0 & 0 \\
\hline $\begin{array}{l}\text { Assessment Plan } \\
\text { Templates }\end{array}$ & 1 & 0 & 0 & 0 \\
\hline $\begin{array}{l}\text { Personal } \\
\text { Contribution to the } \\
\text { Assessment Plan }\end{array}$ & 0 & 1 & 0 & 0 \\
\hline $\begin{array}{l}\text { Service to the } \\
\text { Undergraduate } \\
\text { Committee }\end{array}$ & 0 & 0 & 1 & 1 \\
\hline $\begin{array}{l}\text { Holds } \\
\text { Administrative } \\
\text { Position }\end{array}$ & 0 & 0 & 1 & 0 \\
\hline $\begin{array}{l}\text { Department } \\
\text { Meetings }\end{array}$ & 0 & 0 & 0 & 1 \\
\hline Faculty Retreat & 0 & 0 & 0 & 1 \\
\hline $\begin{array}{l}\text { E-Mail } \\
\text { Communication }\end{array}$ & 0 & 0 & 0 & 1 \\
\hline $\begin{array}{l}\text { Clear } \\
\text { Communication } \\
\text { from Central } \\
\text { Leadership } \\
\end{array}$ & 0 & 0 & 0 & 1 \\
\hline $\begin{array}{l}\text { Culture that Values } \\
\text { Assessment }\end{array}$ & 0 & 0 & 0 & 1 \\
\hline $\begin{array}{l}\text { Availability of } \\
\text { Resources }\end{array}$ & 0 & 0 & 0 & 1 \\
\hline $\begin{array}{l}\text { Institutional } \\
\text { Research Office }\end{array}$ & 0 & 0 & 0 & 1 \\
\hline
\end{tabular}


Table 63

Frequency of theme emergence pertaining to strengths across items: Continued

\begin{tabular}{|l|c|c|c|c|}
\hline Factors & Professor & $\begin{array}{l}\text { Associate } \\
\text { Professor A }\end{array}$ & $\begin{array}{l}\text { Associate } \\
\text { Professor B }\end{array}$ & $\begin{array}{l}\text { Associate } \\
\text { Professor C }\end{array}$ \\
\hline $\begin{array}{l}\text { Commitment of } \\
\text { Program Faculty }\end{array}$ & 0 & 0 & 0 & 1 \\
\hline $\begin{array}{l}\text { Assessment } \\
\text { Methods }\end{array}$ & 0 & 0 & 0 & 0 \\
\hline $\begin{array}{l}\text { Assessment } \\
\text { Experts on Campus }\end{array}$ & 1 & 0 & 0 & 0 \\
\hline $\begin{array}{l}\text { Financial Support } \\
\text { to Attend } \\
\text { Conferences }\end{array}$ & 1 & 0 & 0 & 1 \\
\hline $\begin{array}{l}\text { Availability of } \\
\text { Developmental } \\
\text { Workshops }\end{array}$ & 0 & 0 & 0 & 1 \\
\hline $\begin{array}{l}\text { Availability of } \\
\text { Grants to Support } \\
\text { Assessment } \\
\text { Activities }\end{array}$ & 0 & 0 & 0 & 1 \\
\hline $\begin{array}{l}\text { Merit Based Pay } \\
\text { Raises }\end{array}$ & 0 & 0 & 0 & 1 \\
\hline $\begin{array}{l}\text { Peer Reviews to } \\
\text { Evaluate Teaching }\end{array}$ & 0 & 0 & 0 & 0 \\
\hline $\begin{array}{l}\text { Assessment Data } \\
\text { Utilized to Review } \\
\text { Teaching } \\
\text { Techniques }\end{array}$ & 0 & 0 & 0 & 1 \\
\hline $\begin{array}{l}\text { Assessment Data } \\
\text { Utilized to Improve } \\
\text { Student Advising } \\
\text { Services }\end{array}$ & 0 & 0 & 0 & \\
\hline
\end{tabular}

The most frequently identified themes pertaining to assessment challenges were:

- faculty resistance,

- the lack of an implemented assessment plan,

- the constant state of revision of the assessment plan,

- challenges with analyzing assessment data, 
- $\quad$ and the lack of incentives for assessment activities (see Table 64).

The professor and associate professor B each reported that faculty resistance challenged the development of an assessment plan. The professor further noted that faculty resistance to assessment impeded their ability to use assessment data in academic decision making. Additionally, the professor noted that faculty resistance to assessment reduced the effectiveness of program faculty leadership. The professor and associate professor B reported that an assessment plan was not implemented while associate professors $\mathrm{A}$ and $\mathrm{C}$ reported that the assessment plan was under revision. The professor noted that challenges associate with analyzing data impeded the development of an assessment plan while associate professor A noted that this challenge prevented its implementation. The professor and associate professor A reported that challenges “keeping up” with assessment data impeded their satisfaction with the plan. The professor reported that the lack of incentives reduced his satisfaction with the assessment plan while associate professor A reported that the lack of incentives reduced his desire to participate in developmental workshops about assessment.

Table 64

Frequency of theme emergence pertaining to challenges across items

\begin{tabular}{|l|c|c|c|c|}
\hline Factors & Professor & $\begin{array}{l}\text { Associate } \\
\text { Professor A }\end{array}$ & $\begin{array}{l}\text { Associate } \\
\text { Professor B }\end{array}$ & $\begin{array}{l}\text { Associate } \\
\text { Professor C }\end{array}$ \\
\hline Faculty Resistance & 3 & 0 & 1 & 0 \\
\hline $\begin{array}{l}\text { Assessment Plan } \\
\text { Has Not Been } \\
\text { Implemented }\end{array}$ & 2 & 0 & 1 & 0 \\
\hline $\begin{array}{l}\text { Assessment Data } \\
\text { Not Utilized to } \\
\text { Inform Academic } \\
\text { Decisions }\end{array}$ & 0 & 1 & 0 & 0 \\
\hline $\begin{array}{l}\text { Assessment Plan is } \\
\text { Under Revision }\end{array}$ & 0 & 1 & 0 & 1 \\
\hline
\end{tabular}


Table 64

Frequency of theme emergence pertaining to challenges across items: Continued

\begin{tabular}{|c|c|c|c|c|}
\hline Factors & Professor & $\begin{array}{l}\text { Associate } \\
\text { Professor A }\end{array}$ & $\begin{array}{l}\text { Associate } \\
\text { Professor B }\end{array}$ & $\begin{array}{l}\text { Associate } \\
\text { Professor C }\end{array}$ \\
\hline $\begin{array}{l}\text { Merit Points Not } \\
\text { Rewarded for } \\
\text { Assessment } \\
\text { Activities }\end{array}$ & 0 & 1 & 1 & 1 \\
\hline $\begin{array}{l}\text { Lack of Rewards } \\
\text { for Assessment } \\
\text { Activities } \\
\text { Conducted by } \\
\text { Faculty }\end{array}$ & 1 & 0 & 1 & 0 \\
\hline $\begin{array}{l}\text { Difficult to Keep } \\
\text { Up With Data }\end{array}$ & 1 & 1 & 0 & 0 \\
\hline Lack of Incentives & 1 & 1 & 0 & 0 \\
\hline $\begin{array}{l}\text { Assessment Plan } \\
\text { Lacks Systematic } \\
\text { Methods }\end{array}$ & 0 & 0 & 0 & 1 \\
\hline $\begin{array}{l}\text { Minimal Quantity } \\
\text { of Assessments } \\
\text { Have Been } \\
\text { Implemented }\end{array}$ & 0 & 1 & 0 & 0 \\
\hline $\begin{array}{l}\text { Program } \\
\text { Administrator } \\
\text { Resistance } \\
\end{array}$ & 0 & 0 & 1 & 0 \\
\hline $\begin{array}{l}\text { Lack of } \\
\text { Understanding of } \\
\text { Assessment } \\
\end{array}$ & 0 & 1 & 0 & 0 \\
\hline $\begin{array}{l}\text { Determining } \\
\text { Priorities }\end{array}$ & 0 & 1 & 0 & 0 \\
\hline $\begin{array}{l}\text { Lack of Incentives } \\
\text { to Attend } \\
\text { Developmental } \\
\text { Workshops About } \\
\text { Assessment }\end{array}$ & 0 & 1 & 0 & 0 \\
\hline $\begin{array}{l}\text { Quality Assessment } \\
\text { Data Not Collected }\end{array}$ & 0 & 1 & 0 & 0 \\
\hline
\end{tabular}




\section{Undergraduate Nursing Program}

The School of Nursing faculty awarded the Degree of Bachelor Science in Nursing.

Faculty offered an accelerated B. S. N. program for students who had already earned a baccalaureate degree in another discipline. According to the 2006 catalog, the mission of the department was

to create a community of learning that addresses society's need for caring and scientifically prepared nurse professionals, as well as the educational and developmental needs of students, faculty, staff, and alumni from diverse backgrounds.

The nursing program consisted of approximately 87 full-time faculty members. Interview data revealed that approximately 200 part-time faculty taught courses in the Department. Undergraduate nursing students were primarily enrolled full-time. Class sizes ranged between 100 to 130 students; however, program faculty maintained at least a ratio of one faculty member for every 10 students.

\section{Study Participants}

The researcher conducted interviews with the associate dean, an associate clinical professor, and an assistant clinical professor. The associate dean was serving her second year as an administrator in her ninth year as a professor at AU. She worked in higher education for 20 years. The associate dean purported to be "pretty" knowledgeable about student outcomes assessment. She reported that the development of program curriculum "really evolved into assessment and evaluation" activities. The associate dean attended three conferences that focused on student outcomes assessment and two conferences that included assessment sessions on the program in the past two years. She presented 
assessment results at one conference and published one paper pertaining to student outcomes assessment.

The second participant, an associate clinical professor, was serving her sixteenth year at AU. She has worked in higher education for 28 years. She purported to be "fairly" knowledgeable about student outcomes assessment as she designed survey questionnaires for the department. The associate clinical professor did not attend any conferences that focused on student outcomes assessment; however, she attended two conferences and presented assessment results at these conferences in the past two years. The associate clinical professor had not published any papers pertaining to student assessment; however, she completed three assessment working papers.

The third participant, an assistant clinical professor, was serving her sixteenth year at AU. She worked in higher education for 16 years. She purported to be "pretty" knowledgeable about student outcomes assessment. The assistant clinical professor contributed her development of assessment knowledge to professional accreditation visits. She had not attended any conferences that focused on student outcomes assessment; however, she attended four conferences that included assessment sessions on the program in the past two years. The assistant clinical professor reported assessment results at three of the conferences she attended. She had not published any papers pertaining to student outcomes assessment in the past two years. Characteristics of Effective Assessment Practice

The researcher analyzed interview data, the 2006 university catalog, and the assessment plan to identify characteristics of effective practice. 
Credible evidence of learning. Documents and interview respondents illustrated various components of the assessment plan that demonstrated learning was relevant to the major and assessment measures were reliable. Faculty assessed twenty-two student learning outcomes. The outcomes for the nursing major spanned all six of the cognitive domains contained within Bloom’s Taxonomy (Anderson, et al., 2001). The outcomes were skewed to the less sophisticated domains. Nine percent of the outcomes focused on the remember domain, nine percent represented the understand domain, fifty-nine percent represented the apply domain, four percent represented the analyze domain, fourteen percent represented the evaluate domain, and four percent represented the create domain (see Table 65). None of the outcomes were representative of the affective domain. These outcomes were learner-centered and were clear, measurable, spanned multiple learning domains, and were directly related to the program’s mission statement.

Examples of the intended learning outcomes within the remember domain included:

- identify conditions surrounding patient situations for the purpose of problem solving and

- identify conditions surrounding patient situations for the purpose of selecting a course of action.

Table 65

Distribution of intended cognitive learning outcomes

\begin{tabular}{|c|c|c|}
\hline Cognitive Domain & $\mathrm{N}$ & $\%$ \\
\hline Create & 1 & 4.5 \\
\hline Evaluate & 3 & 13.6 \\
\hline Analyze & 1 & 4.5 \\
\hline Apply & 13 & 59 \\
\hline Understand & 2 & 9 \\
\hline Remember & 2 & 9 \\
\hline
\end{tabular}


Examples of intended learning outcomes within the understand domain included:

- comprehend conditions surrounding patient situations for the purpose of problem solving and

- comprehend conditions surrounding patient situations for the purpose of selecting a course of action.

Examples of intended learning outcomes within the apply domain included:

- demonstrate competence in order to safely engage in the practice of nursing and

- use the sense of hearing to make correct judgments regarding patient conditions.

An example of an intended learning outcome within the analyze domain included:

- analyze to engage competently in the safe practice of nursing.

Examples of intended learning outcomes within the evaluate domain included:

- assess conditions surrounding patient situations for the purpose of problem solving and

- assess conditions surrounding patient situations for the purpose of selecting a course of action.

An example of an intended learning outcome within the create domain included:

- synthesize to engage competently in the safe practice of nursing.

The nursing faculty had developed a comprehensive assessment plan. They conceptualized critical thinking, integration and application of knowledge, intellectual depth, breadth, and adaptiveness, understanding society and culture, and values and ethics across each of the PULs and program learning outcomes. Program faculty utilized a matrix containing benchmark data and three years of results to support program changes. The B. S. N. program faculty utilized multiple assessment methods to measure 
student achievement (see Table 66 ). Direct assessments utilized by program faculty included a capstone experience rubric, the Registered Nurse Computer Adaptive Test (RN-CAT), and the National Council Licensure Exam for Registered Nurses (NCLEX). Indirect assessments utilized by program faculty included a self-report exit survey developed by Educational Benchmarking, Inc. (EBI), an alumni survey, and an employer survey.

The associate dean reported that the clinically-oriented capstone experience was assessed by faculty, preceptors, and students utilizing a Likert scale. She stated that students were required to "to pull all of their educational experience and practical experience together and kind of work in that transitional role of nurse under the guidance of an experienced nurse” in order to demonstrate their competency as a nurse. The clinical assistant professor reported that faculty developed the rubric based on the program outcomes.

The RN-CAT was a commercially developed examination that was administered electronically. This examination was developed by Educational Resources, Incorporated (ERI) to simulate the NCLEX test. The RN-CAT consisted of 75 to 265 questions intended to gather knowledge pertaining to mental health, nursing fundamentals, maternity, pediatric nursing, and medical/surgical areas.

The NCLEX was a commercially developed licensing assessment, also developed by ERI, administered at the conclusion of the academic program. Students completed NCLEX testing on an annual basis. 
Table 66

Assessment measures

\begin{tabular}{|c|c|c|c|c|c|c|}
\hline \multirow{2}{*}{$\begin{array}{l}\text { Assessment } \\
\text { Methods }\end{array}$} & \multicolumn{6}{|c|}{ Principles of Undergraduate Learning/Program Outcomes } \\
\hline & $\begin{array}{l}\text { Critical } \\
\text { Thinking }\end{array}$ & $\begin{array}{l}\text { Core } \\
\text { Communication } \\
\text { and } \\
\text { Quantitative } \\
\text { Skills/Effective } \\
\text { Communicator }\end{array}$ & $\begin{array}{l}\text { Integration and } \\
\text { Application of } \\
\text { Knowledge/Competent } \\
\text { Care Provider }\end{array}$ & $\begin{array}{l}\text { Intellectual Depth, } \\
\text { Breadth, and } \\
\text { Adaptiveness/Competent } \\
\text { Care Provider }\end{array}$ & $\begin{array}{l}\text { Understanding } \\
\text { Society and } \\
\text { Culture/Culturally } \\
\text { Competent } \\
\text { Person }\end{array}$ & $\begin{array}{l}\text { Values and } \\
\text { Ethics/Conscientious } \\
\text { Practitioner and } \\
\text { Role Model }\end{array}$ \\
\hline $\begin{array}{l}\text { Senior } \\
\text { Capstone } \\
\text { Course } \\
\text { With } \\
\text { Assessment } \\
\text { Rubric } \\
\end{array}$ & $\mathrm{X}$ & $\mathrm{X}$ & $\mathrm{X}$ & & $\mathrm{X}$ & $\mathrm{X}$ \\
\hline $\begin{array}{l}\text { EBI Exit } \\
\text { Senior } \\
\text { Survey } \\
\text { Results }\end{array}$ & $\mathrm{X}$ & $\mathrm{X}$ & $\mathrm{X}$ & $\mathrm{X}$ & $\mathrm{X}$ & \\
\hline $\begin{array}{l}\text { Alumni } \\
\text { Survey }\end{array}$ & $\mathrm{X}$ & $\mathrm{X}$ & $\mathrm{X}$ & $\mathrm{X}$ & & \\
\hline $\begin{array}{l}\text { Employer } \\
\text { Survey }\end{array}$ & & & $\mathrm{X}$ & & & \\
\hline
\end{tabular}


According to the National Council of State Boards of Nursing, entry into the practice of nursing in the United States and its territories is regulated by the licensing authorities within each jurisdiction. To ensure public protection, each jurisdiction requires a candidate for licensure to pass an examination that measures the competencies needed to perform safely and effectively as a newly licensed, entry level registered nurse.

NCLEX results revealed that students performed above the performance expectations for the outcome intellectual depth, breadth, and adaptiveness.

The EBI exit senior survey was administered to students at the conclusion of the academic program. According to the EBI website, “[the] undergraduate Nursing Education Exit Assessment is a comprehensive evaluation of the learning outcomes, effectiveness of institutional resources and the overall educational experience of graduates.” Specifically, the EBI exit senior survey included measures related to:

- the quality of nursing instruction,

- $\quad$ work and class size,

- course lecture and interaction,

- facilities and administration,

- classmates,

- professional values,

- core competencies,

- technical skills,

- core knowledge,

- $\quad$ role development, and 
- overall program effectiveness.

Students completed EBI senior exit surveys bi-annually. The EBI senior exit survey revealed that students were not achieving performance expectations for the following outcomes:

- critical thinking,

- integration and application of knowledge,

- intellectual depth, breadth, and adaptiveness, and

- $\quad$ understanding society and culture.

The associate dean reported that alumni completed surveys six months, one year, and five years after they had graduated. Faculty analyzed core sets of questions pertaining to each of the following outcomes:

- critical thinking,

- core communication and quantitative skills,

- integration and application of knowledge, and

- intellectual depth, breadth, and adaptiveness.

Faculty reported that alumni survey response rates were too low to produce valid indirect measures of student achievement.

Faculty conducted employer focus groups to gather data pertaining to the integration and application of knowledge. Focus group participants represented potential employers of the university's graduates.

The analysis of data from the capstone assessment, exit survey, RN-CAT, employer survey, RN-CLEX, and alumni survey was appropriate. Faculty reported descriptive statistics for each measure annually and they compared assessment results to performance 
expectations. The assessment results pertained to the PULs (general education outcomes) and the program outcomes.

Continuous Improvement. The 2006 PRAC Assessment Report provided evidence of program changes or improvements that faculty implemented based on assessment data. The capstone assessment provided faculty with evidence to support the promotion of writing skills across the program curriculum, diversity education across the nursing curriculum, and ethics and values education. Assessment results from the EBI exit survey supported the need for learning experiences "that incorporate the concepts of diversity and culture as a way to continue to emphasize cultural competence.” Thus “faculty [were] designing learning experiences that incorporate the concepts of diversity and culture as a way to continue to emphasize cultural competence.” While alumni survey returns were too low to gather valid data, an advisory group of potential employers reported that abilities in critical thinking and communication were important. Thus, program faculty were increasing the opportunities that students had to practice critical thinking and communication skills across the curriculum as members of interdisciplinary teams. Members of the advisory clinical group that participated in the employer focus group reported that students needed more computer training. They claimed that as a result of "a more paperless environment, there is a growing need for increased competence so students are being exposed to various systems through simulations.”

Accountability to internal stakeholders. The associate dean maintained that program faculty utilized assessment data to inform academic decisions. She stated, 
“administrative decisions are all driven by...evidence.” The associate dean also reported that assessment reports were provided to central administration annually.

Ongoing assessment. Interview respondents and documents supported that assessment occurred on a predictable schedule within the nursing program. The associate dean reported that professional accreditation agencies required annual reports that included assessment data and necessitated constant evaluation. She reported that the creation of her position was the result the program faculty’s commitment to assessment. She concluded, "I think with the commitment the school has made in the development of this office...” supports ongoing assessment activities.

Ongoing Evaluation and Improvement. Interview data and documents revealed that the assessment plan within the School of Nursing did not contain a formal method to evaluate and improve the assessment plan itself.

The associate dean and assistant clinical professor purported to be satisfied with the program's assessment plan while the associate clinical professor purported to be dissatisfied. The associate dean reported that the assessment plan was improving (see Table 67). The associate clinical professor identified faculty participation and a shared vision of student achievement as important factors related to her satisfaction. She reported that program faculty "get together once a month and we talk about [assessment].” Additionally, she noted that program faculty "have a shared vision of where we want our students to be.” However, the associate clinical professor noted that program faculty did not have autonomy to change things. 
Table 67

Assessment plan: Perceived strengths

\begin{tabular}{|l|c|l|l|}
\hline Factors & Associate Dean & $\begin{array}{l}\text { Associate } \\
\text { Clinical } \\
\text { Professor }\end{array}$ & $\begin{array}{l}\text { Assistant } \\
\text { Clinical } \\
\text { Professor }\end{array}$ \\
\hline $\begin{array}{l}\text { Assessment } \\
\text { Plan Was } \\
\text { Improving }\end{array}$ & $\mathrm{X}$ & \\
\hline $\begin{array}{l}\text { Faculty } \\
\text { Participation }\end{array}$ & & $\mathrm{X}$ & \\
\hline $\begin{array}{l}\text { Share Vision of } \\
\text { Student } \\
\text { Achievement }\end{array}$ & & $\mathrm{X}$ & \\
\hline
\end{tabular}

The assistant clinical professor reported that program faculty for each course “decided how they were going to assess learning." She noted that a formalized assessment plan did not exist although the researcher was given an assessment plan (see Table 68).

Table 68

Assessment plan: Perceived challenges

\begin{tabular}{|l|c|l|l|}
\hline Factors & Associate Dean & $\begin{array}{l}\text { Associate } \\
\text { Clinical } \\
\text { Professor }\end{array}$ & $\begin{array}{l}\text { Assistant } \\
\text { Clinical } \\
\text { Professor }\end{array}$ \\
\hline $\begin{array}{l}\text { Lack of } \\
\text { Autonomy to } \\
\text { Make }\end{array}$ & & \\
$\begin{array}{l}\text { Programmatic } \\
\text { Changes }\end{array}$ & & $\mathrm{X}$ & \\
\hline $\begin{array}{l}\text { No Formalized } \\
\text { Assessment } \\
\text { Plan }\end{array}$ & & & \\
\hline
\end{tabular}




\section{Institutional Commitments and Resources}

Commitments. University and program leaders demonstrated their commitment to assessment. When asked if the utilization of student assessment data was considered in evaluating and rewarding faculty, the associate dean stated, "not really." When queried about the policies and practices that facilitated the communication of student assessment purposes, the associate dean did not identify any specific policies. However, she noted that programmatic changes supported by assessment data must be reported annually to professional accreditation agencies.

When asked about policies to promote the involvement of student affairs personnel and students in assessment efforts, the associate dean reported that no such policies existed. She stated that executive-level support for student assessment was evident from the Office of the Senior Vice Chancellor. When asked to describe the culture of assessment within the nursing program, the associate dean reported that assessment was "becoming more central to the program itself.” The associate dean reported that a document containing guiding principles for assessment existed. Additionally, she identified the PRAC as a campus-wide assessment committee with broad representation. She reported that one faculty member and one administrator from each school served on the committee.

When queried about the incorporation of outcomes assessment into the scholarship of teaching in promotion and tenure guidelines, the associate dean confirmed that the scholarship of teaching had been incorporated into promotion and tenure guidelines. In summary, the significant commitments included:

- evidence of executive-level support through the Office of the Vice Chancellor, 
- guiding principles for assessment,

- campus-wide assessment committee with broad representation (PRAC), and

- the incorporation of outcomes assessment into the scholarship of teaching in promotion and tenure guidelines.

Resources. Resources associated with the assessment activities on campus included financial support for testing, professional development opportunities, and access to consulting services. When asked to identify resources that were allocated to the School of Nursing from the institution, the associate dean identified the Office of the Vice Chancellor and the Office of Information Management and Institutional Research. The associate dean reported that a comprehensive student assessment database was directly available to the School of Nursing and was maintained by the Office of Information Management and Intuitional Research. The associate dean reported that program faculty, academic administrators, and student affairs staff and administrators had access to developmental workshops pertaining to assessment.

Support for faculty to attend professional conferences on student assessment was available. The associate dean stated, "ever since I've been here each faculty has had a certain amount of money to travel to conferences.” She reported that internal and external consulting services for student assessment were available. The associate dean noted that administrators representing the Office of the Vice Chancellor worked with faculty on request.

The associate dean reported that there were limited types of assistance (in the form of paid leaves, stipends, mini-grants, or course reductions) for faculty to work on assessment activities. She noted that the PRAC offered grants to faculty to work on 
assessment activities. Additionally, the associate dean reported that the School of Nursing had been awarded two external grants to support assessment.

The associate dean identified both the Office of the Associate Dean within the School of Nursing and the Office of Information Management and Institutional Research as being helpful with coordinating data-gathering initiatives such as surveys and standardized tests. Additionally, she noted that an institutional-level and program-level assessment office existed. In summary, the significant resources available from the institution included:

- Office of the Vice Chancellor,

- Office of Information Management and Institutional Research,

- comprehensive student assessment database,

- developmental workshops,

- financial support to attend conferences,

- internal consulting services,

- external consulting services,

- $\quad$ assessment mini-grants, and

- the Office of the Associate Dean.

Faculty Satisfaction with Assessment and the Assessment Plan

Faculty satisfaction with program assessment was determined by analyzing interview data from two individuals: (1) an associate clinical professor and (2) an assistant clinical professor. These items elicited information regarding their satisfaction with implementation of the current assessment plan, opportunities to participate in policy making, central leadership support for assessment, faculty leadership support, 
professional development, evaluations and rewards, academic decision making, and the impact of student assessment on the program.

Satisfaction with the Implementation of the Current Assessment Plan. The associate clinical professor purported to be satisfied with the implementation of the current assessment plan while the assistant clinical professor purported to be somewhat satisfied. The associate clinical professor reported that the utilization of commercial assessment instruments enabled faculty to identify areas that students needed remediation (see Table 69). The assistant clinical professor identified multiple assessment methods as an important factor related to her satisfaction.

However, the assistant clinical professor expressed a challenge with authoring accreditation reports containing assessment data. She stated, "it can be really complicated when it really gets down to preparing [reports] for our accreditors to come in... and it's extremely time consuming.” She continued, "I wish that there were an easier way [to prepare accreditation reports] but it typically involves a lot of time spent on data collections and looking at how our students performed in different areas.”

Table 69

Implementation of the current assessment plan:

Perceived strengths

\begin{tabular}{|l|l|l|}
\hline Factors & $\begin{array}{l}\text { Associate } \\
\text { Clinical } \\
\text { Professor }\end{array}$ & $\begin{array}{l}\text { Assistant } \\
\text { Clinical } \\
\text { Professor }\end{array}$ \\
\hline $\begin{array}{l}\text { Commercial } \\
\text { Assessment } \\
\text { Instruments }\end{array}$ & $\mathrm{X}$ & \\
\hline $\begin{array}{l}\text { Multiple } \\
\text { Methods of } \\
\text { Assessment }\end{array}$ & & $\mathrm{X}$ \\
\hline
\end{tabular}


Faculty Satisfaction with Participation in Assessment Decisions. The associate clinical professor purported to be somewhat satisfied with her opportunities to participate in policy making about student assessment while the assistant clinical professor declined to respond to this item. The associate clinical stated, "I have as much involvement as I want." She identified informal faculty discussions and the use of student assessment data as important factors related to her satisfaction (see Table 70).

Table 70

Participation in assessment decisions:

Perceived strengths

\begin{tabular}{|l|l|l|}
\hline Factors & $\begin{array}{l}\text { Associate } \\
\text { Clinical } \\
\text { Professor }\end{array}$ & $\begin{array}{l}\text { Assistant } \\
\text { Clinical } \\
\text { Professor }\end{array}$ \\
\hline $\begin{array}{l}\text { Informal } \\
\text { Faculty } \\
\text { Discussion }\end{array}$ & $\mathrm{X}$ & \\
\hline $\begin{array}{l}\text { Use of } \\
\text { Assessment } \\
\text { Data to Inform } \\
\text { Academic } \\
\text { Decisions }\end{array}$ & $\mathrm{X}$ & \\
\hline
\end{tabular}

Faculty Satisfaction with Central Leadership Support for Assessment. The associate clinical professor purported to be very satisfied with central leadership support for assessment while the assistant clinical professor purported to be satisfied. The associate clinical professor reported that central leadership prioritized student retention (see Table 71). She reported that central administrators were "contacting [students] to find out why they're not coming back.” The associate clinical professor also noted that data ascertained from retention studies informed strategic planning at the institutional level. 
The assistant clinical professor identified the support of the associate dean as an important factor related to her satisfaction.

Table 71

Central leadership support for assessment: Perceived strengths

\begin{tabular}{|l|l|l|}
\hline Factors & $\begin{array}{l}\text { Associate } \\
\text { Clinical } \\
\text { Professor }\end{array}$ & $\begin{array}{l}\text { Assistant } \\
\text { Clinical } \\
\text { Professor }\end{array}$ \\
\hline $\begin{array}{l}\text { Student } \\
\text { Retention }\end{array}$ & $\mathrm{X}$ & \\
\hline $\begin{array}{l}\text { Use of Student } \\
\text { Assessment } \\
\text { Data to Inform } \\
\text { Strategic } \\
\text { Planning }\end{array}$ & $\mathrm{X}$ & \\
\hline Associate Dean & & \\
\hline
\end{tabular}

Faculty Satisfaction with Nursing Program Faculty Leadership Support. The associate and assistant clinical professors reported to be satisfied with program faculty leadership support for assessment. The associate clinical professor noted that faculty discussed assessment results during frequent departmental meetings (see Table 72). The assistant clinical professor identified the expertise of the associate dean as an important factor related to her satisfaction.

Table 72

Nursing faculty program leadership support:

Perceived strengths

\begin{tabular}{|l|l|l|}
\hline Factors & $\begin{array}{l}\text { Associate } \\
\text { Clinical } \\
\text { Professor }\end{array}$ & $\begin{array}{l}\text { Assistant } \\
\text { Clinical } \\
\text { Professor }\end{array}$ \\
\hline $\begin{array}{l}\text { Faculty } \\
\text { Meetings }\end{array}$ & $\mathrm{X}$ & \\
\hline $\begin{array}{l}\text { Expertise of } \\
\text { Associate Dean }\end{array}$ & & $\mathrm{X}$ \\
\hline
\end{tabular}


However, the assistant clinical professor noted that the associate dean was "pulled in many different directions.” She also reported that faculty within the School of Nursing faced many changes as a result of its growth (see Table 73).

Table 73

Nursing faculty program leadership support:

Perceived challenges

\begin{tabular}{|l|l|c|}
\hline Factors & $\begin{array}{l}\text { Associate } \\
\text { Clinical } \\
\text { Professor }\end{array}$ & $\begin{array}{l}\text { Assistant } \\
\text { Clinical } \\
\text { Professor }\end{array}$ \\
\hline $\begin{array}{l}\text { Associate Dean } \\
\text { Was Very Busy }\end{array}$ & & $\mathrm{X}$ \\
\hline $\begin{array}{l}\text { Program in a } \\
\text { State of Change }\end{array}$ & & $\mathrm{X}$ \\
\hline
\end{tabular}

Faculty Satisfaction with Professional Development for Student Assessment. Both of the professors reported to be satisfied with professional development for student assessment. The associate clinical professor revealed that faculty received money to attend one conference a year (see Table 74). She stated, "the undergraduate faculty tend to go to more education conferences where a lot of the focus is on assessment.” The associate and assistant clinical professors also reported that faculty attended developmental workshops pertaining to assessment on-campus. However, the assistant clinical professor also reported faculty had access to on-line materials about student assessment.

Faculty Satisfaction with Evaluations and Rewards Based on Student Assessment Data or Involvement. The associate clinical professor reported to be satisfied with evaluations and rewards based on student assessment data or involvement while the 
Table 74

Professional development for student assessment:

Perceived strengths

\begin{tabular}{|l|c|c|}
\hline Factors & $\begin{array}{l}\text { Associate } \\
\text { Clinical } \\
\text { Professor }\end{array}$ & $\begin{array}{l}\text { Assistant } \\
\text { Clinical } \\
\text { Professor }\end{array}$ \\
\hline $\begin{array}{l}\text { Conference } \\
\text { Support }\end{array}$ & $\mathrm{X}$ & $\mathrm{X}$ \\
\hline $\begin{array}{l}\text { Availability of } \\
\text { Professional } \\
\text { Development } \\
\text { Workshops }\end{array}$ & $\mathrm{X}$ & $\mathrm{X}$ \\
\hline $\begin{array}{l}\text { On-line } \\
\text { Developmental } \\
\text { Materials }\end{array}$ & & $\mathrm{X}$ \\
\hline
\end{tabular}

assistant clinical professor reported to be dissatisfied. The associate clinical professor identified the lack of value associated with assessment activities within the annual review (see Table 75). She noted that there was not a formalized documentation process for preparing annual reports. The associate clinical professor stated, “what you share in your annual report is up to you." The assistant clinical professor claimed "too much emphasis is put on what students say.”

\section{Table 75}

Evaluations and rewards based on student assessment data or involvement: Perceived strengths

\begin{tabular}{|l|l|l|}
\hline Factors & $\begin{array}{l}\text { Associate } \\
\text { Clinical } \\
\text { Professor }\end{array}$ & $\begin{array}{l}\text { Assistant } \\
\text { Clinical } \\
\text { Professor }\end{array}$ \\
\hline $\begin{array}{l}\text { Assessment } \\
\text { Work is Not an } \\
\text { Important } \\
\text { Component of } \\
\text { Annual Review }\end{array}$ & \multicolumn{1}{|c}{} & \\
\hline
\end{tabular}




\section{Table 75}

Evaluations and rewards based on student assessment data or involvement: Perceived strengths continued

\begin{tabular}{|l|l|l|}
\hline Factors & $\begin{array}{l}\text { Associate } \\
\text { Clinical } \\
\text { Professor }\end{array}$ & $\begin{array}{l}\text { Assistant } \\
\text { Clinical } \\
\text { Professor }\end{array}$ \\
\hline Too Much & & \\
Emphasis is & & \\
Placed on & & \\
Student's & & \\
Opinions & & \\
\hline
\end{tabular}

Faculty Satisfaction with the Use of Student Assessment Data in Making Academic Decisions. The associate clinical professor purported to be very satisfied with the use of student assessment data in making academic decisions while the assistant clinical professor purported to be neutral. The associate clinical professor reported that faculty utilized assessment data and student feedback to inform academic decisions (see Table 76). The assistant clinical professor noted faculty often "rushed" into academic decisions. She reported that faculty based some decisions "upon the five students that are struggling and not the 95 students in the class that are doing well.”

Table 76

Use of student assessment data in making academic decisions: Perceived strengths

\begin{tabular}{|l|c|l|}
\hline Factors & $\begin{array}{l}\text { Associate } \\
\text { Clinical } \\
\text { Professor }\end{array}$ & $\begin{array}{l}\text { Assistant } \\
\text { Clinical } \\
\text { Professor }\end{array}$ \\
\hline $\begin{array}{l}\text { Assessment Data } \\
\text { Was Utilized to } \\
\text { Inform }\end{array}$ & $\mathrm{X}$ & \\
AcademicDecisions & & \\
\hline Student Feedback & $\mathrm{X}$ & \\
\hline
\end{tabular}


Faculty Satisfaction with the Impact Student Assessment had on the Nursing Program. The associate clinical professor purported to be satisfied with the impact student assessment had on the nursing program while the assistant clinical professor purported to be very satisfied. The associate clinical professor reported that program assessment activities occurred among the faculty teaching the course, rather than as the result of a formalized plan. However, she noted that the assessment data was utilized regularly for program improvements (see Table 77).

The assistant clinical professor reported that assessment data informed program changes. Specifically, she noted that seniors were recently required to attend the Kaplan Review for the NCLEX. However, she cautioned that decisions were sometimes made too quickly.

Table 77

Impact student assessment had on the nursing program: Perceived strengths

\begin{tabular}{|l|l|l|}
\hline Factors & $\begin{array}{l}\text { Associate } \\
\text { Clinical } \\
\text { Professor }\end{array}$ & $\begin{array}{l}\text { Assistant } \\
\text { Clinical } \\
\text { Professor }\end{array}$ \\
\hline Assessment & & \\
Data Was & & \\
Utilized to & $\mathrm{X}$ & $\mathrm{X}$ \\
Inform & & \\
Academic & & \\
Decisions & & \\
\hline
\end{tabular}

Faculty Satisfaction Summary. Table 78 illustrates the frequency of themes across items related to strengths in assessment. The most frequently identified themes pertaining to assessment strengths were:

- the use of assessment data to inform academic decisions, 
- financial support to attend conferences, and

- the availability of professional development workshops.

The associate and assistant clinical professor revealed that assessment data were utilized to inform academic decisions. Additionally, the associate clinical professor cited the utilization of assessment data to inform academic decisions as an important factor related to her satisfaction with participation in assessment decisions. The associate and assistant clinical professor each reported that financial support to attend conferences and the availability of developmental workshops were important factors related to their satisfaction with professional development.

Table 78

Frequency of theme emergence pertaining to strengths across items

\begin{tabular}{|l|l|l|l|}
\hline Factors & $\begin{array}{l}\text { Associate } \\
\text { Dean }\end{array}$ & $\begin{array}{l}\text { Associate } \\
\text { Clinical } \\
\text { Professor }\end{array}$ & $\begin{array}{l}\text { Assistant } \\
\text { Clinical } \\
\text { Professor }\end{array}$ \\
\hline $\begin{array}{l}\text { Assessment Data } \\
\text { Was Utilized to } \\
\text { Inform Academic } \\
\text { Decisions }\end{array}$ & & 2 & 1 \\
\hline $\begin{array}{l}\text { Financial Support } \\
\text { to Attend } \\
\text { Conferences }\end{array}$ & & 1 & 1 \\
\hline $\begin{array}{l}\text { Availability of } \\
\text { Professional } \\
\text { Development } \\
\text { Workshops }\end{array}$ & & 1 & 1 \\
\hline $\begin{array}{l}\text { Assessment Plan } \\
\text { was Improving }\end{array}$ & & 1 & \\
\hline $\begin{array}{l}\text { Faculty } \\
\text { Participation }\end{array}$ & & 1 & \\
\hline $\begin{array}{l}\text { Shared Vision of } \\
\text { Assessment }\end{array}$ & & 1 & \\
\hline $\begin{array}{l}\text { Commercial } \\
\text { Assessment } \\
\text { Instruments }\end{array}$ & & 1 & \\
\hline
\end{tabular}


Table 78

Frequency of theme emergence pertaining to strengths across items:

\section{Continued}

\begin{tabular}{|l|l|l|l|}
\hline Factors & $\begin{array}{l}\text { Associate } \\
\text { Dean }\end{array}$ & $\begin{array}{l}\text { Associate } \\
\text { Clinical } \\
\text { Professor }\end{array}$ & $\begin{array}{l}\text { Assistant } \\
\text { Clinical } \\
\text { Professor }\end{array}$ \\
\hline $\begin{array}{l}\text { Multiple Methods } \\
\text { of Assessment }\end{array}$ & & 1 \\
\hline $\begin{array}{l}\text { Informal Faculty } \\
\text { Discussions }\end{array}$ & & 1 & \\
\hline $\begin{array}{l}\text { Use of Assessment } \\
\text { Data to Inform } \\
\text { Academic } \\
\text { Decisions }\end{array}$ & & 1 & \\
\hline Student Retention & & 1 & \\
\hline $\begin{array}{l}\text { Use of Student } \\
\text { Assessment Data to } \\
\text { Inform Strategic } \\
\text { Planning }\end{array}$ & & & \\
\hline $\begin{array}{l}\text { Leadership of the } \\
\text { Associate Dean }\end{array}$ & & & \\
\hline Faculty Meetings & & & \\
\hline $\begin{array}{l}\text { Expertise of the } \\
\text { Associate Dean }\end{array}$ & & & \\
\hline $\begin{array}{l}\text { On-Line } \\
\text { Developmental } \\
\text { Materials }\end{array}$ & & & \\
\hline Student Feedback & & & \\
\hline
\end{tabular}

The researcher found no common themes related to perceived challenges with assessment (see Table 79). 
Table 79

Frequency of theme emergence pertaining to challenges across items

\begin{tabular}{|c|c|c|c|}
\hline Factors & Associate Dean & $\begin{array}{l}\text { Associate } \\
\text { Clinical } \\
\text { Professor } \\
\end{array}$ & $\begin{array}{l}\text { Assistant } \\
\text { Clinical } \\
\text { Professor }\end{array}$ \\
\hline $\begin{array}{l}\text { Lack of } \\
\text { Autonomy to } \\
\text { Make } \\
\text { Programmatic } \\
\text { Changes }\end{array}$ & & 1 & \\
\hline $\begin{array}{l}\text { No Formalized } \\
\text { Assessment } \\
\text { Plan }\end{array}$ & & & 1 \\
\hline $\begin{array}{l}\text { Accreditation } \\
\text { Reports were } \\
\text { Complicated to } \\
\text { Author }\end{array}$ & & & 1 \\
\hline $\begin{array}{l}\text { Associate Dean } \\
\text { Was Very Busy }\end{array}$ & & & 1 \\
\hline $\begin{array}{l}\text { Program in a } \\
\text { State of Change }\end{array}$ & & & 1 \\
\hline $\begin{array}{l}\text { Assessment } \\
\text { Work is Not an } \\
\text { Important } \\
\text { Component of } \\
\text { the Annual } \\
\text { Review }\end{array}$ & & 1 & \\
\hline $\begin{array}{l}\text { Too Much } \\
\text { Emphasis is } \\
\text { Placed on } \\
\text { Student's } \\
\text { Opinions }\end{array}$ & & & 1 \\
\hline $\begin{array}{l}\text { Academic } \\
\text { Decisions } \\
\text { Based on } \\
\text { Student } \\
\text { Assessment } \\
\text { Data Was } \\
\text { Frequently } \\
\text { "Rushed" }\end{array}$ & & & 1 \\
\hline
\end{tabular}




\section{Undergraduate Biology Program}

The Department of Biology awarded Bachelor of Science and Bachelor of Arts degrees. The Department of Biology 2006 Self-Study revealed that the Bachelor of Arts degree "is utilized predominantly by students with an interest in professional school and offers sufficient science training for most purposes while allowing students a wider breadth of educational experiences across other disciplines.” The Bachelor of Arts Degree "is elected by students who see themselves as working biologists and by students who wish to pursue graduate training in biology.” According to the Department of Biology 2006 Self-Study,

The specific aims of the Department are to provide the highest quality teaching in Biology for AU students from all disciplines and at all levels - non-major, undergraduate, and graduate; to provide a framework in which creative scholarship of first-rate Biology faculty can flourish so that they can conduct the highest level of teaching and research at AU; to serve as a resource for the University through collaborative teaching, research, and service activities; and to serve as an academic resource for [the city] and the community, and, in doing so, to complement the roles played by [its related institutions].

The biology program consisted of 20 full-time faculty members. Nineteen part-time faculty taught courses in the Department. Undergraduate biology students were primarily enrolled full-time. Class sizes ranged between 50 to 60 students.

\section{Study Participants}

The researcher conducted interviews with the department chair, an associate professor, a lecturer, and a senior lecturer. The department chair was in his thirty-fourth year as a 
professor at the institution and was serving his fifteenth year as the chairperson. He had worked in higher education for 34 years. He reported that he was "someplace in the middle” in terms of his knowledge with student assessment. The department chair had not attended any conferences that focused on student outcomes assessment nor any conferences that included assessment sessions on the program in the past two years. He had not published any papers pertaining to student outcomes assessment in the past two years.

The second participant, an associate professor, was serving his twelfth year at the AU. He had worked in higher education for 21 years. He purported to be fairly knowledgeable about student outcomes assessment. The associate professor attended one conference that focused on student outcomes assessment in the past two years. He had not published any papers pertaining to student assessment nor had he presented assessment results at any of the conferences he attended in the past two years.

The third participant, a lecturer, was serving her fourth year at AU. She had worked in higher education for 20 years. She purported to be fairly knowledgeable about student outcomes assessment. The lecturer attended one conference that focused on student outcomes assessment in the past two years. She had not published any papers pertaining to student assessment nor had she presented assessment results at any of the conferences she attended in the past two years.

The fourth participant, a senior lecturer, was serving his thirteenth year at AU. He had worked in higher education for 16 years. He purported to be fairly knowledgeable about student outcomes assessment. The senior lecturer attended one conference that focused on student outcomes assessment in the past two years. He had not published any papers 
pertaining to student assessment nor had he presented assessment results at any of the conferences he attended in the past two years.

\section{Characteristics of Effective Assessment Practice}

The researcher analyzed interview data, the 2006 Department of Biology Self-Study, and the assessment plan to identify characteristics of effective practice.

Credible evidence of learning. Documents and interview respondents illustrated various components of the assessment plan that demonstrated learning was relevant to the major and assessment measures were reliable. Faculty assessed sixteen student learning outcomes. The outcomes for the biology major spanned two of the six cognitive domains contained within Bloom’s Taxonomy (Anderson, et al., 2001). The outcomes were sharply skewed to the less sophisticated domains. Eighty-one percent of the outcomes focused on the understand domain and $18 \%$ represented the apply domain (see Table 80). None of the outcomes were representative of the affective domain. These outcomes were learner-centered, clear, measurable, and directly related to the program’s mission statement.

Table 80

Distribution of intended cognitive learning outcomes

\begin{tabular}{|c|c|c|}
\hline Cognitive Domain & $\mathrm{N}$ & $\%$ \\
\hline Create & 0 & 0 \\
\hline Evaluate & 0 & 0 \\
\hline Analyze & 0 & 0 \\
\hline Cognitive Domain & $\mathrm{N}$ & 18.7 \\
\hline Apply & 3 & 81.3 \\
\hline Understand & 13 & 0 \\
\hline Remember & 0 & \\
\hline
\end{tabular}


Examples of the intended learning outcomes within the understand domain included:

- understand the control processes of biomolecules and

- $\quad$ understand the mechanisms regulating the development of multicellular organisms.

Examples of intended learning outcomes within the apply domain included:

- apply the scientific method in a biology setting and

- apply selected techniques commonly used in field and laboratory studies. Program faculty utilized multiple methods of assessment to measure student achievement. According to the self-study, faculty utilized multiple-choice and, essay/short answer examinations, quizzes, writing assignments (lab reports and research papers), laboratory exercises, class presentations, and class activities to assess student learning related to program outcomes. A curriculum map revealed that faculty had implemented multiple assessment methods for each program outcome across multiple courses.

The alignment of general education outcomes to some assessment methods was presented in the self-study (see Table 81). However, only half of the general education outcomes were assessed by faculty. The Assessment Progress Template for the School of Science revealed that biology program faculty were in the process of "identifying or creating methods to measure the [student learning outcomes]" and “collecting data to see if the [student learning outcomes] are being accomplished.” 
Table 81

Assessment of the Principles of Undergraduate Learning by Biology Department faculty

\begin{tabular}{|c|c|c|c|c|c|c|}
\hline \multirow{2}{*}{$\begin{array}{l}\text { Assessment } \\
\text { Methods }\end{array}$} & \multicolumn{6}{|c|}{ Principles of Undergraduate Learning } \\
\hline & $\begin{array}{l}\text { Core } \\
\text { Communication } \\
\text { and } \\
\text { Quantitative } \\
\text { Skills }\end{array}$ & $\begin{array}{l}\text { Critical } \\
\text { Thinking } \\
\text { and } \\
\text { Problem } \\
\text { Solving }\end{array}$ & $\begin{array}{l}\text { Integration } \\
\text { and } \\
\text { Application } \\
\text { of } \\
\text { Knowledge }\end{array}$ & $\begin{array}{l}\text { Intellectual } \\
\text { Depth, } \\
\text { Breadth, and } \\
\text { Adaptiveness }\end{array}$ & $\begin{array}{l}\text { Understating } \\
\text { Society and } \\
\text { Culture }\end{array}$ & $\begin{array}{l}\text { Values } \\
\text { and } \\
\text { Ethics }\end{array}$ \\
\hline $\begin{array}{l}\text { Laboratory } \\
\text { Reports }\end{array}$ & $\mathrm{X}$ & & & & & \\
\hline $\begin{array}{l}\text { Capstone } \\
\text { Papers }\end{array}$ & $\mathrm{X}$ & & $\mathrm{X}$ & & & \\
\hline $\begin{array}{l}\text { Classroom } \\
\text { Presentations }\end{array}$ & $\mathrm{X}$ & & & & & \\
\hline $\begin{array}{l}\text { Course } \\
\text { Assignments }\end{array}$ & & $\mathrm{X}$ & & & & \\
\hline $\begin{array}{l}\text { Laboratory } \\
\text { Exercises }\end{array}$ & & $\mathrm{X}$ & & & & \\
\hline $\begin{array}{l}\text { No Specific } \\
\text { Assessment } \\
\text { Activities } \\
\text { Identified }\end{array}$ & & & & $\mathrm{X}$ & $\mathrm{X}$ & $\mathrm{X}$ \\
\hline
\end{tabular}

Continuous Improvement. The department chair did not identify any program changes that were based on student assessment data. Additionally, no program changes based on assessment data were identified in the self-study.

Accountability to internal stakeholders. The department chair revealed that a schoolwide committee required that "very detailed” reports pertaining to each of its programs be submitted to central administration.

Ongoing assessment. Interview respondents and documents supported that assessment occurred on a predictable schedule within the Biology Department. The program curriculum map revealed that assessments occurred within every core course. However, 
the department chair stated that assessment within the program occurred episodically “and the episodes probably occur right before accreditation.”

Ongoing Evaluation and Improvement. Interview data revealed that faculty constantly analyzed and evaluated the assessment plan.

All of the participants purported to be satisfied with the assessment plan. The department chair stated, "I think [the assessment plan] meets the requirements. It certainly isn't emphasized the way it is at other institutions where they have a whole assessment day on campus and stuff like that.” The associate professor, lecturer, and senior lecturer revealed that faculty had implemented the assessment plan in the program's core courses (see Table 82). They further reported that faculty had developed the plan and that assessment data were analyzed and that the plan was constantly evaluated. The lecturer stated, "we're in the process of revising so I think that's a positive approach.” The senior lecturer reported that the program faculty’s assessment activities were "consistent with what's going on in the school.”

Table 82

Assessment plan: Perceived strengths

\begin{tabular}{|l|c|c|c|c|}
\hline Factors & $\begin{array}{l}\text { Department } \\
\text { Chair }\end{array}$ & $\begin{array}{l}\text { Associate } \\
\text { Professor }\end{array}$ & Lecturer & Senior Lecturer \\
\hline $\begin{array}{l}\text { Meets } \\
\text { Institutional } \\
\text { Requirements }\end{array}$ & $\mathrm{X}$ & & & \\
\hline $\begin{array}{l}\text { Assessment } \\
\text { Plan Has Been } \\
\text { Implemented }\end{array}$ & & $\mathrm{X}$ & $\mathrm{X}$ & $\mathrm{X}$ \\
\hline $\begin{array}{l}\text { Assessment } \\
\text { Plan Was } \\
\text { Developed by } \\
\text { Faculty }\end{array}$ & & $\mathrm{X}$ & $\mathrm{X}$ & $\mathrm{X}$ \\
\hline
\end{tabular}


Table 82

Assessment plan: Perceived strengths: Continued

\begin{tabular}{|l|l|c|c|c|}
\hline Factors & $\begin{array}{l}\text { Department } \\
\text { Chair }\end{array}$ & $\begin{array}{l}\text { Associate } \\
\text { Professor }\end{array}$ & Lecturer & Senior Lecturer \\
\hline $\begin{array}{l}\text { Assessment } \\
\text { Data Had Been } \\
\text { Analyzed }\end{array}$ & $\mathrm{X}$ & $\mathrm{X}$ & $\mathrm{X}$ \\
\hline $\begin{array}{l}\text { Assessment } \\
\text { Plan is } \\
\text { Constantly } \\
\text { Evaluated }\end{array}$ & $\mathrm{X}$ & $\mathrm{X}$ & $\mathrm{X}$ \\
\hline $\begin{array}{l}\text { Faculty's } \\
\text { Assessment } \\
\begin{array}{l}\text { Activities Are } \\
\text { Consistent With } \\
\text { the School }\end{array}\end{array}$ & $\mathrm{X}$ & $\mathrm{X}$ & $\mathrm{X}$ \\
\hline
\end{tabular}

However, the associate professor, lecturer, and senior lecturer identified some challenges to the assessment plan. They reported that some courses failed to address learning outcomes and that learning outcomes needed to be revised (see Table 83).

Table 83

Assessment plan: Perceived challenges

\begin{tabular}{|l|l|c|c|c|}
\hline Factors & $\begin{array}{l}\text { Department } \\
\text { Chair }\end{array}$ & $\begin{array}{l}\text { Associate } \\
\text { Professor }\end{array}$ & Lecturer & Senior Lecturer \\
\hline $\begin{array}{l}\text { Some Courses } \\
\text { Fail to Address } \\
\begin{array}{l}\text { Specific } \\
\text { Intended }\end{array}\end{array}$ & & $\mathrm{X}$ & $\mathrm{X}$ & $\mathrm{X}$ \\
$\begin{array}{l}\text { Learning } \\
\text { Outcomes }\end{array}$ & & $\mathrm{X}$ & $\mathrm{X}$ & $\mathrm{X}$ \\
\hline $\begin{array}{l}\text { Learning } \\
\text { Outcomes Need } \\
\text { to be Revised }\end{array}$ & & & & \\
\hline
\end{tabular}




\section{Institutional Commitments and Resources}

Commitments. University and program leaders demonstrated their commitment to assessment. When asked if the utilization of student assessment data was considered in evaluating and rewarding faculty, the department chair stated, "there’s no policy that would credit [assessment work] in any specific kind of way.” He also reported that assessment expertise was "absolutely not” considered in the hiring process for new faculty.

When queried about the policies and practices that facilitated the communication of student assessment purposes, the department chair reported that some syllabi might include such information. He stated that executive-level support for student assessment was evident. The department chair reported that one faculty member from the department each year was supported by central administrators to attend an assessment conference held on-campus. When asked to describe the culture of assessment within the biology program, he reported that assessment was "behind the scenes for most [faculty]." The department chair reported that a document containing guiding principles for assessment had not been authored. He identified the PRAC as a campus-wide assessment committee with broad representation. The department chair reported that one faculty member and one administrator from each school served on the committee. When queried about the incorporation of outcomes assessment into the scholarship of teaching in promotion and tenure guidelines, he claimed that the scholarship of teaching had not been incorporated into promotion and tenure guidelines. In summary, the significant commitments included:

- executive-level support for student assessment and 
- a campus-wide assessment committee with broad representation.

Resources. On-campus resources associated with the assessment activities included financial support for testing, professional development opportunities, and access to consulting services. When asked to identify resources that were allocated to the Department of Biology from the institution, the department chair stated, "I'm not really aware of any.” He reported that a comprehensive student assessment database was not available to program faculty. The department chair reported that faculty development workshops pertaining to assessment "may" be available. However, he reported to be unaware of student assessment workshops for deans, department chairs, other academic administrators and student affairs staff.

Support for faculty to attend professional conferences on student assessment was available. The department chair reported that internal consulting services for student assessment was available from the Center for Teaching and Learning. He noted that assistance (in the form of paid leaves, stipends, mini-grants, or course reductions) for faculty to work on assessment activities was not available. The department chair identified the Office of Information Management and Institutional Research as being helpful with coordinating data-gathering initiatives such as surveys and standardized tests. Additionally, he noted that an institutional-level assessment office existed. In summary, the significant resources available from the institution included:

- financial support to attend conferences,

- internal consulting services,

- faculty development workshops,

- Center for Teaching and Learning, 
- Institutional Research Office, and

- an institutional-level assessment office.

\section{Faculty Satisfaction with Assessment and the Assessment Plan}

Faculty satisfaction with program assessment was determined by analyzing interview data from four participants: (1) the department chair, (2) an associate professor, (3) a lecturer, and (4) a senior lecturer. The department chair was asked a sample of the items included on the Faculty Satisfaction Interview Protocol. These items elicited information regarding their satisfaction with the implementation of the current assessment plan, opportunities to participate in decision making, and central leadership support for assessment. Only the faculty members were invited to respond to items pertaining to faculty leadership support, professional development, evaluations and rewards, academic decision making, and the impact of student assessment on the program.

Satisfaction with the Implementation of the Current Assessment Plan. The associate professor, lecturer, and senior lecturer purported to be satisfied with the implementation of the current assessment plan. They reported that the implementation of the assessment plan was not intrusive and covered the program's core courses. The associate professor noted that "each course has its own stand alone plan that the instructor is comfortable with.” Additionally, they identified faculty autonomy with assessment as a factor of their satisfaction.

The department chair was not satisfied with the implementation of the assessment plan. He noted it was challenging to use assessment data to inform academic decision making. He stated, “I don’t think we’ve closed the loop, or at least it's not obvious how we've closed the loop on using [assessment data]” (see Table 84). 
Table 84

Implementation of the current assessment plan: Perceived strengths

\begin{tabular}{|l|c|c|c|c|}
\hline Factors & $\begin{array}{l}\text { Department } \\
\text { Chair }\end{array}$ & $\begin{array}{l}\text { Associate } \\
\text { Professor }\end{array}$ & Lecturer & Senior Lecturer \\
\hline $\begin{array}{l}\text { Implementation } \\
\text { Was Not } \\
\text { Intrusive }\end{array}$ & & $\mathrm{X}$ & $\mathrm{X}$ & $\mathrm{X}$ \\
\hline $\begin{array}{l}\text { Assessment } \\
\text { Plan Covers } \\
\begin{array}{l}\text { Program's Core } \\
\text { Courses }\end{array}\end{array}$ & $\mathrm{X}$ & $\mathrm{X}$ & $\mathrm{X}$ \\
\hline $\begin{array}{l}\text { Faculty } \\
\text { Autonomy } \\
\text { With }\end{array}$ & & $\mathrm{X}$ & $\mathrm{X}$ & $\mathrm{X}$ \\
Assessment & & & & \\
\hline
\end{tabular}

Faculty Satisfaction with Participation in Assessment Decisions. The department chair and the associate professor purported to be satisfied with their opportunities to participate in assessment decisions while the senior lecturer purported to be dissatisfied. The lecturer remained neutral in her response.

The department chair reported that he had opportunities to participate in assessment decisions; however, he had not participated. He noted that there had been on-campus meeting and workshops about assessment. The department chair reported that his attendance at national conferences kept him informed about assessment. The associate professor, lecturer, and senior lecturer identified faculty input as an important factor of their satisfaction (see Table 85 ). The associate professor revealed that assessment "was really under [program faculty's] control and that the assessment plans would be what we wanted them to be as long as [the plan] met certain basic needs.” 
Table 85

Participation in assessment decisions: Perceived strengths

\begin{tabular}{|l|c|c|c|c|}
\hline Factors & $\begin{array}{l}\text { Department } \\
\text { Chair }\end{array}$ & $\begin{array}{l}\text { Associate } \\
\text { Professor }\end{array}$ & Lecturer & Senior Lecturer \\
\hline $\begin{array}{l}\text { Access to } \\
\text { Venues to } \\
\begin{array}{l}\text { Participate in } \\
\text { Assessment } \\
\text { Decisions }\end{array}\end{array}$ & $\mathrm{X}$ & & \\
\hline $\begin{array}{l}\text { On-Campus } \\
\text { Meetings }\end{array}$ & $\mathrm{X}$ & & & \\
\hline $\begin{array}{l}\text { Assessment } \\
\text { Workshops }\end{array}$ & $\mathrm{X}$ & & & \\
\hline $\begin{array}{l}\text { National } \\
\text { Conferences }\end{array}$ & $\mathrm{X}$ & & $\mathrm{X}$ & \\
\hline $\begin{array}{l}\text { Faculty Input to } \\
\text { Assessment }\end{array}$ & & $\mathrm{X}$ & $\mathrm{X}$ & \\
\hline $\begin{array}{l}\text { Faculty } \\
\text { Ownership }\end{array}$ & & $\mathrm{X}$ & $\mathrm{X}$ \\
\hline
\end{tabular}

They also reported that assessment policies were dictated from administrators (see

Table 86 ). The senior lecturer stated, assessment guidelines “came down from the top as opposed to up from the bottom." According to the associate professor, "when [assessment guidelines] first came down to us that we had to do this and we had to do that...it rankled many of us.”

Table 86

Participation in assessment decisions: Perceived challenges

\begin{tabular}{|l|l|c|c|c|}
\hline Factors & $\begin{array}{l}\text { Department } \\
\text { Chair }\end{array}$ & $\begin{array}{l}\text { Associate } \\
\text { Professor }\end{array}$ & Lecturer & Senior Lecturer \\
\hline $\begin{array}{l}\text { Assessment } \\
\text { Policies Were } \\
\text { Dictated From } \\
\text { Administration }\end{array}$ & & $\mathrm{X}$ & $\mathrm{X}$ & $\mathrm{X}$ \\
\hline
\end{tabular}


Faculty Satisfaction with Central Leadership Support for Assessment. The associate professor, lecturer, and senior lecturer purported to be satisfied with central leadership support while the department chair purported to be neutral. The department chair stated, “I think [our assessment activities] are running pretty much without any need for any major types of resource allocations, but it’s probably not as extensive as it might be.” The associate professor, lecturer, and senior lecturer identified central leadership support as an important factor of their satisfaction with assessment. However, they also revealed that assessment policies were dictated by administrators (see Table 87).

Table 87

Central leadership support for assessment: Perceived strengths

\begin{tabular}{|l|l|c|c|c|}
\hline Factors & $\begin{array}{l}\text { Department } \\
\text { Chair }\end{array}$ & $\begin{array}{l}\text { Associate } \\
\text { Professor }\end{array}$ & Lecturer & Senior Lecturer \\
\hline $\begin{array}{l}\text { Central } \\
\text { Leadership } \\
\text { Support }\end{array}$ & & $\mathrm{X}$ & $\mathrm{X}$ & $\mathrm{X}$ \\
\hline
\end{tabular}

Faculty Satisfaction with Biology Program Faculty Leadership Support. The associate professor, lecturer, and senior lecturer reported to be satisfied with program faculty leadership support for assessment. They identified faculty autonomy with assessment and the culture of assessment within the department as important factors related to their satisfaction. The associate professor noted that the positive assessment culture was the result of informal assessment discussions (see Table 88).

However, the associate professor, lecturer, and senior lecturer reported some challenges with program faculty leadership support for assessment. They reported that the intended learning outcomes for the program needed to be revised and that the faculty needed to be “refreshed” on the assessment process (see Table 89). 
Table 88

Biology program faculty leadership support: Perceived strengths

\begin{tabular}{|l|c|c|c|}
\hline Factors & $\begin{array}{l}\text { Associate } \\
\text { Professor }\end{array}$ & Lecturer & Senior Lecturer \\
\hline $\begin{array}{l}\text { Faculty } \\
\text { Autonomy with } \\
\text { Assessment }\end{array}$ & $\mathrm{X}$ & $\mathrm{X}$ & $\mathrm{X}$ \\
\hline $\begin{array}{l}\text { Culture that } \\
\text { Values } \\
\text { Assessment }\end{array}$ & $\mathrm{X}$ & $\mathrm{X}$ & $\mathrm{X}$ \\
\hline
\end{tabular}

Table 89

Biology program faculty leadership support: Perceived challenges

\begin{tabular}{|l|c|c|c|}
\hline Factors & $\begin{array}{l}\text { Associate } \\
\text { Professor }\end{array}$ & Lecturer & Senior Lecturer \\
\hline $\begin{array}{l}\text { Intended } \\
\text { Learning } \\
\text { Outcomes Need } \\
\text { Revised }\end{array}$ & $\mathrm{X}$ & $\mathrm{X}$ & $\mathrm{X}$ \\
\hline $\begin{array}{l}\text { Faculty Need to } \\
\text { be Updated of } \\
\text { the Assessment } \\
\text { Process }\end{array}$ & $\mathrm{X}$ & $\mathrm{X}$ & $\mathrm{X}$ \\
\hline
\end{tabular}

Faculty Satisfaction with Professional Development for Student Assessment. All three participants purported to be unsatisfied with professional development for student assessment. They revealed that the Office of Professional Development facilitated various seminars (see Table 90 ). However, the associate professor, lecturer, and senior lecturer reported that developmental programming specifically focused on assessment was not available. They reported that professional development pertaining to question design would be helpful. 
Faculty Satisfaction with Evaluations and Rewards Based on Student Assessment

Data or Involvement. All three participants reported to be unsatisfied with evaluations and rewards based on student assessment data or involvement. The three participants noted that faculty rewards were not based on student assessment involvement. The associate professor reported that student satisfaction surveys provided the most significant sources of data utilized by program administrators to evaluate faculty performance.

Table 90

Evaluations and rewards based on student assessment data or involvement: Perceived challenges

\begin{tabular}{|l|c|c|c|}
\hline Factors & $\begin{array}{l}\text { Associate } \\
\text { Professor }\end{array}$ & Lecturer & Senior Lecturer \\
\hline $\begin{array}{l}\text { Lack of } \\
\text { Rewards For } \\
\text { Student }\end{array}$ & $\mathrm{X}$ & $\mathrm{X}$ & $\mathrm{X}$ \\
$\begin{array}{l}\text { Assessment } \\
\text { Data or } \\
\text { Involvement }\end{array}$ & & & \\
\hline $\begin{array}{l}\text { Student } \\
\text { Satisfaction of } \\
\text { Teaching } \\
\text { Surveys }\end{array}$ & $\mathrm{X}$ & $\mathrm{X}$ & $\mathrm{X}$ \\
\hline
\end{tabular}

Faculty Satisfaction with the Use of Student Assessment Data in Making Academic

Decisions. All three participants purported to be satisfied with the use of assessment data in making academic decisions. They reported that central administrators utilized assessment data for retention efforts. The associate professor noted that data gathered for this purpose was utilized to identify gateway courses which are the "large courses that students take to enter into various programs.” They also reported that administrators were 
able to predict student success at the university based on students' previous performance in high school (see Table 91).

Table 91

Use of student assessment data in making academic decisions:

Perceived strengths

\begin{tabular}{|l|c|c|c|}
\hline Factors & $\begin{array}{l}\text { Associate } \\
\text { Professor }\end{array}$ & Lecturer & Senior Lecturer \\
\hline $\begin{array}{l}\text { Retention } \\
\text { Efforts }\end{array}$ & $\mathrm{X}$ & $\mathrm{X}$ & $\mathrm{X}$ \\
\hline $\begin{array}{l}\text { Identification of } \\
\text { Gateway } \\
\text { Courses }\end{array}$ & $\mathrm{X}$ & $\mathrm{X}$ & $\mathrm{X}$ \\
\hline $\begin{array}{l}\text { Prediction of } \\
\text { Student } \\
\text { Performance }\end{array}$ & $\mathrm{X}$ & $\mathrm{X}$ & $\mathrm{X}$ \\
\hline
\end{tabular}

Faculty Satisfaction with the Impact Student Assessment had on the Biology Program.

The associate professor and the lecturer purported to be satisfied with the impact student assessment had on the biology program while the senior lecturer was neutral in his response. They identified improvements in student achievement and increased graduation rates as important factors with their satisfaction (see Table 92).

Table 92

Impact student assessment had on the biology program:

Perceived strengths

\begin{tabular}{|l|c|c|c|}
\hline Factors & $\begin{array}{l}\text { Associate } \\
\text { Professor }\end{array}$ & Lecturer & Senior Lecturer \\
\hline $\begin{array}{l}\text { Increased } \\
\text { Student } \\
\text { Achievement }\end{array}$ & $\mathrm{X}$ & $\mathrm{X}$ & $\mathrm{X}$ \\
\hline $\begin{array}{l}\text { Increased } \\
\text { Graduation } \\
\text { Rates }\end{array}$ & $\mathrm{X}$ & $\mathrm{X}$ & $\mathrm{X}$ \\
\hline
\end{tabular}


However, they reported that assessment data had not been fully analyzed, longitudinal assessment data had not been collected, and the lack of implemented common assessment activities across courses impeded their satisfaction. They noted that assessment was becoming more important within the department (see Table 93).

Table 93

Use of student assessment data in making academic decisions:

Perceived challenges

\begin{tabular}{|c|c|c|c|}
\hline Factors & $\begin{array}{l}\text { Associate } \\
\text { Professor }\end{array}$ & Lecturer & Senior Lecturer \\
\hline $\begin{array}{l}\text { Assessment } \\
\text { Data Had Not } \\
\text { Been Fully } \\
\text { Analyzed }\end{array}$ & $\mathrm{X}$ & $\mathrm{X}$ & $\mathrm{X}$ \\
\hline $\begin{array}{l}\text { Lack of } \\
\text { Common } \\
\text { Assessment } \\
\text { Measures } \\
\text { Across Courses }\end{array}$ & $X$ & $\mathrm{X}$ & $\mathrm{X}$ \\
\hline $\begin{array}{l}\text { No } \\
\text { Longitudinal } \\
\text { Assessment } \\
\text { Data }\end{array}$ & $X$ & $\mathrm{X}$ & $\mathrm{X}$ \\
\hline
\end{tabular}

Faculty Satisfaction Summary. Table 94 illustrates the frequency of themes across items related to strengths in assessment. The most frequently identified themes pertaining to assessment strengths were:

- faculty autonomy with assessment,

- the implementation of the assessment plan,

- faculty development of the assessment plan,

- analysis of assessment data,

- constant evaluation of the assessment plan, 
- consistency of program assessment activities with school assessment activities,

- non-intrusive nature of implementation of the assessment plan,

- assessment plan covers core courses,

- faculty input to assessment,

- faculty ownership of the assessment plan,

- central leadership support,

- retention efforts,

- identification of gateway courses,

- prediction of student performance,

- culture that values assessment,

- increased student achievement, and

- increased graduation rates.

The associate professor, lecturer, and senior lecturer identified the implementation of the assessment plan, the contribution of program faculty to the assessment plan, the analysis of assessment data, the constant evaluation of the assessment plan, and the consistency of departmental assessment activities with the School of Science as important factors with their satisfaction of the assessment plan. The associate professor, lecturer, and senior lecturer reported that the non-intrusive nature of the assessment plan, the capacity of the assessment plan to cover the program's core courses, and faculty's autonomy with assessment as important factors pertaining to the implementation of the current assessment plan. They also identified faculty autonomy with assessment as an important factor of their satisfaction related to program faculty leadership support. 
These participants identified faculty input into assessment decisions and faculty ownership of assessment as important in assessment decision making. The associate professor, lecturer, and senior lecturer reported that the support of central leaders was an important factor of their satisfaction with central leadership for assessment. All three participants revealed that the positive culture of assessment contributed to their satisfaction with program faculty leadership support. The associate professor, lecturer, and senior lecturer identified retention efforts, the identification of gateway courses, and the predictability of student performance as important factors of their satisfaction pertaining to the use of student assessment data in making academic decisions. The three aforementioned participants identified increased student achievement and increased graduation rates as important impacts student assessment had on the biology program. The associate professor and the lecturer reported that increased student achievement and graduate rates were important factors of their satisfaction with the impact student assessment had on the biology program (see Table 94).

Table 94

Participation in assessment decisions: Perceived strengths

\begin{tabular}{|c|c|c|c|c|}
\hline Factors & $\begin{array}{l}\text { Department } \\
\text { Chair }\end{array}$ & $\begin{array}{l}\text { Associate } \\
\text { Professor }\end{array}$ & Lecturer & Senior Lecturer \\
\hline $\begin{array}{l}\text { Faculty } \\
\text { Autonomy } \\
\text { With } \\
\text { Assessment }\end{array}$ & 0 & 2 & 2 & 2 \\
\hline $\begin{array}{l}\text { Assessment } \\
\text { Plan Has Been } \\
\text { Implemented }\end{array}$ & 0 & 1 & 1 & 1 \\
\hline $\begin{array}{l}\text { Assessment } \\
\text { Plan Was } \\
\text { Developed by } \\
\text { Faculty }\end{array}$ & 0 & 1 & 1 & 1 \\
\hline
\end{tabular}


Table 94

Participation in assessment decisions: Perceived strengths continued

\begin{tabular}{|c|c|c|c|c|}
\hline Factors & $\begin{array}{l}\text { Department } \\
\text { Chair }\end{array}$ & $\begin{array}{l}\text { Associate } \\
\text { Professor }\end{array}$ & Lecturer & Senior Lecturer \\
\hline $\begin{array}{l}\text { Assessment } \\
\text { Data Had Been } \\
\text { Analyzed }\end{array}$ & 0 & 1 & 1 & 1 \\
\hline $\begin{array}{l}\text { Assessment } \\
\text { Plan is } \\
\text { Constantly } \\
\text { Evaluated }\end{array}$ & 0 & 1 & 1 & 1 \\
\hline $\begin{array}{l}\text { Faculty's } \\
\text { Assessment } \\
\text { Activities Are } \\
\text { Consistent With } \\
\text { the School } \\
\end{array}$ & 0 & 1 & 1 & 1 \\
\hline $\begin{array}{l}\text { Implementation } \\
\text { of the } \\
\text { Assessment } \\
\text { Plan Was Not } \\
\text { Intrusive }\end{array}$ & 0 & 1 & 1 & 1 \\
\hline $\begin{array}{l}\text { Assessment } \\
\text { Plan Covers } \\
\text { Program's Core } \\
\text { Courses }\end{array}$ & 0 & 1 & 1 & 1 \\
\hline $\begin{array}{l}\text { Faculty Input } \\
\text { To Assessment }\end{array}$ & 0 & 1 & 1 & 1 \\
\hline $\begin{array}{l}\text { Faculty } \\
\text { Ownership of } \\
\text { the Assessment } \\
\text { Plan }\end{array}$ & 0 & 1 & 1 & 1 \\
\hline $\begin{array}{l}\text { Central } \\
\text { Leadership } \\
\text { Support for } \\
\text { Assessment }\end{array}$ & 0 & 1 & 1 & 1 \\
\hline $\begin{array}{l}\text { Retention } \\
\text { Efforts }\end{array}$ & 0 & 1 & 1 & 1 \\
\hline $\begin{array}{l}\text { Identification of } \\
\text { Gateway } \\
\text { Courses }\end{array}$ & 0 & 1 & 1 & 1 \\
\hline $\begin{array}{l}\text { Prediction of } \\
\text { Student } \\
\text { Performance }\end{array}$ & 0 & 1 & 1 & 1 \\
\hline
\end{tabular}


Table 94

Participation in assessment decisions: Perceived strengths continued

\begin{tabular}{|c|c|c|c|c|}
\hline Factors & $\begin{array}{l}\text { Department } \\
\text { Chair }\end{array}$ & $\begin{array}{l}\text { Associate } \\
\text { Professor }\end{array}$ & Lecturer & Senior Lecturer \\
\hline $\begin{array}{l}\text { Culture that } \\
\text { Values } \\
\text { Assessment }\end{array}$ & 0 & 1 & 1 & 1 \\
\hline $\begin{array}{l}\text { Increased } \\
\text { Student } \\
\text { Achievement } \\
\end{array}$ & 0 & 1 & 1 & 1 \\
\hline $\begin{array}{l}\text { Increased } \\
\text { Graduation } \\
\text { Rates }\end{array}$ & 0 & 1 & 1 & 1 \\
\hline $\begin{array}{l}\text { Meets } \\
\text { Institutional } \\
\text { Requirements } \\
\end{array}$ & 1 & 0 & 0 & 0 \\
\hline $\begin{array}{l}\text { Access to } \\
\text { Venues to } \\
\text { Participate in } \\
\text { Assessment } \\
\text { Decisions }\end{array}$ & 1 & 0 & 0 & 0 \\
\hline $\begin{array}{l}\text { On-Campus } \\
\text { Meetings About } \\
\text { Assessment } \\
\end{array}$ & 1 & 0 & 0 & 0 \\
\hline $\begin{array}{l}\text { Developmental } \\
\text { Workshops }\end{array}$ & 1 & 0 & 0 & 0 \\
\hline $\begin{array}{l}\text { National } \\
\text { Conferences }\end{array}$ & 1 & 0 & 0 & 0 \\
\hline
\end{tabular}

The most frequently identified themes pertaining to assessment challenges were:

- needed revisions to learning outcomes,

- failure of some courses to address specific intended learning outcomes,

- dictation of assessment policies by administration,

- need to update faculty of the assessment process,

- lack of developmental programming focused specifically on assessment,

- lack of rewards for student assessment data or involvement, and 
- student satisfaction of teaching surveys (see Table 95).

The associate professor, lecturer, and senior lecturer reported that the inconsistency of program courses to address specific intended learning outcomes and the need for revised intended learning outcomes impeded their satisfaction with the assessment plan. They also noted that the need for revised learning outcomes and the need to update faculty of the assessment process were challenges for program faculty leadership support. The associate professor, lecturer, and the senior lecturer reported that administrative mandates pertaining to assessment were a challenge to their participation in assessment decisions. They reported that the lack of developmental programming focused on assessment impeded their satisfaction with professional development.

The associate professor, lecturer, and senior lecturer reported that the lack of rewards for student assessment data or involvement and the use of student satisfaction of teaching surveys were challenges related to evaluations and rewards based on student assessment data or involvement. They identified the lack of analyzed assessment data, common assessment measures across multiple courses, and longitudinal assessment data as challenges to the impact student assessment had on the program.

Table 95

Participation in assessment decisions: Perceived challenges

\begin{tabular}{|l|c|c|c|c|}
\hline Factors & $\begin{array}{l}\text { Department } \\
\text { Chair }\end{array}$ & $\begin{array}{l}\text { Associate } \\
\text { Professor }\end{array}$ & Lecturer & Senior Lecturer \\
\hline $\begin{array}{l}\text { Learning } \\
\begin{array}{l}\text { Outcomes Need } \\
\text { to be Revised }\end{array}\end{array}$ & 0 & 2 & 2 & 2 \\
\hline
\end{tabular}


Table 95

Participation in assessment decisions: Perceived challenges continued

\begin{tabular}{|c|c|c|c|c|}
\hline Factors & $\begin{array}{l}\text { Department } \\
\text { Chair }\end{array}$ & $\begin{array}{l}\text { Associate } \\
\text { Professor }\end{array}$ & Lecturer & Senior Lecturer \\
\hline $\begin{array}{l}\text { Some Courses } \\
\text { Fail to Assess } \\
\text { Specific } \\
\text { Intended } \\
\text { Learning } \\
\text { Outcomes } \\
\end{array}$ & 0 & 1 & 1 & 1 \\
\hline $\begin{array}{l}\text { Assessment } \\
\text { Policies Were } \\
\text { Dictated From } \\
\text { Administrators }\end{array}$ & 0 & 1 & 1 & 1 \\
\hline $\begin{array}{l}\text { Faculty Need to } \\
\text { be Reminded of } \\
\text { the Assessment } \\
\text { Process }\end{array}$ & 0 & 1 & 1 & 1 \\
\hline $\begin{array}{l}\text { Developmental } \\
\text { Programming } \\
\text { Did Not Focus } \\
\text { on Assessment }\end{array}$ & 0 & 1 & 1 & 1 \\
\hline $\begin{array}{l}\text { Lack of } \\
\text { Rewards For } \\
\text { Student } \\
\text { Assessment } \\
\text { Data or } \\
\text { Involvement }\end{array}$ & 0 & 1 & 1 & 1 \\
\hline $\begin{array}{l}\text { Student } \\
\text { Satisfaction of } \\
\text { Teaching } \\
\text { Surveys } \\
\end{array}$ & 0 & 1 & 1 & 1 \\
\hline $\begin{array}{l}\text { Assessment } \\
\text { Data Had Not } \\
\text { Been Fully } \\
\text { Analyzed }\end{array}$ & 0 & 1 & 1 & 1 \\
\hline $\begin{array}{l}\text { Lack of } \\
\text { Common } \\
\text { Assessment } \\
\text { Measures } \\
\text { Across Courses } \\
\end{array}$ & 0 & 1 & 1 & 1 \\
\hline
\end{tabular}


Table 95

Participation in assessment decisions: Perceived challenges continued

\begin{tabular}{|l|c|c|c|c|}
\hline Factors & $\begin{array}{l}\text { Department } \\
\text { Chair }\end{array}$ & $\begin{array}{l}\text { Associate } \\
\text { Professor }\end{array}$ & Lecturer & Senior Lecturer \\
\hline $\begin{array}{l}\text { No } \\
\begin{array}{l}\text { Assessment } \\
\text { Data }\end{array}\end{array}$ & 0 & 1 & 1 & 1 \\
\hline
\end{tabular}

Undergraduate English Program

Faculty within the Department of English awarded Bachelor of Arts Degrees in English with specializations in creative writing, film studies, linguistics, literature, writing and literacy, and individualized studies. Program faculty awarded minors in literature, writing, creative writing, business and professional writing, linguistics, and film studies. According to the department's website,

Through its courses and other activities in linguistics, writing, creative writing, film, and literature, the Department of English works to create and sustain evolving communities of learners interested in the contributions of language to what has been called the examined life: a thoughtful, morally aware, and civically and personally responsible existence. Faculty and students aim for excellence in analyzing, understanding, and communicating about language and its beauties.

The English program faculty consisted of 14 professors, 13 associate professors, one assistant professor, and 34 lecturers. Interview data revealed that approximately 80 parttime faculty taught courses in the department. Undergraduate English students were primarily enrolled part-time. Class sizes ranged between 20 to 35 students. 


\section{Study Participants}

The researcher conducted interviews with the department chair, a professor, and an associate professor. The department chair was serving her first year as a program administrator and had worked in higher education for about 16 years. The department chair reported that she was very knowledgeable about assessment. She stated, "writing assessment is my field of specialty in composition studies.” She attended one assessment conference where she presented assessment results in the past two years and published one paper pertaining to student outcomes assessment in the past two years.

The second participant, an associate professor, was serving his fourteenth year at AU. He worked in higher education for 17 years. The associate professor claimed that he was moderately knowledgeable about assessment. He reported that he was involved in an assessment project with the writing program. The associate professor had not attended any conferences that focused on student outcomes assessment; however, he attended three conferences that included assessment sessions on the program in the past two years. He did not present assessment results at any of the conferences he attended and did not publish any papers pertaining to student outcomes assessment in the past two years.

The third participant, an associate professor, was serving his tenth year at AU. He had worked in higher education for 20 years. The associate professor purported to be fairly knowledgeable about student outcomes assessment. He noted that his commitment to assessment and his work with the PRAC contributed to his knowledge of assessment. The associate professor attended two conferences that focused on student outcomes assessment in the past two years; however, he did not present assessment results at either 
conference. He had not published any papers pertaining to student outcomes assessment in the past two years.

\section{Characteristics of Effective Assessment Practice}

The researcher analyzed interview data, the 2005 - 2006 School of Liberal Arts Assessment Report, and the assessment plan to identify characteristics of effective practice.

Credible evidence of learning. Interview respondents and documents illustrated various components of the assessment plan that ensured learning was relevant and assessment measures were reliable. The researcher was not given access to intended learning outcomes for the program.

The department chair stated that “[program faculty] do not have a particularly organized approach to assessing outcomes in the major.” She reported that faculty were developing a “more systematic [assessment plan].” The 2005 - 2006 School of Liberal Arts Assessment Report revealed that faculty were "completing the pilot phase of a [program] assessment project.” According to the report, “[program faculty] ran a test of the initial [assessment plan] using one semester’s capstone senior projects.”

The department chair reported that the capstone assessment activity was not standardized across course sections. She stated, “[faculty] all share a commitment to some kind of assignment that asks students to reflect on what they've learned over the course of their major.” She noted that some faculty related the capstone assignment to the PULs (general education outcomes). The department chair reported that students enrolled in the capstone course "have been in the habit for several years of writing letters about their experiences in the department, which have been turned over to the previous 
department chair. The previous department chair had never done anything with them in terms of analyzing patterns.”

The department chair observed that faculty "have been moving toward developing rubrics to go with each level of achievement correlated to the different PULs.” She also noted that this indirect assessment activity would become a component of the students' electronic portfolios. Ultimately, faculty will implement a system that "will involve using [program specialization] grids developed by each [faculty] from each separate track in the department. The goals on these grids will [relate] to the PULs.”

The researcher was not given access to data from the aforementioned assessment activities.

Continuous Improvement. The department chair revealed that program faculty did not discuss assessment results. She stated, one of the weaknesses of our department organization at the moment is that the people who are running different programs in the department don't tend to talk to each other very much because the organization has been more like people talking to each other about their own [specialization content] instead of talking about things across the program.

However, she reported that program faculty have "made as good of use as possible of informal faculty conversations about student performance.” The department chair was hopeful that would "get away from our individual students and grades so that we could learn a lot and it would help us see how they're doing and decide if we need to do some things differently.” 
The department chair reported that a random sample of portfolios "from across the spectrum of our first-year composition course” were assessed several years ago. She stated, "we were able to pay faculty to spend two days reading them and to talk about what they saw in them.” She continued, "out of that developed both some curricular changes and different changes in faculty development opportunities.”

The department chair reported that students enrolled in the capstone course reflected on their learning over several years and wrote about their experiences. She revealed that the previous department chair did not utilize the data gathered from this assessment. The department chair stated, "the students write [the reflections] but nobody has done anything with them. So we've had more evidence than we've made use of [for academic decisions].”

Accountability to internal stakeholders. The program's assessment committee and the annual assessment document submitted as a component of the School of Liberal Art's Annual Assessment Report necessitated assessment accountability within the program.

Ongoing assessment. The department chair reported that program faculty accepted responsibility for assessment within their own courses than they did for the entire department. She stated, "the department as a whole has been slower to see assessment as something that should be rolled into it's regular business.” She reported that some faculty representing various program specializations were more advanced with their assessments than others. She explained that within one specialization, faculty tried to rotate different sorts of assessment activities or focus on looking at different parts of the writing program over time so that over time every course or 
every part of the writing program would get some kind of attention from us as planners, advisors, implementers, and sustainers of the program.

Ongoing Evaluation and Improvement. The department chair reported that the quantity of faculty participating in assessment ensured that the plan was constantly evaluated and improved. She stated, whatever assessment plan the department ultimately adopts is going to need to be used by 57 people not just by the 6 committed people on the assessment committee. So, in an odd way, the thing that slows down our assessment process also enhances it's quality in the long run. It means that enough people will object to things they don't like about it and those objections can be incorporated into [the plan].

The department chair and both associate professors purported to be unsatisfied with the program's assessment plan. The department chair noted that the program's assessment plan was disorganized, slow in developing, and time consuming for faculty (see Table 96). With regard to the commitment of time required by assessment activities, the department chair revealed that "there was at least one semester when every portfolio was read. It was a mammoth undertaking and that was not possible to sustain.” Associate professor A reported that the previous department chair impeded the faculty's ability to develop an assessment plan. He stated, "there was really no support from [the previous department chair] for pushing assessment in the department.” However, he noted that the current department chair valued assessment more highly. Associate professor A expressed concerns about conflicting priorities of faculty and administrators. 
He stated, “the [department chair] and I have a different sense of what is the most important thing for us to do at this stage [with assessment].”

Table 96

Assessment plan: Perceived challenges

\begin{tabular}{|c|c|c|c|}
\hline Factors & $\begin{array}{l}\text { Department } \\
\text { Chair }\end{array}$ & $\begin{array}{l}\text { Associate } \\
\text { Professor A }\end{array}$ & $\begin{array}{l}\text { Associate } \\
\text { Professor B }\end{array}$ \\
\hline Disorganized & $\mathrm{X}$ & & \\
\hline $\begin{array}{l}\text { Time } \\
\text { Consuming } \\
\text { Process } \\
\end{array}$ & $\mathrm{X}$ & & $\mathrm{X}$ \\
\hline $\begin{array}{l}\text { Slow Progress } \\
\text { in Assessment } \\
\text { Plan } \\
\text { Development }\end{array}$ & $\mathrm{X}$ & & \\
\hline $\begin{array}{l}\text { Previous } \\
\text { Administrator } \\
\text { Did Not Value } \\
\text { Assessment }\end{array}$ & & $\mathrm{X}$ & \\
\hline $\begin{array}{l}\text { Conflicting } \\
\text { Priorities } \\
\text { Between } \\
\text { Faculty and } \\
\text { Administrators }\end{array}$ & & $\mathrm{X}$ & \\
\hline $\begin{array}{l}\text { Assessment } \\
\text { Plan Did Not } \\
\text { Exist }\end{array}$ & & & $X$ \\
\hline
\end{tabular}

Associate professor B reported that faculty developed course- and program-level assessments and that faculty participated in assessment activities. He expressed concerns with the lack of a program assessment plan. However, he noted that faculty were in the process of developing an assessment plan for the program (see Table 97). Associate professor B also reported that time was a challenge to assessment. He stated, "we have to make the most of the little time [we have].” However, he was happy with the progress being made by the program assessment committee. The department chair reported that 
the assessment committee was preparing a pilot study that would assess reading comprehension, writing, and critical thinking outcomes.

Table 97

Assessment plan: Perceived strengths

\begin{tabular}{|l|l|c|c|}
\hline Factors & $\begin{array}{l}\text { Department } \\
\text { Chair }\end{array}$ & $\begin{array}{l}\text { Associate } \\
\text { Professor A }\end{array}$ & $\begin{array}{l}\text { Associate } \\
\text { Professor B }\end{array}$ \\
\hline $\begin{array}{l}\text { Faculty Were } \\
\text { Developing An } \\
\text { Assessment } \\
\text { Plan }\end{array}$ & & & \\
\hline $\begin{array}{l}\text { Department } \\
\text { Chair Values }\end{array}$ & & & X \\
Assessment & & X & \\
\hline
\end{tabular}

\section{Institutional Commitments and Resources}

Commitments. When asked if the utilization of student assessment data was considered in evaluating and rewarding faculty, the department chair stated that "tenure and promotion dossiers included a section dedicated to assessment.” She continued, “you have to have a section of your dossier that talks about student learning outcomes and how you know that students are meeting those learning outcomes.” Additionally, the department chair reported that student assessment expertise was not considered in the hiring process for new faculty. However, she reported that her initial position at AU required the coordination of assessment activities. She reported that the institutional assessment leader and PRAC members held discussions pertaining to assessment reports with representatives of academic departments. However, she believed central administrators could communicate assessment purposes more effectively.

When asked about policies to promote the involvement of student affairs personnel and students in assessment efforts, the department chair indicated that no relationship 
between the Department of English and any student affairs personnel existed. She illustrated executive-level support through the Office of the Vice Chancellor as she made available one registration to the assessment conference held on-campus.

When asked to describe the culture of assessment within the Department of English, the department chair stated, "faculty are in very different places of their understanding of assessment...I would say there isn't unified culture of assessment because some people see assessment as something that comes naturally to teachers and other people see it as an imposed external distraction.” She reported that guiding principles for assessment existed.

Additionally, the department chair reported that the PRAC was a campus-wide assessment committee with broad representation. The department chair stated that outcomes assessment had been incorporated into the scholarship of teaching in promotion and tenure guidelines.

In summary, the significant commitments included:

- incorporation of the scholarship of teaching in promotion and tenure guidelines,

- executive-level support through the Office of the Vice Chancellor,

- guiding principles for assessment, and

- a campus-wide committee with broad representation.

Resources. On-campus resources associated with the assessment activities included financial support for testing, professional development opportunities, and access to consulting services. When asked to identify resources allocated to the AU English faculty, the department chair reported that the Office of the Vice Chancellor and professional development opportunities were important to the implementation of 
assessment. She stated that professional development assessment workshops were offered at AU once or twice per semester. She reported that support for faculty to attend professional conferences on student assessment was available. However, financial support to attend a conference was more readily available to faculty who would be presenting assessment results. According to the department chair, internal consulting services for faculty on the use of student assessment in course design and instruction were available from the Center for Teaching and Learning.

According to the department chair, program faculty did not have access to a comprehensive student assessment database. However, she reported that the Office of Information Management and Institutional Research provided custom reports that might include such data.

The department chair reported that assistance (in the form of paid leaves, stipends, mini-grants, or course reductions) for faculty to work on assessment activities was available. She noted that faculty could compete for mini-grants from the PRAC. Furthermore, the department chair reported to be unaware of assessment workshops for deans, department chairs, and other academic administrators or student affairs staff and student affairs administrators. However, she claimed that "there is an emerging movement to provide support for new department chairs and directors.” The department chair reported that there was no office charged with coordinating data-gathering initiatives such as surveys and standardized tests. Additionally, she noted that a programlevel assessment office did not exist. However, the department chair identified the Office of the Vice Chancellor as the institutional assessment office.

In summary, the significant resources available from the institution included: 
- institutional assessment office,

- professional development workshops for faculty,

- Office of Institutional Research,

- financial support to attend conferences,

- internal consulting services on the use of course design and instruction,

- Center for Teaching and Learning, and

- mini-grants.

Faculty Satisfaction with Assessment and the Assessment Plan

Faculty satisfaction with program assessment was determined by analyzing interview data from three individuals: the department chair who was also a professor and two associate professors. The department chair was asked a sample of the items included on the Faculty Satisfaction Interview Protocol. These items were intended to elicit information regarding their satisfaction with implementation of the current assessment plan, opportunities to participate in policy making, and central leadership support for assessment. Only the professor and associate professor were invited to respond to the items pertaining to faculty leadership support, professional development, evaluations and rewards, academic decision making, and the impact of student assessment on the program.

Satisfaction with the Implementation of the Current Assessment Plan. The department chair purported to be satisfied with the implementation of the current assessment plan while the associate professors purported to be unsatisfied. The department chair reported that "[faculty] aren't nearly as resistant [to assessment] as they had been." She also noted that the pilot assessment project was progressing. Even though associate professor A 
reported to be unsatisfied, he stated, “I'm very happy with the work the assessment committee has done” (see Table 98).

Table 98

Implementation of the current assessment plan: Perceived strengths

\begin{tabular}{|l|l|l|l|}
\hline Factors & $\begin{array}{l}\text { Department } \\
\text { Chair }\end{array}$ & $\begin{array}{l}\text { Associate } \\
\text { Professor A }\end{array}$ & $\begin{array}{l}\text { Associate } \\
\text { Professor B }\end{array}$ \\
\hline $\begin{array}{l}\text { Faculty } \\
\text { Participation }\end{array}$ & $\mathrm{X}$ & & \\
\hline $\begin{array}{l}\text { Progress of } \\
\text { Pilot } \\
\text { Assessment } \\
\text { Activities }\end{array}$ & $\mathrm{X}$ & & \\
\hline $\begin{array}{l}\text { Progress of the } \\
\text { Assessment } \\
\text { Committee }\end{array}$ & & & \\
\hline
\end{tabular}

Associate professor A and B identified the lack of an assessment plan as a challenge. Associate professor B stated, "I'd say we're implementing at the course level and mapping course and faculty values, and I think that's moving along. But we haven’t implemented a programmatic assessment yet.” He continued, “we have course goals and program-wide goals and we've refined those and we've tried to make them more student friendly in the last year and I'm lots of good feedback about that” (see Table 99).

Table 99

Implementation of the current assessment plan: Perceived strengths

\begin{tabular}{|l|l|c|c|}
\hline Factors & $\begin{array}{l}\text { Department } \\
\text { Chair }\end{array}$ & $\begin{array}{l}\text { Associate } \\
\text { Professor A }\end{array}$ & $\begin{array}{l}\text { Associate } \\
\text { Professor B }\end{array}$ \\
\hline $\begin{array}{l}\text { Assessment } \\
\text { Plan Did Not } \\
\text { Exist }\end{array}$ & & $\mathrm{X}$ & $\mathrm{X}$ \\
\hline
\end{tabular}


Faculty Satisfaction with Participation in Assessment Decisions. The department chair purported to be somewhat satisfied with her participation in assessment decisions while both associate professors purported to be satisfied. The department chair reported that she participated in assessment decisions when she was the Director of Assessment for the writing program. She also participated in various committees including assessment activities with the institutional assessment leader and the development of electronic portfolio requirements (see Table 100).

Associate professor A reported that the English Department assessment committee provided a venue for him to participate in assessment decisions. Associate professor B noted the job description of his current position and service to the writing coordinating committee. He also explained that gateway forums offered a venue to the university community to discuss the relationships between the Principles of Undergraduate Learning and individual courses. He stated, "forums are a way for faculty to come together and talk about gateway courses which are defined that a lot of entering students take.”

Table 100

Participation in assessment decisions: Perceived strengths

\begin{tabular}{|l|c|c|c|}
\hline Attributes & $\begin{array}{l}\text { Department } \\
\text { Chair }\end{array}$ & $\begin{array}{l}\text { Associate } \\
\text { Professor A }\end{array}$ & $\begin{array}{l}\text { Associate } \\
\text { Professor B }\end{array}$ \\
\hline $\begin{array}{l}\text { Previous } \\
\text { Involvement in } \\
\text { Assessment }\end{array}$ & $\mathrm{X}$ & & \\
\hline $\begin{array}{l}\text { Committee } \\
\text { Service }\end{array}$ & $\mathrm{X}$ & $\mathrm{X}$ & $\mathrm{X}$ \\
\hline $\begin{array}{l}\text { Participation in } \\
\text { Assessment } \\
\begin{array}{l}\text { Activities with } \\
\text { the Institutional }\end{array}\end{array}$ \\
$\begin{array}{l}\text { Assessment } \\
\text { Leader }\end{array}$ & $\mathrm{X}$ & & \\
\hline
\end{tabular}


Table 100

Participation in assessment decisions: Perceived strengths continued

\begin{tabular}{|l|l|l|l|}
\hline Attributes & $\begin{array}{l}\text { Department } \\
\text { Chair }\end{array}$ & $\begin{array}{l}\text { Associate } \\
\text { Professor A }\end{array}$ & $\begin{array}{l}\text { Associate } \\
\text { Professor B }\end{array}$ \\
\hline $\begin{array}{l}\text { Participation in } \\
\text { the }\end{array}$ & & & \\
$\begin{array}{l}\text { Development of } \\
\text { Electronic } \\
\text { Portfolio } \\
\text { Requirements }\end{array}$ & $\mathrm{X}$ & & \\
\hline $\begin{array}{l}\text { Current } \\
\text { Involvement in } \\
\text { Assessment }\end{array}$ & & & $\mathrm{X}$ \\
\hline $\begin{array}{l}\text { Gateway } \\
\text { Forums }\end{array}$ & & & $\mathrm{X}$ \\
\hline
\end{tabular}

Faculty Satisfaction with Central Leadership Support for Assessment. All of the participants reported to be very satisfied with central leadership support for assessment. The department chair identified the culture of assessment and central leadership support as important factors of her satisfaction. The department chair stated, I think there has been good support for working out assessment issues at the classroom level and at the major level so that a big department like mine could be helped to see how it is possible to do assessment.” Associate professor B explained that “if you want help, it's there.” He reported that grants to support assessment activities and an on-campus assessment conference were available to faculty (see Table 101).

The department chair reported that assistance with course- and program-level assessment was a challenge. She stated that it would be helpful for a "big department like mine...to see how to do assessment.” The department chair also noted that incentives for participating in assessment activities were limited. She stated, “we’ve had 
Table 101

Central leadership support for assessment: Perceived strengths

\begin{tabular}{|l|l|l|l|}
\hline Factors & $\begin{array}{l}\text { Department } \\
\text { Chair }\end{array}$ & $\begin{array}{l}\text { Associate } \\
\text { Professor A }\end{array}$ & $\begin{array}{l}\text { Associate } \\
\text { Professor B }\end{array}$ \\
\hline $\begin{array}{l}\text { Culture that } \\
\text { Values }\end{array}$ & $\mathrm{X}$ & \\
Assessment & & & \\
\hline $\begin{array}{l}\text { Central } \\
\text { Leadership } \\
\text { Support }\end{array}$ & & & \\
\hline Mini-Grants & & & $\mathrm{X}$ \\
\hline $\begin{array}{l}\text { On-Campus } \\
\text { Assessment } \\
\text { Conference }\end{array}$ & & & $\mathrm{X}$ \\
\hline
\end{tabular}

raises under the cost of living for the past five years or longer than that here, so people don't like to be asked to do things that they see as extra when raises are [so low].”

Associate professor A identified the lack of direction from institutional leaders and the lack of rewards for participating in assessment activities as challenges (see Table 102). He stated, "I feel as though [central administrators] could perhaps be giving more direct thought on how to encourage and reward faculty participation in student assessment. Right now it tends to count under service which is not the most prestigious category in promotion and tenure dossiers." Associate professor A also noted that he would have liked “more direct actual rewards for [participating in assessment activities].

Table 102

Central leadership support for assessment: Perceived challenges

\begin{tabular}{|l|c|c|l|}
\hline Factors & $\begin{array}{l}\text { Department } \\
\text { Chair }\end{array}$ & $\begin{array}{l}\text { Associate } \\
\text { Professor A }\end{array}$ & $\begin{array}{l}\text { Associate } \\
\text { Professor B }\end{array}$ \\
\hline $\begin{array}{l}\text { Too Much } \\
\text { Direction from } \\
\text { Central Leadership }\end{array}$ & $\mathrm{X}$ & $\mathrm{X}$ & \\
\hline
\end{tabular}


Table 102

Central leadership support for assessment: Perceived challenges continued

\begin{tabular}{|l|l|c|l|}
\hline Factors & $\begin{array}{l}\text { Department } \\
\text { Chair }\end{array}$ & $\begin{array}{l}\text { Associate } \\
\text { Professor A }\end{array}$ & $\begin{array}{l}\text { Associate } \\
\text { Professor B }\end{array}$ \\
\hline $\begin{array}{l}\text { Assessment Work } \\
\text { Counts Towards } \\
\text { Service }\end{array}$ & & $\mathrm{X}$ & \\
\hline $\begin{array}{l}\text { Lack of } \\
\text { Rewards/Incentives } \\
\text { for Participating in } \\
\text { Assessment } \\
\text { Activities }\end{array}$ & $\mathrm{X}$ & $\mathrm{X}$ & \\
\hline
\end{tabular}

Faculty Satisfaction with English Program Faculty Leadership Support. Both of the associate professors purported to be satisfied with the English program's faculty leadership support. Associate professor B reported that the faculty value assessment. He stated, [faculty are] very open to assessing what we do and how students are learning." Even though associate professor A purported to be satisfied with program faculty leadership, he noted that the support of program administrators was a challenge. He stated, “although I very much respect [the department chair's] priorities in terms of assessment, [the chair] thinks this is boring and that's a little depressing.”

Faculty Satisfaction with Professional Development for Student Assessment. Both of the associate professors purported to be satisfied with professional development for student assessment and identified financial support to attended conferences as an important factor. Associate professor A reported that he attend workshops about various assessment topics. He also noted that a subcommittee within the PRAC assisted in the development of program review dossiers. Associate professor A stated, "[the committee] brings together people from departments who have just finished a [program] review and 
[faculty] who are getting ready to [complete a program review] so that they can give each other advice, share concerns, and ask questions.” Associate professor B identified an oncampus assessment conference and the Center for Teaching and Learning as additional factors of his satisfaction (see Table 103).

Table 103

Professional development for student assessment:

Perceived strengths

\begin{tabular}{|l|c|c|}
\hline Factors & $\begin{array}{l}\text { Associate } \\
\text { Professor A }\end{array}$ & $\begin{array}{l}\text { Associate } \\
\text { Professor B }\end{array}$ \\
\hline $\begin{array}{l}\text { Financial } \\
\text { Support to } \\
\text { Attend } \\
\text { Conferences }\end{array}$ & $\mathrm{X}$ & $\mathrm{X}$ \\
\hline $\begin{array}{l}\text { Professional } \\
\text { Development } \\
\text { Workshops }\end{array}$ & $\mathrm{X}$ & \\
\hline $\begin{array}{l}\text { Assistance with } \\
\text { Program } \\
\text { Reviews }\end{array}$ & $\mathrm{X}$ & \\
\hline $\begin{array}{l}\text { On-Campus } \\
\text { Assessment } \\
\text { Conference }\end{array}$ & & $\mathrm{X}$ \\
\hline $\begin{array}{l}\text { Center for } \\
\text { Teaching and } \\
\text { Learning }\end{array}$ & & $\mathrm{X}$ \\
\hline
\end{tabular}

\section{Faculty Satisfaction with Evaluations and Rewards Based on Student Assessment}

Data or Involvement. Both associate professors purported to be satisfied with evaluations and rewards based on student assessment data. Associate professors A and B revealed that assessment activities were rewarded in promotion and tenure dossiers. Associate professor A stated, "if you do [assessment activities] and phrase it in terms that fit the form you're filling out, you can in fact be rewarded for it. I just think that it should be 
more transparent and more emphasized.” Associate professor A continued, “it’s becoming possible under teaching to link your assessment [activities] if it's directly related to something you teach.” However, he reported that participating in assessmentrelated committees would count towards service.

\section{Faculty Satisfaction with the Use of Student Assessment Data in Making Academic}

Decisions. Both associate professors purported to be unsatisfied with the use of student assessment data in making academic decisions. Both associate professors reported that the lack of assessment data was a challenge. Associate professor A stated, "even though AU in many respects is ahead of the assessment implementation curve compared to a lot of schools, there is still particularly within the academic units I think a set of traditions and procedures that haven't historically included [assessment].” Even though associate professor B was unsatisfied, he revealed that program faculty recently assessed a random sample of portfolios and the assessment data informed a program change.

Faculty Satisfaction with the Impact Student Assessment had on Their Program. Both associate professors purported to be satisfied with the impact student assessment had on their program. Associate professor A revealed that assessment data guided program faculty in the design of specializations within the English major. He stated, "in the process of designing the major, we did surveys, we asked students what they liked about the major as it currently was. We asked them what courses they would like to have that we weren't teaching. We used information like that to design [content specializations].” However, he noted the surveys only informed the aforementioned program change. He stated, “assessment hasn’t had any carry over value because it was all focused on this one specific task.” Associate professor B stated, “I feel like we’ve done what we can so far, 
but we can do more.” He continued, “I'm not satisfied that we've found the best ways to assess that yet but at a program level or even at a course level, I think there's always room to get better at that."

Faculty Satisfaction Summary. Table 104 illustrates the frequency of theme emergence across items related to strengths. Program faculty identified committee service, financial support to attend conferences, the ability of promotion and tenure reviews to reward assessment activities, and the use of assessment data to inform program changes as assessment strengths. All three participants reported that service on committees was an important venue for participating in assessment decisions. Associate professor A and B both identified financial support to attend conferences as important factors of their satisfaction with professional development. Both associate professors also revealed that the promotion and tenure process rewarded assessment-related activities. Associate professor A reported that the use of assessment data to inform program changes contributed to the impact student assessment data had on the program. Associate professor B also noted that faculty utilized assessment data to inform program changes (see Table 104).

Table 104

Frequency of theme emergence pertaining to strengths across items

\begin{tabular}{|l|c|c|c|}
\hline Factors & $\begin{array}{l}\text { Department } \\
\text { Chair }\end{array}$ & $\begin{array}{l}\text { Associate } \\
\text { Professor A }\end{array}$ & $\begin{array}{l}\text { Associate } \\
\text { Professor B }\end{array}$ \\
\hline Committee Service & 1 & 1 & 1 \\
\hline $\begin{array}{l}\text { Financial Support } \\
\text { to Attend } \\
\text { Conferences }\end{array}$ & 0 & 1 & 1 \\
\hline $\begin{array}{l}\text { Assessment Work } \\
\text { Rewarded in } \\
\text { Promotion and } \\
\text { Tenure Processes }\end{array}$ & 0 & 1 & 1 \\
\hline
\end{tabular}


Table 104

Frequency of theme emergence pertaining to strengths across items:

Continued

\begin{tabular}{|l|c|c|c|}
\hline Factors & $\begin{array}{l}\text { Department } \\
\text { Chair }\end{array}$ & $\begin{array}{l}\text { Associate } \\
\text { Professor A }\end{array}$ & $\begin{array}{l}\text { Associate } \\
\text { Professor B }\end{array}$ \\
\hline $\begin{array}{l}\text { Use of Assessment } \\
\text { Data to Inform } \\
\text { Program Changes }\end{array}$ & 0 & 1 & 1 \\
\hline $\begin{array}{l}\text { Faculty Were } \\
\text { Developing An } \\
\text { Assessment Plan }\end{array}$ & 0 & 0 & 1 \\
\hline $\begin{array}{l}\text { Department Chair } \\
\text { Values Assessment }\end{array}$ & 0 & 1 & 0 \\
\hline $\begin{array}{l}\text { Faculty } \\
\text { Participation }\end{array}$ & 1 & 0 & 0 \\
\hline $\begin{array}{l}\text { Progress of Pilot } \\
\text { Assessment } \\
\text { Activities }\end{array}$ & 1 & 0 & 0 \\
\hline $\begin{array}{l}\text { Progress of the } \\
\text { Program } \\
\text { Assessment } \\
\text { Committee }\end{array}$ & 0 & 0 & 0 \\
\hline $\begin{array}{l}\text { Previous } \\
\text { Employment Roles }\end{array}$ & 1 & 0 & 0 \\
\hline $\begin{array}{l}\text { Participation in } \\
\text { Assessment } \\
\text { Activities with the } \\
\text { Institutional } \\
\text { Assessment Leader }\end{array}$ & 1 & 0 & 0 \\
\hline $\begin{array}{l}\text { Development of } \\
\text { Electronic Portfolio } \\
\text { Requirements }\end{array}$ & 0 & 0 & 0 \\
\hline $\begin{array}{l}\text { Current } \\
\text { Employment Roles }\end{array}$ & 0 & 0 & 1 \\
\hline Gateway Forums & 0 & 0 & 0 \\
\hline $\begin{array}{l}\text { Culture that Values } \\
\text { Assessment }\end{array}$ & 0 & 0 & 0 \\
\hline Mini-Grants & 0 & 0 & 0 \\
\hline $\begin{array}{l}\text { On-Campus } \\
\text { Consessment }\end{array}$ & 0 & 0 & 0 \\
\hline
\end{tabular}


Table 104

Frequency of theme emergence pertaining to strengths across items:

Continued

\begin{tabular}{|l|c|c|c|}
\hline Factors & $\begin{array}{l}\text { Department } \\
\text { Chair }\end{array}$ & $\begin{array}{l}\text { Associate } \\
\text { Professor A }\end{array}$ & $\begin{array}{l}\text { Associate } \\
\text { Professor B }\end{array}$ \\
\hline $\begin{array}{l}\text { Professional } \\
\text { Development } \\
\text { Workshops }\end{array}$ & 0 & 1 & 0 \\
\hline $\begin{array}{l}\text { On-Campus } \\
\text { Assessment } \\
\text { Conference }\end{array}$ & 0 & 0 & 1 \\
\hline $\begin{array}{l}\text { Center for } \\
\text { Teaching and } \\
\text { Learning }\end{array}$ & 0 & 0 & 1 \\
\hline
\end{tabular}

Program faculty identified the lack of a program assessment plan, time requirements necessary to conduct assessment, direction from central leadership, the lack of rewards for conducting assessment, and that assessment counts towards service as challenges with assessment (see Table 105). Associate professors A and B reported that the lack of an assessment plan was a challenge to its implementation. The department chair and associate professor B identified intensive time requirements of assessment as a challenge with the assessment plan. The department chair and associate professor A reported that mandates from administrators and the lack of rewards for participating in assessment activities impeded their satisfaction with central leadership support. Associate professor A reported that assessment activities mainly counted towards service and he wished that there would be more emphasis on assessment within research required for promotion and tenure. Both associate professors identified the lack of assessment data was a challenge because it was not available to use in academic decisions. 
Table 105

Frequency of theme emergence pertaining to challenges across items

\begin{tabular}{|c|c|c|c|}
\hline Factors & $\begin{array}{l}\text { Department } \\
\text { Chair }\end{array}$ & $\begin{array}{l}\text { Associate } \\
\text { Professor A }\end{array}$ & $\begin{array}{l}\text { Associate } \\
\text { Professor B }\end{array}$ \\
\hline $\begin{array}{l}\text { Assessment Plan } \\
\text { Did Not Exist }\end{array}$ & 0 & 1 & 2 \\
\hline $\begin{array}{l}\text { Assessment Was } \\
\text { Time Consuming }\end{array}$ & 1 & 0 & 1 \\
\hline $\begin{array}{l}\text { Direction From } \\
\text { Central Leadership }\end{array}$ & 1 & 1 & 0 \\
\hline $\begin{array}{l}\text { Lack of Rewards } \\
\text { for Participating in } \\
\text { Assessment } \\
\text { Activities }\end{array}$ & 1 & 1 & 0 \\
\hline $\begin{array}{l}\text { Lack of } \\
\text { Assessment Data }\end{array}$ & 0 & 1 & 1 \\
\hline $\begin{array}{l}\text { Assessment Work } \\
\text { Counts Toward } \\
\text { Service }\end{array}$ & 0 & 2 & 0 \\
\hline $\begin{array}{l}\text { Assessment Plan } \\
\text { Was Disorganized }\end{array}$ & 1 & 0 & 0 \\
\hline $\begin{array}{l}\text { Slow Progress in } \\
\text { Assessment Plan } \\
\text { Development }\end{array}$ & 1 & 0 & 0 \\
\hline $\begin{array}{l}\text { Previous Program } \\
\text { Administrator Did } \\
\text { Not Value } \\
\text { Assessment }\end{array}$ & 0 & 1 & 0 \\
\hline $\begin{array}{l}\text { Conflicting } \\
\text { Priorities Between } \\
\text { Faculty and } \\
\text { Administrators }\end{array}$ & 0 & 1 & 0 \\
\hline
\end{tabular}

In this case study, the researcher presented the institutional background as it pertains to assessment and described the programs and participants. Participants in this AU case study included the institutional assessment leader, program administrators (four department chairs and one assistant dean), and faculty from the Departments of 
Mathematics and Statistics, Psychology, Biology, Secondary Education, English and Nursing.

The researcher fully analyzed data gathered from the interviews and documents. The major results pertaining to each research question are highlighted and presented by each academic program. In addition, the frequency of themes pertaining to participants' satisfaction with assessment is discussed including strengths and challenges. In Chapter 7, the researcher presents the major results from the cross-site analysis which includes participants’ demographic information, comparison of assessment practices across participating programs at the three universities pertinent to the sustainment and improvement phase (Banta, 2002). Commitments and resources provided to assessment and faculty satisfaction data are also discussed in Chapter 7.

\section{Undergraduate Secondary Education Program}

The secondary education program faculty awarded a Bachelor of Science in Education with middle/high school teaching licensure. According to the university catalog, Each discipline in the secondary education program (English, Foreign Language, Mathematics, Science, and Social Studies) requires a unique and highly prescribed program of studies...Courses in these program fall into three categories: the common core curriculum, the discipline-based preparation program, and the teacher education program. In all areas of these programs, the courses are carefully selected to prepare students to meet the rigorous content and teaching standards required for a middle school and high school teaching license in the discipline.

According to the School of Education's website, the mission of the school is: 
to improve teaching, learning, and human development in a diverse, rapidly changing, and increasingly technological society. We prepare reflective, caring, and highly skilled educational practitioners and scholars who lead in their chosen professions; inform educational theory and practice through research; and work in partnership with a range of constituents to effect change from the local to national levels and throughout the world.

Interview data revealed that approximately six faculty members worked primarily with secondary education students and no part-time instructors taught courses in the department. Undergraduate secondary education students were primarily enrolled fulltime. The average class size was approximately 30 students.

\section{Study Participants}

The researcher conducted interviews with the department chair, assistant dean, professor, assistant professor, and clinical professor. The senior department chair was in his thirteenth year as a professor at AU and his second year as the chairperson. He had worked in higher education for 19 years. He claimed that he had more to learn about student outcomes assessment. He stated, “there’s so many layers and aspects and I haven't had my hands in all of those so I think that I've got lots that I can learn and lots that we can improve.” The department chair did not attend any conferences that focused on student outcomes assessment; however, he attended six conferences that included assessment sessions on the program in the past two years. He had not published any papers pertaining to student outcomes assessment in the past two years nor had he presented assessment results at any conferences. 
The second participant, an assistant dean, was serving her tenth year at AU and her fourth year as an administrator. She worked in higher education for 10 years. The assistant dean purported to be “fairly" knowledgeable about student outcomes assessment. She stated, “I am a Board of Examiners Member for NCATE, so I’ve been trained to be an assessor for that. I also do program assessment for the State of Rhode Island. I've gone through training to do that." The assistant dean attended two conferences that focused on student outcomes assessment and three conferences that included assessment sessions on the program. She had not published any papers pertaining to student outcomes assessment in the past two years; however, she presented assessment results at two of the conferences she attended.

The third participant was a professor. He worked in higher education for approximately 36 years. The professor purported to be fairly knowledge about student outcomes assessment. He stated, "I do certain kinds of assessments in my classroom...I'm not an expert.” The professor had not attended any conferences that focused on student outcomes assessment. In the past two years, he attended and presented assessment results at two conferences that included assessment sessions on the program and published five papers pertaining to student outcomes assessment.

The fourth participant, an assistant professor, was serving his third year at AU. He worked in higher education for eight years. The assistant professor purported to be “very” knowledgeable about student outcomes assessment and previously served as the director of assessment at another institution. He attended two conferences that focused on student outcomes assessment and three conferences that included assessment sessions on the program in the past two years. In the past two years, he published two papers 
pertaining to student outcomes assessment and presented assessment results at three conferences.

The fifth participant, a clinical professor, was serving his third year at AU. He worked in higher education for 12 years. The clinical professor purported to be “moderately” knowledgeable about student outcomes assessment. He stated, “within classroom assessment, I feel knowledgeable. Overall assessment, when you are assessing large groups of students...I find that much more problematic.” The clinical professor attend three conferences that focused on student outcomes assessment in the past two years. He did not publish any papers pertaining to student outcomes assessment nor present assessment results at any of the conferences he attended.

\section{Characteristics of Effective Assessment Practice}

The researcher analyzed interview data and the 2006 School of Education Annual Assessment Report to identify characteristics of effective practice.

Credible evidence of learning. Documents and interview respondents illustrated various components of the assessment plan that demonstrated learning was relevant to the major and assessment measures were reliable. Secondary education program faculty assessed 18 student learning outcomes.

The outcomes for the secondary education program spanned three of six cognitive domains contained within Bloom’s Taxonomy (Anderson, et al., 2001). The outcomes were skewed to the mid-level cognitive domains. None of the cognitive outcomes were representative of the remember, analyze, or create domains. Fourteen percent of the outcomes represented the understand domain, $71 \%$ of the outcomes represented the apply domain, and 14\% of the outcomes represented the evaluate domain (see Table 106). 
Eleven outcomes were representative of the affective domain. These outcomes were learner-centered, clear, measurable, spanned multiple learning domains, and were directly related to the school's mission.

Table 106

Distribution of intended cognitive learning outcomes

\begin{tabular}{|c|c|c|}
\hline Cognitive Domain & N & $\%$ \\
\hline Create & 0 & 0 \\
\hline Evaluate & 0 & 0 \\
\hline Analyze & 2 & 22.2 \\
\hline Apply & 1 & 11.1 \\
\hline Understand & 5 & 55.5 \\
\hline Remember & 0 & 0 \\
\hline
\end{tabular}

An example of an intended learning outcome within the understand domain included:

- writing reflects knowledge of the areas the student will teach.

Examples of intended learning outcomes within the apply domain included:

- use APA formatting and

- demonstrate clear speaking.

An example of an intended learning outcome within the evaluate domain included:

- demonstrate critical thinking skills.

Examples of the affective outcomes included:

- shows respect for peers and instructors and

- demonstrates enthusiasm for teaching.

The secondary education program faculty developed a comprehensive assessment plan. They conceptualized program goals that included knowledge and habits of the mind, written and oral communication, interaction with teachers and students, and disposition and professional behavior across their program outcomes. Program faculty 
utilized a matrix containing benchmark data and two years of results to support program changes. The secondary education program faculty utilized multiple assessment methods to measure student achievement. Direct assessment measures included electronic portfolios that faculty assessed with a rubric. The department chair stated, "we've designated particular products or evidence that we need [students] to submit as they move through the program. He noted that the artifacts were "indicators that [students] are on the right track.” The department chair also reported that the portfolio assessment method was “fairly new." He also revealed that student teaching evaluations were completed during the students' last semester in the program. He reported that mentor teachers utilized a rubric to assess "various pieces of evidence of performance or indicators that students need to demonstrate while they're out in the field.”

Indirect measures of student achievement included self-reflections (pre-survey/postsurvey), faculty focus groups, and graduate surveys. According to the annual assessment report, "a team of instructors who have had the students in class during the fall and spring semester respectively met as a group to rate each students' achievement within the constructs of [knowledge and habits of the mind, written and oral communication, interaction with teachers and students, and disposition and professional behavior across their program outcomes]." The results of the faculty focus groups were compared to student self-reports. Faculty reported only pre- and post-survey and focus group data within their annual assessment report. Program faculty identified specific learning activities that were assessed in relation to certain learning outcomes. For example, faculty assessed all program goals in the students’ field experience. Activities assessed by program faculty included field experiences, class discussions, readings, cooperative 
learning exercise, case studies of teaching, APA citation assignments, journal entries, and class presentations (see Table 107).

Table 107

\section{Learning activities}

\begin{tabular}{|l|c|c|c|c|}
\hline \multirow{2}{*}{\begin{tabular}{l} 
Activities \\
\cline { 2 - 5 }
\end{tabular}} & $\begin{array}{l}\text { Knowledge } \\
\text { and Habits } \\
\text { of Mind }\end{array}$ & $\begin{array}{l}\text { Written and } \\
\text { Oral } \\
\text { Communication }\end{array}$ & $\begin{array}{l}\text { Interaction } \\
\text { with Teachers } \\
\text { and Students }\end{array}$ & $\begin{array}{l}\text { Disposition and } \\
\text { Professional } \\
\text { Behavior }\end{array}$ \\
\hline $\begin{array}{l}\text { Field } \\
\text { Experiences }\end{array}$ & $\mathrm{X}$ & $\mathrm{X}$ & $\mathrm{X}$ & $\mathrm{X}$ \\
\hline $\begin{array}{l}\text { Class } \\
\text { Discussions }\end{array}$ & $\mathrm{X}$ & $\mathrm{X}$ & $\mathrm{X}$ & $\mathrm{X}$ \\
\hline Readings & $\mathrm{X}$ & $\mathrm{X}$ & $\mathrm{X}$ \\
\hline $\begin{array}{l}\text { Cooperative } \\
\text { Learning } \\
\text { Exercises }\end{array}$ & $\mathrm{X}$ & $\mathrm{X}$ & $\mathrm{X}$ & \\
\hline $\begin{array}{l}\text { Case Studies } \\
\text { of Teaching }\end{array}$ & $\mathrm{X}$ & $\mathrm{X}$ & & \\
\hline $\begin{array}{l}\text { APA } \\
\text { Citation } \\
\text { Assignments }\end{array}$ & & $\mathrm{X}$ & & \\
\hline $\begin{array}{l}\text { Journal } \\
\text { Entries }\end{array}$ & & & & \\
\hline $\begin{array}{l}\text { Class } \\
\text { Presentations }\end{array}$ & & & & \\
\hline
\end{tabular}

Continuous Improvement. The 2006 annual assessment report provided evidence to document program changes or improvements that were implemented based on assessment data. The report contained the results of the pre/post survey and the faculty focus groups. According to the assessment report, faculty identified weaknesses within each learning goal. After one semester in the program, faculty identified students' abilities to reflect, take an active role in the class, and to judge personal strengths and weaknesses as challenges pertaining to the goal of knowledge and habits of mind. At the conclusion of the second semester in the program, faculty identified students' abilities to engage in 
critical thinking, reflect about teaching, and to take an active role in the class as challenges pertaining to the same goal. According to the assessment report, "[faculty] discussions are underway to address these concerns.”

After one semester in the program, faculty identified students' ability to use APA formatting as a challenge pertaining to written and oral communication. At the conclusion of the second semester, faculty identified writing competency as a challenge. As a result of these challenges, "revised supervisory sheets and reflection prompts for student teaching are being developed."

After one semester in the program, faculty identified students' abilities related to working in teams, appreciating multiple perspectives, focusing on the positive, and helping others as weaknesses related to interaction with teachers and students. At the conclusion of two semesters, faculty identified weaknesses related to the ability of students to remain focused on the positive during a challenging circumstance. The assessment report did not reveal any program changes or discussions pertaining to this finding.

After one semester in the program, faculty identified students' abilities to receive help and constructive feedback, complete assigned readings, meet deadlines, and display good time management skills as weaknesses related to dispositions and professional behaviors. At the conclusion of two semesters, faculty once again identified the ability of students' to complete assigned readings as a weakness. The assessment report did not reveal any program changes or discussions pertaining to this finding.

Additionally, the department revealed that assessment discussions occurred monthly during program faculty meetings. He noted that assessment related issues were not a 
“standing agenda item.” However, he identified e-portfolio implementation, survey development, and student teaching assessment as common points of discussion.

Accountability to internal stakeholders. The department chair revealed that the assistant dean maintained assessment accountability to internal stakeholders through faculty and assessment meetings. The assistant dean reported assessment results were shared at various faculty meetings. Additionally, the yearly assessment report submitted to the campus-wide assessment committee by program faculty maintained accountability to internal stakeholders.

Ongoing assessment. The department chair and annual report revealed that various assessments occurred on a predictable schedule. Students complete pre/post surveys and faculty participated in focus groups annually. Instructors also evaluated students’ teaching during their last semester in the program.

Ongoing Evaluation and Improvement. The department chair revealed that faculty discussed various potential improvements to the assessment plan regularly. He stated, “as we conduct each round [of assessment] it presents opportunities to tweak and improve [the assessment process].” He continued, “[evaluation and improvement occurs] through our analysis of what we learned and then how that information was communicated to the various parties including students.” Satisfaction with the Assessment Plan. The department chair, assistant dean, professor, and assistant professor purported to be satisfied with the assessment plan while the clinical lecturer purported to be unsatisfied. The assistant dean identified faculty participation and communication of assessment results as important factors of her satisfaction (see Table 108). The professor and the assistant professor reported that 
implemented assessments measure higher-level thinking. The professor stated, "I think that [faculty] do overall a really good job of getting to know where our students are because the majority of [faculty] do not give strict recall scoring kinds of tests. It's all done on performance based and a lot of reflection.” The assistant professor cited the assistant dean of evaluation and program review, a culture that values assessment, the collection of retention data, portfolio assessment, and the incorporation of multiple assessment methods into the plan, and support from assessment grants as important factors of his satisfaction.

Table 108

Assessment plan: Perceived strengths

\begin{tabular}{|l|l|l|c|c|c|}
\hline Factors & $\begin{array}{l}\text { Department } \\
\text { Chair }\end{array}$ & $\begin{array}{l}\text { Assistant } \\
\text { Dean }\end{array}$ & Professor & $\begin{array}{l}\text { Assistant } \\
\text { Professor }\end{array}$ & $\begin{array}{l}\text { Clinical } \\
\text { Lecturer }\end{array}$ \\
\hline $\begin{array}{l}\text { Faculty } \\
\text { Participation }\end{array}$ & & $\mathrm{X}$ & & & \\
\hline $\begin{array}{l}\text { Communication } \\
\text { of Assessment } \\
\text { Results }\end{array}$ & & & & & \\
\hline $\begin{array}{l}\text { Assessment } \\
\text { Measures } \\
\text { Higher-Order } \\
\text { Thinking }\end{array}$ & & & $\mathrm{X}$ & $\mathrm{X}$ & \\
\hline $\begin{array}{l}\text { Assistant Dean } \\
\text { of Evaluation } \\
\text { and Program } \\
\text { Review }\end{array}$ & & & & $\mathrm{X}$ & \\
\hline $\begin{array}{l}\text { Culture that } \\
\text { Values } \\
\text { Assessment }\end{array}$ & & & & $\mathrm{X}$ & \\
\hline $\begin{array}{l}\text { Collection of } \\
\text { Retention Data }\end{array}$ & & & & $\mathrm{X}$ & \\
\hline $\begin{array}{l}\text { Portfolio } \\
\text { Assessment }\end{array}$ & & & & & \\
\hline $\begin{array}{l}\text { Multiple } \\
\text { Measures of } \\
\text { Assessment }\end{array}$ & & & & & \\
\hline
\end{tabular}


Table 108

Assessment plan: Perceived strengths continued

\begin{tabular}{|l|l|l|l|l|l|}
\hline Factors & $\begin{array}{l}\text { Department } \\
\text { Chair }\end{array}$ & $\begin{array}{l}\text { Assistant } \\
\text { Dean }\end{array}$ & Professor & $\begin{array}{l}\text { Assistant } \\
\text { Professor }\end{array}$ & $\begin{array}{l}\text { Clinical } \\
\text { Lecturer }\end{array}$ \\
\hline $\begin{array}{l}\text { Support from } \\
\text { Assessment } \\
\text { Grants }\end{array}$ & & & & $\mathrm{X}$ & \\
\hline
\end{tabular}

The assistant professor also reported the inability of the assessment plan to measure school-level outcomes and the NCATE mandates for assessment as challenges to the assessment plan (see Table 109). The assistant dean reported that faculty had not implemented a capstone assessment. She stated, “[faculty need] a performance task closer to the end of the program.” The department chair revealed that he lacked confidence in the assessment instruments. He stated, “perhaps it's time to get an outside set of eyes to come in and help us with [instrument development].” The professor identified the fragmentation of the assessment plan and the lack of utilization of the assessment data. He stated, “[assessment] has been difficult because of the hierarchal structure of our administration.”

Table 109

Assessment plan: perceived challenges

\begin{tabular}{|l|l|l|l|l|l|}
\hline Factors & $\begin{array}{l}\text { Department } \\
\text { Chair }\end{array}$ & $\begin{array}{l}\text { Assistant } \\
\text { Dean }\end{array}$ & Professor & $\begin{array}{l}\text { Assistant } \\
\text { Professor }\end{array}$ & $\begin{array}{l}\text { Clinical } \\
\text { Lecturer }\end{array}$ \\
\hline $\begin{array}{l}\text { Assessments } \\
\text { Do Not } \\
\text { Measure } \\
\text { School-Level } \\
\text { Outcomes }\end{array}$ & & & & & \\
\hline $\begin{array}{l}\text { NCATE } \\
\text { Mandates }\end{array}$ & & & & $\mathrm{X}$ & \\
\hline
\end{tabular}


Table 109

Assessment plan: perceived challenges: Continued

\begin{tabular}{|l|l|l|c|l|l|}
\hline Factors & $\begin{array}{l}\text { Department } \\
\text { Chair }\end{array}$ & $\begin{array}{l}\text { Assistant } \\
\text { Dean }\end{array}$ & Professor & $\begin{array}{l}\text { Assistant } \\
\text { Professor }\end{array}$ & $\begin{array}{l}\text { Clinical } \\
\text { Lecturer }\end{array}$ \\
\hline $\begin{array}{l}\text { Lack of a } \\
\text { Capstone } \\
\text { Assessment }\end{array}$ & & $\mathrm{X}$ & & & \\
\hline $\begin{array}{l}\text { Lack of } \\
\text { Confidence in } \\
\text { Assessment } \\
\text { Instruments }\end{array}$ & $\mathrm{X}$ & & & & \\
\hline $\begin{array}{l}\text { Fragmentation } \\
\text { of the } \\
\begin{array}{l}\text { Assessment } \\
\text { Plan }\end{array}\end{array}$ & & & $\mathrm{X}$ & & \\
\hline $\begin{array}{l}\text { Assessment } \\
\text { Data is Not } \\
\text { Utilized }\end{array}$ & & & $\mathrm{X}$ & & \\
\hline
\end{tabular}

\section{Institutional Commitments and Resources}

Commitments. When asked if the utilization of student assessment data was considered in evaluating and rewarding faculty, the department chair and assistant dean reported that promotion and tenure dossiers could include assessment information. The department chair related assessment activities to faculty awards for teaching. He stated, “we have student nominated awards for faculty for their teaching expertise and so on. I think it would be indirect but not explicit.” Additionally, the department chair and assistant dean reported that student assessment expertise was not considered in the hiring process for new faculty. The department chair claimed that assessment expertise would only be considered if someone were "stepping into an [assessment related] role." When queried about the policies and practices that facilitated the communication of student assessment purposes, both participants confirmed that such policies existed. Both 
participants chair identified new student orientation sessions as an important venues to communicate student assessment purposes to students. The department chair stated, "as part of their [new student] packet, we have information in there about benchmark assessment and our faculty will be present to walk them though what they expect.” He also reported that multiple student associations had opportunities to discuss program requirements with administrators, faculty, and with juniors and seniors.

When asked about policies to promote the involvement of student affairs personnel and students in assessment efforts, the department chair reported that "all of our student advisors and student services personnel have ongoing roles in informing students about assessments and advising as they go through the various testing that they need to move through our program.” He also noted, “we offer tutoring sessions for students who can’t seem to pass tests or have test anxiety and so on.” The assistant dean illustrated executive-level support through the creation of her position. She stated, "I think that when my position was created that was a strong message.” The assistant dean maintained that the creation of her position illustrated the central leader's support for assessment. The department chair revealed that the assistant dean was "very good” about keeping assessment "front and center."

When asked to describe the culture of assessment within the secondary education program, the assistant dean stated, I think that we are far enough along in assessment that the faculty have seen the results of this. They know it helps the students get better. They know it helps us find the areas where students aren't going to the degree where we'd like them to and we can get them special help. 
The department chair reported that assessment was "alive and improving." He continued, “[assessment] is very constantly a topic of good conversations and acknowledgement that we are still improving. We still have more to do...still have to smooth the edges of the pieces.” However, the department chair and the assistant dean reported that guiding principles for assessment had not been developed.

The assistant dean reported that a campus-wide assessment committee existed. She noted that two representatives from each college served on the committee. The department chair stated, "we have so many layers of committees with assessment as a key component.” However, he was not certain of the composition of the committees. The department chair reported that outcomes assessment had been incorporated into the scholarship of teaching in promotion and tenure guidelines. He stated, "the best indicator in promotion and tenure would be student evaluation feedback for classes.” He also reported that "[faculty] solicit student’s feedback about particular instructors.”

In summary, the significant commitments included:

- assessment data were considered in evaluating and rewarding faculty,

- policies and practices that facilitated the communication of student assessment purposes,

- policies to promote the involvement of student affairs personnel and students in assessment efforts,

- executive-level support through the creation of the position of the assistant dean for assessment,

- culture that values assessment,

- campus-wide assessment committee with broad representation, and 
- the incorporation of outcomes assessment into the scholarship of teaching in promotion and tenure guidelines.

Resources. On-campus resources associated with the assessment activities included financial support for testing, professional development opportunities, and access to consulting services. When asked to identify resources allocated to the AU secondary education faculty, the department chair revealed that personnel time and grant funds were important resources. The assistant dean reported that her own position for assessment was one resource. She also reported that the institution's technology department "has put in a lot of hours working with [secondary education program faculty] on electronic assessments.”

According to the department chair and the assistant dean, program faculty did not have access to a comprehensive student assessment database. However, the assistant dean reported that a comprehensive student assessment database was being developed.

The department chair stated that professional development assessment workshops were offered at AU. He identified the Office of the Vice Chancellor, brown bag lunches, on-campus conferences, and the Center for Teaching and Learning as important venues to participate in professional development. The department chair and assistant dean reported that limited financial support for faculty to attend professional conferences on student assessment was available. According to the department chair, internal consulting services for faculty on the use of student assessment in course design and instruction were available from "resident experts.” The assistant dean identified the Center for Teaching and Learning as an avenue to ascertain internal consulting services. 
The department chair and assistant dean reported that assistance (in the form of paid leaves, stipends, mini-grants, or course reductions) for faculty to work on assessment activities was available. Furthermore, the department chair and assistant dean reported to be unaware of assessment workshops for deans, department chairs, and other academic administrators or student affairs staff and student affairs administrators. The department chair and the assistant dean reported that the program-level assessment office was charged with coordinating data-gathering initiatives such as surveys and standardized tests within the school. The assistant dean coordinated these activities. The department chair and the assistant dean identified the office of the assistant dean for assessment as the program-level assessment office. They also identified the Office of the Vice Chancellor as the institutional assessment office. In summary, the significant resources available from the institution included:

- personnel time,

- grant funds,

- assistant dean for assessment,

- technology department,

- professional development workshops pertinent to assessment,

- financial support to attend conferences,

- internal consulting services,

- Center for Teaching and Learning,

- program-level assessment office: charged with coordinating data-gathering initiatives such as surveys and standardized tests, and

- institutional-level assessment office. 


\section{Faculty Satisfaction with Assessment}

Faculty satisfaction with program assessment was determined by analyzing interview data from three individuals: two associate professors and a senior lecturer. The researcher elicited information regarding their satisfaction with the implementation of the current assessment plan, opportunities to participate in policy making, central leadership support for assessment, faculty leadership support, professional development, evaluations and rewards, academic decision making, and the impact of student assessment on the program.

Satisfaction with the Implementation of the Current Assessment Plan. The assistant dean, professor, and assistant professor purported to be satisfied with the implementation of the current assessment plan while the department chair and the clinical lecturer purported to be unsatisfied. The department chair reported that implementation was going well "with some improvement and development to go.” The professor identified the evaluation of the assessment plan as a strength. He stated, “[one] thing that I think we've done really well is that we've re-evaluated [the assessment plan] and that is why [faculty are revising the assessment plan].” The professor also noted the importance of PRAC grants to support assessment projects (see Table 110).

\section{Table 110}

Implementation of the current assessment plan: Perceived strengths

\begin{tabular}{|l|l|l|c|l|l|}
\hline Factors & $\begin{array}{l}\text { Department } \\
\text { Chair }\end{array}$ & $\begin{array}{l}\text { Assistant } \\
\text { Dean }\end{array}$ & Professor & $\begin{array}{l}\text { Assistant } \\
\text { Professor }\end{array}$ & $\begin{array}{l}\text { Clinical } \\
\text { Lecturer }\end{array}$ \\
\hline $\begin{array}{l}\text { Assessment } \\
\text { Plan } \\
\text { Evaluation }\end{array}$ & & & $\mathrm{X}$ & & \\
\hline $\begin{array}{l}\text { Assessment } \\
\text { Grants }\end{array}$ & & & $\mathrm{X}$ & & \\
\hline
\end{tabular}


The assistant professor identified the non-systematic implementation process and the lack of utilization of assessment data as challenges to implementation. He stated, “[implementation] has not been a very intentional [process].” With regard to assessment data utilization, the assistant professor explained that "[faculty] hustle to write the [assessment] report” but did not utilize the data to inform program changes (see Table 111).

Table 111

Implementation of the current assessment plan: Perceived challenges

\begin{tabular}{|l|l|l|c|c|c|}
\hline Factors & $\begin{array}{l}\text { Department } \\
\text { Chair }\end{array}$ & $\begin{array}{l}\text { Assistant } \\
\text { Dean }\end{array}$ & Professor & $\begin{array}{l}\text { Assistant } \\
\text { Professor }\end{array}$ & $\begin{array}{l}\text { Clinical } \\
\text { Lecturer }\end{array}$ \\
\hline $\begin{array}{l}\text { Non- } \\
\text { Systematic } \\
\text { Implementation }\end{array}$ & & & & $\mathrm{X}$ & \\
\hline $\begin{array}{l}\text { Assessment } \\
\text { Data Was Not } \\
\text { Utilized }\end{array}$ & & & & $\mathrm{X}$ & \\
\hline
\end{tabular}

Faculty Satisfaction with Participation in Assessment Decisions. The department

chair and assistant dean reported to be very satisfied with their participation in assessment decisions while the professor, assistant professor, and clinical lecturer reported to be satisfied. The department chair and the professor identified open access to venues to participate in assessment decisions and their service to various committees as important factors of their satisfaction (see Table 112). The professor stated, "anyone who has really wanted to be involved and try to work through [assessment] has had the opportunity.” The department chair identified the autonomy of program faculty in assessment endeavors as an important factor of his satisfaction. He stated, "we have a lot of autonomy within our program and collaboration with other units to design and develop 
what we need and want to meet our needs.” The assistant dean identified informal discussions with faculty as important factor of her satisfaction.

The assistant professor reported that PRAC grants often lead to campus-wide faculty discussions about assessment. He stated,

through the e-portfolio grant that was received [by program faculty] helped move [the institution's portfolio] policy along because we committed to doing certain things around student learning outcomes. We presented to the faculty then they said go ahead and try to get the grant. Now we have it so they're kind of committed to being a part of that work."

He noted that the accountability associated with grant funds was helpful in moving the eportfolio project forward. He claimed that the PRAC monitored the progress of assessment projects utilizing grant funding.

\section{Table 112}

Participation in assessment decisions: Perceived strengths

\begin{tabular}{|c|c|c|c|c|c|}
\hline Factors & $\begin{array}{l}\text { Department } \\
\text { Chair }\end{array}$ & $\begin{array}{l}\text { Assistant } \\
\text { Dean }\end{array}$ & Professor & $\begin{array}{l}\text { Assistant } \\
\text { Professor }\end{array}$ & $\begin{array}{l}\text { Clinical } \\
\text { Lecturer }\end{array}$ \\
\hline $\begin{array}{l}\text { Open Access to } \\
\text { Venues to } \\
\text { Participate in } \\
\text { Assessment } \\
\text { Discussions }\end{array}$ & X & & $X$ & & \\
\hline $\begin{array}{l}\text { Service to } \\
\text { Various } \\
\text { Committees }\end{array}$ & X & & $\mathrm{X}$ & & \\
\hline $\begin{array}{l}\text { Autonomy of } \\
\text { Program } \\
\text { Faculty in } \\
\text { Assessment } \\
\text { Decisions }\end{array}$ & X & & & & \\
\hline $\begin{array}{l}\text { Informal } \\
\text { Discussions } \\
\text { With Faculty }\end{array}$ & & $X$ & & & \\
\hline
\end{tabular}


Table 112

Participation in assessment decisions: Perceived strengths continued

\begin{tabular}{|l|l|l|l|l|l|}
\hline Factors & $\begin{array}{l}\text { Department } \\
\text { Chair }\end{array}$ & $\begin{array}{l}\text { Assistant } \\
\text { Dean }\end{array}$ & Professor & $\begin{array}{l}\text { Assistant } \\
\text { Professor }\end{array}$ & $\begin{array}{l}\text { Clinical } \\
\text { Lecturer }\end{array}$ \\
\hline $\begin{array}{l}\text { Assessment } \\
\text { Grants }\end{array}$ & & & & $\mathrm{X}$ & \\
\hline
\end{tabular}

However, the clinical lecturer reported discussions about assessment often did not lead to action. He stated, I think we get together as a secondary [education] group and we talk about doing something but we just don’t move. There is not a lot of inertia.”

Faculty Satisfaction with Central Leadership Support for Assessment. The department chair and professor purported to be very satisfied with central leadership support for assessment while the assistant dean purported to be satisfied and the clinical professor purported to be unsatisfied. The assistant professor did not respond to this question.

The professor identified the institutional assessment office and grant funds for assessment as important factors of his satisfaction (see Table 113). He claimed that the institutional assessment leader "runs a pretty good operation.” He noted, “I’ve been involved in getting some assessment mini-grants and things like that which are useful.” The assistant professor reported that central leaders supported assessment.

\section{Table 113}

Central leadership support for assessment: Perceived strengths

\begin{tabular}{|l|l|l|c|l|l|}
\hline Factors & $\begin{array}{l}\text { Department } \\
\text { Chair }\end{array}$ & $\begin{array}{l}\text { Assistant } \\
\text { Dean }\end{array}$ & Professor & $\begin{array}{l}\text { Assistant } \\
\text { Professor }\end{array}$ & $\begin{array}{l}\text { Clinical } \\
\text { Lecturer }\end{array}$ \\
\hline $\begin{array}{l}\text { Institutional } \\
\text { Assessment } \\
\text { Leader }\end{array}$ & & & $\mathrm{X}$ & & \\
\hline $\begin{array}{l}\text { Grant Support } \\
\text { for Assessment }\end{array}$ & & & $\mathrm{X}$ & & \\
\hline
\end{tabular}


The department chair revealed that faculty must be proactive in seeking support for assessment (see Table 114). He claimed that faculty had to initiate processes related to ascertaining grant funds or financial support to attend conferences. The professor reported that some faculty did not have a voice to express their thoughts on assessment. He stated, I think effective leadership listens to all voices and tries to identify a plan both for the present and for the future. That hasn't been there. That may be because there is a lack of support and time to do these things. I think that the stumbling block that I've seen here towards the progress in assessment is that everybody is doing so many jobs that they can’t possibly get anything done well.

The assistant professor identified widely disbursed leadership across multiple campuses, the lack of substantial faculty representation on the campus-wide assessment committee, the uncertainty of specific leaders’ position on assessment, and his lack of confidence with assessment indicators. With regard to the campus-wide assessment committee, he stated, "the people who come to the [campus-wide assessment committee] tend to be the assistant dean types who have some responsibilities for assessment and people on the campus. While I think that's powerful, faculty representation is not as strong as I'd like to see.” The assistant professor noted that a new Vice Chancellor joined the central leaders. He stated,

we have a new Vice Chancellor whose position on assessment is yet to be determined. I don't hear the things that I would like to [hear], but there are a lot of other things on his plate as he comes in and we're in the middle of a student 
crisis of some sort so that's taken some of both the Chancellor and Vice Chancellor's time.

Additionally, the assistant professor expressed concerns with implemented assessment indicators. He stated, we don’t have good indicators [to inform academic decision making]. So I'm not comfortable, even in a psychometric sense of the terms we would use...I think that people could be mislead at the ratings if they look at them at face value. Sort of like alert levels for national security. They become meaningless because [people] don’t really know what they are comprised of so you can’t articulate what it means in those areas.

\section{Table 114}

Central leadership support for assessment: Perceived challenges

\begin{tabular}{|l|l|l|l|l|l|}
\hline Factors & $\begin{array}{l}\text { Department } \\
\text { Chair }\end{array}$ & $\begin{array}{l}\text { Assistant } \\
\text { Dean }\end{array}$ & Professor & $\begin{array}{l}\text { Assistant } \\
\text { Professor }\end{array}$ & $\begin{array}{l}\text { Clinical } \\
\text { Lecturer }\end{array}$ \\
\hline $\begin{array}{l}\text { Faculty Must } \\
\text { Be Proactive } \\
\text { To Ascertain } \\
\text { Support for }\end{array}$ & & & & & \\
Assessment & & & & & \\
\hline $\begin{array}{l}\text { Faculty Lacked } \\
\text { a Voice in }\end{array}$ & & & & & \\
Assessment & & & & & \\
Decisions & & & & & \\
\hline $\begin{array}{l}\text { Widely- } \\
\text { Disbursed }\end{array}$ & & & & & \\
Leadership & & & & & \\
Across & & & & & \\
Multiple & & & & & \\
Campuses & & & & & \\
\hline
\end{tabular}


Table 114

Central leadership support for assessment: Perceived challenges continued

\begin{tabular}{|l|l|l|l|l|l|}
\hline Factors & $\begin{array}{l}\text { Department } \\
\text { Chair }\end{array}$ & $\begin{array}{l}\text { Assistant } \\
\text { Dean }\end{array}$ & Professor & $\begin{array}{l}\text { Assistant } \\
\text { Professor }\end{array}$ & $\begin{array}{l}\text { Clinical } \\
\text { Lecturer }\end{array}$ \\
\hline $\begin{array}{l}\text { Lack of } \\
\text { Substantial } \\
\text { Faculty } \\
\text { Representation } \\
\text { on the Campus- } \\
\text { Wide }\end{array}$ & & & & & \\
$\begin{array}{l}\text { Assessment } \\
\text { Committee }\end{array}$ & & & & $\mathrm{X}$ & \\
\hline $\begin{array}{l}\text { Uncertainty of } \\
\text { A Leader's } \\
\text { Position on } \\
\text { Assessment }\end{array}$ & & & & & \\
\hline $\begin{array}{l}\text { Lack of } \\
\text { Confidence }\end{array}$ & & & & $\mathrm{X}$ & \\
With & & & & & \\
Assessment & & & & & \\
Indicators & & & & & \\
\hline Lack of Time & & & & & \\
\hline
\end{tabular}

Faculty Satisfaction with Secondary Education Program Faculty Leadership Support.

The professor and clinical lecturer reported to be satisfied with secondary education program faculty leadership support with the assistant professor was neutral. The professor noted that faculty were knowledgeable about assessment and that the department chair was becoming more active with assessment endeavors. He stated, “we’ve got some really good people that are driving [assessment and]...the chairs...are taking a more active role in trying to look at their own individual evaluation of their programs.” The clinical lecturer reported that a colleague was leading the implementation of an electronic portfolio (see Table 115). 


\section{Table 115}

Secondary education program faculty leadership support:

Perceived strengths

\begin{tabular}{|l|c|l|l|}
\hline Factors & Professor & $\begin{array}{l}\text { Assistant } \\
\text { Professor }\end{array}$ & $\begin{array}{l}\text { Clinical } \\
\text { Lecturer }\end{array}$ \\
\hline $\begin{array}{l}\text { Faculty Were } \\
\text { Knowledgeable } \\
\text { About } \\
\text { Assessment }\end{array}$ & $\mathrm{X}$ & & \\
\hline $\begin{array}{l}\text { Department } \\
\text { Chair Were } \\
\text { Becoming } \\
\text { More Involved } \\
\text { With }\end{array}$ & $\mathrm{X}$ & & \\
Assessment & & & \\
\hline $\begin{array}{l}\text { Implementation } \\
\text { of Electronic- } \\
\text { Portfolio }\end{array}$ & & & \\
\hline
\end{tabular}

However, the clinical lecturer reported that too many faculty members and

administrators were involved in assessment. With regard to his colleagues’ work with electronic portfolios he stated, "the problem is when he presents [possible measures from the portfolio], you've got so many voices coming in.”

The assistant professor identified the lack of faculty participation, the time commitment required to participate in assessment endeavors, and the belief that assessment may interfere with academic freedom as challenges with assessment. He noted given the small number of faculty within the secondary education department, they needed to "pull together” to accomplish assessment-related tasks. With regard to academic freedom, that assistant professor stated, we’ve developed a system where there's certain times in the program where either assignments or experiences happen...some faculty, under the guise of academic 
freedom, don't want to be told what they need to do and so we're mindful of that and I work very personally with a few of the folks to lessen their discomfort while presenting a strong argument why this is valued and why it's important and doesn’t infringe on their personal academic freedom (see Table 116).

Table 116

Secondary education program faculty leadership support:

Perceived challenges

\begin{tabular}{|c|c|c|c|}
\hline Factors & Professor & $\begin{array}{l}\text { Assistant } \\
\text { Professor }\end{array}$ & $\begin{array}{l}\text { Clinical } \\
\text { Lecturer }\end{array}$ \\
\hline $\begin{array}{l}\text { Too Many } \\
\text { Voices in } \\
\text { Assessment } \\
\text { Decision } \\
\text { Making }\end{array}$ & & & $\mathrm{X}$ \\
\hline $\begin{array}{l}\text { Lack of Faculty } \\
\text { Participation }\end{array}$ & & $X$ & \\
\hline $\begin{array}{l}\text { Time Required } \\
\text { to Participate in } \\
\text { Assessment } \\
\text { Endeavors }\end{array}$ & & $\mathrm{X}$ & \\
\hline $\begin{array}{l}\text { Faculty } \\
\text { Believed that } \\
\text { Assessment } \\
\text { Would } \\
\text { Interfere With } \\
\text { Academic } \\
\text { Freedom }\end{array}$ & & $X$ & \\
\hline
\end{tabular}

Faculty Satisfaction with Professional Development for Student Assessment. The assistant professor purported to be satisfied with professional development for student assessment while the clinical professor purported to be unsatisfied. The professor offered no response (see Table 117). 
The assistant professor identified an annual on-campus assessment conference, the institutional assessment leader, and the Center for Teaching and Learning as important factors of his satisfaction. The clinical lecturer reported that brown bag lunches and informal faculty discussions about assessment occurred regularly. He stated, I think the [course] level assessment that we use in our classes comes out of the collaboration that we do and the conversations that we share throughout the year about how we're trying to assess students and what problems we're having. That is a pretty positive thing.

However, the clinical lecturer noted that were few opportunities to participate in formal assessment workshops pertaining to outcomes assessment at the program or course level.

\section{Table 117}

Evaluations and rewards based on student data or

Involvement: Perceived strengths

\begin{tabular}{|l|c|c|c|}
\hline Factors & Professor & $\begin{array}{l}\text { Assistant } \\
\text { Professor }\end{array}$ & $\begin{array}{l}\text { Clinical } \\
\text { Lecturer }\end{array}$ \\
\hline $\begin{array}{l}\text { On-Campus } \\
\text { Assessment } \\
\text { Conference }\end{array}$ & & $\mathrm{X}$ & \\
\hline $\begin{array}{l}\text { Institutional } \\
\text { Assessment } \\
\text { Leader }\end{array}$ & & $\mathrm{X}$ & \\
\hline $\begin{array}{l}\text { Center for } \\
\text { Teaching and } \\
\text { Learning }\end{array}$ & & $\mathrm{X}$ & \\
\hline $\begin{array}{l}\text { Brown Bag } \\
\text { Lunches About } \\
\text { Assessment }\end{array}$ & & & $\mathrm{X}$ \\
\hline $\begin{array}{l}\text { Informal } \\
\text { Faculty } \\
\text { Discussions }\end{array}$ & & & $\mathrm{X}$ \\
\hline
\end{tabular}




\section{Faculty Satisfaction with Evaluations and Rewards Based on Student Assessment}

Data or Involvement. The assistant professor and clinical lecturer purported to be unsatisfied with evaluations and rewards based on student assessment data or involvement while the professor remained neutral. The professor and assistant professor reported that there were few rewards available for participating in assessment-related activities. The assistant professor reported that work associated with assessment counted as service. He stated, “I would like to [assessment research] move under research and add value as it being a valued scholarship.” The professor reported that participation in assessment-related activities takes time away from "other things that you could be doing.” The clinical lecturer reported that rewards for participating in assessment-related activities were “non-existent” (see Table 118).

Table 118

Evaluations and rewards based on student assessment data

or involvement: Perceived challenges

\begin{tabular}{|l|c|c|c|}
\hline Factors & Professor & $\begin{array}{l}\text { Assistant } \\
\text { Professor }\end{array}$ & $\begin{array}{c}\text { Clinical } \\
\text { Lecturer }\end{array}$ \\
\hline $\begin{array}{l}\text { Few Rewards } \\
\text { for } \\
\text { Participating in } \\
\text { Assessment } \\
\text { Activities }\end{array}$ & $\mathrm{X}$ & $\mathrm{X}$ & \\
\hline $\begin{array}{l}\text { Assessment } \\
\text { Work Counts } \\
\text { Towards } \\
\text { Service }\end{array}$ & & $\mathrm{X}$ & \\
\hline $\begin{array}{l}\text { Time } \\
\text { Commitment to } \\
\text { Participate in } \\
\text { Assessment }\end{array}$ & & $\mathrm{X}$ & \\
Activities & & & \\
\hline
\end{tabular}




\section{Faculty Satisfaction with the Use of Student Assessment Data in Making Academic}

Decisions. The assistant professor purported to be unsatisfied with the use of student assessment data in making academic decisions while the professor and clinical lecturer remained neutral. The professor and the assistant professor reported that assessment data was not utilized for decision making. The professor stated, “we haven’t done a whole lot with [assessment data].” The clinical lecturer reported that course-level assessments were more informative for decision making than program-level assessments.

The clinical lecturer reported that assessment data had been utilized to inform curricular changes. He stated, "if there is a textbook that they absolutely hate or a reading that they absolutely hate for reasons, [students and faculty] try to figure out why." The clinical lecturer also noted that the multiple methods of assessment that were implemented by program faculty was an important factor of his satisfaction (see Table 119).

Table 119

Use of student assessment data in making academic

decisions: Perceived strengths

\begin{tabular}{|l|l|l|c|}
\hline Factors & Professor & $\begin{array}{l}\text { Assistant } \\
\text { Professor }\end{array}$ & $\begin{array}{l}\text { Clinical } \\
\text { Lecturer }\end{array}$ \\
\hline $\begin{array}{l}\text { Assessment } \\
\text { Data Informed } \\
\text { Curricular } \\
\text { Changes }\end{array}$ & & & \\
\hline $\begin{array}{l}\text { Multiple } \\
\text { Methods of } \\
\text { Assessment }\end{array}$ & & & $\mathrm{X}$ \\
\hline
\end{tabular}

Faculty Satisfaction with the Impact Student Assessment had on the Secondary

Education Program. The assistant professor and clinical lecturer purported to be 
unsatisfied with the impact student assessment had on the secondary education program while the professor purported to be very satisfied. The professor stated, "I think that [the assessment plan] is a really good process and we need to make sure we keep fine tuning it.” The assistant professor stated, "I think assessment has had a minimal impact at this point, although the last review on student services may have some impact because it identified some concerns [that pertain to the affective domain]. Faculty Satisfaction Summary. Table 120 illustrates the frequency of themes across items related to strengths in assessment. The most frequently identified themes pertaining to assessment strengths were:

- assessment grants,

- assessment measures higher-order thinking,

- open access to venues to participate in assessment decisions,

- $\quad$ service to various committees,

- multiple measures of assessment, and

- the institutional assessment leader.

The professor reported that assessment grants assisted with the implementation of the current assessment plan and in developing support for central leadership. The assistant professor noted that assessment grants were important to the assessment plan and in facilitating assessment related discussions. The professor and the assistant professor identified higher-order thinking measures as important factors of their satisfaction with the assessment plan. The department chair and professor revealed that access to venues to participate in assessment decisions was available. They both reported that their service to various committees also provided a venue to participate in assessment decisions. The 
assistant professor identified multiple methods of assessment as an important factor of his satisfaction with the assessment plan. The clinical lecturer reported that multiple methods of assessment was an important factor of his satisfaction with the impact student assessment had on the secondary education program.

Table 120

Frequency of theme emergence pertaining to strengths across items

\begin{tabular}{|c|c|c|c|c|c|}
\hline Factors & $\begin{array}{l}\text { Department } \\
\text { Chair }\end{array}$ & $\begin{array}{l}\text { Assistant } \\
\text { Dean }\end{array}$ & Professor & $\begin{array}{l}\text { Assistant } \\
\text { Professor }\end{array}$ & $\begin{array}{l}\text { Clinical } \\
\text { Lecturer }\end{array}$ \\
\hline Assessment Grants & 0 & 0 & 2 & 2 & 0 \\
\hline $\begin{array}{l}\text { Assessment } \\
\text { Measures Higher- } \\
\text { Order Thinking }\end{array}$ & 0 & 0 & 1 & 1 & 0 \\
\hline $\begin{array}{l}\text { Open Access to } \\
\text { Venues to } \\
\text { Participate in } \\
\text { Assessment } \\
\text { Decisions }\end{array}$ & 1 & 0 & 1 & 0 & 0 \\
\hline $\begin{array}{l}\text { Service to Various } \\
\text { Committees }\end{array}$ & 1 & 0 & 1 & 0 & 0 \\
\hline $\begin{array}{l}\text { Multiple Measures } \\
\text { of Assessment }\end{array}$ & 0 & 0 & 0 & 1 & 1 \\
\hline $\begin{array}{l}\text { Institutional } \\
\text { Assessment } \\
\text { Leader }\end{array}$ & 0 & 0 & 1 & 1 & 0 \\
\hline $\begin{array}{l}\text { Faculty } \\
\text { Participation }\end{array}$ & 0 & 1 & 0 & 0 & 0 \\
\hline $\begin{array}{l}\text { Communication of } \\
\text { Assessment } \\
\text { Results }\end{array}$ & 0 & 1 & 0 & 0 & 0 \\
\hline $\begin{array}{l}\text { Assistant Dean of } \\
\text { Evaluation and } \\
\text { Program Review }\end{array}$ & 0 & 0 & 0 & 1 & 0 \\
\hline $\begin{array}{l}\text { Culture that } \\
\text { Values } \\
\text { Assessment }\end{array}$ & 0 & 0 & 0 & 1 & 0 \\
\hline $\begin{array}{l}\text { Collection of } \\
\text { Retention Data }\end{array}$ & 0 & 0 & 0 & 1 & 0 \\
\hline $\begin{array}{l}\text { Portfolio } \\
\text { Assessment }\end{array}$ & 0 & 0 & 0 & 1 & 0 \\
\hline
\end{tabular}


Table 120

Frequency of theme emergence pertaining to strengths across items: Continued

\begin{tabular}{|c|c|c|c|c|c|}
\hline Factors & $\begin{array}{l}\text { Department } \\
\text { Chair }\end{array}$ & $\begin{array}{l}\text { Assistant } \\
\text { Dean }\end{array}$ & Professor & $\begin{array}{l}\text { Assistant } \\
\text { Professor }\end{array}$ & $\begin{array}{l}\text { Clinical } \\
\text { Lecturer }\end{array}$ \\
\hline $\begin{array}{l}\text { Assessment Plan } \\
\text { Evaluation }\end{array}$ & 0 & 0 & 1 & 0 & 0 \\
\hline $\begin{array}{l}\text { Autonomy of } \\
\text { Program Faculty } \\
\text { in Assessment } \\
\text { Decisions }\end{array}$ & 1 & 0 & 0 & 0 & 0 \\
\hline $\begin{array}{l}\text { Informal } \\
\text { Discussions With } \\
\text { Faculty }\end{array}$ & 0 & 1 & 0 & 0 & 1 \\
\hline $\begin{array}{l}\text { Faculty Were } \\
\text { Knowledgeable } \\
\text { About Assessment }\end{array}$ & 0 & 0 & 1 & 0 & 0 \\
\hline $\begin{array}{l}\text { Department Chairs } \\
\text { Were Becoming } \\
\text { More Involved } \\
\text { With Assessment }\end{array}$ & 0 & 0 & 1 & 0 & 0 \\
\hline $\begin{array}{l}\text { Implementation of } \\
\text { ElectronicPortfolio }\end{array}$ & 0 & 0 & 0 & 1 & 0 \\
\hline $\begin{array}{l}\text { On-Campus } \\
\text { Assessment } \\
\text { Conference } \\
\end{array}$ & 0 & 0 & 0 & 1 & 0 \\
\hline $\begin{array}{l}\text { Center for } \\
\text { Teaching and } \\
\text { Learning }\end{array}$ & 0 & 0 & 0 & 1 & 0 \\
\hline $\begin{array}{l}\text { Brown Bag } \\
\text { Lunches About } \\
\text { Assessment }\end{array}$ & 0 & 0 & 0 & 0 & 1 \\
\hline $\begin{array}{l}\text { Assessment Data } \\
\text { Informed } \\
\text { Curricular } \\
\text { Changes }\end{array}$ & 0 & 0 & 0 & 0 & 1 \\
\hline
\end{tabular}

Common themes pertaining to challenges with assessment included:

- few rewards for participating in assessment activities,

- assessment data was not utilized, and

- $\quad$ time required to participate in assessment activities (see Table 121 ). 
The professor, assistant professor, and clinical lecturer reported that few rewards were available for participating in assessment related activities. The professor revealed that assessment data was used within the assessment plan while the assistant professor revealed that the failure to utilize assessment data impeded the implementation of the assessment plan. The professor and assistant professor identified the excessive time required to participate in assessment endeavors as a challenge.

Table 121

Frequency of theme emergence pertaining to challenges across items

\begin{tabular}{|l|c|c|c|c|c|}
\hline Factors & $\begin{array}{l}\text { Department } \\
\text { Chair }\end{array}$ & $\begin{array}{l}\text { Assistant } \\
\text { Dean }\end{array}$ & Professor & $\begin{array}{l}\text { Assistant } \\
\text { Professor }\end{array}$ & $\begin{array}{c}\text { Clinical } \\
\text { Lecturer }\end{array}$ \\
\hline $\begin{array}{l}\text { Few Rewards } \\
\text { for } \\
\text { Participating in } \\
\begin{array}{l}\text { Assessment } \\
\text { Activities }\end{array}\end{array}$ & 0 & 0 & 1 & 1 & 1 \\
\hline $\begin{array}{l}\text { Assessment } \\
\text { Data Was Not } \\
\text { Utilized }\end{array}$ & 0 & 0 & 1 & 1 & 0 \\
\hline $\begin{array}{l}\text { Time Required } \\
\text { to Participate in } \\
\text { Assessment } \\
\text { Endeavors }\end{array}$ & 0 & 0 & 2 & 1 & 0 \\
\hline $\begin{array}{l}\text { Assessments } \\
\text { Do Not } \\
\text { Measure } \\
\text { School-Level } \\
\text { Outcomes }\end{array}$ & 0 & 0 & 0 & 1 & 0 \\
\hline $\begin{array}{l}\text { NCATE } \\
\text { Mandates }\end{array}$ & 0 & 0 & 0 & 0 & 0 \\
\hline $\begin{array}{l}\text { Lack of a } \\
\text { Capstone } \\
\text { Assessment }\end{array}$ & 0 & 1 & 0 & 0 & 0 \\
\hline $\begin{array}{l}\text { Lack of } \\
\text { Confidence in } \\
\text { Assessment } \\
\text { Instruments }\end{array}$ & 0 & 0 & 0 & 1 & 0 \\
\hline
\end{tabular}


Table 121

Frequency of theme emergence pertaining to challenges across items: Continued

\begin{tabular}{|c|c|c|c|c|c|}
\hline Factors & $\begin{array}{l}\text { Department } \\
\text { Chair }\end{array}$ & $\begin{array}{l}\text { Assistant } \\
\text { Dean }\end{array}$ & Professor & $\begin{array}{l}\text { Assistant } \\
\text { Professor }\end{array}$ & $\begin{array}{l}\text { Clinical } \\
\text { Lecturer }\end{array}$ \\
\hline $\begin{array}{l}\text { Fragmentation } \\
\text { of the } \\
\text { Assessment } \\
\text { Plan }\end{array}$ & 0 & 0 & 1 & 0 & 0 \\
\hline $\begin{array}{l}\text { Non-Systematic } \\
\text { Implementation }\end{array}$ & 0 & 0 & 0 & 1 & 0 \\
\hline $\begin{array}{l}\text { Assessment } \\
\text { Discussions Do } \\
\text { Not Lead to } \\
\text { Action }\end{array}$ & 0 & 0 & 0 & 0 & 1 \\
\hline $\begin{array}{l}\text { Faculty Must } \\
\text { be Proactive to } \\
\text { Ascertain } \\
\text { Support for } \\
\text { Assessment }\end{array}$ & 1 & 0 & 0 & 0 & 0 \\
\hline $\begin{array}{l}\text { Faculty Lacked } \\
\text { a Voice in } \\
\text { Assessment } \\
\text { Decisions }\end{array}$ & 0 & 0 & 1 & 0 & 0 \\
\hline $\begin{array}{l}\text { Widely- } \\
\text { Disbursed } \\
\text { Leadership } \\
\text { Across } \\
\text { Multiple } \\
\text { Campuses }\end{array}$ & 0 & 0 & 0 & 1 & 0 \\
\hline $\begin{array}{l}\text { Lack of } \\
\text { Substantial } \\
\text { Faculty } \\
\text { Representation } \\
\text { on the Campus- } \\
\text { Wide } \\
\text { Assessment } \\
\text { Committee }\end{array}$ & 0 & 0 & 0 & 1 & 0 \\
\hline $\begin{array}{l}\text { Uncertainty of } \\
\text { Some Leader’s } \\
\text { Position on } \\
\text { Assessment }\end{array}$ & 0 & 0 & 0 & 1 & 0 \\
\hline
\end{tabular}


Table 121

Frequency of theme emergence pertaining to challenges across items: Continued

\begin{tabular}{|c|c|c|c|c|c|}
\hline Factors & $\begin{array}{l}\text { Department } \\
\text { Chair }\end{array}$ & $\begin{array}{l}\text { Assistant } \\
\text { Dean }\end{array}$ & Professor & $\begin{array}{l}\text { Assistant } \\
\text { Professor }\end{array}$ & $\begin{array}{l}\text { Clinical } \\
\text { Lecturer }\end{array}$ \\
\hline $\begin{array}{l}\text { Lack of } \\
\text { Confidence } \\
\text { With } \\
\text { Assessment } \\
\text { Indicators }\end{array}$ & 0 & 0 & 0 & 1 & 0 \\
\hline $\begin{array}{l}\text { Too Many } \\
\text { Voices in } \\
\text { Assessment } \\
\text { Decision } \\
\text { Making }\end{array}$ & 0 & 0 & 0 & 0 & 1 \\
\hline $\begin{array}{l}\text { Lack of Faculty } \\
\text { Participation in } \\
\text { Assessment }\end{array}$ & 0 & 0 & 0 & 1 & 0 \\
\hline $\begin{array}{l}\text { Faculty } \\
\text { Believed that } \\
\text { Assessment } \\
\text { Would Interfere } \\
\text { With Academic } \\
\text { Freedom }\end{array}$ & 0 & 0 & 0 & 1 & 0 \\
\hline $\begin{array}{l}\text { Assessment } \\
\text { Work Counts } \\
\text { Towards } \\
\text { Service }\end{array}$ & 0 & 0 & 0 & 1 & 0 \\
\hline
\end{tabular}

In this case study, the researcher presented the institutional background as it pertains to assessment and described the programs and participants. Participants in this AU case study included the institutional assessment leader, program administrators (four department chairs and one assistant dean), and faculty from the Departments of Mathematics and Statistics, Psychology, Biology, Secondary Education, English and Nursing.

The researcher fully analyzed data gathered from the interviews and documents. The major results pertaining to each research question are highlighted and presented by each 
academic program. In addition, the frequency of themes pertaining to participants' satisfaction with assessment is discussed including strengths and challenges. In Chapter 7, the researcher presents the major results from the cross-site analysis which includes participants’ demographic information, comparison of assessment practices across participating programs at the three universities pertinent to the sustainment and improvement phase (Banta, 2002). Commitments and resources provided to assessment and faculty satisfaction data are also discussed in Chapter 7. 


\section{Chapter 6}

\section{Gamma University}

\section{Institutional Background}

Gamma University (GU) is identified by the Carnegie Foundation for the Advancement of Teaching (2006) as a master's college and university with larger programs (basic classification). GU is located in the mid-Atlantic region of the United States. During the 2006-2007 academic year, 17,393 students were enrolled in approximately 93 programs. GU employs 2,359 full-time faculty and 300 part-time faculty. According to the GU website (2007), the mission of the institution is to “...facilitate a community committed to preparing students to be educated and enlightened citizens who lead productive and meaningful lives.” Participating GU programs in this research study included Psychology, Mathematics and Statistics, Biology, and Nursing.

The assessment of student learning outcomes at GU was comprehensive and included many measures of student achievement. GU won multiple awards for student outcomes assessment and had been identified by nationally recognized assessment leaders as a model for outcomes assessment. GU also maintained a Center for Assessment and Research Studies (CARS). The Center played a key role in supporting assessment activities on campus. According to the CARS website (2007),

the mission of the Center for Assessment and Research Studies at Gamma University is to provide quality assessment service to the university, to provide applied graduate training in both assessment and measurement, to increase the use of innovative technology in assessment practice, to increase the rigor of 
measurement and statistical techniques used in assessment practice, and to produce quality scholarship in assessment and measurement.

The Center also facilitated course work leading to a Master of Arts Degree in Psychological Sciences with a concentration in quantitative methods as well as a Doctor of Philosophy Degree in Assessment and Measurement. Furthermore, each academic year, the institution had a spring and fall assessment day. According to the institution's website (2007),

All GU students are required to participate in assessment day. Students are tested first as incoming first year students and then again when they have earned fortyfive to seventy credit hours. Even transfer students participate in GU assessment. During these assessments, students are tested on their knowledge in one of the general education areas of history, science, mathematics, or fine arts. In addition, students may also complete tests measuring critical thinking, cultural knowledge, intellectual and personal development.

Additionally, many programs utilized this particular day to conduct assessments pertaining to specific majors. Assessment Reporting Background

Program-level assessment plans were reported within the Assessment Progress Template for Annual Academic Department Reporting and Departmental Annual Reports at Gamma University. Detailed assessment information was contained within both documents. Both reports are submitted to CARS by program administrators.

According to the Assessment Progress Template for Annual Academic Reporting, “The purpose of the [Template for Annual Academic Reporting] is to provide the most 
current assessment related information for each of GU's academic programs.” The template required programs to report:

- program objectives,

- course/learning experiences,

- evaluation/assessment methods,

- objective accomplishments/results,

- dissemination methods, and

- uses of evaluation/assessment results and actions taken.

Departments are also required to compile and submit an Annual Report to CARS. Departmental Annual Reports contained information regarding the:

- mission statement,

- summary of academic activity,

- $\quad$ significant achievement for the unit,

- $\quad$ statistical profile for the unit,

- uses of assessment in maintaining and improving units,

- strategic planning/action plans,

- faculty productivity,

- grant data, and

- service.

The Departmental Annual Reports contained multiple sections, but for the purposes of this study the researcher focused primarily on the uses of assessment in maintaining and improving units. The Department Annual Reports and the Assessment Progress 
Templates both utilized the same or similar data in regard to maintaining and improving units. The researcher analyzed the documents he could obtain.

\section{Undergraduate Psychology Program}

The Department of Psychology awarded a Bachelor of Arts Degree and a Bachelor of

Science Degree. An optional concentration in behavior analysis was also available.

According to the 2006-2007 catalog,

The mission of the undergraduate program is to provide broad training in psychological principles and in research methodology as applied to the study of psychology. The program is designed to prepare psychology majors for professional and scientific graduate level training in psychology and related fields and/or for employment in bachelor's degree level positions in fields such as human services and business. The program contributes significantly to the university’s general education program and also provides service courses for students in other academic programs. The program contributes to graduate education in psychology through close affiliation with the Department of Graduate Psychology. The faculty members in the department are committed to providing superlative teaching, engaging in significant scholarly activity, and providing broad service to the university, community, and profession.

The psychology program faculty consisted of ten professors, 9 associate professors, and 5 assistant professors. Interview data revealed that between 10 to 20 part-time faculty taught courses in the Department. Undergraduate psychology students were primarily enrolled full-time. Class sizes ranged between 12 to 300 students. 


\section{Study Participants}

The researcher interviewed the department chair, the institutional assessment leader, and two associate professors. The department chair was in his fifteenth year as a professor at the institution and was serving his fourth year as the chairperson. He had worked in higher education for 29 years. He purported to be very knowledgeable about student outcomes assessment. The department chair participated within a departmental committee that discussed assessment related issues, authored a chapter in a book pertaining to assessment and psychology, and conducted workshops about program review. This administrator and faculty member had not attended any conferences that focused on student outcomes assessment nor had he attended any conferences that included assessment sessions on the program in the past two years. He had not published any papers pertaining to student outcomes assessment in the past two years; however, he had one working paper focused on this topic.

The second participant, the institutional assessment leader, was serving her third year at the rank of professor and as the Executive Director of the Center for Assessment and Research Studies. She had worked in higher education for approximately 26 years. She purported to be "pretty" knowledgeable about student outcomes assessment as she "work[s] with faculty across disciplines and departments [to] develop assessment instruments and designs using multiple methods [and] train[s] students to do [the same]." This administrator and faculty member had attended six conferences that focused on student outcomes assessment and two conferences that included assessment sessions on the program in the past two years. She had published four papers pertaining to student outcomes assessment in the past two years. Additionally, the institutional assessment 
leader had presented assessment results at all of the conferences she had attended in the past two years.

The third participant, an associate professor, was serving his third year at GU. He had worked in higher education for about 10 years. He purported to be fairly knowledgeable about student outcomes assessment. The associate professor served as the chair of the assessment committee within the psychology department and credits the development of his knowledge to reading the assessment literature, discussions with colleagues, and the Center for Assessment and Research Studies. This faculty member had not attended any conferences that focused on student outcomes assessment; however, he had attended two conferences that included assessment sessions on the program in the past two years. He had not published any papers pertaining to student outcomes assessment in the past two years.

The fourth participant, an associate professor, was serving his third year at GU. He had worked in higher education for eight years. He purported to be well-versed in student outcomes assessment and states, “...the more you know the less you know in terms of even saying how well developed your knowledge of assessment is.” As a graduate student, he assisted faculty with the development of assessment tools to assess undergraduate psychology majors. He also reported that CARS played a role in his interest to pursue a career at GU. This faculty member had attended four conferences over the past four years which he maintained were substantially related to student outcomes assessment. He had authored ten publications pertaining to student outcomes assessment within the past two years. 


\section{Characteristics of Effective Assessment Practice}

The researcher analyzed interview data and the 2006 Department of Psychology Annual Report to identify characteristics of effective practice. Additionally, the researcher evaluated the assessment plan to determine the degree to which its implementation demonstrated characteristics of effective practice.

Credible evidence of learning. Documents and interview respondents illustrated various components of the assessment plan that demonstrated learning was relevant to the major and assessment measures were reliable. Thirty-five student learning outcomes from general psychology, methodology, natural and social science, upper level specialty content, capstone, and socio-cultural awareness courses were assessed. The outcomes for the psychology major spanned five of six cognitive domains contained within Bloom’s Taxonomy (Anderson, et al., 2001). The outcomes were sharply skewed to the less sophisticated domains. Nine percent of the outcomes focused on the remember domain, forty-two percent represented the understand domain, thirty-six percent represented the apply domain, three percent represented the analyze domain, six percent represented the evaluate domain, and three percent represented the create domain (see Table 122). There were two outcomes representative of the affective domain. These outcomes were learnercentered and were clear, measurable, spanned multiple learning domains, and were directly related to the program's mission statement.

Examples of the intended learning outcomes within the remember domain included:

- recognize the historical and cultural influences on basic psychological processes, research findings, and psychological theories and

- recognize the key components of critical thinking. 
Table 122

Distribution of intended cognitive learning outcomes

\begin{tabular}{|c|c|c|}
\hline Cognitive Domain & N & $\%$ \\
\hline Create & 1 & 3 \\
\hline Evaluate & 2 & 6 \\
\hline Analyze & 1 & 3 \\
\hline Apply & 12 & 36 \\
\hline Understand & 14 & 42 \\
\hline Remember & 3 & 9 \\
\hline
\end{tabular}

Examples of intended learning outcomes within the understand domain included:

- describe the empirical nature of scientific inquiry and

- $\quad$ summarize basic research procedures used within the field of psychology.

Examples of intended learning outcomes within the apply domain included:

- demonstrate information competence and

- apply psychological principles to critical issues within the area of specialization for the specific course.

An example of an intended learning outcome within the analyze domain included:

- analyze information from primary sources to address psychologically relevant issues.

Examples of intended learning outcomes within the evaluate domain included:

- $\quad$ synthesize information from primary sources to address psychologically relevant issues and

- evaluate information from primary sources to address psychologically relevant issues. 
An example of an intended learning outcome within the create domain included:

- use critical and creative thinking, skeptical inquiry, and when possible the scientific approach to solve problems related to behavior and mental processes.

The Department of Psychology utilized multiple methods of assessment to measure student achievement. The department chair revealed that one of the major multiple choice assessment methods included The Area Concentration Achievement Test (ACAT) in Psychology (a nationally-normed examination designed to measure content knowledge). Ten content areas related to psychology were selected to be assessed by the Psychology Assessment Committee. The 2006 Annual Report further stated, “The test is intended for senior psychology majors who are not necessarily graduate school bound. It examines mastery of concepts, principles, and knowledge expected of students at the end of their program.” A sample of 106 seniors completed this two-hour assessment in the 2005 - 2006 academic year. The department chair maintained that the ACAT is "probably" the most direct measure of student learning. With regard to the ACAT he stated, “...good scores can only reflect students’ knowledge of the content of psychology including statistics as well as the various content areas.”

Another assessment instrument noted by the Department Chair was a locally developed information literacy examination. According to the 2006 Annual Report, the information literacy test for psychology majors was developed by a psychology faculty member "in consultation with the assessment subcommittee and with the Center for Assessment and Research (CARS).” This locally developed examination is composed of 59 multiple choice items that assess student achievement in "basic skills, database searching, Internet, APA style, and evaluation of sources.” The report stated that, "The 
test measure[s] both knowledge (44 items) and ability to apply knowledge by finding information in electronic sources (15 items). To answer the application questions students [are] required to search LEO, PsycINFO, and the Internet to find answers.” A sample of 106 students completed this examination during the 2005 - 2006 academic year.

The department chair also noted that two GU psychology faculty had developed a selfreflection exercise related to the goals of the American Psychology Association (APA) for psychology majors. This indirect assessment measure presented students with the ten Learning Goals for the Psychology major. According to the department chair, students first “...indicate if they felt they had personally met the learning goal...” then indicate “...if they felt the psychology department provided adequate resources/opportunities to meet each goal.” Students expecting to graduate in either May or December were asked to complete this exercise.

The final assessment method identified by the department chair was the job-readiness questionnaire (similar to an exit survey). The job-readiness survey was developed locally and contains four sections. According to the 2006 Annual Report of the Psychology Department,

The first section measures whether or not a student has completed specific activities to begin searching for a job. The second section measures students' attitudes about finding a job. The third section of this survey is an activity checklist. For this section, students indicate which services they have used from both the Academic Advising \& Career Development Office and Peer Advising 
office. The final section of the survey asks students about their future plans and their job history.

The 2006 Annual Report revealed that students also completed an academic skills inventory, an on-demand writing assessment, and an exit survey. The academic skills inventory was a 90 item survey instrument designed to collect information regarding student's abilities in different skill areas related to psychology. According to the 2006 Annual Report, "the inventory lists ten different skill areas (e.g., writing/oral communication) with specific skills listed under each area (e.g., I have made at least 3 oral presentations in a classroom).” This instrument did not assess student achievement pertinent to the intended learning outcomes. Rather, the inventory examined the opportunities students had to practice specific skills related to programmatic outcomes and the types of activities (e.g., publications, poster presentations). The academic skills inventory was available in the public domain.

The on-demand writing assessment test was locally developed utilizing resources from the assessment subcommittee and CARS. This assessment required students to read a summary of a psychology related research study and then write a reaction paper. Students were prompted to “discuss the strengths, weaknesses, and possible applications of the study.” This assessment was not conducted in the 2005-2006 academic year.

The Senior Exit Survey of the Department of Psychology was a locally developed instrument created by the assessment subcommittee “...to collect data for Academic Program Reviews.” The on-line survey was composed of 113 items related to “...aspects of [the] student experience in the major.” Specifically, the survey elicited data pertinent to "faculty and peer advising, relationships with school administrators and staff, 
communications, course evaluation, overall satisfaction with the major, achievement of goals and objectives, reasons for choosing a Psychology major, special learning experiences, and future plans.” All psychology majors expecting to graduate in 2006 were asked to complete this on-line survey. Two hundred sixteen students participated.

A brief discussion with the department chair about the indirect measures elicited a warning about the interpretation of the results from these assessments. The department chair maintained that indirect results “...could be distorted by [student’s] misperceptions of their own knowledge.”

The analysis of data from the aforementioned assessment activities was appropriate. Descriptive statistics were provided for each measure. ACAT results included standardized scores. However, the assessment results did not link directly to the intended learning outcomes of the program. Rather, assessment results were reported in terms of goals or broad learning outcomes.

Continuous Improvement. Interview respondents and the 2006 Annual Report provided evidence to document program changes or improvements had been implemented based on assessment data. The department chair revealed that discussions about assessment data occur from time to time in faculty meetings. Furthermore, he disclosed that recently the Psychology program underwent “...major revisions of the curriculum and assessment data was the primary information used for making those programmatic curriculum changes.” Thus, the "biggest focus” on assessment data discussions occurred “...during the period from about 3 years ago to last year...” when revisions were made. 
The department chair provided an example of how the assessment results could be used to make targeted changes. He reported that the "...senior exit survey is [used] quite extensively to monitor and to improve the quality of various services provided to students...” The exit survey contained “... an assessment of the advising that the students have received and that feedback goes back to the faculty and advisors to hopefully improve the quality of that service.”

The 2006 Annual Report revealed a more detailed analysis of the actions taken to facilitate continuous improvement. The Department of Psychology Program Assessment Committee “...compared student performance on our Content Assessment [ACAT] with the pattern of coursework students actually completed and discovered that students who had completed more content-area courses performed better on this test than students who completed fewer courses.” Thus, the Department of Psychology increased the number of credits for the Psychology major from 38 hours to 44 hours. Other actions taken as a result of an analysis of the assessment results from the ACAT included:

- exploring alternative methods to teach statistics and research-based courses,

- examining course sequencing utilized to develop statistics and research skills,

- $\quad$ adding a new elective course in Advanced Psychological Statistics to provide students with an opportunity to enhance skills related to statistics, and

- $\quad$ increasing the number of research opportunities for students.

The self-reflection exercise data related to the APA's Learning Goals for the Psychology Major revealed weaknesses in student achievement in Socio-cultural and International Awareness. As a result of this finding, the Department of Psychology added “....a number of 200-level and 400-level course offerings about this topic.” A new 
undergraduate psychology curriculum, implemented in the Fall of 2006, "requires that all students complete at least one course that addresses socio-cultural issues.” Additionally, new courses were "added to the curriculum to help students develop skills in this domain...” The assessment data also revealed that career development within the Department of Psychology could be improved. The Department of Psychology Program Assessment Committee concluded that “...most of our students are actually quite well prepared for graduate study or entry-level positions, but they do not recognize their own skills, and sometimes lack the specific skills necessary to take their next career step with confidence.” Actions taken as a result of this finding included:

- revised web-site to bolster information about career options,

- addition of alumni profiles within the web-site to illustrate career paths,

- increased the relationship between the Department of Psychology and the Office of Academic Advising and Career Development,

- $\quad$ revised weekly e-mail news,

- $\quad$ revised the orientation program for new majors, and

- "improved the quality of our peer advising program."

According to the Annual Report and the department chair, faculty identified several program modifications based upon the results from the senior exit survey. These modifications included:

- more frequent offerings of Industrial Organizational (I/O) Psychology,

- $\quad$ increasing the number of opportunities students have to practice their writing skills across the program, and 
- increasing the "number of opportunities for students to work with faculty individually or in small groups on research practicum, directed readings, or teaching assistantship experiences.”

The numerous examples of program modifications illustrated by the department head and the 2006 Annual Report of the Psychology Department suggested that faculty utilized assessment results to improve student learning. Faculty were using assessment data as a basis to modify course curriculum. Most directly, increasing the number of opportunities for students to practice writing required curricular modifications. All of these actions supported the strategic goal of maintaining and improving the quality of the psychology major.

Accountability to internal stakeholders. The department chair maintained that “...the senior exit survey has some of the most direct and immediate type of effect in [the domain of accountability]...” He justified his perspective by stating, “...because people know that at the end of each year the seniors will be reporting how well we did various things and that feedback goes back to the individuals who might be responsible to me and they all know...that these pieces of our work will be evaluated and there is a feedback loop...” An analysis of the 2006 Annual Report of the Department of Psychology revealed that assessment results were shared electronically and personalized reports were disseminated to faculty members. Faculty discussed assessment results during their faculty meetings.

Ongoing assessment. Interview respondents and documents revealed that assessment occurred on a predictable schedule within the Psychology Department. The department chair noted that assessments occurred at specific times throughout the curriculum. The 
department chair stated that the Psychology Department was collecting “...too much data...” However, he reported that “...being the compulsive people that we are people have been reluctant to cut anything out...” He further stated there was

...not enough time to do everything that faculty need to do, want to do, and also analyze fully reams and reams of data. The summary is just descriptive of this method and [the] result is a 60 to 80 page document every year. Generating that is a lot of work, but that is not really the best use of the assessment data.

The department chair suggested that a better use of the assessment data “... would be an analysis of that data to draw conclusions and recommendations..."

Ongoing Evaluation and Improvement. Interview data revealed that the assessment plan within the Department of Psychology did not contain a formal method to evaluate and improve the assessment plan itself. When asked about the ability of the assessment plan to facilitate ongoing evaluation and improvement, the department chair reported that throughout “...the last six years it has not done that very well.” He further stated that this component of the assessment plan would be reviewed in the near future.

The department chair, institutional assessment leader, and both faculty members purported to be satisfied with the program's approach to assessment. The department chair and both associate professors emphasized the implementation of multiple assessment methods as a key factor affecting their satisfaction with program assessment (see Table 123). The junior associate professor claimed, “we do have a very multifaceted program, we bring students back in their senior year for exit exams and surveying of their attitudes, their content knowledge, their skill sets as they actually get put into meaningful 
exercises like literally pulling stuff of the Internet and judging its quality...” He continued by highlighting the use of the ACAT test.

Table 123

Assessment plan: Perceived strengths

\begin{tabular}{|l|l|l|c|c|}
\hline Factors & $\begin{array}{l}\text { Department } \\
\text { Chair }\end{array}$ & $\begin{array}{l}\text { Institutional } \\
\text { Assessment } \\
\text { Leader }\end{array}$ & $\begin{array}{l}\text { Senior } \\
\text { Associate } \\
\text { Professor }\end{array}$ & $\begin{array}{l}\text { Junior } \\
\text { Associate } \\
\text { Professor }\end{array}$ \\
\hline $\begin{array}{l}\text { Faculty } \\
\text { Commitment to } \\
\text { Assessment }\end{array}$ & & & $\mathrm{X}$ & \\
\hline $\begin{array}{l}\text { Faculty } \\
\text { Willingness to Try } \\
\text { New Things }\end{array}$ & & & $\mathrm{X}$ & \\
\hline $\begin{array}{l}\text { Creativity of } \\
\text { Faculty }\end{array}$ & & & $\mathrm{X}$ & \\
\hline $\begin{array}{l}\text { Institutionalization } \\
\text { of Assessment }\end{array}$ & & $\mathrm{X}$ & $\mathrm{X}$ & \\
\hline $\begin{array}{l}\text { Multiple Methods } \\
\text { of Assessment }\end{array}$ & $\mathrm{X}$ & $\mathrm{X}$ & $\mathrm{X}$ \\
\hline $\begin{array}{l}\text { Continuous } \\
\text { Monitoring of } \\
\text { Assessment Data }\end{array}$ & & $\mathrm{X}$ & & \\
\hline Assessment Day & & $\mathrm{X}$ & & \\
\hline $\begin{array}{l}\text { Inclusion of } \\
\text { Assessment Data in } \\
\text { Program Review }\end{array}$ & & & & \\
\hline $\begin{array}{l}\text { Comprehensiveness } \\
\text { of Assessment Plan }\end{array}$ & $\mathrm{X}$ & & & \\
\hline
\end{tabular}

The institutional assessment leader identified the continuous monitoring of assessment data, assessment day, and the inclusion of assessment data in program review as a reason for her high degree of satisfaction. With regard to continuous monitoring, the assessment leader noted, “[we] really care about students here...I think that's a major part of what assessment is.” She stated, "the opportunity for real quality data collection in every major is there because of assessment day.” The institutional assessment leader also noted 
the inclusion of assessment data, generated as a result of assessment day, in academic program review.

With regard to commitment, creativity, and willingness to try new things, the senior associate professor highlighted these attributes by stating "We have a group of faculty who are really committed to [assessment], the faculty work hard to come up with some good assessments, they are creative, and we are not afraid to try new things.”

The junior associate professor identified the institutionalization of assessment on the campus. He also highlighted attributes pertaining to multiple assessment methods by discussing assessment day and describing the assessment plan as multifaceted as well as comprehensive.

Even though faculty reported their satisfaction with the program's assessment approach, some themes emerged as cautions (see Table 124). The department chair noted concerns with the overabundance of data collection and the lack of assessment data analysis. He further explained, "I like what we are doing with the exception that I think we do too much data collection and not enough data analysis.” The senior associate professor highlighted concerns with the development of writing assessments. Additionally, he expressed a need to improve the assessment tools associated with sociocultural awareness. Weaknesses in developing assessment tools to accurately assess writing skills and the need to improve the assessment tools associated with socio-cultural awareness were identified by one of the associate professors. The senior associate professor stated, “we have had writing assessment in the past but it was very difficult to score and have inter-rater reliability.” Additionally the senior associate professor claims, “Our new major has a socio-cultural awareness component and we need to develop a 
better way to assess that.” He further stated, “Our current tools told us that we have a problem with social cultural awareness and that students from some self-report items and some rating scale items didn't feel like they had enough of that, but we would like to have a better way to assess our students [in that area].”

Table 124

Assessment plan: Perceived challenges

\begin{tabular}{|l|l|l|l|l|}
\hline Factors & $\begin{array}{l}\text { Department } \\
\text { Chair }\end{array}$ & $\begin{array}{l}\text { Institutional } \\
\text { Assessment } \\
\text { Leader }\end{array}$ & $\begin{array}{l}\text { Senior } \\
\text { Associate } \\
\text { Professor }\end{array}$ & $\begin{array}{l}\text { Junior } \\
\text { Associate } \\
\text { Professor }\end{array}$ \\
\hline $\begin{array}{l}\text { Overabundance } \\
\text { of Data } \\
\text { Collected }\end{array}$ & $\mathrm{X}$ & & & \\
\hline $\begin{array}{l}\text { Lack of } \\
\text { Analysis of } \\
\text { Data }\end{array}$ & $\mathrm{X}$ & & & \\
\hline $\begin{array}{l}\text { Challenges } \\
\text { Developing } \\
\text { Writing }\end{array}$ & & & $\mathrm{X}$ & \\
Assessments & & & & \\
\hline $\begin{array}{l}\text { Improve } \\
\text { Assessment } \\
\text { Methods } \\
\text { Related to } \\
\text { Socio-cultural } \\
\text { Awareness }\end{array}$ & & & & \\
\hline
\end{tabular}

Institutional Commitments and Resources

Commitments. University and program leaders demonstrated their commitment to assessment. When asked if the utilization of student assessment data was considered in the evaluation and rewarding of faculty, the department chair stated, the contribution that faculty make to assessment are considered a valuable activity...so if a faculty member had evidence that they had contributed in a 
significant way to program assessment it would be viewed as high as other kinds of service commitments to the department.

Additionally, the department chair reported that student assessment expertise would be considered in the hiring process for new faculty; however, “...it probably wouldn’t be the primary thing we sought.”

When queried about the policies and practices that facilitated the communication of student assessment purposes, the department chair noted directives from CARS to the Department of Psychology. He stated, "For example, there was a structure imposed [by CARS] about two years ago on the way that we would report our assessment data in our annual reports. We did get that information and use that structure in the way that we design the reports that we create." The newsletter e-mailed from the department chair was a more direct communication of the purposes of outcomes assessment. The department chair stated,

I send out an e-mail newsletter every week to all of the psychology majors and so when assessment day is approaching I would include in there a paragraph about whey we do assessment in addition to the detail of exactly what the students need to do, where they need to show up, and how long they need to make themselves available.

When asked about policies to promote the involvement of student affairs personnel and students in assessment efforts, the department chair stated that he was “...not sure to what extent those other entities would be involved...” He stated that executive level support for student assessment was evident and illustrated this through an encounter with the university president. The department chair reported, "the president came to our 
department meeting and talked about the value of connecting the mission of the department to the mission of the university and told us that we did a good job of program assessment.”

When asked to describe the culture of assessment within the Psychology program, the department chair felt as though the department “...understand[s] the value of assessment...” because they use assessment data to inform curricular changes. The department chair reported that no guiding principles for assessment had been articulated. Additionally, he reported to be unaware of a campus wide assessment committee with broad representation.

When queried about the incorporation of outcomes assessment into the scholarship of teaching in promotion and tenure guidelines, the department chair stated that there was nothing “...explicitly in the guidelines...” However he further stated, “...if someone published something or presented something about assessment data it would be valued equally with any other presentation or publication.”

In summary, the significant commitments included:

- counts towards service,

- consideration of assessment expertise in the hiring process for new faculty,

- communication of student assessment purposes,

- $\quad$ executive level support, and

- a culture that values assessment.

Resources. Resources associated with the assessment activities on campus included financial support for testing, professional development opportunities, and access to consulting services. When asked to identify resources that were allocated to the 
Department of Psychology from the institution, the department chair identified the central assessment office and their financial support of testing to be crucial. According to the department chair, “...the assessment office has been very helpful in paying for the costs of the ACAT tests which is a significant expense." Specifically, the Center for Assessment and Research Studies supports the Department of Psychology’s assessment program by paying for 100 ACAT exams every year. The department chair noted that support for the ACAT examinations is the only funding specifically for assessment provided to the program. Culturally, he claimed that “...the institution has a value of doing assessment that is really embedded into many things that we do.”

While a comprehensive student assessment database was not directly available to the Department of Psychology, the department chair accessed information typically available in such a database through CARS. The department chair purported to be unaware of any professional development assessment workshops offered at GU. However he stated that the “...assessment office does consult with departments...” When queried about the availability of one-on-one attention for assessment assistance, the chair maintained that “...you [would] get one-on-one attention whether you liked it or not.”

Support for faculty to attend professional conferences on student assessment was available. However, the chair was unaware of a specific fund for this type of activity. Rather, the chair reported that “...certainly if a faculty in this department would want to go to an assessment focused conference the attendance at that conference would be considered equally valuable to any other kind of conference they might want to attend.”

According to the department chair, internal consulting services for faculty on the use of student assessment in course design and instruction were very available from the 
Center for Faculty Innovation, the Center for Innovative Technology, and the Center for Assessment Research Studies. He claimed, "they all advertise their availability to assist with the areas that they are focused on.” With regard to the Center for Faculty Innovation, the chair stated that the center “...focuses on course design and instructional design and pedagogy in general, [however] they may actually have some assessment related workshops but that is not their main focus.” According to the chair, The Center for Assessment and Research Studies focused on program assessment.

The department chair reported that there were very limited types of assistance (in the form of paid leaves, stipends, mini-grants, or course reductions) for faculty to work on assessment activities. However, the CARS offered a fellowship program. According to the department chair, “... one of our faculty was an assessment fellow last summer, so she worked over at the CARS office on projects related to developing her own skills and assessment methods.” Additionally, "the Department from time to time has offered stipends for faculty to do some assessment related activities for special purposes..." The department chair reported an interest in “...doing this on a more regular basis.” However, central leadership opposes “...paying faculty for assessment as extra work.” Furthermore, the department chair reported to be unaware of assessment workshops for deans, department chairs, and other academic administrators or student affairs staff and student affairs administrators.

The department chair identified both the Center for Assessment Research Studies and the Office of Institutional Research as being helpful with coordinating data-gathering initiatives such as surveys and standardized tests. According to the department chair, the Office of Institutional Research "supervises the implementation of Web Surveyor which 
is for on-line testing and they do training for that system and provide assistance in that." In addition, "they do a lot of institutional level data collection." The department chair further stated that even though a lot of the work conducted by the Office of Institutional Research “...is not specifically assessment focused, but a lot of the information can be used as part of assessment blended with assessment data so that things like alumni surveys [may be examined].” However, he cautioned that he was not exactly sure if such data collection would be conducted by the Office of Institutional Research or the Center for Assessment Research Studies. Additionally, he noted that a program-level assessment office did not exist. In summary, the significant resources available from the institution included:

- funding for examinations (ACAT),

- consulting services from CARS,

- avenues of financial support to attend assessment conferences,

- Center for Faculty Innovation (CFI),

- Center for Innovative Technology (CIT),

- assessment fellowships,

- stipends for assessment related activities,

- Office of Institutional Research, and

- access to on-line survey software.

Faculty Satisfaction with Assessment and the Assessment Plan

Faculty satisfaction with program assessment was determined by analyzing interview data from four individuals: the department chair who was also a professor, two associate professors of psychology, and the institutional assessment leader. The department chair 
and institutional assessment leader were asked a sample of the items included on the Faculty Satisfaction Interview Protocol. These items elicited information regarding their satisfaction with implementation of the current assessment plan, opportunities to participate in policy making, and central leadership support for assessment. Only the associate professors were invited to respond to the items pertaining to faculty leadership support, professional development, evaluations and rewards, academic decision making, and the impact of student assessment on the program.

Satisfaction with the Implementation of the Current Assessment Plan. All four participants were satisfied with the implementation of the current assessment plan. The department chair noted the effectiveness of the assessment committee and faculty volunteers. The institutional assessment leader identified high participation rates in assessment activities by students and the collection of credible evidence of learning. The senior associate professor discussed the utilization of assessment day and student participation. The junior associate professor highlighted the opportunity for all faculty within the department to have a "voice" on the assessment committee (see Table 125).

The department chair identified the effectiveness of the assessment committee in “...getting the job done” and the participation of faculty volunteers. The chair elaborated on faculty volunteers by stating, "faculty volunteer for example on assessment day from that assessment committee and a few others contribute also to actually supervise that process." The chair explained the need of the faculty volunteers on assessment day, [the] process is complicated because it is over 200 students who will show up in a 
place that they don't really know what to do it all has to happen and there is a makeup process for students who don’t show up. We get a very high level of compliance as a result of the process we have put into place.

The institutional assessment leader reported that there was a 98\% student participation rate across the institution for assessment day. She maintained that the implementation of a good data collection plan, assessment methods, and instruments yields credible evidence of student learning that faculty value.

The senior associate professor identified the utilization of assessment day and the willingness of students to participate and submit rich data as major reasons for his satisfaction with the implementation of the assessment plan. He stated, "most of our assessments are done as part of assessment day so it is not embedded in courses it is embedded as part of assessment day and that works well, the vast majority or our students show upon assessment day.” The senior associate professor continued, “[the students] can complete the tasks... we have measures to suggest that [students] are well motivated, so that works well.” With regard to the richness of data collected from students the senior associate professor stated, “I am always amazed at how much students write.” He further stated, "I think the [senior exit survey] itself has 87 questions [it] is very long, it’s an exhaustive survey... and I would think from a student's perspective you would get tired doing that and leave some of the short answers blank but they write paragraphs and paragraphs about what they like best about the program and what were the [weakest attributes] of the program.” 
Table 125

Implementation of the current assessment plan: Perceived strengths

\begin{tabular}{|l|l|l|l|l|}
\hline Attributes & $\begin{array}{l}\text { Department } \\
\text { Chair }\end{array}$ & $\begin{array}{l}\text { Institutional } \\
\text { Assessment } \\
\text { Leader }\end{array}$ & $\begin{array}{l}\text { Senior } \\
\text { Associate } \\
\text { Professor }\end{array}$ & $\begin{array}{l}\text { Junior } \\
\text { Associate } \\
\text { Professor }\end{array}$ \\
\hline $\begin{array}{l}\text { Effectiveness of } \\
\text { Assessment } \\
\text { Committee }\end{array}$ & $\mathrm{X}$ & & & \\
\hline $\begin{array}{l}\text { Faculty } \\
\text { Volunteers }\end{array}$ & $\mathrm{X}$ & & & \\
\hline $\begin{array}{l}\text { Faculty } \\
\text { "Voices" on the }\end{array}$ & & & & $\mathrm{X}$ \\
$\begin{array}{l}\text { Assessment } \\
\text { Committee }\end{array}$ & & $\mathrm{X}$ & $\mathrm{X}$ & \\
\hline $\begin{array}{l}\text { Student } \\
\text { Participation }\end{array}$ & & $\mathrm{X}$ & & \\
\hline $\begin{array}{l}\text { Credible } \\
\text { Evidence of } \\
\text { Learning }\end{array}$ & & & $\mathrm{X}$ & \\
\hline $\begin{array}{l}\text { Assessment } \\
\text { Day }\end{array}$ & & & & \\
\hline
\end{tabular}

However, the senior associate professor also described inefficiencies in the sharing of assessment results with faculty as impeding his satisfaction. He believed the department can do a better job discussing the assessment results with faculty. The senior associate professor explained,

the way [sharing of assessment results] works [is] a group of faculty write an assessment report every year. That assessment report is available for faculty to read if they choose. It is put on a digital format so that all faculty can get to it from a web-site but we don’t always have the time to talk about our assessment results at faculty meetings and so I think we can improve.

Faculty Satisfaction with Participation in Assessment Decisions. The department chair, institutional assessment leader, and both of the associate professors were satisfied 
with the opportunities they had to participate in assessment decision-making (see Table 126). They illustrated key factors that were associated with their satisfaction. The department chair explained, "I have very good communication with the CARS people both directly and indirectly through faculty who are very connected with that group, so I'm pretty satisfied.”

Table 126

Participation in assessment decisions: Perceived strengths

\begin{tabular}{|l|l|l|l|l|}
\hline Attributes & $\begin{array}{l}\text { Department } \\
\text { Chair }\end{array}$ & $\begin{array}{l}\text { Institutional } \\
\text { Assessment } \\
\text { Leader }\end{array}$ & $\begin{array}{l}\text { Senior } \\
\text { Associate } \\
\text { Professor }\end{array}$ & $\begin{array}{l}\text { Junior } \\
\text { Associate } \\
\text { Professor }\end{array}$ \\
\hline $\begin{array}{l}\text { Communication } \\
\text { with CARS }\end{array}$ & \multicolumn{1}{|c|}{$\mathrm{X}$} & $\mathrm{X}$ & \\
\hline $\begin{array}{l}\text { Service to the } \\
\text { Assessment } \\
\text { Advisory } \\
\text { Committee }\end{array}$ & & & & \\
\hline $\begin{array}{l}\text { Department } \\
\text { Assessment } \\
\text { Subcommittee } \\
\text { Chair }\end{array}$ & & & & \\
\hline $\begin{array}{l}\text { Participated in } \\
\text { the } \\
\text { Development of } \\
\text { the } \\
\text { Motivational } \\
\text { Research } \\
\text { Institute }\end{array}$ & & & & \\
\hline
\end{tabular}

The institutional assessment leader noted her work with the assessment advisory committee. She maintained that their work assisted with the development of the assessment progress template that was utilized for reporting purposes.

Both of the associate professors were in unique positions to participate in major discussions pertaining to assessment. The senior associate professor served as the 
Assessment Subcommittee Chair for the department. This faculty member also assisted in the development of a social science major. He claimed, "as part of that we talked about how to assess that major as an interdisciplinary major.” Additionally, he participated in an advising initiative that included discussions about how to assess advising. The junior associate professor participated in the development of the Motivational Research Institute that is housed within the Center for Assessment and Research Studies.

Faculty Satisfaction with Central Leadership Support for Assessment. The department chair, institutional assessment leader, and both of the associate professors were satisfied with the central leadership support for student assessment. They discussed key attributes that supported their satisfaction. The department chair noted that central leaders were very supportive and that directives issued from central leadership were easy to satisfy. Both associate professors noted financial and intellectual assistance from CARS and a culture that values assessment. The junior associate professor noted the strong administrative knowledge base pertaining to assessment held by the department chair, dean, and provost (see Table 127).

The department chair maintained that the administrative leadership support for assessment is excellent. He qualified his response by stating that the administrative leadership was "easily accessible, you see their initiatives and it is easy to respond to initiatives and things of that nature.” The institutional assessment leader maintained that executive leadership was crucial in the development of assessment practices at the institution. She noted that the previous president "saw [assessment] as a real political 
tool and he used it like a craftsman.” She credited the previous chief executive officer with "build[ing] this university into what it is today."

Table 127

Central leadership support for assessment: Perceived strengths

\begin{tabular}{|l|c|c|c|c|}
\hline Factors & $\begin{array}{l}\text { Department } \\
\text { Chair }\end{array}$ & $\begin{array}{l}\text { Institutional } \\
\text { Assessment } \\
\text { Leader }\end{array}$ & $\begin{array}{l}\text { Senior } \\
\text { Associate } \\
\text { Professor }\end{array}$ & $\begin{array}{l}\text { Junior } \\
\text { Associate } \\
\text { Professor }\end{array}$ \\
\hline $\begin{array}{l}\text { Support from } \\
\text { Central Leaders }\end{array}$ & $\mathrm{X}$ & $\mathrm{X}$ & $\mathrm{X}$ & $\mathrm{X}$ \\
\hline $\begin{array}{l}\text { Culture that } \\
\text { Values } \\
\text { Assessment }\end{array}$ & $\mathrm{X}$ & $\mathrm{X}$ & $\mathrm{X}$ \\
\hline $\begin{array}{l}\text { Financial } \\
\text { Assistance from } \\
\text { CARS }\end{array}$ & & & $\mathrm{X}$ & $\mathrm{X}$ \\
\hline $\begin{array}{l}\text { Intellectual } \\
\text { Assistance from } \\
\text { CARS }\end{array}$ & & & $\mathrm{X}$ & $\mathrm{X}$ \\
\hline $\begin{array}{l}\text { Knowledge } \\
\text { Base of } \\
\text { Administrators }\end{array}$ & & & & \\
\hline $\begin{array}{l}\text { Realistic } \\
\text { Directives }\end{array}$ & $\mathrm{X}$ & & & \\
\hline
\end{tabular}

Both of the associate professors identified the financial assistance provided to the program to purchase ACAT examinations, the culture of the institution to support assessment, and the strong administrative knowledge base pertaining to assessment. The senior associate professor reported, "we tell [CARS] what we want to do or what we need to do and they help [the departments] make it happen.” He illustrated this by explaining, “They buy standardized tests [ACAT] for part of our assessment and they are more than willing to do that for us." The junior associate professor explained that "the culture is such that we want to measure...” He further explained that "our Deans obviously support the idea [of assessment] and certainly our provost supports assessment, they both happen 
to be school psychologists [and] they are even more well-versed [with assessment] probably than most of [the faculty] about operationalizing and getting valid tools of measurement.”

Faculty Satisfaction with Psychology Program Faculty Leadership Support. The associate professors reported to be highly satisfied with program faculty leadership support for assessment. Both associate professors noted the importance of the department chair's support for assessment. The senior associate professor identified faculty participation as a positive attribute. The junior associate professor identified the program’s culture of assessment as a positive characteristic (see Table 128).

Table 128

Program faculty leadership support: Perceived strengths

\begin{tabular}{|l|c|c|}
\hline Factors & $\begin{array}{l}\text { Senior } \\
\text { Associate } \\
\text { Professor }\end{array}$ & $\begin{array}{l}\text { Junior } \\
\text { Associate } \\
\text { Professor }\end{array}$ \\
\hline $\begin{array}{l}\text { Department } \\
\text { Chair Support }\end{array}$ & $\mathrm{X}$ & $\mathrm{X}$ \\
\hline $\begin{array}{l}\text { Faculty } \\
\text { Participation }\end{array}$ & $\mathrm{X}$ & \\
\hline $\begin{array}{l}\text { Program } \\
\text { Culture that } \\
\text { Values } \\
\text { Assessment }\end{array}$ & & $\mathrm{X}$ \\
\hline
\end{tabular}

With regard to the support of the department chair, the senior associate professor stated, “our department head is on the assessment committee and he’s very supportive of assessment, he is very supportive of wanting us to do quality assessments and good assessments and [he] is very much hands-on and very much involved in the process...” 
The junior associate professor credited the department chair as "the major reason why we have such a multifaceted [assessment program].”

The senior associate professor addressed faculty’s willingness to participate in critiquing writing assessment during the summer months. He reported that faculty were requested to "come in over the summer not for any money at all, I think we offered to buy them lunch, and grade essays.” The senior associate professor continued, “faculty for the most part were willing to do that and I think that says a lot because in the summer we were not required to be here...”

Faculty Satisfaction with Professional Development for Student Assessment. The two associate professors were satisfied with professional development opportunities for student assessment. Both associate professors noted that the Center for Faculty Innovation was important because staff offer professional development for student assessment. The junior associate professor identified assessment fellowships, CARS liaisons, and conference support as significant elements that contribute to his positive satisfaction (see Table 129).

Table 129

Professional development for student assessment:

Perceived strengths

\begin{tabular}{|l|l|l|}
\hline Factors & $\begin{array}{l}\text { Senior } \\
\text { Associate } \\
\text { Professor }\end{array}$ & $\begin{array}{l}\text { Junior } \\
\text { Associate } \\
\text { Professor }\end{array}$ \\
\hline $\begin{array}{l}\text { Center for } \\
\text { Faculty } \\
\text { Innovation }\end{array}$ & $\mathrm{X}$ & $\mathrm{X}$ \\
\hline $\begin{array}{l}\text { Assessment } \\
\text { Fellowships }\end{array}$ & & $\mathrm{X}$ \\
\hline CARS Liaison & & $\mathrm{X}$ \\
\hline
\end{tabular}


Table 129

Professional development for student assessment:

Perceived strengths continued

\begin{tabular}{|l|l|l|}
\hline Factors & $\begin{array}{l}\text { Senior } \\
\text { Associate } \\
\text { Professor }\end{array}$ & $\begin{array}{l}\text { Junior } \\
\text { Associate } \\
\text { Professor }\end{array}$ \\
\hline $\begin{array}{l}\text { Conference } \\
\text { Support }\end{array}$ & & $\mathrm{X}$ \\
\hline
\end{tabular}

Both associate professors discussed the Center for Faculty Innovation. The senior associate professor stated, “the Center Faculty Innovation Office [does] tons of workshops on all sorts of different things and in fact last year...they did a whole series of talks on assessment.” He elaborated, “[the series] focus[ed] on student learning and assessment [and] how to do that type of thing.”

The junior associate professor illustrated professional development through assessment fellowships and described the opportunity to serve as an assessment fellow with CARS over the summer months. He stated that the fellowship is "for people to work on an assessment project and get paid for it...” This associate professor also highlighted the assessment liaison from CARS that served on the assessment subcommittee and stated, “[the liaison] helps us walk things through when we are trying something brand-new.” One associate professor discussed support to attend the annual First-Year Experience Conference. He explained that his work with learning communities directly related to this conference.

\section{Faculty Satisfaction with Evaluations and Rewards Based on Student Assessment}

Data or Involvement. Each of the associate professors responded differently when queried about their satisfaction with evaluations and rewards based on student assessment 
data or involvement. The junior associate professor was content with the intrinsic satisfaction of participating in assessment activities (see Table 130).

However, the junior associate professor maintained that because assessment activities were valued within the department's culture "its easier for faculty to invest the time.” He further stated that the department had a broad definition of scholarship and cited the culture of assessment as a facilitator of the intrinsic value of associated activities.

Table 130

Evaluations and rewards based on student assessment data or involvement: Perceived strengths

\begin{tabular}{|l|l|c|}
\hline Factors & $\begin{array}{l}\text { Senior } \\
\text { Associate } \\
\text { Professor }\end{array}$ & $\begin{array}{l}\text { Junior } \\
\text { Associate } \\
\text { Professor }\end{array}$ \\
\hline Intrinsic Value & & X \\
\hline $\begin{array}{l}\text { Culture that } \\
\text { Values } \\
\text { Assessment }\end{array}$ & & X \\
\hline
\end{tabular}

The senior associate professor was concerned about the extrinsic rewards for the quantity of time invested in the assessment endeavor. He was "a little bit less satisfied [with evaluations and rewards based on student assessment data or involvement] than I have been with the other [items]. He elaborated by stating, my department head is very supportive of [assessment] but it is a lot of work and it's work that could be put forth into doing other things that may be more rewarded like writing a research grant would probably be more rewarded or working on a publication would probably be more rewarded.

The senior associate professor further stated, 
at the end of the day I don't know how much [assessment involvement] is factored into promotion and tenure decisions and so forth. They count as part of my service but I don't know if the weight of that is appropriate.

Faculty Satisfaction with the Use of Student Assessment Data in Making Academic Decisions. Both associate professors were satisfied with the use of student assessment data in academic decision making. The senior and junior associate professors indicated that assessment data was used frequently to guide academic decisions. The senior associate professor indicated that senior exit survey data was important in the decision making process. The junior associate professor noted the importance of student satisfaction survey data and ACAT data because this information was used in making academic decisions (see Table 131).

Table 131

Use of assessment data in making academic

decisions: Perceived strengths

\begin{tabular}{|l|l|c|}
\hline Factors & $\begin{array}{l}\text { Senior } \\
\text { Associate } \\
\text { Professor }\end{array}$ & $\begin{array}{l}\text { Junior } \\
\text { Associate } \\
\text { Professor }\end{array}$ \\
\hline $\begin{array}{l}\text { Student } \\
\text { Satisfaction } \\
\text { Survey Data }\end{array}$ & & $\mathrm{X}$ \\
\hline $\begin{array}{l}\text { Senior Exit } \\
\text { Survey Data }\end{array}$ & $\mathrm{X}$ & \\
\hline ACAT Data & & $\mathrm{X}$ \\
\hline
\end{tabular}

The senior associate professor noted a change in the number of opportunities students had to practice their writing skills. He explained that data from the senior exit survey supported the need to provide additional opportunities for students to practice this skill. As a result, the department chair encouraged faculty to add more writing assignments, 
reduce class size so that faculty had time to critique writing assignments, and instituted a writing assessment.

The junior associate professor noted the implementation of an advising initiative at the university level that was based on satisfaction data. The initiative was the result of relatively low scores within advising-based items from student satisfaction surveys. The junior associate professor also noted that ACAT data was utilized in the decision making process. Specifically, ACAT scores were correlated to course taking and course performance to identify weaknesses in student achievement and reasons that those weaknesses may exist. However, the junior associate professor noted his concern with high-stakes testing. He stated,

I think we do a fairly good job of using the assessment data that we have to inform decisions and changing the curriculum in changing opportunities for the students or finding new opportunities for students or new ways to advertise things.

Faculty Satisfaction with the Impact Student Assessment had on Their Program. Both of the associate professors were highly satisfied with the impact student assessment had on their program. The senior associate professor stated,

I’m very satisfied with that....as I mentioned before we could talk about it more as a department but time is really precious and there is only so much time in the day and there always seems to be more burning issues.

However, the junior associate professor again noted his concern with high-stakes testing. He further emphasized the need for credible measures of student achievement (see Table 132). 
Table 132

Impact student assessment has had on the program:

Perceived challenges

\begin{tabular}{|l|l|l|}
\hline Factors & $\begin{array}{l}\text { Senior } \\
\text { Associate } \\
\text { Professor }\end{array}$ & $\begin{array}{l}\text { Junior } \\
\text { Associate } \\
\text { Professor }\end{array}$ \\
\hline $\begin{array}{l}\text { Assessment } \\
\text { Results Not } \\
\text { Shared }\end{array}$ & $\mathrm{X}$ & \\
\hline $\begin{array}{l}\text { High-Stakes } \\
\text { Testing }\end{array}$ & & $\mathrm{X}$ \\
\hline $\begin{array}{l}\text { Credible } \\
\text { Measures of } \\
\text { Student } \\
\text { Achievement }\end{array}$ & & \\
\hline
\end{tabular}

Faculty Satisfaction Summary. Table 133 illustrates the frequency of themes across items related to strengths in assessment. The most frequently identified themes pertaining to assessment strengths were:

- culture that values assessment,

- $\quad$ support from central leaders,

- implementation of multiple assessment methods,

- assessment day,

- financial assistance from CARS,

- intellectual assistance from CARS,

- department chair support,

- center for faculty innovation,

- knowledge base of administrators,

- $\quad$ student participation, and 
- comprehensiveness of the assessment plan.

The department chair and senior and junior associate professors each identified a culture that values assessment as important factors influencing their satisfaction within the context of central leadership support. The junior associate professor also noted a culture that values assessment within program faculty leadership and evaluations and rewards based on student assessment data or involvement. Each of the participants identified central leadership support for assessment as important factors influencing their satisfaction with assessment. The department chair and both associate professors identified multiple assessment methods as an important factor within the context of the program's assessment plan. The institutional assessment leader identified assessment day as an important factor influencing her satisfaction with assessment while the senior associate professor noted the importance of assessment day during the implementation of the assessment plan. The senior and junior associate professors identified financial assistance from CARS, intellectual assistance from CARS, and the knowledge base of administrators as important factors influencing their satisfaction with central leadership support for assessment. The senior and junior associate professor identified department chair support as an important factor influencing their satisfaction with program faculty leadership support. The Center for Faculty Innovation was identified by both associate professors within the context of professional development for student assessment. 
Table 133

Frequency of theme emergence pertaining to strengths across items

\begin{tabular}{|c|c|c|c|c|}
\hline Factors & $\begin{array}{l}\text { Department } \\
\text { Chair }\end{array}$ & $\begin{array}{l}\text { Institutional } \\
\text { Assessment } \\
\text { Leader } \\
\end{array}$ & $\begin{array}{l}\text { Senior } \\
\text { Associate } \\
\text { Professor } \\
\end{array}$ & $\begin{array}{l}\text { Junior } \\
\text { Associate } \\
\text { Professor } \\
\end{array}$ \\
\hline $\begin{array}{l}\text { Culture that Values } \\
\text { Assessment }\end{array}$ & 1 & 0 & 1 & 3 \\
\hline $\begin{array}{l}\text { Support from } \\
\text { Central Leaders }\end{array}$ & 1 & 1 & 1 & 1 \\
\hline $\begin{array}{l}\text { Multiple } \\
\text { Assessment } \\
\text { Methods }\end{array}$ & 1 & 0 & 1 & 1 \\
\hline Assessment Day & 0 & 1 & 1 & 0 \\
\hline $\begin{array}{l}\text { Financial } \\
\text { Assistance from } \\
\text { CARS }\end{array}$ & 0 & 0 & 1 & 1 \\
\hline $\begin{array}{l}\text { Intellectual } \\
\text { Assistance from } \\
\text { CARS }\end{array}$ & 0 & 0 & 1 & 1 \\
\hline $\begin{array}{l}\text { Knowledge Base of } \\
\text { Administrators }\end{array}$ & 0 & 0 & 1 & 1 \\
\hline $\begin{array}{l}\text { Department Chair } \\
\text { Support }\end{array}$ & 0 & 0 & 1 & 1 \\
\hline $\begin{array}{l}\text { Center for Faculty } \\
\text { Innovation }\end{array}$ & 0 & 0 & 1 & 1 \\
\hline $\begin{array}{l}\text { Student } \\
\text { Participation }\end{array}$ & 0 & 1 & 1 & 0 \\
\hline $\begin{array}{l}\text { Comprehensiveness } \\
\text { of the Assessment } \\
\text { Plan }\end{array}$ & 1 & 0 & 0 & 1 \\
\hline $\begin{array}{l}\text { Creativity of } \\
\text { Faculty }\end{array}$ & 0 & 0 & 1 & 0 \\
\hline $\begin{array}{l}\text { Institutionalization } \\
\text { of Assessment }\end{array}$ & 0 & 0 & 0 & 1 \\
\hline $\begin{array}{l}\text { Continuous } \\
\text { Monitoring of } \\
\text { Assessment Data }\end{array}$ & 0 & 1 & 0 & 0 \\
\hline $\begin{array}{l}\text { Credible Evidence } \\
\text { of Learning }\end{array}$ & 0 & 1 & 0 & 0 \\
\hline $\begin{array}{l}\text { Communication } \\
\text { with CARS }\end{array}$ & 1 & 0 & 0 & 0 \\
\hline
\end{tabular}


Table 133

Frequency of theme emergence pertaining to strengths across items: Continued

\begin{tabular}{|c|c|c|c|c|}
\hline Factors & $\begin{array}{l}\text { Department } \\
\text { Chair }\end{array}$ & $\begin{array}{l}\text { Institutional } \\
\text { Assessment } \\
\text { Leader }\end{array}$ & $\begin{array}{l}\text { Senior } \\
\text { Associate } \\
\text { Professor }\end{array}$ & $\begin{array}{l}\text { Junior } \\
\text { Associate } \\
\text { Professor }\end{array}$ \\
\hline $\begin{array}{l}\text { Service to the } \\
\text { Assessment } \\
\text { Advisory } \\
\text { Committee }\end{array}$ & 0 & 1 & 0 & 0 \\
\hline $\begin{array}{l}\text { Department } \\
\text { Assessment } \\
\text { Subcommittee } \\
\text { Chair }\end{array}$ & 0 & 0 & 1 & 0 \\
\hline $\begin{array}{l}\text { Participation in the } \\
\text { Development of the } \\
\text { Motivational } \\
\text { Research Institute }\end{array}$ & 0 & 0 & 0 & 1 \\
\hline Realistic Directives & 1 & 0 & 0 & 0 \\
\hline $\begin{array}{l}\text { Faculty } \\
\text { Participation }\end{array}$ & 0 & 0 & 1 & 0 \\
\hline $\begin{array}{l}\text { Assessment } \\
\text { Fellowship from } \\
\text { CARS }\end{array}$ & 0 & 0 & 0 & 1 \\
\hline CARS Liaison & 0 & 0 & 0 & 1 \\
\hline $\begin{array}{l}\text { Conference } \\
\text { Support }\end{array}$ & 0 & 0 & 0 & 1 \\
\hline $\begin{array}{l}\text { Intrinsic Value of } \\
\text { Assessment }\end{array}$ & 0 & 0 & 0 & 1 \\
\hline $\begin{array}{l}\text { Student } \\
\text { Satisfaction Survey } \\
\text { Data }\end{array}$ & 0 & 0 & 0 & 1 \\
\hline $\begin{array}{l}\text { Senior Exit Survey } \\
\text { Data }\end{array}$ & 0 & 0 & 1 & 0 \\
\hline ACAT Data & 0 & 0 & 0 & 1 \\
\hline
\end{tabular}

The only theme related to perceived challenges and identified twice related to assessment data sharing (see Table 134). The senior associate professor referred to this factor within the context of the implementation of the current assessment plan and the impact student assessment had on the psychology program. 
Table 134

Frequency of theme emergence pertaining to challenges across items

\begin{tabular}{|l|c|c|c|c|}
\hline Factors & $\begin{array}{l}\text { Department } \\
\text { Chair }\end{array}$ & $\begin{array}{l}\text { Institutional } \\
\text { Assessment } \\
\text { Leader }\end{array}$ & $\begin{array}{l}\text { Senior } \\
\text { Associate } \\
\text { Professor }\end{array}$ & $\begin{array}{l}\text { Junior } \\
\text { Associate } \\
\text { Professor }\end{array}$ \\
\hline $\begin{array}{l}\text { Overabundance } \\
\text { of Data }\end{array}$ & 1 & 0 & 0 & 0 \\
\hline $\begin{array}{l}\text { Lack of } \\
\text { Analysis of } \\
\text { Data }\end{array}$ & 1 & 0 & 0 & 0 \\
\hline $\begin{array}{l}\text { Challenges } \\
\text { Developing } \\
\text { Writing } \\
\text { Assessments }\end{array}$ & 0 & 0 & 1 & 0 \\
\hline $\begin{array}{l}\text { Improve } \\
\text { Assessment } \\
\text { Methods } \\
\text { Related to } \\
\text { Socio-cultural } \\
\text { Awareness }\end{array}$ & 0 & 0 & 1 & 0 \\
\hline $\begin{array}{l}\text { Assessment } \\
\text { Results not } \\
\text { Shared }\end{array}$ & 0 & 0 & 0 & 1 \\
\hline $\begin{array}{l}\text { Lack of Value } \\
\text { in Promotion } \\
\text { and Tenure } \\
\text { Guidelines }\end{array}$ & 0 & 0 & 0 & 0 \\
\hline $\begin{array}{l}\text { High Stakes } \\
\text { Testing }\end{array}$ & 0 & 0 & 1 & 0 \\
\hline $\begin{array}{l}\text { Credible } \\
\text { Measures of } \\
\text { Student } \\
\text { Achievement }\end{array}$ & 0 & 0 & 0 & \\
\hline
\end{tabular}

Undergraduate Mathematics and Statistics Program

The Department of Mathematics and Statistics awarded a Bachelor of Arts Degree and a Bachelor of Science Degree in Mathematics and a Bachelor of Science in Statistics with tracks in Applied Statistics and Mathematical Statistics. The Department also offered a 
minor in both Mathematics and Statistics. According to the 2006 - 2007 university catalog,

The Department of Mathematics and Statistics provides a program of study in the mathematical sciences which meets the needs of a wide variety of students and makes a continuing contribution to the advancement of mathematical and statistical knowledge and its dissemination. The program provides opportunities for in-depth study that can lead to careers as mathematicians and statisticians in private and public sectors, teachers of mathematics, and further study in graduate school. The program provides support for the mathematical and statistical needs of students in the natural sciences, integrated sciences, social sciences, and professional and pre-professional programs. The program meets the general education needs of all students, providing an understanding of mathematical and statistical thinking and approaches to problem solving. We are committed to promoting mathematics and statistics as an art of human endeavor as well as a fundamental method of inquiry into the sciences and a vast array of other disciplines. We are committed to encouraging an attitude of appreciation and support for mathematics and statistics in current university students and, through them, the next generation of citizens. We are also committed to fostering an appreciation for the effective use of applied mathematics and statistics in connection with and support of other disciplines for those students majoring in other subjects.

According to the 2006 - 2007 university catalog, there were 36 full-time faculty consisting of 16 professors, seven associate professors, ten assistant professors, and three 
instructors. Interview data revealed that between 10 to fifteen part-time faculty actively teach within the Department. Students were primarily enrolled full-time within the Department of Mathematics and Statistics. Class sizes ranged between 15 to 35 students.

\section{Study Participants}

The researcher interviewed the department chair and one full professor. The department chair was in his eleventh year as a professor and chairperson at GU. He worked in higher education for 25 years. He purported to have a medium level of knowledge about student outcomes assessment. The chair claimed that his knowledge was “a bit dated” as the department had not participated in assessment related activities in the last five or six years. The chair had not attended any conferences that focused on student outcomes assessment; however, he had attended four conferences that included assessment sessions on the program in the past two years. He had not published any papers pertaining to student outcomes assessment in the past two years; however, he did publish a paper more than two years ago that contained assessment related topics.

The second participant, a full professor, was serving his thirtieth year at GU. He has worked in higher education for 35 or 40 years. The professor purported to be moderately knowledgeable about student outcomes assessment. He served as the coordinator for assessment in the Department of Mathematics and Statistics “for a number of years." He had not attended any conferences that focused on student outcomes assessment, nor, had he attended any conferences that included assessment sessions on the program in the past two years. The professor had not published any papers pertaining to student outcomes assessment in the past two years. 


\section{Characteristics of Effective Assessment Practice}

The researcher analyzed interview data and the 2006 Assessment Progress Template for Annual Academic Department Reporting to identify characteristics of effective practice. Additionally, the researcher evaluated the assessment plan to determine the degree to which its implementation demonstrated characteristics of effective practice.

Credible evidence of learning. The researcher analyzed various documents and interview responses to examine different components of the assessment plan that were intended to foster relevant learning and reliable assessment measures. Eighty-four outcomes based on six objectives were assessed in the Department of Mathematics and Statistics. These objectives included:

- develop an understanding of the logical structure and style of mathematics,

- develop ability to use mathematical tools to solve problems and to transfer this knowledge to analogous situations,

- develop computational skills,

- develop an understanding of the theory of calculus and algebraic structures,

- $\quad$ provide knowledge of the theory and application of statistics appropriate for (1) graduate work in statistics or (2) an entry level statistics position in business, industry, or government, and

- $\quad$ provide knowledge of the theory and application of statistics appropriate for (1) an entry level statistics position in business, industry, or government which requires collaboration with a statistician or (2) for graduate work in biomedical, social-behavioral and management sciences as well as education. 
Intended learning outcomes for the mathematics and statistics major spanned all six cognitive domains contained within Bloom’s Taxonomy (Anderson, et al., 2001). The outcomes were sharply skewed to the less sophisticated domains. Thirty-nine percent of the outcomes focused on the remember domain, four percent represented the understand domain, forty-two percent represented the apply domain, one percent represented the analyze domain, four percent represented the evaluate domain, and three percent represented the create domain (see Table 135). There were no outcomes representative of the affective domain. The majority of the outcomes were learner-centered and were clear, measurable, and directly related to the program's mission statement. However, some outcomes required detailed analysis to identify the appropriate related cognitive domain. Approximately, three outcomes were not included in this analysis since they were not learner-centered, clear, nor measurable.

Examples of the intended learning outcomes within the remember domain included:

- the concept of a vector space and subspace and

- the theory of maxima and minima of functions.

Table 135

Distribution of intended cognitive learning outcomes

\begin{tabular}{|c|c|c|}
\hline Cognitive Domain & N & $\%$ \\
\hline Create & 3 & 3 \\
\hline Evaluate & 4 & 4 \\
\hline Analyze & 1 & 1 \\
\hline Apply & 42 & 47 \\
\hline Understand & 4 & 4 \\
\hline Remember & 35 & 39 \\
\hline
\end{tabular}

An example of an intended learning outcome within the understand domain included:

- $\quad$ understand the concept of sampling variability and its relevance in inference. 
Examples of intended learning outcomes within the apply domain included:

- using differentiation to solve problems involving optimization and rates of change and

- using the principles of survey and experimental design for gathering data.

Examples of intended learning outcomes within the analyze domain included:

- organize data graphically and numerically and

- perform statistical interpretations of graphs and numerical summaries of data.

Examples of intended learning outcomes within the evaluate domain included:

- determine whether a given set of vectors forms a basis for a vector space and

- determine the matrix of a linear transformation relative to given bases.

Examples of intended learning outcomes within the create domain included:

- construct proofs of mathematical theorems using direct and indirect arguments and

- write a computer program in a high level computer language.

The Department of Mathematics and Statistics utilized multiple methods of assessment to measure student achievement. The department chair revealed that the primary method of assessment was "a set of questions that [were] embedded in the final exams.” This department did not utilize Assessment Day. Rather, faculty chose to embed items within class-based final examinations. According to the April 2005 Math Assessment Report, [embedded] questions are designed to assess the fundamental knowledge and skills portion of our program objectives. Class performance is measured against the score accepted for $\mathrm{C}$ level work and individual student performance is 
measured against an expected score determined by the grade the student makes in the course. The grade distribution of the students taking the examination is used to determine a weighting factor which is used to calculate an expected score for each embedded assessment question and for the course as a whole. This data is collected each semester and analyzed with regard to the overall class performance and relative to each student's performance.

Individual faculty could decide if they wanted to include or count the results of these items within the final course grade. However, the results of these items along with the course grade were reported for program assessment purposes. Program assessment leaders then analyzed the deviation between course embedded item results and course grades. The 2006 Assessment Progress Template revealed that placement examination data, success rates, and course evaluations were also utilized for assessment purposes.

Continuous Improvement. Interview respondents provided evidence to demonstrate program changes/improvements that were implemented based on assessment data. The department chair revealed that a departmental assessment committee was the main vehicle for discussing undergraduate assessment results. However, the assessment committee had been inactive for the past two years. The department chair claimed that "too many other things [have been] going on that tore away from the time that those folks could devote [to assessment activities].” Furthermore, he disclosed that a new assessment committee was convened during the 2006 - 2007 academic year. The committee of five faculty members will be "doing a revision of all [of] the questions and [they] will actually look at the whole assessment plan to see if they want to stick with it, add to it, or completely revise it.” 
When asked about the use of assessment data to continuously improve programs and services, the department chair stated, “assessment results will be looked at every year [and] they should be looked at by our assessment committee.” However, he reported that program coordinators in the department reviewed assessment results with him and identified areas that needed revision and discussed potential adjustments to improve the program.

According to the department chair, non-mathematics majors were previously required to complete a course in linear algebra or differential equations. However, the chair claimed that both courses were necessary in order for students "to look at things carefully.” Thus, the linear algebra course and differential equations course were merged into one required course of both major and non-major students. The 2006 Assessment Progress Template reveals another potential programmatic change. Placement examination data, success rates, course examinations, and common embedded examination items provided evidence to support the development of an advanced course in linear algebra for students in the Curriculum and Instruction and the pure mathematics programs.

Accountability to internal stakeholders. The department chair maintained that the primary vehicle utilized for accomplishing internal accountability was the Annual Report. He further reported that the Annual Report "[is] the primary thing that we [use] to communicate outside of the department about assessment results.” However, the assessment committee (when active) also provided a vehicle to demonstrate accountability to internal stakeholders. 
Ongoing assessment. The department chair highlighted that "embedded questions are used every semester and looked at every semester.” He reported that this was the primary means by which ongoing assessment was achieved. However, he qualified his response by stating, "we don't have the mechanism that we need to ensure that the assessment committee doesn't go sort of off the map with becoming too involved in other things.”

Ongoing Evaluation and Improvement. Interview data revealed that the assessment plan within the Department of Mathematics and Statistics did not contain a formal method to evaluate and improve the assessment plan itself. When asked about the ability of the assessment plan to facilitate ongoing evaluation and improvement, the department chair reported that "for the last six years it has not done that particularly well." He further stated that the department hoped to implement evaluation and improvement procedures during the Spring 2007 semester. He maintained that this component of the assessment plan will be considered during the review of the current plan.

When asked to describe their satisfaction with the program’s approach to student assessment, faculty purported to be moderately satisfied. The department chair and professor each identified strengths and challenges regarding the program's approach to assessment. They both reported that some assessments generated good data. The department chair maintained that "we have some procedures that can supply some useful information.” The professor further supported this notion by stating,

Each core course in the major has a built-in assessment component in the final examination and so it's possible to keep a running record of how majors in general are progressing through the major and that gives a pretty good picture of how well students in various core courses are meeting the goals and objectives for 
those courses so in that sense I think that's a good feature of our assessment system.

Even though faculty reported to be moderately satisfied with the program's assessment approach, there were some areas of concern (see Table 136). The department chair noted that the current assessment methods were "rather dated and we have not looked at them for some time.” Additionally, he noted that some faculty attempted to avoid assessment practices as it may interfere with their daily activities. He stated, “...a primary attitude a few years ago was [that assessment] is something that we have to do [so] we will put up something that won't interfere too much and maybe we'll get some help from it."

The professor also thought that the faculty "could do more with using the results of the assessments to modify and change the structure of our major.” He continued, we are in the process right now of remodeling or redesigning the core [program curriculum] for the major and I am hoping that the assessment data will play an important role in how that is done, but that remains to be seen.

Table 136

Assessment plan: Perceived challenges

\begin{tabular}{|l|c|c|}
\hline Factors & $\begin{array}{l}\text { Department } \\
\text { Chair }\end{array}$ & Professor \\
\hline $\begin{array}{l}\text { Outdated } \\
\text { Assessment } \\
\text { Activities }\end{array}$ & $\mathrm{X}$ & \\
\hline $\begin{array}{l}\text { Interference of } \\
\text { Assessment } \\
\text { Work with } \\
\text { Daily Activities }\end{array}$ & $\mathrm{X}$ & \\
\hline Utilize Results & & \\
\hline
\end{tabular}




\section{Institutional Commitments and Resources}

Commitments. University and program leaders demonstrated their commitment to assessment. When asked if the utilization of student assessment data was considered in evaluating and rewarding of faculty, the department chair reported that this information was not considered. Additionally, he reported that student assessment expertise would be considered in the hiring process for new faculty; however, “...[it] may be [considered] along with one hundred other things.” He further stated, “frankly we have never had a faculty search where that was one of the identified criteria that we were looking at...” However, he did claim that after an initial sorting of applications consideration may be given to

a kind of anamorphous category of what are the other contributions a person could make to the program and [assessment expertise] might be...one of a dozen things that this person could help with... and [that] might give them a little extra boost.

When queried about the policies and practices that facilitate the communication of student assessment purposes, the department chair reported that the communication of assessment purposes was currently not addressed. When asked about policies to promote the involvement of student affairs personnel and students in assessment efforts, he reported that no such policies exist. The chair stated that executive level support for student assessment was evident. The chair emphasized, “...if I need help with a faculty member who may need some support for [an] assessment activity or travel to a conference or something like that it's generally easy to find the support.” 
When asked to describe the culture of assessment within the mathematics and statistics program, the department chair felt as though the culture is "mixed." He justified his claim by stating, “we have some people who would be, I think, quite interested [and] enthusiastic [and] some [people] who would view [assessment] more as...a chore or something I have to do keep some administrators somewhere happy.” When queried about the articulation of guiding principles for assessment, the chair stated, “...I believe there are, but I could not tell you exactly where to find them.” Furthermore he stated, "I think maybe when we were going through this major development a number of years ago I could have probably told you that more specifically.” Additionally, the chair believed that a campus wide assessment committee has been established; however, he was not sure who served on the committee. When queried about the incorporation of outcomes assessment into the scholarship of teaching in promotion and tenure guidelines, he stated that there was nothing specific.

In summary, the significant commitments included:

- $\quad$ executive level support and

- a campus-wide assessment committee.

Resources. When asked to identify resources that were allocated to the Department of Mathematics and Statistics from the institution, the department chair reported that there was "nothing specifically for that." However, later in the interview he reported that the department utilized a liaison from CARS. He further stated, "we have worked with [the liaison] in the past in dealing with some of the questions and some of the procedures...about assessment.” Furthermore, he reported that no comprehensive student assessment information database was available. 
The department chair reported that faculty workshops on student assessment were offered. However, when queried about the availability of student assessment workshops the chair stated, "I would guess annually.” Support for faculty to attend professional conferences on student assessment was available. The chair stated, "if a faculty member is interested in a conference on assessment that would be the same as any other conference in the department. Generally we would support them if possible...” If the department did not have the resources to support the faculty, the chair maintained that the dean of the college, the dean of general education, or CARS would likely assist.

According to the department chair, internal consulting services for faculty on the use of student assessment in course design and instruction were available from CARS. He claimed, "if I call them they will return my phone calls, if I want to set up a meeting they would be happy to come over and meet with us.”

The department chair reported that he was unaware of any formal assistance from the university (in the form of paid leaves, stipends, mini-grants, or course reductions) for faculty to work on assessment activities. However, he did state,

I would guess if we had a situation and we wanted to set up a course release or something like that for someone who is interested in developing something new [with] assessment...I probably would be able to get the support either from the dean’s office of from somewhere else if I weren’t able to handle it internally.

According to the department chair, there were student assessment workshops for deans, department chairs, and other academic administrators. He estimated that these workshops were "probably [offered] once a year.” The chair was not aware of any student assessment workshops for student affairs staff and administrators. Furthermore, 
he reported that there was no specific annual budget allocated to academic units to support student assessment. However, he identified the CARS as the institutional assessment office. He further reported that no departmental assessment office existed and that there were no offices charged with coordinating data-gathering initiatives such as surveys and standardized tests. However, he reported that there "is certainly a procedure" to accomplish those tasks.

In summary, the significant resources available from the institution and identified by the department chair included:

- consulting services from CARS (liaison),

- avenues of financial support to attend assessment conferences,

- course releases,

- developmental workshops for administrators, and

- the institutional assessment office.

Faculty Satisfaction with Assessment and the Assessment Plan

Faculty satisfaction with program assessment was determined by analyzing interview data from two participants: (1) the department chair who is also a professor and (2) another professor of mathematics. The department chair leader was asked a sample of the items included on the Faculty Satisfaction Interview Protocol. These items were intended to gauge their satisfaction with implementation of the current assessment plan, opportunities to participate in policy making, and central leadership support for assessment. Only the professor was invited to respond to the items pertaining to faculty leadership support, professional development, evaluations and rewards, academic decision making, and the impact of student assessment on the program. 
Satisfaction with the Implementation of the Current Assessment Plan. The department chair and the professor were both satisfied with the implementation of the current assessment plan. The chair noted that the assessment program is "minimal in the amount it might interfere with other aspects of the program [by] having questions embedded in the final examinations as the primary [assessment] method.” He concluded that the current assessment plan is "under the surface” (see Table 137).

The professor supported the comments of the department chair. The professor claimed that the assessment plan was

relatively painless because the embedded questions in the final exam are available for each faculty member who's teaching the core course and they don't have to do anything except record the scores on those questions separately from the rest of the final examination.

He continued, “Therefore, I don't think the faculty find it a very onerous task to collect data that way."

Table 137

Implementation with the current assessment plan: Perceived strengths

\begin{tabular}{|l|c|c|}
\hline Factors & $\begin{array}{l}\text { Department } \\
\text { Chair }\end{array}$ & Professor \\
\hline $\begin{array}{l}\text { Minimal } \\
\text { Interference } \\
\text { with Teaching } \\
\text { and Learning }\end{array}$ & $\mathrm{X}$ & $\mathrm{X}$ \\
\hline $\begin{array}{l}\text { Course } \\
\text { Embedded } \\
\text { Assessment }\end{array}$ & $\mathrm{X}$ & $\mathrm{X}$ \\
\hline
\end{tabular}


Faculty Satisfaction with Participation in Assessment Decisions. The department chair and professor were satisfied with the opportunities they had to participate in policy making. The department chair stated, "I think those opportunities have been fine.” He noted his opportunities to "work directly with the folks in [CARS]" (see Table 138).

The professor reported that opportunities to participate in policy making have "been quite satisfactory.” He noted the democratic nature of the department. The professor stated,

we operate within the department pretty democratically and so if we are going to institute something it's usually initiated and approved by the faculty. The same thing is true with the assessment questions that we use and the method that they're administered...

He further claimed, "I would say people feel pretty free to have input either through the head of the department or the [departmental] assessment committee.” Additionally, he noted his service to the departmental assessment committee as a reason for his positive degree of satisfaction.

Table 138

Participation in assessment decisions: Perceived

strengths

\begin{tabular}{|l|l|c|}
\hline Factors & $\begin{array}{l}\text { Department } \\
\text { Chair }\end{array}$ & Professor \\
\hline CARS & \multicolumn{1}{|c|}{ X } & \\
\hline Democratic & & X \\
Nature of the & & \\
Department & & X \\
\hline $\begin{array}{l}\text { Department } \\
\text { Assessment } \\
\text { Subcommittee }\end{array}$ & & \\
\hline
\end{tabular}


Faculty Satisfaction with Central Leadership Support for Assessment. The department chair and the professor were satisfied with the central leadership support for student assessment. However, their degrees of satisfaction varied.

The department chair stated that central leadership support for assessment "has been fine.” He maintained that the support for travel to assessment related conference has been helpful (see Table 139). The chair further noted release time for a faculty member from the dean's office.

The professor reported that central leadership support for assessment was "excellent.” The professor emphasized the support of administrators with regard to assessment plan development. He stated,

[they] have been willing to come and help us with setting up things, interpreting data if necessary, encouraging report writing that addressed feedback and goals and objectives and clarification of what we ought to be doing. I think that there has been an unusually strong central administration focus and assistance on assessment at this school.

Table 139

Central leadership support for assessment:

Perceived strengths

\begin{tabular}{|l|c|c|}
\hline Factors & $\begin{array}{l}\text { Department } \\
\text { Chair }\end{array}$ & Professor \\
\hline $\begin{array}{l}\text { Conference } \\
\text { Support }\end{array}$ & $\mathrm{X}$ & \\
\hline $\begin{array}{l}\text { Faculty Release } \\
\text { Time }\end{array}$ & $\mathrm{X}$ & \\
\hline $\begin{array}{l}\text { Support from } \\
\text { Central Leaders }\end{array}$ & & $\mathrm{X}$ \\
\hline
\end{tabular}


Faculty Satisfaction with Program Faculty Leadership Support. The professor reported to be satisfied with program faculty leadership support for assessment. The professor reported that faculty are happy to go along with [assessment] but I would not describe faculty as enthusiastic assessors. They feel that they are assessing within the individual courses that they teach through their tests and exams and quizzes and so on and this external layer of assessment, while it's good for the total program, I don't think faculty are particularly enamored of engaging in that activity.

He maintained that the leadership within the department could be more dynamic. He further stated that he would like to see "more emphasis on the results of assessment [and] more sharing of how things are proceeding so that as we work through curricular changes we can better utilize what we know about our program” (see Table 140).

Table 140

Program faculty leadership support

for assessment: Perceived challenges

\begin{tabular}{|l|c|}
\hline Factors & Professor \\
\hline $\begin{array}{l}\text { Departmental } \\
\text { Leadership }\end{array}$ & $\mathrm{X}$ \\
\hline $\begin{array}{l}\text { Use of } \\
\text { Assessment } \\
\text { Results }\end{array}$ & $\mathrm{X}$ \\
\hline $\begin{array}{l}\text { Assessment } \\
\text { Results not } \\
\text { Discussed }\end{array}$ & $\mathrm{X}$ \\
\hline
\end{tabular}

Faculty Satisfaction with Professional Development for Student Assessment. The professor reported to be satisfied with professional development for student assessment. He stated that there were many opportunities to attend professional develop activities (see 
Table 141). The professor elaborated on opportunities that existed within the department as well interdisciplinary events. He stated, "there are just numerous cases not only within the department [but] also other interdisciplinary things.” The professor noted the possibility to be involved with various teams of faculty within the university that address issues pertinent to student attitudes and/or academic endeavors. Additionally, he noted the assessment fellowships offered by CARS. He explained that a workshop about developing student satisfaction questionnaires was an event that a fellow may attend. Table 141

Professional development for student assessment: Perceived strengths

\begin{tabular}{|l|c|}
\hline Factors & Professor \\
\hline $\begin{array}{l}\text { Developmental } \\
\text { Workshops }\end{array}$ & $\mathrm{X}$ \\
\hline $\begin{array}{l}\text { Working with } \\
\text { Various Teams }\end{array}$ & $\mathrm{X}$ \\
\hline $\begin{array}{l}\text { Assessment } \\
\text { Fellowship } \\
\text { from CARS }\end{array}$ & $\mathrm{X}$ \\
\hline
\end{tabular}

\section{Faculty Satisfaction with Evaluations and Rewards Based on Student Assessment}

Data or Involvement. The professor reported to be satisfied when with evaluations and rewards based on student assessment data or involvement. When asked to consider how a publication pertaining to outcomes assessment may be considered for evaluation and rewards, the professor noted the importance of service in the review process. He stated, “service is an important component of what's looked at for promotion and tenure and certainly anything you did like that would be counted as service. Whether it would be 
counted as an academic pursuit...I'm not sure.” He concluded by stating, “I would think you would receive a favorable nod.”

Faculty Satisfaction with the Use of Student Assessment Data in Making Academic Decisions. The professor reported to be less satisfied with the use of student assessment data in making academic decisions. The professor indicated that assessment data is "only moderately well used” to guide academic decisions. He maintained that the data could be used more effectively. However, he offered no illustrations pertaining to a more effective use of assessment data in academic decision making.

Faculty Satisfaction with the Impact Student Assessment had on Their Program. The professor reported to be satisfied with the good impact student assessment had on his program. He qualified his statement by claiming, “[it] could be better and [it] should be better.” He did not offer any illustrations pertaining to the impact student assessment had on the program.

Faculty Satisfaction Summary. Table 142 illustrates the frequencies of themes across items related to satisfaction with assessment. The professor was asked an extra subset of questions related to satisfaction. The only theme identified twice pertaining to assessment strengths was the use of course-embedded assessments. The department chair and the professor identified course-embedded assessments as important factors influencing their satisfaction with the implementation of the assessment plan. 
Table 142

Frequency of theme emergence pertaining to strengths across items

\begin{tabular}{|c|c|c|}
\hline Factors & $\begin{array}{l}\text { Department } \\
\text { Chair }\end{array}$ & Professor \\
\hline $\begin{array}{l}\text { Course } \\
\text { Embedded } \\
\text { Assessment }\end{array}$ & 1 & 1 \\
\hline $\begin{array}{l}\text { Generation of } \\
\text { Useful } \\
\text { Information }\end{array}$ & 1 & 0 \\
\hline $\begin{array}{l}\text { Minimal } \\
\text { Interference } \\
\text { with Teaching } \\
\text { and Learning }\end{array}$ & 1 & 0 \\
\hline CARS & 1 & 0 \\
\hline $\begin{array}{l}\text { Democratic } \\
\text { Nature of the } \\
\text { Department }\end{array}$ & 0 & 1 \\
\hline $\begin{array}{l}\text { Service to the } \\
\text { Departmental } \\
\text { Assessment } \\
\text { Committee }\end{array}$ & 0 & 1 \\
\hline $\begin{array}{l}\text { Conference } \\
\text { Support }\end{array}$ & 1 & 0 \\
\hline $\begin{array}{l}\text { Faculty Release } \\
\text { Time }\end{array}$ & 1 & 0 \\
\hline $\begin{array}{l}\text { Support from } \\
\text { Central Leaders }\end{array}$ & 0 & 1 \\
\hline $\begin{array}{l}\text { Faculty } \\
\text { Participation }\end{array}$ & 0 & 1 \\
\hline $\begin{array}{l}\text { Developmental } \\
\text { Workshops }\end{array}$ & 0 & 1 \\
\hline $\begin{array}{l}\text { Teams } \\
\text { Associated with } \\
\text { Student } \\
\text { Attitudes or } \\
\text { Academic } \\
\text { Endeavors }\end{array}$ & 0 & 1 \\
\hline $\begin{array}{l}\text { Assessment } \\
\text { Fellowship } \\
\text { from CARS }\end{array}$ & 0 & 1 \\
\hline
\end{tabular}


Table 142

Frequency of theme emergence pertaining to strengths across items

\begin{tabular}{|l|l|c|}
\hline Factors & $\begin{array}{l}\text { Department } \\
\text { Chair }\end{array}$ & Professor \\
\hline $\begin{array}{l}\text { Counts Toward } \\
\text { Service }\end{array}$ & 0 & 1 \\
\hline
\end{tabular}

The only theme identified twice was the challenge of using assessment data (see Table 143). The department chair referred to the need for program faculty to more effectively utilize assessment data within the context of the program's faculty leadership support and the use of assessment data in academic decision making.

Table 143

Frequency of theme emergence pertaining to challenges across items

\begin{tabular}{|l|c|c|}
\hline Factors & $\begin{array}{l}\text { Department } \\
\text { Chair }\end{array}$ & Professor \\
\hline $\begin{array}{l}\text { Use of } \\
\text { Assessment } \\
\text { Data }\end{array}$ & 0 & 2 \\
\hline $\begin{array}{l}\text { Departmental } \\
\text { Leadership }\end{array}$ & 0 & 1 \\
\hline $\begin{array}{l}\text { Share } \\
\text { Assessment } \\
\text { Data }\end{array}$ & 0 & 1 \\
\hline $\begin{array}{l}\text { Out-Dated } \\
\text { Assessment } \\
\text { Activities }\end{array}$ & 1 & 0 \\
\hline $\begin{array}{l}\text { Interference of } \\
\text { Assessment } \\
\text { Work with } \\
\text { Daily Activities }\end{array}$ & 1 & 0 \\
\hline
\end{tabular}




\section{Undergraduate Biology Program}

The Department of Biology awarded a Bachelor of Arts Degree and a Bachelor of Science Degree with a concentration in Clinical Lab Science. Additionally, the Department offered a Bachelor of Science in Biotechnology in conjunction with the Department of Integrated Science and Technology. The Department facilitated a dual degree curriculum with forestry and offers minors in biochemistry and molecular biology as well as general biology. According to the 2006 - 2007 university catalog,

The Department of Biology holds as its primary core value a commitment to providing superlative teaching for students. To accomplish this mission, we will create an environment for learning that will include opportunities for undergraduate research, a broadly based academic program, a supportive, diverse and collaborative faculty, an understanding of the process of science, and a recognition of the importance of community outreach and involvement.

According to the University's 2006 - 2007 catalog, there were 28 full-time faculty consisting of ten professors, 16 associate professors, 11 assistant professors, and one instructor. Interview data revealed that there were 15 part-time faculty active within the Department. Students were primarily enrolled full-time within the Department of Biology. Class sizes ranged between 60 to 120 students.

\section{Study Participants}

The researcher interviewed the department chair and an assistant professor. The department chair was in her fifth year as an associate professor at GU and was serving her third year as the chairperson. She had worked in higher education for 14 years. She purported to be moderately knowledgeable about student outcomes assessment. The 
department chair cited her experience as a teacher and administrator as well as attendance at assessment related workshops as important to her development of assessment expertise. The department chair had not attended any conferences that focused on student outcomes assessment; however, she had attended two or three conferences that included assessment sessions on the program in the past two years. She had not published any papers pertaining to student outcomes assessment in the past two years.

The second participant, an assistant professor, was serving his third year at GU. He thought he lacked knowledge about student outcomes assessment. However, he did claim to be "learning as [he] go[es]." The development of his knowledge about outcomes assessment was gained primarily though working with other faculty members. The assistant professor had not attended any conferences that focused on student outcomes assessment; nor, had he attended any conferences that included assessment sessions on the program in the past two years. He had not published any papers pertaining to student outcomes assessment in the past two years.

\section{Characteristics of Effective Assessment Practice}

The researcher analyzed interview data and the 2006 Biology Assessment Progress Template to identify characteristics of effective practice. Additionally, the researcher evaluated the biology assessment plan to determine the degree to which its implementation demonstrates characteristics of effective practice.

Credible evidence of learning. Documents and interview respondents illustrated various components of the assessment plan that ensured that learning was relevant and assessment measures were reliable. Faculty articulated 28 statements based on content, experiences, and skills that were assessed. However, the content and experience 
statements were not learner-centered nor measurable. These statements were not considered learning outcomes because they did not state what students should know and be able to do as a result of their program.

Five of the six intended learning outcomes were clear and measurable. All six cognitive outcomes were in the application category and directly related to the program's mission statement.

Examples of the intended learning outcomes within the apply domain included:

- use mathematics to understand biological phenomena and

- use technology to gather data.

The Department of Biology utilized multiple methods of assessment to measure student achievement. The department chair revealed that the primary method of assessment "is a set of questions that are embedded in the final exams...” The Department of Biology utilized Assessment Day to conduct student learning and satisfaction assessments. The department chair reported that a content test was administered during the senior year for biology majors. The 2006 Assessment Progress Template revealed that the Majors Level Achievement Test developed by Educational Testing Services was utilized to assess content area objectives. Experience and skills objectives were assessed by utilizing two locally developed assessment instruments. According to the 2006 Assessment Progress Template, the Academic Sills Inventory (ASI) was used to "explore the students' perspective of the skills they have acquired during their undergraduate training.” The second assessment instrument utilized to assess experience and skills objectives was the Natural World Examination (NWE). According to the 2006 Assessment Progress Template, “The NWE is designed to assess quantitative 
reasoning and scientific logic skills.” In addition, the department chair revealed that focus groups were conducted to ascertain satisfaction data.

Continuous Improvement. Interview respondents and the 2006 Biology Assessment Progress Template did not provide evidence to support that program changes and improvements were implemented by the faculty. When asked about the use of assessment data to continuously improve programs and services, the department chair stated, “... [it occurs] haphazardly at this point until we get a real handle on the curriculum.” However, she reported that the department has "used all of [their] informal and formal assessment procedures to look at...individual courses [and] satisfaction.” She maintained that assessment based discussions will be more formal in the future. According to the 2006 Biology Assessment Progress Template, We are still in the process of evaluating [ASI and NWE] results. Given that some of our graduating seniors also took this exam when they entered as freshmen, we should be able to draw conclusions regarding the impact of our program on their skill level.

Furthermore, the 2006 Biology Assessment Progress Template revealed that "plans to use the assessment data are being formulated by one of the departmental curriculum committees.”

The department chair revealed that department faculty did not discuss assessment results frequently enough. She reported that "last year’s graduating class completed a new curriculum and so this is our year to really assess that curriculum..." However, she claimed that informal discussions between faculty members occurred frequently. 
Accountability to internal stakeholders. The department chair maintained that assessment results were available to the entire faculty. She further reported that the combination of "numbers and prose" help to demonstrate accountability.

Ongoing assessment. The department chair highlighted that assessment occurred yearly. She stated, “if you have a campus that says there is an assessment day and you're going to [conduct assessments], then that is not episodic.” The department chair also predicated her response on institutional assessment. She purported, "we have a whole department of assessment and we've got a graduate program in assessment, so I don’t think there is any worry that this is episodic.”

Ongoing Evaluation and Improvement. Interview data revealed that the assessment plan within the Department of Biology did not contain a formal method to evaluate and improve the assessment plan itself. When asked if the faculty regularly evaluated and improved the assessment plan, the department chair responded, “I don’t know [how this occurs].” Furthermore, there were no indications of a formal ongoing evaluation and improvement strategy throughout the interview. However, faculty were currently adopting an assessment plan to complement a recently implemented biology curriculum. The department chair and assistant professor each reported to be satisfied with the program's approach to assessment. The department chair stated, "we are expanding [our assessment activities] to include our undergraduate research and we are trying to assess transfer students success in a separate way” (see Table 144). However, the department chair reported that she would like to see "more done with the data." When asked to describe the ways in which she would like to see assessment data utilized, she reported, 
"that's the problem...the [program assessment leader] wants me to tell her what data to give me and I want the [program assessment leader] to figure out what data to give me.” Table 144

Assessment plan: Perceived strengths

\begin{tabular}{|l|l|c|}
\hline Factors & $\begin{array}{l}\text { Department } \\
\text { Chair }\end{array}$ & $\begin{array}{l}\text { Assistant } \\
\text { Professor }\end{array}$ \\
\hline $\begin{array}{l}\text { Faculty } \\
\text { Participation }\end{array}$ & & $\mathrm{X}$ \\
\hline $\begin{array}{l}\text { Expansion of } \\
\text { the Assessment }\end{array}$ & & \\
$\begin{array}{l}\text { Plan to Include } \\
\text { Undergraduate } \\
\text { Research }\end{array}$ & $\quad \mathrm{X}$ & \\
\hline $\begin{array}{l}\text { Assess Transfer } \\
\text { Students }\end{array}$ & $\mathrm{X}$ & \\
\hline
\end{tabular}

The assistant professor noted that the faculty were "working hard to at least get quantifiable data that will justify our change in curriculum." He purported, "I think there is room for improvement.” The assistant professor continued,

I deal mainly with the major field assessment and so that is what I'm most familiar with and I know that whoever puts out the major field assessment is very protective of their data...so we get data that we can use although the data is not mapped to individual questions...it is mapped to blocks of questions (see Table 145).

He concluded, "I think access to the whole bank of student answers would be advantageous." 
Table 145

Assessment plan: Perceived challenges

\begin{tabular}{|l|l|l|}
\hline Factors & $\begin{array}{l}\text { Department } \\
\text { Chair }\end{array}$ & $\begin{array}{l}\text { Assistant } \\
\text { Professor }\end{array}$ \\
\hline $\begin{array}{l}\text { Underutilized } \\
\text { Assessment } \\
\text { Data }\end{array}$ & X & \\
\hline Alignment of & & \\
Items Included & & \\
in & & \\
Commercially & & \\
Developed & & \\
Assessments to & & \\
Program & & \\
Outcomes & & \\
\hline
\end{tabular}

\section{Institutional Commitments and Resources}

Commitments. University and program leaders demonstrated their commitment to assessment. When asked if the utilization of student assessment data was considered in evaluating and rewarding faculty members, the department chair reported that "student evaluations for individual courses [do] matter.” When asked if student evaluations included items that required students to self-report how well they believe they achieved specific outcomes, she reported that they did not. However, the department chair expressed a desire to modify the course evaluations. She reported that student assessment expertise was not specifically considered in the hiring process for new faculty. She further stated, “you always listen for buzz words...so that if someone indicates [they] understand something about pedagogy, something about writing a syllabus, something about getting feedback...but that wouldn't be the deal breaker.” When asked if assessment expertise would be one of many factors considered in the hiring process, the department chair affirmed that it would be considered. 
When queried about the policies and practices that facilitate the communication of student assessment purposes, the department chair maintained "I don't think we are that far along.” She noted that students were made aware of assessment day requirements. When asked about policies to promote the involvement of student affairs personnel and students in assessment efforts, the department chair reported that she has "no idea" if such policies exist. However, she reported, “although [student affairs assessment] interests me...I don't have a lot of hands on [participation] with it.” The department chair stated that executive level support for student assessment is evident. She stated, "there is a faculty development program here that is blessed by the provost and they have funding.”

When asked to describe the culture of assessment within the biology program, the department chair reported, “nobody says why are we doing [assessment] and they accept my rationales...” She justified her claim by stating, "I think most people realize GU is ahead of the curve on assessment and therefore we are sort of stars on [assessment] and people just accept it as part of what we do.” When queried about the articulation of guiding principles for assessment, the chair stated, “it might be a good thing, but I don’t think we have [guiding principles].” Additionally, the department chair believed that a campus wide assessment committee had been established; however, she was uncertain of her response. She noted, "I think I can assume that there is because this entire campus shuts down for the day so that has to have broad representation.” When queried about the incorporation of outcomes assessment into the scholarship of teaching in promotion and tenure guidelines, the department chair stated, “that's a tricky question.” She reported 
that assessment activities were included within promotion and tenure guidelines formally and/or informally. She noted that these guidelines were recently revised.

In summary, significant commitments included:

- $\quad$ executive level support,

- a culture that values assessment,

- a campus-wide assessment committee, and

- consideration of assessment activities within promotion and tenure guidelines.

Resources. When asked to identify resources that are allocated to the Department of Biology from the institution, the department chair reported that one associate biology professor was utilized half-time by the biology department and half-time by the Center for Faculty Innovation to focus on assessment. In order to focus on assessment, the associate professor received a course load reduction. Additionally, she reported the availability of assessment liaisons from CARS. Furthermore, she reported that no comprehensive student assessment information database was available.

The department chair reported that faculty workshops on student assessment were offered approximately twice a year. Support for faculty to attend professional conferences on student assessment was available. She stated, "I wouldn't say that there is a specific line for that but there is support for people doing different kinds of things and assessment would be included.” She illustrated this by stating that the Provost's Office recently supported her to attend a Project Kaleidoscope off-campus developmental workshop based on assessment. Additionally, the chair affirmed that enough assistance would be available to support attending a conference about assessment annually. 
According to the department chair, internal consulting services for faculty on the use of student assessment in course design and instruction were very available from CARS. Additionally, the chair reported that the Department of Biology also had funding available within their own budget and/or foundation funds to support external consultants.

According to the department chair, there were no student assessment workshops for deans, department chairs, other academic administrators, student affairs staff or student affairs administrators. Furthermore, she reported that there was no specific annual budget allocated to academic units to support student assessment. The department chair reported that there was an institutional assessment office (CARS) and that no departmental assessment office exists. She indicated that there was an office charged with coordinating data-gathering initiatives such as surveys and standardized tests and maintained that support was available to develop and implement online surveys. However, she did not indicate the specific office that was charged with these duties.

In summary, the significant resources available from the institution and identified by the department chair included:

- course load reduction,

- consulting services from CARS (liaison),

- faculty development workshops,

- financial support to attend assessment conferences,

- external consulting services,

- institutional assessment office (CARS),

- office charged with data gathering initiatives, and 
- $\quad$ access to online survey software.

Faculty Satisfaction with Assessment and the Assessment Plan

Faculty satisfaction with program assessment was determined by analyzing interview data from two participants: (1) the department chair who is also an associate professor and (2) an assistant professor of biology. The department chair was asked a sample of the items included on the Faculty Satisfaction Interview Protocol. These items elicited information regarding their satisfaction with the implementation of the current assessment plan, opportunities to participate in policy making, and central leadership support for assessment. Only the assistant professor was invited to respond to items pertaining to faculty leadership support, professional development, evaluations and rewards, academic decision making, and the impact of student assessment on the program.

Satisfaction with the Implementation of the Current Assessment Plan. Both participants were satisfied with the implementation of the current assessment plan. The department chair noted that "faculty...come around.” She acknowledged that some recent assessments relating to the biology courses and general education generated participation from the entire faculty. The department chair concluded "I [am] happy with their participation.”

The assistant professor also noted that the faculty were willing to participate in assessment activities. The assistant professor concluded, "so far so good.”

Faculty Satisfaction with Opportunities to Participate in Assessment Decisions. The department chair purported to be satisfied with the opportunities she had to participate in policy making. She stated, "I haven’t had any...not in a big way.” The department chair 
noted that she was involved with program assessment activities, but that she had not evaluated assessment instruments.

The assistant professor reported that he had not sought out opportunities to participate in policy making. Thus, he remained neutral about his satisfaction in this arena. However, he did note that he had access to CARS through his work with the CARS liaison.

Faculty Satisfaction with Central Leadership Support for Assessment. The department chair and the assistant professor were satisfied with the central leadership support for student assessment. However, their degrees of satisfaction varied. The department chair stated that central leadership support for assessment was "great." She reported that if an individual contacts CARS, assistance with assessment endeavors is "a matter of days away” (see Table 146).

The assistant professor reported that central leadership support for assessment is “fine.” The assistant professor stated, “I have not seen [central leadership support for assessment] and that is my own limitation.” However, he acknowledged the relationship between the department and CARS.

Table 146

Central leadership support for assessment: Perceived strengths

\begin{tabular}{|l|l|l|}
\hline Factors & $\begin{array}{l}\text { Department } \\
\text { Chair }\end{array}$ & $\begin{array}{l}\text { Assistant } \\
\text { Professor }\end{array}$ \\
\hline Assistance with & & \\
Assessment & & \\
Endeavors & $\mathrm{X}$ & \\
Immediately & & \\
Available & & \\
\hline
\end{tabular}


Table 146

Central leadership support for assessment: Perceived

Strengths continued

\begin{tabular}{|l|l|c|}
\hline Factors & $\begin{array}{l}\text { Department } \\
\text { Chair }\end{array}$ & $\begin{array}{l}\text { Assistant } \\
\text { Professor }\end{array}$ \\
\hline Internal & & \\
Consulting & & $\mathrm{X}$ \\
Services from & & \\
CARS & & \\
\hline
\end{tabular}

Faculty Satisfaction with Program Faculty Leadership Support. The assistant professor reported that his satisfaction with program faculty leadership support was excellent. He maintained that, We have a strong leader...our assessment committee chair is very motivated, very organized, and has a plan. She is very clear about communicating that plan and is very good about delegating responsibilities and keeping up with the people that are in charge of doing those directives.

Faculty Satisfaction with Professional Development for Student Assessment. When queried about the opportunities to participate in professional development activities the assistant professor stated, "I can not answer that question.” However, he placed responsibility on himself for not seeking out developmental opportunities. He noted the possibility of becoming an assessment fellow with CARS.

Faculty Satisfaction with Evaluations and Rewards Based on Student Assessment Data or Involvement. The assistant professor reported that the department might be moving in a direction that would enable it to offer rewards based on student assessment involvement. However, he further noted that assessment was included within service 
activities. Thus, he maintained that participation in assessment related activities was "part of the job description."

Faculty Satisfaction with the Use of Student Assessment Data in Making Academic Decisions. The assistant professor reported that the department was not able to utilize assessment data for academic decision making. He maintained that a recent switch to a new curriculum prevented department leaders from using assessment data in making academic decisions. The assistant professor affirmed that the department has a vision to utilize assessment data for academic decision making purposes in the future.

Faculty Satisfaction with the Impact Student Assessment had on Their Program. The assistant professor stated that he did not know the degree to which student assessment impacted the biology program. He again noted that the switch to a new biology curriculum prevented the use of assessment data for various purposes.

Faculty Satisfaction Summary. Table 147 illustrates the frequencies of themes across items related to satisfaction with assessment. The assistant professor was asked an extra subset of questions related to satisfaction and those results are included in Table 147. The most frequently identified theme pertaining to assessment strengths was faculty participation. The department chair and the professor each made one reference to faculty participation within the context of the program's implementation of the assessment plan. The assistant professor again noted faculty participation within the context of the program's approach to assessment. Internal consulting services from CARS were identified by the assistant professor within the context of participation in policy making and central leadership support for assessment. 
Table 147

Frequency of theme emergence pertaining to strengths

across items

\begin{tabular}{|c|c|c|}
\hline Factors & $\begin{array}{l}\text { Department } \\
\text { Chair }\end{array}$ & $\begin{array}{l}\text { Assistant } \\
\text { Professor }\end{array}$ \\
\hline $\begin{array}{l}\text { Faculty } \\
\text { Participation }\end{array}$ & 1 & 2 \\
\hline $\begin{array}{l}\text { Internal } \\
\text { Consulting } \\
\text { Services from } \\
\text { CARS }\end{array}$ & 0 & 2 \\
\hline $\begin{array}{l}\text { Expansion of } \\
\text { the Assessment } \\
\text { Plan to Include } \\
\text { Undergraduate } \\
\text { Research }\end{array}$ & 1 & 0 \\
\hline $\begin{array}{l}\text { Assess Transfer } \\
\text { Students }\end{array}$ & 1 & 0 \\
\hline $\begin{array}{l}\text { Assistance with } \\
\text { Assessment } \\
\text { Endeavors } \\
\text { Immediately } \\
\text { Available }\end{array}$ & 1 & 0 \\
\hline $\begin{array}{l}\text { Effective } \\
\text { Program } \\
\text { Leadership }\end{array}$ & 0 & 1 \\
\hline $\begin{array}{l}\text { Assessment } \\
\text { Fellowship } \\
\text { from CARS }\end{array}$ & 0 & 1 \\
\hline $\begin{array}{l}\text { Assessment } \\
\text { Counts } \\
\text { Towards } \\
\text { Service }\end{array}$ & 0 & 1 \\
\hline
\end{tabular}

The only assessment challenge identified twice within the biology department was the implementation of a new curriculum (see Table 148). The assistant professor discussed this issue within the context of using student assessment data in making academic 
decisions and within the context of the impact student assessment had on the biology program.

Table 148

Frequency of theme emergence pertaining to challenges across items

\begin{tabular}{|l|c|c|}
\hline Factors & $\begin{array}{l}\text { Department } \\
\text { Chair }\end{array}$ & $\begin{array}{l}\text { Assistant } \\
\text { Professor }\end{array}$ \\
\hline $\begin{array}{l}\text { Implementation } \\
\text { of a New } \\
\text { Curriculum }\end{array}$ & 0 & 2 \\
\hline $\begin{array}{l}\text { Underutilized } \\
\text { Assessment } \\
\text { Data }\end{array}$ & 1 & 0 \\
\hline $\begin{array}{l}\text { Alignment of } \\
\text { Items Included } \\
\text { in } \\
\text { Commercially } \\
\text { Developed } \\
\text { Assessments to } \\
\text { Program } \\
\text { Outcomes }\end{array}$ & & \\
\hline
\end{tabular}

\section{Undergraduate Nursing Program}

The Department of Nursing awarded a Bachelor of Science Degree in Nursing with an optional concentration in behavior analysis. According to the University’s 2006 - 2007 catalog,

The primary mission of the nursing department is to provide quality, professional undergraduate and graduate nursing education that prepares nursing leaders to influence a changing profession, society, health care system, and global health needs.

According to the University’s 2006 - 2007 catalog, there were 13 full-time faculty consisting of two professors, four associate professors, two assistant professors, and five 
instructors. The University’s 2006 - 2007 catalog also listed six part-time faculty. Students were primarily enrolled full-time within the Department of Nursing. Class sizes ranged between 12 to 300 students.

\section{Study Participants}

The researcher conducted interviews with the department chair, an associate professor that also served as the Bachelor of Science in Nursing (B. S. N.) program coordinator, and an assistant professor. The department chair was serving her eighth year as the chairperson. She had worked in higher education for approximately 18 years. The department chair purported to be fairly knowledgeable about student outcomes assessment. She maintained that "nursing programs typically do a fair amount of student assessment and they do it fairly systematically.” The department chair further claimed, "because of our accreditation requirements...we are preparing students to practice a profession...we are looking for pretty tangible outcomes.” She had not attended any conferences that focused on student outcomes assessment; however, she had attended one conference that included assessment sessions within the program in the past two years. She had not published any papers pertaining to student outcomes assessment in past two years, nor had she presented assessment results at any conferences.

The second participant was serving her first year as the B. S. N. program coordinator at GU and was an associate professor for the last eight years. She purported to be moderately knowledgeable about student outcomes assessment. The assistant professor reported to "have worked with [assessment] some in the past" and that a "focus" of her Ph.D. program was based on curriculum development and program evaluation. She had not attended any conferences that focused on student outcomes assessment; however, she 
had attended two conferences that included assessment sessions on the program in the past two years. The associate professor had not published any papers pertaining to student outcomes assessment in the past two years.

The third participant was an assistant professor completing her fourth year at GU. She had worked in higher education for approximately nine years. She reported that assessment had been an “ongoing learning experience.” The assistant professor further reported that some of the classes included within her master's degree curriculum and electives completed at the doctoral level pertained to student learning outcomes assessment. Additionally, she cited her collaboration with other faculty and professional development opportunities as important experiences in the development of her knowledge of outcomes assessment. The assistant professor had not attended any conferences that focused on student outcomes assessment, nor, had she attended any conferences that included assessment sessions on the program in the past two years. She had not published any papers pertaining to student outcomes assessment in the past two years.

Characteristics of Effective Assessment Practice

The researcher analyzed interview data, the 2005 - 2006 Department of Nursing Annual Report, and the assessment plan to identify characteristics of effective practice. Credible evidence of learning. Documents and interview respondents illustrated various components of the assessment plan that ensured learning was relevant and assessment measures were reliable. Twenty-seven outcomes from health/promotion/illness care, critical thinking, therapeutic relationships, communication, professional role development, ethics and professional self development, and scholarship were assessed. 
Intended learning outcomes for the B. S. N. program spanned two of the six cognitive domains contained within Bloom’s Taxonomy (Anderson, et al., 2001). All of the outcomes were representative of the apply and create domains. However, the four outcomes associated with scholarship were not analyzed as they were neither measurable nor clear.

Fifty-five percent of the outcomes focused on the apply domain and forty-four percent represented the create domain (see Table 149). Some outcomes were representative of the affective domain. The outcomes that were analyzed were learner-centered and were clear, measurable, and directly related to the program’s mission statement.

Table 149

Distribution of intended cognitive learning outcomes

\begin{tabular}{|c|r|r|}
\hline Cognitive Domain & N & $\%$ \\
\hline Create & 12 & 44 \\
\hline Evaluate & 0 & 0 \\
\hline Analyze & 0 & 0 \\
\hline Apply & 15 & 55 \\
\hline Understand & 0 & 0 \\
\hline Remember & 0 & 0 \\
\hline
\end{tabular}

Examples of intended learning outcomes within the apply domain included:

- $\quad$ provide comprehensive nursing care interventions to individuals and

- use effective communication to establish therapeutic relationships with clients.

Examples of intended learning outcomes within the create domain included:

- $\quad$ synthesize skills from established practice and science of nursing to engage in critical thinking and the nursing process in the care of clients and

- synthesize technology from established practice and science of nursing to engage in critical thinking and the nursing process in the care of clients. 
Examples of intended learning outcomes within the affective domain included:

- develop caring relationships with clients that are sensitive to diverse personal characteristics and

- develop caring relationships with clients that are sensitive to socio-cultural characteristics.

The B. S. N. program faculty utilized multiple methods of assessment to measure student achievement. The department chair and the 2005 - 2006 Department of Nursing Annual Report both revealed that the B.S.N. curriculum was "undergoing comprehensive revision.” The department chair noted that the Health Education Systems, Incorporated (HESI) examinations that function as a predictor test for the National Council Licensure Exam for Registered Nurses (NCLEX) examination were being implemented. HESI examinations are commercially available assessments administered electronically that are intended to simulate the NCLEX. Prior to the 2006 - 2007 academic year, a similar examination developed by Educational Resources, Inc. (ERI) was utilized. The NCLEX is a commercially developed licensing assessment. The 2005 - 2006 Annual Report states that "HESI testing will be integrated into many courses." The department had been unable to fully implement HESI testing due to technological difficulties.

According to the 2005 - 2006 Department of Nursing Annual Report a pre/post test developed by ERI was administered to assess critical thinking skills. A rubric (practicum evaluation tool) designed to assess student learning within the practicum settings was implemented across courses. Other assessments identified in the annual report included a senior portfolio, senior exit self-assessment of meeting program goals, alumni survey, and a senior exit interview. 
The 2005 - 2006 Department of Nursing Annual Report outlined the assessment measures utilized to assess specific intended learning outcomes. Outcomes related to the provision of comprehensive nursing care to various entities were assessed by utilizing the practicum evaluation tool, the senior exit self-assessment of meeting program goals, the ERI registered nurse assessment test (HESI examinations were administrated to the class of 2006), and the senior exit interview. Outcomes related to the synthesis of skills, technology, and knowledge from various disciplines pertinent to nursing were assessed by utilizing the practicum evaluation tool, the senior exit self-assessment of meeting program goals, the ERI registered nurse assessment test (HESI examinations were administered to the class of 2006), NCLEX results, ERI critical thinking pre-test/posttest, and senior exit interview. Outcomes related to the development of caring relationships with clients were assessed by utilizing the practicum evaluation tool, the senior exit self-assessment of meeting program goals, and the senior exit interview. Outcomes related to the use of effective communication were assessed by utilizing the practicum evaluation tool, the senior exit self-assessment of meeting program goals, and the senior exit interview. Outcomes related to the demonstration of skills that provide various health related benefits were assessed by utilizing the practicum evaluation tool, the senior exit self-assessment of meeting program goals, and the senior exit interview. Outcomes related to the enhancement of professional skills were assessed utilizing the practicum evaluation tool, the senior exit self-assessment of meeting program goals, the senior portfolio, the alumni survey, and the senior exit interview. Outcomes related to the promotion of self-awareness, self growth, ethical accountability, and legal responsibility were assessment utilizing the practicum evaluation tool, the senior 
portfolio, senior exit self-assessment of meeting program goals, alumni survey, and the senior exit interview (see Table 150). All outcomes were assessed by multiple methods. The department chair noted that faculty did "aggregate mean data on courses in the senior year as an indicator of how students [were] performing in their clinical practice.” An analysis of assessment results was provided in the annual report. Mean data was presented for the practicum evaluation tool, senior exit survey, ERI registered nurse assessment test, NCLEX examination, and the ERI critical thinking pre/post examination. Pass rates for the NCLEX predictor (ERI) examination and the NCLEX examination were presented. The pass rates for each examination were also compared to the national pass rates. Mean data from the assessment activities was aligned to specific learning outcomes and indicated the degree of student achievement. 
Table 150

Assessment methods

\begin{tabular}{|c|c|c|c|c|c|c|c|}
\hline \multirow{2}{*}{$\begin{array}{l}\text { Assessment } \\
\text { Methods }\end{array}$} & \multicolumn{7}{|c|}{ Outcomes } \\
\hline & $\begin{array}{l}\text { Comprehensive } \\
\text { Nursing Care }\end{array}$ & $\begin{array}{l}\text { Synthesis of } \\
\text { Skills, } \\
\text { Technology, } \\
\text { and } \\
\text { Knowledge }\end{array}$ & $\begin{array}{l}\text { Development } \\
\text { of Caring } \\
\text { Relationships }\end{array}$ & Communication & $\begin{array}{l}\text { Skills } \\
\text { That } \\
\text { Provide } \\
\text { Various } \\
\text { Health } \\
\text { Related } \\
\text { Benefits }\end{array}$ & $\begin{array}{l}\text { Enhancement } \\
\text { of } \\
\text { Professional } \\
\text { Skills }\end{array}$ & $\begin{array}{l}\text { Promotion of } \\
\text { Self- } \\
\text { Awareness, } \\
\text { Self Growth, } \\
\text { Ethical } \\
\text { Accountability, } \\
\text { and Legal } \\
\text { Responsibility }\end{array}$ \\
\hline $\begin{array}{l}\text { Practicum } \\
\text { Evaluation } \\
\text { Tool }\end{array}$ & $\mathrm{X}$ & $\mathrm{X}$ & $\mathrm{X}$ & $\mathrm{X}$ & $\mathrm{X}$ & $\mathrm{X}$ & $\mathrm{X}$ \\
\hline $\begin{array}{l}\text { Senior } \\
\text { Portfolio }\end{array}$ & & & & & & $\mathrm{X}$ & $\mathrm{X}$ \\
\hline $\begin{array}{l}\text { ERI } \\
\text { Critical } \\
\text { Thinking } \\
\text { Pre- } \\
\text { Test/Post- } \\
\text { Test }\end{array}$ & & $\mathrm{X}$ & & $\mathrm{X}$ & & & \\
\hline $\begin{array}{l}\text { Senior Exit } \\
\text { Self- } \\
\text { Assessment } \\
\text { of Meeting } \\
\text { Program } \\
\text { Goals }\end{array}$ & $\mathrm{X}$ & $\mathrm{X}$ & $\mathrm{X}$ & $\mathrm{X}$ & $\mathrm{X}$ & $\mathrm{X}$ & $\mathrm{X}$ \\
\hline
\end{tabular}


Table 150

Assessment method: Continued

\begin{tabular}{|l|l|l|l|l|l|l|l|}
\hline $\begin{array}{l}\text { Assessment } \\
\text { Methods }\end{array}$ & $\begin{array}{l}\text { Comprehensive } \\
\text { Nursing Care }\end{array}$ & $\begin{array}{l}\text { Synthesis of } \\
\text { Skills, } \\
\text { Technology, } \\
\text { and } \\
\text { Knowledge } \\
\text { of Caring } \\
\text { Relationships }\end{array}$ & $\begin{array}{l}\text { Development } \\
\text { Communication }\end{array}$ & $\begin{array}{l}\text { Skills } \\
\text { That } \\
\text { Provide } \\
\text { Various } \\
\text { Health } \\
\text { Related } \\
\text { Benefits }\end{array}$ & $\begin{array}{l}\text { Enhancement } \\
\text { of } \\
\text { Professional } \\
\text { Skills }\end{array}$ & $\begin{array}{l}\text { Promotion of } \\
\text { Self- } \\
\text { Awareness, } \\
\text { Self Growth, } \\
\text { Ethical } \\
\text { Accountability, } \\
\text { and Legal } \\
\text { Responsibility }\end{array}$ \\
\hline $\begin{array}{l}\text { ERI } \\
\text { Registered } \\
\text { Nurse } \\
\text { Assessment } \\
\text { Test }\end{array}$ & $\mathrm{X}$ & $\mathrm{X}$ & & $\mathrm{X}$ & & & \\
\hline $\begin{array}{l}\text { NCLEX } \\
\text { Results }\end{array}$ & $\mathrm{X}$ & $\mathrm{X}$ & $\mathrm{X}$ & $\mathrm{X}$ & $\mathrm{X}$ & & \\
\hline $\begin{array}{l}\text { Alumni } \\
\text { Survey }\end{array}$ & $\mathrm{X}$ & $\mathrm{X}$ & $\mathrm{X}$ & $\mathrm{X}$ & $\mathrm{X}$ & \\
\hline $\begin{array}{l}\text { Senior Exit } \\
\text { Interview }\end{array}$ & $\mathrm{X}$ & & $\mathrm{X}$ & $\mathrm{X}$ & $\mathrm{X}$ & \\
\hline
\end{tabular}


Continuous Improvement. The department chair revealed that discussions about assessment data occurred annually. She further explained that assessment results were discussed at the faculty retreats held in May and August. The department chair indicated that the

...[assessment data] is used actively within faculty meetings...some of the data go to the curriculum committee...some of the data go to the full faculty in our retreat and we use [the data]...to inform us as we are doing continuous revision of the curriculum and the programs.

One example elicited from the department chair pertaining to NCLEX scores induced a change in the use of commercially available preparation materials for the NCLEX examination. The department chair and the 2005 - 2006 Department of Nursing Annual Report each revealed that the faculty switched to HESI preparation materials due to declining NCLEX scores. The 2005 - 2006 Department of Nursing Annual Report also described a finding from the senior exit survey. Data from the senior exit survey indicated that students felt anxious about the transition from school to practice. Thus, the nursing program faculty decided to

- $\quad$ expand opportunities to practice content, including capstone practicum, during final semester of program and

- develop case scenarios using Sim-Man to assess student synthesis of knowledge, skills, and their application during final semester.

These program changes provided evidence that assessment results were used by faculty in an attempt to improve student learning. 
Accountability to internal stakeholders. The department chair maintained that the Department of Nursing Annual Report and electronic planning database demonstrated accountability to internal stakeholders. An analysis of the 2005 - 2006 Department of Nursing Annual Report revealed that the Master Plan for Evaluation document was available upon request. Assessment results were clearly presented in alignment with program learning outcomes within the Annual Report.

Ongoing assessment. The department chair stated that "within our annual report we need to indicate how we are using assessment and demonstrate that we are using [assessment data] annually.” She further linked ongoing assessment to the timing of various assessments. The department chair stated, "we have indicated within the master plan when things happen and they happen very predictably...so we have a timeframe and methods section for everything that we do.” She also noted that the trend in providing assessment data within the Annual Report has necessitated ongoing assessment activities.

Ongoing Evaluation and Improvement. When asked about the ability of the assessment plan to facilitate ongoing evaluation and improvement, the department chair reported that this occurred primarily through their accreditation review self-study. She further stated that ongoing evaluation and improvement of the assessment plan was also manifested in curriculum revisions. The 2005 - 2006 Department of Nursing Annual Report provided no evidence that the intended learning outcomes were revised based upon student assessment results. Additionally, the Report provided no evidence that suggested that the assessment plan incorporated ongoing evaluation and improvement.

The department chair and associate professor purported to be satisfied with the program’s assessment plan. The department chair stated, “I think it’s well done because 
we spent a lot of time on it a year ago...I am really satisfied with [the plan].” However, the department chair qualified her response by stating, "[the nursing faculty] really need to figure out even better approaches [to assessment].” She linked her inconsistency in response to her belief that the department was not yet "where it needs to be." The department chair noted that the department was currently undergoing program revisions and expansion.

The associate professor stated, "I think we...do a lot of different types of assessment and I think it has been pretty effective" (see Table 151). She noted that her satisfaction with program assessment was predicated upon the utilization of assessment data to inform programmatic changes. The associate professor concluded, “I am really satisfied that we really worked together as a group to know when changes are needed and we plan ahead and we take it seriously.”

\section{Table 151}

Assessment plan: Perceived strengths

\begin{tabular}{|l|l|c|c|}
\hline Factors & $\begin{array}{l}\text { Department } \\
\text { Chair }\end{array}$ & $\begin{array}{l}\text { Associate } \\
\text { Professor }\end{array}$ & $\begin{array}{l}\text { Assistant } \\
\text { Professor }\end{array}$ \\
\hline $\begin{array}{l}\text { Multiple } \\
\text { Measures of } \\
\text { Assessment }\end{array}$ & & $\mathrm{X}$ & \\
\hline $\begin{array}{l}\text { Use of } \\
\text { Assessment to } \\
\text { Inform } \\
\begin{array}{l}\text { Programmatic } \\
\text { Changes }\end{array}\end{array}$ & & $\mathrm{X}$ & \\
\hline $\begin{array}{l}\text { Faculty } \\
\text { Participation }\end{array}$ & & & \\
\hline $\begin{array}{l}\text { Online } \\
\text { Examinations }\end{array}$ & $\mathrm{X}$ & $\mathrm{X}$ & \\
\hline
\end{tabular}


The assistant professor described the program’s assessment plan as “narrow.” However she maintained that “our plan is good at least in theory it's very good.” She noted that examinations will soon be administered online. Thus, students will have an opportunity to practice completing online examinations before taking the online state board examination.

This assistant professor based her dissatisfaction with the faculty's focus on pass rates of state board examinations. The assistant professor further noted that faculty were striving to raise their standards for student achievement. Specifically, faculty were developing assessment items to measure student performance at the application level. She maintained that students must practice application in order to succeed on state board examinations. Furthermore, she noted the importance of critical thinking (see Table 152).

\section{Table 152}

Assessment plan: Perceived challenges

\begin{tabular}{|l|l|l|c|}
\hline Factors & $\begin{array}{l}\text { Department } \\
\text { Chair }\end{array}$ & $\begin{array}{l}\text { Associate } \\
\text { Professor }\end{array}$ & $\begin{array}{l}\text { Assistant } \\
\text { Professor }\end{array}$ \\
\hline Program & $\mathrm{X}$ & & \\
Expansion & & & \\
\hline Develop & & & \\
Assessments to & & & \\
Measure & & & \\
Student & & & \\
Achievement in & & & \\
More & & & \\
Sophisticated & & & \\
Cognitive & & & \\
Domains & & & \\
\hline
\end{tabular}


Table 152

Assessment plan: Perceived challenges continued

\begin{tabular}{|c|c|c|c|}
\hline Factors & $\begin{array}{l}\text { Department } \\
\text { Chair }\end{array}$ & $\begin{array}{l}\text { Associate } \\
\text { Professor }\end{array}$ & $\begin{array}{l}\text { Assistant } \\
\text { Professor }\end{array}$ \\
\hline $\begin{array}{l}\text { Few } \\
\text { Opportunities } \\
\text { for Students to } \\
\text { Practice } \\
\text { Activities } \\
\text { within Higher } \\
\text { Order Domains }\end{array}$ & & & $\mathrm{X}$ \\
\hline
\end{tabular}

Institutional Commitments and Resources

Commitments. University and program leaders demonstrated their commitment to assessment. When asked if the utilization of student assessment data was considered in the evaluation and rewarding of faculty, the department chair noted the new B. S. N. program coordinator position. Specifically, she stated that the B. S. N. program coordinator was "receiving ... additional compensation for all of the work she is doing with curriculum revision and everything else in that respect.” The department chair concluded that evidence of student assessment data was considered in the evaluation and rewarding of faculty; however, not formally.

When queried about the policies and practices that facilitate the communication of student assessment purposes, the department chair stated, "I think we communicate to whoever would read our documents.” She further reported that the communication of assessment purposes with students occurred in classes. The department chair maintained that students were informed of the required assessments when they began the curriculum. Furthermore, she reported that students served on both a student concerns committee and the curriculum committee. 
When asked about policies to promote the involvement of student affairs personnel and students in assessment efforts, the department chair stated that student affairs personnel would likely be involved in internal program reviews. She stated that executive level support for student assessment was evident and that assessment has “gotten a little tighter in the past few years.” The department chair continued, “[assessment] hasn’t changed a lot for [the Nursing Department] because we have been doing it...” She based her claim on the implementation of the planning database that centralized data.

When asked to describe the culture of assessment within the nursing program, the department chair felt as though the faculty “...under[stands] that [assessment] is an integral part of [their work]...” She further reported, “I think [assessment] is expected to happen, it's very respected and valued.” The department chair reported that faculty had not developed a document containing guiding principles for assessment. However, she stated that professional and accreditation criteria "guides how we conduct assessment." Additionally, the department chair indicated that there "probably" was a campus wide assessment committee with broad representation; however, she was not sure.

The department chair affirmed that outcomes assessment was incorporated into the scholarship of teaching; however, it was not operationalized. She further stated, “we define scholarship using Broyer’s Model pretty broadly.” The department chair concluded, “faculty could develop innovative ways of assessment as part of their scholarship and that would factor into teaching and promotion very favorably.”

In summary, significant commitments included:

- a program coordinator that focused on assessment, 
- communication of student assessment purposes,

- student participation on assessment related committees,

- student affairs involvement in internal program reviews,

- executive level support,

- culture that values assessment, and

- a campus-wide assessment committee with broad representation.

Resources. When asked to identify resources that were allocated to the Department of Nursing from the institution, the department chair stated, "not much." However, she stated that the department utilized a liaison from CARS. The CARS liaison assisted with analyzing data related to the reliability of the practicum evaluation tool and was available for consultation. The department chair also cited the planning database and previous funding of the ERI developed NCLEX predictor test as resources. However, the ERI is currently purchased by the department. Additional external grant money enabled the department to utilize external consulting services and to send faculty members to conferences.

While a comprehensive student assessment database was not directly available to the Department of Nursing, the department chair noted that some data may be available. The department chair purported that assessment based conferences were supported "just as much as any other topic.” Due to external grant funding, she noted that "we have been able to be very generous." However, she was uncertain about the quantity of support that the department will be able to provide when the grant funding terminates. The department chair further noted that recent program expansion (doubling the number of faculty) stressed the department's budget significantly. When queried about the 
availability of internal or external consultant services for faculty on the use of student assessment in course design or instruction, the chair stated, "there has been a lot of faculty development on course design and instruction...I have seen less on assessment [but] that doesn't mean it doesn't exist.” Furthermore she stated that faculty development workshops on assessment “probably” occurred. The department chair claimed, “I’m too busy to notice.” When queried about faculty development workshops for academic administrators, the chair stated, "I have not attended any [but] that does not mean that they are not available.”

The department chair reported that there was no assistance (in the form of paid leaves, stipends, mini-grants, or course reductions) for faculty to work on assessment activities. Rather, faculty accepted assessment activities as a component of their workload. Additionally, she reported that she had not attended and was unaware of student assessment workshops for deans, department chairs, other academic administrators, and student affairs staff and administrators.

When queried about an annual budget allocated to academic units to support student assessment, the department chair indicated that a specific line did not exist. Rather, assessment was an expectation of the institution. She stated that she would like some support of the ERI developed NCLEX predictor test as it is "fairly pricey."

The department chair reported that the coordination of data-gathering initiatives such as surveys and standardized tests occurred internally. She identified CARS as the institutional assessment office and reported that no departmental assessment office exists.

In summary, the significant resources available from the institution included:

- planning database, 
- financial support for examinations,

- external consultants,

- conference support,

- faculty development workshops, and

- the institutional assessment office (CARS).

Faculty Satisfaction with Assessment and the Assessment Plan

Faculty satisfaction with program assessment was determined by analyzing interview data from three individuals: (1) the department chair who was also a professor, (2) an associate professors who also served as the B. S. N. program coordinator, and (3) an assistant professor. The department chair was asked a sample of the items included on the Faculty Satisfaction Interview Protocol. These items were intended to elicit information regarding their satisfaction with implementation of the current assessment plan, opportunities to participate in policy making, and central leadership support for assessment. Only the associate and assistant professors were invited to respond to the items pertaining to faculty leadership support, professional development, evaluations and rewards, academic decision making, and the impact of student assessment on the program.

Satisfaction with the Implementation of the Current Assessment Plan. The department chair and associate professor reported their satisfaction with the implementation of the current assessment plan. However, they did not offer reasons for their satisfaction. The department chair stated that the department was undergoing significant transition. She explained, "so the implementation is shifting because of all of the change." The department chair continued, "I am not dissatisfied...[implementation] is just challenging 
because with more cooks in the kitchen being systematic [is important].” She also noted that curriculum and course reviews that were completed by the entire faculty now necessitated examination by committee. Finally, the department chair noted the implementation of online course evaluations for students was a positive factor.

The associate professor noted challenges with the implementation of online examinations. Specifically, computer related technology challenges impeded the implementation process. Furthermore, she maintained that "keeping up with technology" was difficult. She also stated, “we have an evolving curriculum here...we are always looking for ways to improve things.”

The assistant professor was neutral in her response. She reported that, "we just changed from [using] percentages to checks and minuses.” The assistant professor further stated, “...so that has been a problem for faculty who are used to doing percentages and students who want numbers for grades” to report assessment results on student assignments (see Table 153). She also maintained that not all assessments were perfectly objective. However, the assistant professor claimed that all of the assessments required by the program “[were] spelled out exactly.”

Table 153

Implementation of the current assessment plan: Perceived challenges

\begin{tabular}{|l|l|c|l|}
\hline Factors & $\begin{array}{l}\text { Department } \\
\text { Chair }\end{array}$ & $\begin{array}{l}\text { Associate } \\
\text { Professor }\end{array}$ & $\begin{array}{l}\text { Assistant } \\
\text { Professor }\end{array}$ \\
\hline $\begin{array}{l}\text { Program } \\
\text { Expansion }\end{array}$ & \multicolumn{1}{|c|}{$\mathrm{X}$} & $\mathrm{X}$ & \\
\hline $\begin{array}{l}\text { Implementation } \\
\text { of Online } \\
\text { Examinations }\end{array}$ & & $\mathrm{X}$ & \\
\hline
\end{tabular}


Table 153

Implementation of the current assessment plan: Perceived challenges continued

\begin{tabular}{|l|l|l|l|}
\hline Factors & $\begin{array}{l}\text { Department } \\
\text { Chair }\end{array}$ & $\begin{array}{l}\text { Associate } \\
\text { Professor }\end{array}$ & $\begin{array}{l}\text { Assistant } \\
\text { Professor }\end{array}$ \\
\hline $\begin{array}{l}\text { Keeping Up } \\
\text { With New } \\
\text { Technologies }\end{array}$ & & $\mathrm{X}$ & \\
\hline $\begin{array}{l}\text { Change in } \\
\text { Grading } \\
\text { Methods }\end{array}$ & & & $\mathrm{X}$ \\
\hline
\end{tabular}

Faculty Satisfaction with Opportunities to Participate in Policy Making. The department chair, the associate, and assistant professors purported to be satisfied with the opportunities they had to participate in policy making. The department chair reported that she was very satisfied with her opportunities to participate in policy making (see Table 154). She noted the "flexibility" with assessment endeavors. The department chair reported that the ability of program faculty to develop their own assessments was a positive factor.

The associate professor cited her service as the curriculum committee chair as her most significant formal venue for participating in policy making. Additionally, she noted informal conversations with the department chair. The associate professor's physical proximity to the department chair enabled frequent informal conversations pertaining to assessment.

The assistant professor stated, "I have had a lot to do with some of the policy stuff.” She noted that her expertise with HESI testing has enabled her to participate in policy making. Furthermore, she noted that her expertise in test item development has played a 
role in participating in policy making. However, she cautioned, "sometimes the chair already [has her] mind made up.”

Table 154

Opportunities to participate in policy making: Perceived strengths

\begin{tabular}{|l|l|c|c|}
\hline Factors & $\begin{array}{l}\text { Department } \\
\text { Chair }\end{array}$ & $\begin{array}{l}\text { Associate } \\
\text { Professor }\end{array}$ & $\begin{array}{l}\text { Assistant } \\
\text { Professor }\end{array}$ \\
\hline $\begin{array}{l}\text { Flexibility with } \\
\text { Assessment } \\
\text { Endeavors }\end{array}$ & $\mathrm{X}$ & & \\
\hline $\begin{array}{l}\text { Committee } \\
\text { Participation }\end{array}$ & & $\mathrm{X}$ & \\
\hline $\begin{array}{l}\text { Informal } \\
\text { Communication }\end{array}$ & & $\mathrm{X}$ & \\
\hline $\begin{array}{l}\text { Specific } \\
\text { Expertise }\end{array}$ & & & $\mathrm{X}$ \\
\hline
\end{tabular}

Faculty Satisfaction with Central Leadership Support for Assessment. The department chair and the associate professor purported their satisfaction with the central leadership support for student assessment. The department chair reported that the central leadership support for assessment "[has] been very strong” (see Table 155). She noted that each year, “additional guidelines and expectations toward [a] more systematic [approach to] gathering data... and reporting [were implemented].” The associate professor noted that “[central leadership has] been very good about looking at different [assessment methods] and assessment tools for [the department].” Additionally, she stated that central leadership conducted evaluations of assessment practices and provided feedback to the programs. However, the assistant professor remained neutral. She reported, "I have never had much interaction with [central leadership].” She continued, “they do not look over our shoulders.” 
Table 155

Central leadership support for assessment: Perceived strengths

\begin{tabular}{|l|l|l|l|}
\hline Factors & $\begin{array}{l}\text { Department } \\
\text { Chair }\end{array}$ & $\begin{array}{l}\text { Associate } \\
\text { Professor }\end{array}$ & $\begin{array}{l}\text { Assistant } \\
\text { Professor }\end{array}$ \\
\hline $\begin{array}{l}\text { Central } \\
\text { Leadership } \\
\text { Evaluation of } \\
\text { Assessment } \\
\text { Practices }\end{array}$ & $\mathrm{X}$ & & \\
\hline $\begin{array}{l}\text { Improved } \\
\text { Guidelines for } \\
\text { Assessment }\end{array}$ & & & \\
Reporting & & $\mathrm{X}$ & \\
\hline
\end{tabular}

Faculty Satisfaction with Program Faculty Leadership Support. The associate professor reported that faculty leadership for student assessment was “excellent.” She noted, "when there is a problem, people pull together to come up with solutions and change things" (see Table 156). Furthermore, she stated that the curriculum committee meets "very regularly” and sometimes taskforces were charged with evaluating program assessment.

Table 156

Program faculty leadership support for assessment:

Perceived strengths

\begin{tabular}{|l|c|c|}
\hline Factors & $\begin{array}{l}\text { Associate } \\
\text { Professor }\end{array}$ & $\begin{array}{l}\text { Assistant } \\
\text { Professor }\end{array}$ \\
\hline $\begin{array}{l}\text { Faculty } \\
\text { Participation }\end{array}$ & $\mathrm{X}$ & $\mathrm{X}$ \\
\hline $\begin{array}{l}\text { Curriculum } \\
\text { Committee }\end{array}$ & & $\mathrm{X}$ \\
\hline
\end{tabular}

The assistant professor stated, “[faculty] are all striving to improve.” She noted that upon her suggestion to challenge students more via the development of more difficult 
examination items, only one faculty member appeared resistant. She concluded that overall faculty “are very supportive.”

Faculty Satisfaction with Professional Development for Student Assessment. The associate and assistant professors reported their satisfied with professional development opportunities for student assessment. The associate professor stated that faculty who attended developmental events held off-campus frequently shared the new information they learned with the faculty as a whole when appropriate (see Table 157). She illustrated the sharing of information through the implementation of HESI testing. A small group of faculty attended specialized training in examination item development. Upon their return to the campus, they trained other faculty members on the methods they had learned pertaining to test item development.

Table 157

Professional development for student assessment:

Perceived strengths

\begin{tabular}{|l|c|c|}
\hline Factors & $\begin{array}{l}\text { Associate } \\
\text { Professor }\end{array}$ & $\begin{array}{l}\text { Assistant } \\
\text { Professor }\end{array}$ \\
\hline $\begin{array}{l}\text { Sharing of } \\
\text { Information }\end{array}$ & $\mathrm{X}$ & \\
\hline $\begin{array}{l}\text { Support for } \\
\text { Off-Campus } \\
\text { Development }\end{array}$ & & $\mathrm{X}$ \\
\hline $\begin{array}{l}\text { Financial } \\
\text { Support to } \\
\text { Attend } \\
\text { Conferences }\end{array}$ & & \\
\hline
\end{tabular}

The assistant professor reported that she was planning on attending an assessment related event in Chicago, Illinois. She wanted "to learn more about test writing skills and state board [examinations]." She claimed, "I have all of the support...I just have to get 
the information together and [the department chair will] make sure the department pays for it.”

\section{Faculty Satisfaction with Evaluations and Rewards Based on Student Assessment}

Data or Involvement. The associate and assistant professors reported to be satisfied with evaluations and rewards based on student assessment data or involvement. The associate professor stated, “faculty are given points on service, scholarship, and teaching so in the areas that assessment might be related to service to the department or teaching of a course they would get merit points on that" (see Table 158). She also stated, "when students pass their [state board examinations] that's a good reward.”

The assistant professor reported, “[assessment data and involvement] is all taken into consideration...[it] looks good in my portfolio for sure.” Like the associate professor, she noted state board examination pass rates. Specifically, the assistant professor cited a recent improvement in pass rates. She further noted that poor state board examination pass rates may impede student recruitment.

Table 158

Evaluations and rewards based on student assessment: Perceived strengths

\begin{tabular}{|l|c|c|}
\hline Factors & $\begin{array}{l}\text { Associate } \\
\text { Professor }\end{array}$ & $\begin{array}{l}\text { Assistant } \\
\text { Professor }\end{array}$ \\
\hline Merit Points & $\mathrm{X}$ & \\
\hline Portfolio & & $\mathrm{X}$ \\
\hline Evidence of & & \\
Student & \\
Learning & $\mathrm{X}$ & $\mathrm{X}$ \\
Through & & \\
External & & \\
Examination & & \\
\hline
\end{tabular}




\section{Faculty Satisfaction with the Use of Student Assessment Data in Making Academic}

Decisions. The associate professor indicated that assessment data was used frequently to guide academic decisions. She stated, "we definitely use assessment data to make academic decisions" (see Table 159). She continued, "for instance a couple of years ago our board scores had dropped and that is taken very seriously... and that was another reason that precipitated our curricular change.” She further noted that the reduction in NCLEX pass rates also influenced the decision to change the curriculum. As a result of the relatively poor NCLEX pass rates, she noted that a change in testing companies for NCLEX predictor tests from ERI to HESI had occurred.

Table 159

Use of student assessment data in making academic decisions: Perceived strengths

\begin{tabular}{|l|c|l|}
\hline Factors & $\begin{array}{l}\text { Associate } \\
\text { Professor }\end{array}$ & $\begin{array}{l}\text { Assistant } \\
\text { Professor }\end{array}$ \\
\hline $\begin{array}{l}\text { Curricular } \\
\text { Change }\end{array}$ & $\mathrm{X}$ & \\
\hline $\begin{array}{l}\text { Change in } \\
\text { Testing } \\
\text { Companies }\end{array}$ & $\mathrm{X}$ & \\
\hline
\end{tabular}

However, the assistant professor seemed less satisfied with the use of student assessment data in making academic decision. She stated, “[assessment data] may not have been as well used as it could be.” She cited a need to discuss current assessment issues with the faculty at an upcoming meeting. Specifically, technological challenges were making some assessment measures impossible to implement. She concluded that as long as she used data to support a decision, faculty were generally willing to accept change. 
Faculty Satisfaction with the Impact Student Assessment has had on Their Program.

The associate and assistant professors each reported that student assessment had a significant impact on the program. The associate professor stated, "I think [assessment data] really validates what we are doing here” (see Table 160). She continued, "I think it impacts us all of the time...we really are planning, implementing, and evaluating all of the time."

The assistant professor stated that assessment data had “a lot of impact." She cited the reduction in pass rates for state board examinations as being the impetus to strengthen test writing and increasing student learning standards. She concluded by stating that the department is also interested in facilitating instruction with more critical thinking courseembedded exercises. She emphasized that the need for critical thinking exercises to provide an opportunity for students to practice application level examination items in preparation for the state board examination.

Table 160

Evaluations and rewards based on student assessment:

Perceived strengths

\begin{tabular}{|l|c|c|}
\hline Factors & $\begin{array}{l}\text { Associate } \\
\text { Professor }\end{array}$ & $\begin{array}{l}\text { Assistant } \\
\text { Professor }\end{array}$ \\
\hline $\begin{array}{l}\text { Validation of } \\
\text { Practices }\end{array}$ & $\mathrm{X}$ & \\
\hline $\begin{array}{l}\text { Improve } \\
\text { Testing Writing }\end{array}$ & & $\mathrm{X}$ \\
\hline
\end{tabular}

Faculty Satisfaction Summary. Table 161 illustrates the frequencies of themes across items related to satisfaction with assessment. The most frequently identified theme pertaining to strengths was faculty participation in assessment. The department chair and 
the associate professor each made one reference to faculty participation within the context of the program's assessment plan. The associate and the assistant professors each made one reference to faculty participation within the context of program faculty leadership support for assessment.

Table 161

Frequency of theme emergence pertaining to strengths across items

\begin{tabular}{|c|c|c|c|}
\hline Factors & $\begin{array}{l}\text { Department } \\
\text { Chair }\end{array}$ & $\begin{array}{l}\text { Associate } \\
\text { Professor }\end{array}$ & $\begin{array}{l}\text { Assistant } \\
\text { Professor }\end{array}$ \\
\hline $\begin{array}{l}\text { Faculty } \\
\text { Participation }\end{array}$ & 1 & 2 & 1 \\
\hline $\begin{array}{l}\text { Multiple } \\
\text { Methods of } \\
\text { Assessment }\end{array}$ & 0 & 1 & 0 \\
\hline $\begin{array}{l}\text { Use of } \\
\text { Assessment } \\
\text { Data to Inform } \\
\text { Programmatic } \\
\text { Changes }\end{array}$ & 0 & 1 & 0 \\
\hline $\begin{array}{l}\text { Online } \\
\text { Examinations }\end{array}$ & 0 & 0 & 1 \\
\hline $\begin{array}{l}\text { Online Course } \\
\text { Evaluations }\end{array}$ & 0 & 1 & 0 \\
\hline $\begin{array}{l}\text { Flexibility with } \\
\text { Assessment } \\
\text { Endeavors }\end{array}$ & 1 & 0 & 0 \\
\hline $\begin{array}{l}\text { Committee } \\
\text { Participation }\end{array}$ & 0 & 1 & 0 \\
\hline $\begin{array}{l}\text { Informal } \\
\text { Communication }\end{array}$ & 0 & 1 & 0 \\
\hline $\begin{array}{l}\text { Specific } \\
\text { Expertise }\end{array}$ & 0 & 0 & 1 \\
\hline $\begin{array}{l}\text { Central } \\
\text { Leadership } \\
\text { Evaluation of } \\
\text { Assessment } \\
\text { Practices }\end{array}$ & 1 & 0 & 0 \\
\hline $\begin{array}{l}\text { Improved } \\
\text { Guidelines for } \\
\text { Assessment } \\
\text { Reporting }\end{array}$ & 0 & 1 & 0 \\
\hline
\end{tabular}


Table 161

Frequency of theme emergence pertaining to strengths across items:

Continued

\begin{tabular}{|l|c|c|c|}
\hline Factors & $\begin{array}{l}\text { Department } \\
\text { Chair }\end{array}$ & $\begin{array}{l}\text { Associate } \\
\text { Professor }\end{array}$ & $\begin{array}{l}\text { Assistant } \\
\text { Professor }\end{array}$ \\
\hline $\begin{array}{l}\text { Curriculum } \\
\text { Committee }\end{array}$ & 0 & 0 & 1 \\
\hline $\begin{array}{l}\text { Sharing of } \\
\text { Information }\end{array}$ & 0 & 1 & 0 \\
\hline $\begin{array}{l}\text { Support for } \\
\text { Off-Campus } \\
\begin{array}{l}\text { Faculty } \\
\text { Development }\end{array}\end{array} \quad 0$ & 0 & 1 \\
\hline Merit Points & 0 & 1 & 0 \\
\hline Portfolio & 0 & 0 & 1 \\
\hline
\end{tabular}

The only theme related to challenges with the assessment endeavor within the

Department of Nursing pertained to the growth of the B. S. N. program. The department chair referred to program expansion as a challenge to creating the assessment plan and a challenge during the implementation phase (see Table 162).

Table 162

Frequency of theme emergence pertaining to challenges across items

\begin{tabular}{|l|c|c|c|}
\hline Factors & $\begin{array}{l}\text { Department } \\
\text { Chair }\end{array}$ & $\begin{array}{l}\text { Associate } \\
\text { Professor }\end{array}$ & $\begin{array}{l}\text { Assistant } \\
\text { Professor }\end{array}$ \\
\hline $\begin{array}{l}\text { Program } \\
\text { Expansion }\end{array}$ & 2 & 0 & 0 \\
\hline $\begin{array}{l}\text { Elevate } \\
\text { Cognitive } \\
\begin{array}{l}\text { Sophistication } \\
\text { Measures }\end{array}\end{array}$ & 0 & 0 & 1 \\
\hline $\begin{array}{l}\text { Focus on } \\
\text { Individual } \\
\text { Assessments }\end{array}$ & 0 & 0 & 1 \\
\hline
\end{tabular}


Table 162

Frequency of theme emergence pertaining to challenges across items:

Continued

\begin{tabular}{|l|c|c|c|}
\hline Factors & $\begin{array}{l}\text { Department } \\
\text { Chair }\end{array}$ & $\begin{array}{l}\text { Associate } \\
\text { Professor }\end{array}$ & $\begin{array}{l}\text { Assistant } \\
\text { Professor }\end{array}$ \\
\hline $\begin{array}{l}\text { Few } \\
\text { Opportunities } \\
\text { for Students to } \\
\text { Practice } \\
\text { Activities } \\
\text { within Higher } \\
\text { Order Domains }\end{array}$ & 0 & 0 & 1 \\
\hline $\begin{array}{l}\text { Implementation } \\
\text { of Online } \\
\text { Examinations }\end{array}$ & 0 & 1 & 0 \\
\hline $\begin{array}{l}\text { Keeping Up } \\
\text { with New } \\
\text { Technologies }\end{array}$ & 0 & 1 & 0 \\
\hline $\begin{array}{l}\text { Change in } \\
\text { Grading } \\
\text { Methods }\end{array}$ & 0 & 0 & 1 \\
\hline $\begin{array}{l}\text { Department } \\
\text { Chair } \\
\text { Predetermines } \\
\text { Course of } \\
\text { Action }\end{array}$ & 0 & 0 & 1 \\
\hline $\begin{array}{l}\text { Technology } \\
\text { Problems }\end{array}$ & 0 & & 1 \\
\hline
\end{tabular}

In this case study, the researcher presented the institutional background as it pertains to assessment and described the programs and participants. Participants in this GU case study included the institutional assessment leader, program administrators (four department chairs), and faculty from the Departments of Psychology, Mathematics and Statistics, Biology, and Nursing.

The researcher fully analyzed data gathered from the interviews and documents. The major results pertaining to each research question are highlighted and presented by each 
academic program. In addition, the frequency of themes pertaining to participants’ satisfaction with assessment is discussed including strengths and challenges. In Chapter 7, the researcher presents the major results from the cross-site analysis which includes participants’ demographic information, comparison of assessment practices across participating programs at the three universities pertinent to the sustainment and improvement phase (Banta, 2002). Commitments and resources provided to assessment and faculty satisfaction data are also discussed in Chapter 7. 


\section{Chapter 7}

\section{Cross Comparative Analysis}

The researcher investigated assessment practices at the undergraduate program level at three universities with assessment plans in the sustainment and improvement phase. The researcher conducted interviews with 40 participants who represented a sample of undergraduate programs based on Biglan’s model (Smart \& Elton, 1987). Even though assessment scholars identified the three participating institutions as maintaining assessment plans in the sustainment and improvement phase, some programs in each institution had not achieved this advanced level of assessment implementation.

\section{Study Participants}

The researcher conducted interviews with department chairs (program administrators) and faculty members representing undergraduate mathematics, English, psychology, secondary education, biology, and nursing programs. Participating programs from Beta University included mathematics, English, and secondary education (see Table 163). Participating programs from Alpha University included mathematics, English, psychology, secondary education, biology, and nursing. Participating programs from Gamma University included mathematics, psychology, biology, and nursing.

Participants included seven individuals from Beta University, 22 individuals from Alpha University, and 11 individuals from Gamma University. Over half of the total number of participants ( $\mathrm{n}=24$ ) reported to be moderately knowledgeable about student outcomes assessment. Eight participants purported to be somewhat knowledgeable about student outcomes assessment while two participants purported to have no knowledge of 
assessment. Five participants reported to be very knowledge about student outcomes

while one participant did not respond to this question (see Table 164).

Table 163

Program participation by institution

\begin{tabular}{|l|c|c|c|c|c|c|}
\hline \multirow{2}{*}{ Institution } & \multicolumn{6}{|c|}{ Undergraduate Programs } \\
\cline { 2 - 7 } & Math & English & Psychology & $\begin{array}{l}\text { Secondary } \\
\text { Education }\end{array}$ & Biology & Nursing \\
\hline $\begin{array}{l}\text { Beta } \\
\text { University }\end{array}$ & $\mathrm{X}$ & $\mathrm{X}$ & & $\mathrm{X}$ & & \\
\hline $\begin{array}{l}\text { Alpha } \\
\text { University }\end{array}$ & $\mathrm{X}$ & $\mathrm{X}$ & $\mathrm{X}$ & $\mathrm{X}$ & $\mathrm{X}$ & $\mathrm{X}$ \\
\hline $\begin{array}{l}\text { Gamma } \\
\text { University }\end{array}$ & $\mathrm{X}$ & & $\mathrm{X}$ & & $\mathrm{X}$ & $\mathrm{X}$ \\
\hline
\end{tabular}

Table 164

Participants self-reported knowledge of assessment: Across institutions

\begin{tabular}{|l|c|c|c|c|c|c|c|c|}
\hline \multirow{2}{*}{$\begin{array}{l}\text { Self-Reported } \\
\text { Knowledge of } \\
\text { Assessment }\end{array}$} & \multicolumn{9}{|c|}{ Participants by Institution } \\
\cline { 2 - 9 } & Beta University & \multicolumn{2}{|c|}{$\begin{array}{c}\text { Alpha } \\
\text { University }\end{array}$} & \multicolumn{2}{c|}{$\begin{array}{c}\text { Gamma } \\
\text { University }\end{array}$} & \multicolumn{2}{|c|}{ Total } \\
\cline { 2 - 9 } & $\mathrm{N}$ & $\%$ & $\mathrm{~N}$ & $\%$ & $\mathrm{~N}$ & $\%$ & $\mathrm{~N}$ & $\%$ \\
\hline $\begin{array}{l}\text { Very } \\
\text { Knowledgeable }\end{array}$ & 1 & 14.3 & 2 & 9.1 & 2 & 18.2 & 5 & 12.5 \\
\hline $\begin{array}{l}\text { Moderately } \\
\text { Knowledgeable }\end{array}$ & 3 & 42.9 & 15 & 68.2 & 6 & 54.5 & 24 & 60 \\
\hline $\begin{array}{l}\text { Somewhat } \\
\text { Knowledgeable }\end{array}$ & 2 & 28.6 & 4 & 18.2 & 2 & 18.2 & 8 & 20 \\
\hline $\begin{array}{l}\text { Not } \\
\text { Knowledgeable }\end{array}$ & 1 & 14.3 & 0 & 0 & 1 & 9.0 & 2 & 5 \\
\hline No Response & 0 & 0 & 1 & 4.5 & 0 & 0 & 1 & 2.5 \\
\hline
\end{tabular}

Many of the participants included within this study were actively involved in assessment research. Forty-five percent of the total number of participants attended conferences that included assessment sessions on the program within the past two years while 35\% attended conferences that focused on outcomes assessment (see Table 165). 
Thirty percent of the participants presented assessment results at conferences while 22\% published an article pertaining to assessment within the past two years.

Fifty percent of the participants from Alpha University attended at least one conference focused on assessment while $40 \%$ presented assessment results at a conference within the past two years. Faculty participation in conference events may be attributed to an annual national assessment conference hosted on the AU campus.

Table 165

Assessment related research activities: Across institutions

\begin{tabular}{|c|c|c|c|c|c|c|c|c|}
\hline \multirow{3}{*}{$\begin{array}{l}\text { Assessment } \\
\text { Related } \\
\text { Research } \\
\text { Activities }\end{array}$} & \multicolumn{8}{|c|}{ Participants by Institution } \\
\hline & \multicolumn{2}{|c|}{ Beta University } & \multicolumn{2}{|c|}{$\begin{array}{c}\text { Alpha } \\
\text { University }\end{array}$} & \multicolumn{2}{|c|}{$\begin{array}{c}\text { Gamma } \\
\text { University }\end{array}$} & \multicolumn{2}{|c|}{ Total } \\
\hline & $\mathrm{N}$ & $\%$ & $\mathrm{~N}$ & $\%$ & $\mathrm{~N}$ & $\%$ & $\mathrm{~N}$ & $\%$ \\
\hline $\begin{array}{l}\text { Attended } \\
\text { Conferences } \\
\text { Focuses on } \\
\text { Assessment }\end{array}$ & 2 & 28.6 & 11 & 50.0 & 1 & 9.1 & 14 & 35 \\
\hline $\begin{array}{l}\text { Attended } \\
\text { Conferences } \\
\text { that } \\
\text { Included } \\
\text { Assessment } \\
\text { Sessions on } \\
\text { the Program }\end{array}$ & 1 & 14.3 & 10 & 45.5 & 7 & 63.6 & 18 & 45 \\
\hline $\begin{array}{l}\text { Published at } \\
\text { Least One } \\
\text { Paper } \\
\text { Pertaining } \\
\text { to } \\
\text { Assessment }\end{array}$ & 2 & 28.6 & 5 & 22.7 & 2 & 18.2 & 9 & 22.5 \\
\hline $\begin{array}{l}\text { Presented } \\
\text { Assessment } \\
\text { Results at a } \\
\text { Conference }\end{array}$ & 2 & 28.6 & 9 & 40.9 & 1 & 9.1 & 12 & 30 \\
\hline
\end{tabular}




\section{Characteristics of Effective Assessment Practice}

The researcher analyzed interview data, annual assessment reports, and assessment plans to identify characteristics of effective practice.

Credible evidence of learning. Intended learning outcomes across most of the institutions spanned all six cognitive domains included within Bloom’s Taxonomy (see Table 166). The outcomes were skewed to the mid-level domains. Sixty-six percent of the outcomes represented the understand and apply domains. Eighteen percent of the outcomes represented the remember domain. Seventeen percent of the outcomes represented higher-order domains. The greatest percentage of outcomes at Beta University and Gamma University represented the apply domain while the greatest percentage of outcomes at Alpha University represented the understand domain.

Table 166

Distribution of intended learning outcomes: Across institutions

\begin{tabular}{|l|c|c|l|c|l|c|c|c|}
\hline $\begin{array}{l}\text { Cognitive } \\
\text { Domains }\end{array}$ & \multicolumn{2}{l|l}{$\begin{array}{l}\text { Beta } \\
\text { University } \\
\text { (BU) }\end{array}$} & $\begin{array}{l}\text { Alpha } \\
\text { University } \\
\text { (AU) }\end{array}$ & \multicolumn{2}{l|}{$\begin{array}{l}\text { Gamma } \\
\text { University } \\
\text { (GU) }\end{array}$} & \multicolumn{2}{|l|}{ Total } \\
\cline { 2 - 11 } & $\mathrm{N}$ & $\%$ & $\mathrm{~N}$ & $\%$ & $\mathrm{~N}$ & $\%$ & $\mathrm{~N}$ & $\%$ \\
\hline Remember & 0 & 0 & 2 & 2.7 & 38 & 28.4 & 40 & 17.7 \\
\hline Understand & 5 & 29.4 & 39 & 52.7 & 18 & 13.4 & 62 & 27.6 \\
\hline Apply & 8 & 47.1 & 24 & 32.4 & 54 & 40.3 & 86 & 38.2 \\
\hline Analyze & 1 & 5.9 & 5 & 6.8 & 2 & 1.5 & 8 & 3.6 \\
\hline Evaluate & 0 & 0 & 3 & 4.1 & 6 & 4.5 & 9 & 4.0 \\
\hline Create & 3 & 17.6 & 1 & 1.4 & 16 & 11.9 & 20 & 8.9 \\
\hline
\end{tabular}

The most commonly utilized direct assessment methods included commercially available content examinations, research projects/papers, portfolios, locally-developed embedded examination items, licensure examinations, clinical observations, and common final examinations (see Table 167). Faculty representing two of the three programs included within the study from BU utilized research projects/papers and portfolios. The 
frequent use of research papers/projects by faculty may be attributed to the required senior project. Faculty from almost every program at BU were required to facilitate a senior project and submit assessment results to the institutional assessment office.

Faculty from AU most frequently utilized research projects/papers while faculty from Gamma University most frequently utilized commercially available content examinations and locally developed embedded examination items.

Table 167

Assessments: Across institutions

\begin{tabular}{|c|c|c|c|c|c|}
\hline \multirow[t]{2}{*}{ Assessments } & \multirow{2}{*}{$\begin{array}{l}\text { Beta } \\
\text { University } \\
\text { (BU) }\end{array}$} & \multirow{2}{*}{$\begin{array}{l}\text { Alpha } \\
\text { University } \\
\text { (AU) }\end{array}$} & \multirow{2}{*}{$\begin{array}{l}\text { Gamma } \\
\text { University } \\
\text { (GU) }\end{array}$} & \multicolumn{2}{|c|}{ Total } \\
\hline & & & & $\mathrm{N}$ & $\%$ \\
\hline \multicolumn{6}{|l|}{ Direct Assessments } \\
\hline $\begin{array}{l}\text { Commercially } \\
\text { Available Content } \\
\text { Examination }\end{array}$ & 1 & 1 & 3 & 5 & 38.5 \\
\hline $\begin{array}{l}\text { Research } \\
\text { Project/Paper }\end{array}$ & 2 & 2 & 0 & 4 & 30.8 \\
\hline Portfolio & 2 & 1 & 1 & 4 & 30.8 \\
\hline $\begin{array}{l}\text { Locally Developed } \\
\text { Embedded } \\
\text { Examination } \\
\text { Items }\end{array}$ & 0 & 1 & 2 & 3 & 23.1 \\
\hline $\begin{array}{l}\text { Licensure } \\
\text { Examination }\end{array}$ & 1 & 1 & 1 & 3 & 23.1 \\
\hline $\begin{array}{l}\text { Clinical } \\
\text { Observations }\end{array}$ & 1 & 1 & 1 & 3 & 23.1 \\
\hline $\begin{array}{l}\text { Common Final } \\
\text { Examinations }\end{array}$ & 1 & 1 & 0 & 2 & 15.4 \\
\hline $\begin{array}{l}\text { Commercially } \\
\text { Developed } \\
\text { Pre/Post Test } \\
\text { Critical Thinking }\end{array}$ & 0 & 0 & 1 & 1 & 7.7 \\
\hline $\begin{array}{l}\text { Locally Developed } \\
\text { Information Literacy } \\
\text { Examination }\end{array}$ & 0 & 0 & 1 & 1 & 7.7 \\
\hline Class Activities & 0 & 1 & 0 & 1 & 7.7 \\
\hline
\end{tabular}


Table 167

Assessments: Across institutions continued

\begin{tabular}{|c|c|c|c|c|c|}
\hline \multirow[t]{2}{*}{ Assessments } & \multirow{2}{*}{\begin{tabular}{|l} 
Beta \\
University \\
(BU)
\end{tabular}} & \multirow{2}{*}{$\begin{array}{l}\text { Alpha } \\
\text { University } \\
\text { (AU) }\end{array}$} & \multirow{2}{*}{\begin{tabular}{|l} 
Gamma \\
University \\
(GU)
\end{tabular}} & \multicolumn{2}{|c|}{ Total } \\
\hline & & & & $\mathrm{N}$ & $\%$ \\
\hline Class Presentations & 0 & 1 & 0 & 1 & 7.7 \\
\hline $\begin{array}{l}\text { Laboratory } \\
\text { Exercises }\end{array}$ & 0 & 1 & 0 & 1 & 7.7 \\
\hline $\begin{array}{l}\text { Essay/Short Answer } \\
\text { Questions }\end{array}$ & 0 & 1 & 0 & 1 & 7.7 \\
\hline Quizzes & 0 & 1 & 0 & 1 & 7.7 \\
\hline $\begin{array}{l}\text { Writing } \\
\text { Assignments }\end{array}$ & 0 & 1 & 0 & 1 & 7.7 \\
\hline \multicolumn{6}{|l|}{ Indirect Assessments } \\
\hline $\begin{array}{l}\text { Senior Exit } \\
\text { Interview/Survey }\end{array}$ & 1 & 3 & 2 & 6 & 46.2 \\
\hline $\begin{array}{l}\text { Student Self- } \\
\text { Reflection of } \\
\text { Program Outcomes } \\
\text { and Goals }\end{array}$ & 0 & 2 & 2 & 4 & 30.8 \\
\hline Alumni Survey & 1 & 1 & 1 & 3 & 23.1 \\
\hline $\begin{array}{l}\text { Academic Skills } \\
\text { Inventory }\end{array}$ & 0 & 0 & 2 & 2 & 15.4 \\
\hline $\begin{array}{l}\text { Student Focus } \\
\text { Groups }\end{array}$ & 0 & 0 & 1 & 1 & 7.7 \\
\hline $\begin{array}{l}\text { Job Readiness } \\
\text { Survey }\end{array}$ & 0 & 0 & 1 & 1 & 7.7 \\
\hline $\begin{array}{l}\text { Employer Focus } \\
\text { Groups }\end{array}$ & 0 & 1 & 0 & 1 & 7.7 \\
\hline $\begin{array}{l}\text { Mentoring Faculty } \\
\text { Survey }\end{array}$ & 0 & 1 & 0 & 1 & 7.7 \\
\hline $\begin{array}{l}\text { Academic Advisor } \\
\text { Survey }\end{array}$ & 0 & 1 & 0 & 1 & 7.7 \\
\hline Pre/Post Survey & 0 & 1 & 0 & 1 & 7.7 \\
\hline $\begin{array}{l}\text { Faculty Focus } \\
\text { Groups }\end{array}$ & 0 & 1 & 0 & 1 & 7.7 \\
\hline
\end{tabular}

The most commonly utilized indirect assessment methods included the senior exit interview/survey, self-reflection of program outcomes, alumni surveys, and an academic skills inventory. The senior exit survey/interview was the most frequently implemented 
indirect assessment activity as faculty from six of the 13 programs had implemented this assessment. Faculty from one program at each institution implemented alumni surveys to gather assessment data. Faculty from two programs at AU and BU utilized student selfreflection papers pertaining to outcome achievement. The academic skills inventory was implemented by faculty representing two programs within GU.

Continuously improve programs and services. Faculty at AU implemented the greatest number of curricular revisions followed by GU and BU respectively (see Table 168). The only curricular revision implemented by faculty within multiple programs was the development of a new required course. Program faculty representing two majors at BU took this course of action.

Table 168

Continuously improve programs and services: Across institutions

\begin{tabular}{|c|c|c|c|}
\hline Actions & $\begin{array}{l}\text { Beta University } \\
\text { (BU) }\end{array}$ & $\begin{array}{l}\text { Alpha } \\
\text { University } \\
\text { (AU) }\end{array}$ & $\begin{array}{l}\text { Gamma } \\
\text { University (GU) }\end{array}$ \\
\hline Curricular Revisions & 4 & 9 & 7 \\
\hline $\begin{array}{l}\text { - Created New Required } \\
\text { Course }\end{array}$ & 2 & 0 & 0 \\
\hline $\begin{array}{ll}\text { - Offered Courses More } \\
\text { Frequently } \\
\end{array}$ & 0 & 0 & 1 \\
\hline $\begin{array}{l}\text { - Offered More Frequent } \\
\text { Opportunities for Students } \\
\text { to Practice Writing }\end{array}$ & 0 & 0 & 1 \\
\hline - $\quad$ Revised Capstone Project & 1 & 0 & 0 \\
\hline - $\quad$ Added Credits to Course & 1 & 0 & 0 \\
\hline - Offer New Electives & 0 & 0 & 1 \\
\hline - Added an Examination & 0 & 1 & 0 \\
\hline $\begin{array}{l}\text { - } \text { Required Additional Oral } \\
\text { Presentations }\end{array}$ & 0 & 1 & 0 \\
\hline $\begin{array}{l}\text { - Incorporated the Use of } \\
\text { Data Analysis Software }\end{array}$ & 0 & 1 & 0 \\
\hline
\end{tabular}


Table 168

Continuously improve programs and services: Across institutions continued

\begin{tabular}{|c|c|c|c|}
\hline Actions & $\begin{array}{l}\text { Beta University } \\
\text { (BU) }\end{array}$ & $\begin{array}{l}\text { Alpha } \\
\text { University } \\
\text { (AU) }\end{array}$ & $\begin{array}{l}\text { Gamma } \\
\text { University (GU) }\end{array}$ \\
\hline $\begin{array}{l}\text { - Created New Learning } \\
\text { Experiences Pertaining } \\
\text { to Diversity }\end{array}$ & 0 & 1 & 0 \\
\hline $\begin{array}{l}\text { Increased the Opportunities } \\
\text { for Students to Practice } \\
\text { Critical Thinking Skills as } \\
\text { Members of } \\
\text { Interdisciplinary Teams }\end{array}$ & 0 & 1 & 0 \\
\hline $\begin{array}{l}\text { Increased the Opportunities } \\
\text { for Students to Practice } \\
\text { Critical Communication } \\
\text { Skills as Members of } \\
\text { Interdisciplinary Teams } \\
\end{array}$ & 0 & 1 & 0 \\
\hline $\begin{array}{ll} & \text { Required APA Formatting } \\
& \text { Across Program Courses } \\
\end{array}$ & 0 & 1 & 0 \\
\hline $\begin{array}{l}\text { Increased the Number of } \\
\text { Credit Hours Required for } \\
\text { the Major }\end{array}$ & 0 & 0 & 1 \\
\hline $\begin{array}{l}\text { - Offered New Courses for } \\
\text { Specific Specializations } \\
\text { Within the Major }\end{array}$ & 0 & 0 & 1 \\
\hline $\begin{array}{l}\text { - Developed New Simulation } \\
\text { Case Scenarios } \\
\end{array}$ & 0 & 0 & 1 \\
\hline $\begin{array}{l}\text { Increased Opportunities for } \\
\text { Student to Practice Newly } \\
\text { Acquired Skills }\end{array}$ & 0 & 0 & 1 \\
\hline 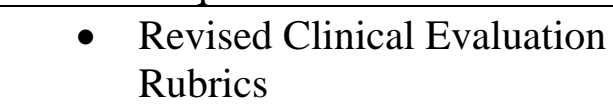 & 0 & 1 & 0 \\
\hline - $\quad$ Revised Reflection Prompts & 0 & 1 & 0 \\
\hline $\begin{array}{l}\text { Increased Faculty Engagement } \\
\text { With Getting Students Into } \\
\text { Graduate School }\end{array}$ & 0 & 1 & 0 \\
\hline $\begin{array}{l}\text { Changed Faculty Development } \\
\text { Opportunities }\end{array}$ & 0 & 1 & 0 \\
\hline Improved Peer Advising & 0 & 0 & 1 \\
\hline $\begin{array}{l}\text { Offered New Courses as a Service } \\
\text { to Other Programs }\end{array}$ & 0 & 0 & 1 \\
\hline
\end{tabular}


Table 168

Continuously improve programs and services: Across institutions continued

\begin{tabular}{|l|c|c|c|}
\hline Actions & $\begin{array}{l}\text { Beta University } \\
\text { (BU) }\end{array}$ & $\begin{array}{l}\text { Alpha } \\
\text { University } \\
\text { (AU) }\end{array}$ & $\begin{array}{l}\text { Gamma } \\
\text { University (GU) }\end{array}$ \\
\hline Revised Website & 0 & 0 & 1 \\
\hline $\begin{array}{l}\text { Increased the Number of } \\
\text { Opportunities for Students to } \\
\text { Conduct Research with Faculty }\end{array}$ & 0 & 0 & 1 \\
\hline $\begin{array}{l}\text { Revised New Student Orientation } \\
\text { Program }\end{array}$ & 0 & 0 & 1 \\
\hline Revised Weekly E-Mail Newsletter & 0 & 1 & 1 \\
\hline Improved Advising Services & 0 & 0 & 1 \\
\hline $\begin{array}{l}\text { Changed Commercial Testing } \\
\text { Companies }\end{array}$ & 0 & 0 & 1 \\
\hline
\end{tabular}

Accountability to internal stakeholders. Program administrators most frequently identified annual assessment reports submitted to central leadership, implemented program changes, school assessment committees, faculty meetings, availability of assessment results to faculty, senior projects/capstone experiences, and program assessment committees as the mechanisms that maintained accountability to internal stakeholders (see Table 169). Annual assessment reports submitted to central leaders was the most frequently identified accountability mechanism utilized by faculty representing five programs at AU and GU. Program administrators representing one program from AU and GU maintained that faculty meetings, the availability of assessment results to faculty, and program assessment committees were important to internal accountability. Program administrators representing one program from BU and AU maintained that the senior project/capstone experience was important to maintaining internal accountability. 
Table 169

Accountability to internal stakeholders: Across institutions

\begin{tabular}{|l|c|c|c|c|c|}
\hline & $\begin{array}{l}\text { Beta } \\
\text { University } \\
\text { (BU) }\end{array}$ & $\begin{array}{l}\text { Alpha } \\
\text { University } \\
\text { (AU) }\end{array}$ & $\begin{array}{l}\text { Gamma } \\
\text { University } \\
\text { (GU) }\end{array}$ & \multicolumn{2}{|c|}{ Total } \\
\cline { 4 - 6 } & 0 & 3 & 2 & 5 & 38.5 \\
\hline $\begin{array}{l}\text { Submitted Annual } \\
\text { Assessment Reports to } \\
\text { Central Leadership }\end{array}$ & 0 & 2 & 0 & 2 & 15.4 \\
\hline $\begin{array}{l}\text { Implemented Program } \\
\text { Changes }\end{array}$ & 0 & 2 & 0 & 2 & 15.4 \\
\hline $\begin{array}{l}\text { School Assessment } \\
\text { Committee }\end{array}$ & 0 & 1 & 1 & 2 & 15.4 \\
\hline Faculty Meetings & 0 & 1 & 1 & 2 & 15.4 \\
\hline $\begin{array}{l}\text { Availability of } \\
\text { Assessment Results to } \\
\text { the Faculty }\end{array}$ & 1 & 1 & 0 & 2 & 15.4 \\
\hline $\begin{array}{l}\text { Senior } \\
\text { Project/Capstone }\end{array}$ & 0 & 1 & 1 & 2 & 15.4 \\
\hline $\begin{array}{l}\text { Program Assessment } \\
\text { Committee }\end{array}$ & 0 & 0 & 1 & 1 & 7.7 \\
\hline Exit Survey & 0 & 0 & 1 & 1 & 7.7 \\
\hline $\begin{array}{l}\text { Personalized } \\
\text { Assessment Reports to } \\
\text { Faculty }\end{array}$ & 0 & 0 & 1 & 1 & 7.7 \\
\hline $\begin{array}{l}\text { Electronic Planning } \\
\text { Database }\end{array}$ & 0 & 1 & 0 & 1 & 7.7 \\
\hline $\begin{array}{l}\text { Discussions of } \\
\text { Assessment Results }\end{array}$ & 0 & 1 & 0 & 1 & 7.7 \\
\hline Common Examinations & 0 & 0 & 0 & 1 & 7.7 \\
\hline “Anecdotal” Evidence & 1 & 0 & 1 & 7.7 \\
\hline $\begin{array}{l}\text { Joint Committee on } \\
\text { Teacher Education }\end{array}$ & 1 & 0 & & & \\
\hline
\end{tabular}

Ongoing assessment. Faculty representing each program included within this study conducted ongoing assessment activities on a predictable schedule (see Table 170). However, additional methods of maintaining ongoing assessment activities were very diverse across the institutions. 
Table 170

Ongoing Assessment: Across institutions

\begin{tabular}{|l|c|c|c|c|c|}
\hline & \multicolumn{1}{|l|}{$\begin{array}{l}\text { Beta } \\
\text { University } \\
\text { (BU) }\end{array}$} & $\begin{array}{l}\text { Alpha } \\
\text { University } \\
\text { (AU) }\end{array}$ & $\begin{array}{l}\text { Gamma } \\
\text { University } \\
\text { (GU) }\end{array}$ & \multicolumn{2}{|c|}{ Total } \\
\cline { 3 - 6 } & 3 & 6 & 4 & 13 & 100 \\
\hline Predictable Schedule & 0 & 1 & 0 & 1 & 7.7 \\
\hline $\begin{array}{l}\text { Commitment of School } \\
\text { or College to } \\
\text { Assessment }\end{array}$ & 0 & 0 & 1 & 1 & 7.7 \\
\hline $\begin{array}{l}\text { Institution Offers } \\
\text { Graduate Programs in } \\
\text { Assessment and } \\
\text { Measurement }\end{array}$ & 1 & 0 & 0 & 1 & 7.7 \\
\hline $\begin{array}{l}\text { Faculty Had } \\
\text { Continuous Assessment } \\
\text { Discussions }\end{array}$ & 1 & 0 & 0 & 1 & 7.7 \\
\hline $\begin{array}{l}\text { Senior } \\
\text { Project/Capstone } \\
\text { Experience }\end{array}$ & 1 & 0 & 0 & 1 & 7.7 \\
\hline $\begin{array}{l}\text { Faculty Aggregate } \\
\text { Assessment Data } \\
\text { Annually }\end{array}$ & 0 & 1 & 0 & 1 & 7.7 \\
\hline $\begin{array}{l}\text { Professional } \\
\text { Accreditation Reports }\end{array}$ & 0 & 1 & 0 & 1 & 7.7 \\
\hline $\begin{array}{l}\text { Regional Accreditation } \\
\text { Reports }\end{array}$ & 0 & 0 & 1 & 1 & 7.7 \\
\hline $\begin{array}{l}\text { Common Examination } \\
\text { Items }\end{array}$ & 0 & 0 & 1 & 1 & 7.7 \\
\hline Indirect Assessments & 0 & 0 & 1 & 1 & 7.7 \\
\hline Assessment Day & 0 & 1 & 0 & 1 & 7.7 \\
\hline $\begin{array}{l}\text { Annual Report } \\
\text { Submitted to Central } \\
\text { Leadership }\end{array}$ & 0 & 0 & & 1 & \\
\hline
\end{tabular}

Ongoing evaluation and improvement. Program faculty from sixty-nine percent of the programs included within the study did not conduct ongoing evaluation and improvement of the assessment plan. Of the faculty from the $31 \%$ of the programs that conducted ongoing evaluation and improvement of the assessment plan, no common evaluation and improvement strategies were identified (see Table 171). 
Table 171

Ongoing evaluation and improvement: Across institutions

\begin{tabular}{|c|c|c|c|c|c|}
\hline \multirow[t]{2}{*}{ Actions } & \multirow{2}{*}{$\begin{array}{l}\text { Beta University } \\
(\mathrm{BU})\end{array}$} & \multirow{2}{*}{$\begin{array}{l}\text { Alpha } \\
\text { University } \\
\text { (AU) }\end{array}$} & \multirow{2}{*}{$\begin{array}{l}\text { Gamma } \\
\text { University } \\
(\mathrm{GU})\end{array}$} & \multicolumn{2}{|c|}{ Total } \\
\hline & & & & $\mathrm{N}$ & $\%$ \\
\hline $\begin{array}{l}\text { Plan Did Not } \\
\text { Encompass this } \\
\text { Element }\end{array}$ & 2 & 4 & 3 & 9 & 69.2 \\
\hline $\begin{array}{l}\text { Accreditation } \\
\text { Review Self- } \\
\text { Study }\end{array}$ & 0 & 1 & 0 & 1 & 7.7 \\
\hline $\begin{array}{l}\text { Informal } \\
\text { Evaluations of } \\
\text { Assessment } \\
\end{array}$ & 1 & 0 & 0 & 1 & 7.7 \\
\hline $\begin{array}{l}\text { Faculty } \\
\text { Constantly } \\
\text { Collected and } \\
\text { Reviewed } \\
\text { Assessment } \\
\text { Data }\end{array}$ & 1 & 0 & 0 & 1 & 7.7 \\
\hline $\begin{array}{l}\text { Quantity of } \\
\text { Faculty } \\
\text { Involved in } \\
\text { Program } \\
\text { Assessment } \\
\end{array}$ & 0 & 1 & 0 & 1 & 7.7 \\
\hline $\begin{array}{l}\text { Faculty } \\
\text { Discussions }\end{array}$ & 0 & 1 & 0 & 1 & 7.7 \\
\hline
\end{tabular}

Institutional Commitments and Resources

Commitments. Program administrators most frequently identified the following assessment commitments:

- executive-level support for assessment,

- campus-wide assessment committees,

- the incorporation of guiding principles of assessment in the promotion and tenure guidelines,

- a culture that values assessment, 
- policies that promote communication about assessment,

- guiding principles for assessment,

- the consideration of assessment data in evaluating and rewarding faculty,

- the consideration of student assessment expertise in the hiring process for new faculty, and

- policies to promote the involvement of student affairs personnel in assessment efforts (see Table 172).

Table 172

Commitments: Across institutions

\begin{tabular}{|c|c|c|c|c|c|}
\hline \multirow[t]{2}{*}{ Commitments } & \multirow{2}{*}{$\begin{array}{l}\text { Beta } \\
\text { University } \\
\text { (BU) }\end{array}$} & \multirow{2}{*}{$\begin{array}{l}\text { Alpha } \\
\text { University } \\
\text { (AU) }\end{array}$} & \multirow{2}{*}{$\begin{array}{l}\text { Gamma } \\
\text { University } \\
\text { (GU) }\end{array}$} & \multicolumn{2}{|c|}{ Total } \\
\hline & & & & $\mathrm{N}$ & $\%$ \\
\hline Executive-Level Support & 3 & 4 & 4 & 11 & 84.6 \\
\hline $\begin{array}{ll}\text { - } & \text { Financial Resources for } \\
\text { Faculty Working on } \\
\text { Assessment Activities }\end{array}$ & 2 & 0 & 1 & 3 & 23.1 \\
\hline $\begin{array}{ll}\text { - } & \begin{array}{l}\text { Permanent Assessment } \\
\text { Office }\end{array} \\
\end{array}$ & 1 & 2 & 0 & 3 & 23.1 \\
\hline $\begin{array}{l}\text { - Financial Resources for } \\
\text { Faculty to Attend } \\
\text { Conferences }\end{array}$ & 0 & 1 & 1 & 2 & 15.4 \\
\hline $\begin{array}{ll}\text { - } & \text { Faculty Development } \\
\text { Program }\end{array}$ & 1 & 0 & 1 & 2 & 15.4 \\
\hline - Assessment Committee & 1 & 0 & 0 & 1 & 7.7 \\
\hline $\begin{array}{ll} & \text { Creation of New } \\
& \text { Assessment Positions }\end{array}$ & 0 & 1 & 0 & 1 & 7.7 \\
\hline - Presidential Involvement & 0 & 0 & 1 & 1 & 7.7 \\
\hline $\begin{array}{l}\text { Campus-Wide Assessment } \\
\text { Committee With Broad } \\
\text { Representation }\end{array}$ & 2 & 4 & 3 & 9 & 69.2 \\
\hline $\begin{array}{l}\text { Incorporation of Guiding } \\
\text { Principles of Assessment in } \\
\text { Promotion and Tenure } \\
\text { Guidelines }\end{array}$ & 2 & 3 & 1 & 6 & 46.2 \\
\hline Culture That Values Assessment & 2 & 1 & 3 & 6 & 46.2 \\
\hline
\end{tabular}


Table 172

Commitments: Across institutions continued

\begin{tabular}{|c|c|c|c|c|c|}
\hline $\begin{array}{l}\text { Policies That Promote } \\
\text { Communication About } \\
\text { Assessment }\end{array}$ & 2 & 2 & 2 & 6 & 46.2 \\
\hline - Assessment Committee & 2 & 1 & 0 & 3 & 23.1 \\
\hline - $\quad$ New Student Orientation & 0 & 1 & 0 & 1 & 7.7 \\
\hline $\begin{array}{ll}\text { - } & \text { E-Mail Newsletter } \\
& \text { Distributed to Students } \\
\end{array}$ & 0 & 0 & 1 & 1 & 7.7 \\
\hline $\begin{array}{ll}\text { - } & \text { Directives From } \\
\text { Institutional Research } \\
\text { Office }\end{array}$ & 0 & 0 & 1 & 1 & 7.7 \\
\hline $\begin{array}{ll}- & \text { Communication } \\
& \text { Occurred in Class } \\
\end{array}$ & 0 & 0 & 1 & 1 & 7.7 \\
\hline $\begin{array}{l}\text { Guiding Principles for } \\
\text { Assessment }\end{array}$ & 2 & 2 & 0 & 4 & 30.8 \\
\hline $\begin{array}{l}\text { Assessment Data Considered in } \\
\text { Evaluating and Rewarding } \\
\text { Faculty }\end{array}$ & & & & & \\
\hline $\begin{array}{l}\text { Student Assessment Expertise } \\
\text { Considered in the Hiring } \\
\text { Process for New Faculty }\end{array}$ & 2 & 0 & 1 & 3 & 23.1 \\
\hline $\begin{array}{l}\text { Policies to Promote the } \\
\text { Involvement of Student Affairs } \\
\text { Personnel and Students in } \\
\text { Assessment Efforts }\end{array}$ & 0 & 1 & 1 & 2 & 15.4 \\
\hline Internal Consulting Services & 2 & 0 & 0 & 2 & 15.4 \\
\hline $\begin{array}{l}\text { - Institutional Assessment } \\
\text { Office }\end{array}$ & 2 & 0 & 0 & 2 & 15.4 \\
\hline $\begin{array}{l}\text { Publications Count Towards } \\
\text { Research }\end{array}$ & 1 & 0 & 0 & 1 & 7.7 \\
\hline Program Coordinator & 0 & 0 & 1 & 1 & 7.7 \\
\hline
\end{tabular}

Executive-level support was evident across all three institutions. Eighty-five percent of the program administrators reported that executive-level support was evident. The most frequently identified examples of executive level support included:

- financial resources for faculty working on assessment activities,

- a permanent assessment office, 
- financial resources for faculty to attend conferences, and

- faculty development programs.

Sixty-nine percent of the program administrators identified a campus-wide assessment committee and $46 \%$ identified the incorporation of guiding principles of assessment in promotion and tenure guidelines and a culture that valued assessment. Thirty-nine percent of the program administrators identified policies that promote communication about assessment. Program administrators reported that each of the aforementioned commitments were evident across the institutions included within the study.

Resources. Program administrators most frequently identified the following assessment resources:

- financial support,

- professional development opportunities,

- assessment related databases,

- consulting services,

- assessment related offices,

- Center for Teaching and Learning,

- technology departments, and

- access to on-line survey software (see Table 173).

Financial support for assessment was evident across all three institutions. Eighty-four percent of the program administrators reported that financial support was available. The most frequently identified examples of financial support included:

- support for faculty to attend assessment related conferences,

- assessment grants, and 
- $\quad$ assistance to purchase commercially available examinations.

Table 173

Resources: Across institutions

\begin{tabular}{|c|c|c|c|c|c|}
\hline \multirow[t]{2}{*}{ Resources } & \multirow{2}{*}{$\begin{array}{l}\text { Beta } \\
\text { University } \\
\text { (BU) }\end{array}$} & \multirow{2}{*}{$\begin{array}{l}\text { Alpha } \\
\text { University } \\
\text { (AU) }\end{array}$} & \multirow{2}{*}{$\begin{array}{l}\text { Gamma } \\
\text { University } \\
\text { (GU) }\end{array}$} & \multicolumn{2}{|c|}{ Total } \\
\hline & & & & $\mathrm{N}$ & $\%$ \\
\hline Financial Support & 3 & 4 & 4 & 11 & 84.6 \\
\hline - Support for Assessment & 1 & 0 & 0 & 1 & 7.7 \\
\hline $\begin{array}{l}\text { - Support for Faculty to } \\
\text { Attend Assessment } \\
\text { Related Conferences }\end{array}$ & 3 & 4 & 4 & 11 & 84.6 \\
\hline $\begin{array}{l}\text { - Course Release for } \\
\text { Assessment Purposes }\end{array}$ & 1 & 0 & 2 & 3 & 23.1 \\
\hline - Assessment Grants & 0 & 3 & 0 & 3 & 23.1 \\
\hline $\begin{array}{l}\text { Assistance to Purchase } \\
\text { Commercial } \\
\text { Examinations }\end{array}$ & 0 & 0 & 2 & 2 & 15.4 \\
\hline - $\quad$ Personnel Time & 0 & 1 & 0 & 1 & 7.7 \\
\hline $\begin{array}{ll}\text { - } & \text { Assessment } \\
& \text { Fellowships } \\
\end{array}$ & 0 & 0 & 1 & 1 & 7.7 \\
\hline $\begin{array}{l}\text { Stipends for } \\
\text { Assessment Related } \\
\text { Activities } \\
\end{array}$ & 0 & 0 & 1 & 1 & 7.7 \\
\hline $\begin{array}{l}\text { Professional Development } \\
\text { Opportunities }\end{array}$ & 3 & 4 & 3 & 10 & 76.9 \\
\hline $\begin{array}{ll}\text { - } & \text { Programming for } \\
& \text { Faculty }\end{array}$ & 3 & 4 & 3 & 10 & 76.9 \\
\hline $\begin{array}{l}\text { Programming for } \\
\text { Academic } \\
\text { Administrators } \\
\end{array}$ & 0 & 1 & 1 & 2 & 15.4 \\
\hline $\begin{array}{ll}\text { - } & \text { Programming for } \\
\text { Student Affairs } \\
\text { Personnel } \\
\end{array}$ & 0 & 1 & 0 & 1 & 7.7 \\
\hline Assessment Related Databases & 1 & 1 & 1 & 3 & 23.1 \\
\hline $\begin{array}{ll}- & \text { Comprehensive } \\
& \text { Assessment Database }\end{array}$ & 1 & 0 & 0 & 1 & 7.7 \\
\hline $\begin{array}{l}\text { - Assessment Related } \\
\text { Database }\end{array}$ & 0 & 1 & 1 & 2 & 15.4 \\
\hline Consulting Services & 2 & 4 & 4 & 10 & 76.9 \\
\hline $\begin{array}{ll}\text { Internal Consulting } \\
\text { Services }\end{array}$ & 2 & 4 & 3 & 9 & 69.2 \\
\hline
\end{tabular}


Table 173

Resources: Across institutions continued

\begin{tabular}{|c|c|c|c|c|c|}
\hline Resources & $\begin{array}{l}\text { Beta } \\
\text { University } \\
\text { (BU) }\end{array}$ & $\begin{array}{l}\text { Alpha } \\
\text { University } \\
\text { (AU) }\end{array}$ & $\begin{array}{l}\text { Gamma } \\
\text { University } \\
\text { (GU) }\end{array}$ & \multicolumn{2}{|c|}{ Total } \\
\cline { 3 - 6 } & 1 & 1 & 2 & 4 & 30.8 \\
\hline $\begin{array}{c}\text { External Consulting } \\
\text { Services }\end{array}$ & 1 & 3 & 4 & 8 & 61.5 \\
\hline $\begin{array}{c}\text { Assessment Related Offices } \\
\bullet \quad \begin{array}{l}\text { Office Charged With } \\
\text { Coordinating Data- } \\
\text { Gathering Initiatives }\end{array}\end{array}$ & 1 & 1 & 1 & 3 & 23.1 \\
\hline $\begin{array}{l}\text { Institutional Research } \\
\text { Office }\end{array}$ & 0 & 3 & 1 & 4 & 30.8 \\
\hline $\begin{array}{l}\text { Permanent Assessment } \\
\text { Office (Institution) }\end{array}$ & 1 & 4 & 3 & 8 & 61.5 \\
\hline $\begin{array}{l}\text { Program-Level/School } \\
\text { Assessment Office }\end{array}$ & 0 & 2 & 0 & 2 & 15.4 \\
\hline $\begin{array}{l}\text { Center for Teaching and } \\
\text { Learning }\end{array}$ & 0 & 3 & 0 & 3 & 23.1 \\
\hline Technology Department & 0 & 1 & 1 & 2 & 15.4 \\
\hline $\begin{array}{l}\text { Access to On-Line Survey } \\
\text { Software }\end{array}$ & 0 & 0 & 2 & 2 & 15.4 \\
\hline Center for Faculty Innovation & 0 & 0 & 1 & 1 & 7.7 \\
\hline Assessment Committee & 1 & 0 & 0 & 1 & 7.7 \\
\hline $\begin{array}{l}\text { "People” That Are Helpful } \\
\text { With Data Gathering Initiatives }\end{array}$ & 1 & 0 & 0 & 1 & 7.7 \\
\hline
\end{tabular}

\section{Mathematics and Statistics Departments}

A total of eight individuals in the Department of Mathematics and Statistics from BU, AU, and GU participated in this study. The researcher interviewed two department chairs and six faculty members.

\section{Characteristics of Effective Assessment Practice}

The researcher analyzed interview data, annual assessment reports, and assessment plans to identify characteristics of effective practice.

Credible evidence of learning. Intended learning outcomes across all of the institutions spanned at least three of the cognitive domains included within Bloom's 
Taxonomy. The outcomes were skewed to the lower to mid-level domains (see Table 174). Eighty-seven percent of the outcomes represented the remember, understand, and apply domains. Thirteen percent of the outcomes represented the analyze, evaluate, and create domains. The highest percentage of outcomes in the mathematics and statistics department at BU represented the create domain, the highest percentage of outcomes at AU represented the understand domain, and the highest percentage of outcomes at GU represented the apply domain.

Table 174

Distribution of intended learning outcomes: Mathematics department

\begin{tabular}{|l|c|c|l|c|c|c|c|c|}
\hline $\begin{array}{l}\text { Cognitive } \\
\text { Domains }\end{array}$ & \multicolumn{2}{l|l}{$\begin{array}{l}\text { Beta } \\
\text { University } \\
\text { (BU) }\end{array}$} & $\begin{array}{l}\text { Alpha } \\
\text { University } \\
\text { (AU) }\end{array}$ & \multicolumn{2}{l|}{$\begin{array}{l}\text { Gamma } \\
\text { University } \\
\text { (GU) }\end{array}$} & \multicolumn{2}{|l|}{} \\
\cline { 2 - 11 } & $\mathrm{N}$ & $\%$ & $\mathrm{~N}$ & $\%$ & $\mathrm{~N}$ & $\%$ & $\mathrm{~N}$ & $\%$ \\
\hline Remember & 0 & 0 & 0 & 0 & 35 & 39.3 & 35 & 33.7 \\
\hline Understand & 2 & 28.6 & 5 & 62.5 & 4 & 4.5 & 11 & 10.6 \\
\hline Apply & 1 & 14.3 & 1 & 12.5 & 42 & 47.2 & 44 & 42.3 \\
\hline Analyze & 1 & 14.3 & 2 & 25 & 1 & 1.1 & 4 & 3.9 \\
\hline Evaluate & 0 & 0 & 0 & 0 & 4 & 4.5 & 4 & 3.9 \\
\hline Create & 3 & 42.9 & 0 & 0 & 3 & 3.4 & 6 & 5.8 \\
\hline
\end{tabular}

Mathematics program faculty exclusively utilized direct assessment of student learning. Faculty at BU and AU implemented common final examinations and research products while faculty at GU implemented course-embedded examination items (see Table 17).

Table 175

Assessments: Mathematics department

\begin{tabular}{|l|l|l|l|}
\hline Assessments & $\begin{array}{l}\text { Beta } \\
\text { University } \\
(\mathrm{BU})\end{array}$ & $\begin{array}{l}\text { Alpha } \\
\text { University } \\
(\mathrm{AU})\end{array}$ & $\begin{array}{l}\text { Gamma } \\
\text { University } \\
\text { (GU) }\end{array}$ \\
\hline Direct Assessments & 2 & 2 & 1 \\
\hline
\end{tabular}


Table 175

Assessments: Mathematics department continued

\begin{tabular}{|c|c|c|c|}
\hline Assessments & $\begin{array}{l}\text { Beta } \\
\text { University } \\
\text { (BU) }\end{array}$ & $\begin{array}{l}\text { Alpha } \\
\text { University } \\
\text { (AU) }\end{array}$ & $\begin{array}{l}\text { Gamma } \\
\text { University } \\
\text { (GU) }\end{array}$ \\
\hline$\bullet \quad \begin{array}{l}\text { Locally Developed Embedded } \\
\text { Examination Items }\end{array}$ & 0 & 0 & 1 \\
\hline$\bullet \quad$ Common Final Examinations & 1 & 1 & 0 \\
\hline$\bullet \begin{array}{l}\text { Research Project/Paper } \\
\text { (Capstone) }\end{array}$ & 1 & 1 & 0 \\
\hline
\end{tabular}

Continuously improve programs and services. Faculty representing BU and GU implemented curricular changes based on assessment data. BU faculty created a new required course, revised their senior/capstone project, and added credit hours to a specific course (see Table 176). GU faculty offered new courses for specific specializations within the mathematics major. Additionally, GU offered new courses as a service to other programs. Program faculty at AU did not implement any changes to improve programs and services based on assessment data.

Table 176

Continuously improve programs and services: Mathematics department

\begin{tabular}{|c|c|c|c|}
\hline Actions & $\begin{array}{l}\text { Beta University } \\
(\mathrm{BU})\end{array}$ & $\begin{array}{l}\text { Alpha } \\
\text { University } \\
\text { (AU) }\end{array}$ & $\begin{array}{l}\text { Gamma } \\
\text { University (GU) }\end{array}$ \\
\hline Curricular Revisions & 3 & 0 & 1 \\
\hline $\begin{array}{l}\text { - Created New Required } \\
\text { Course }\end{array}$ & 1 & 0 & 0 \\
\hline $\begin{array}{ll}\text { - } & \text { Revised Senior/Capstone } \\
& \text { Project } \\
\end{array}$ & 1 & 0 & 0 \\
\hline - $\quad$ Added Credits to Course & 1 & 0 & 0 \\
\hline $\begin{array}{l}\text { - Offer New Courses for } \\
\text { Specific Specializations } \\
\text { Within the Major }\end{array}$ & 0 & 0 & 1 \\
\hline $\begin{array}{l}\text { Offer New Courses as a Service to } \\
\text { Other Programs }\end{array}$ & 0 & 0 & 1 \\
\hline
\end{tabular}


Accountability to internal stakeholders. Program administrators most frequently identified annual assessment reports submitted to central leaders and senior projects as the mechanisms that maintained accountability to internal stakeholders (see Table 177). Table 177

Accountability to internal stakeholders: Mathematics department

\begin{tabular}{|l|c|c|c|c|c|}
\hline & $\begin{array}{l}\text { Beta } \\
\text { University } \\
\text { (BU) }\end{array}$ & $\begin{array}{l}\text { Alpha } \\
\text { University } \\
\text { (AU) }\end{array}$ & $\begin{array}{l}\text { Gamma } \\
\text { University } \\
\text { (GU) }\end{array}$ & \multicolumn{2}{|c|}{ Total } \\
\cline { 3 - 6 } & 0 & 1 & 1 & 2 & 66.6 \\
\hline $\begin{array}{l}\text { Annual Assessment } \\
\text { Reports Submitted to } \\
\text { Central Leadership }\end{array}$ & 1 & 1 & 0 & 2 & 66.6 \\
\hline $\begin{array}{l}\text { Senior } \\
\text { Project/Capstone }\end{array}$ & 0 & 0 & 1 & 1 & 33.3 \\
\hline $\begin{array}{l}\text { School Assessment } \\
\text { Committee }\end{array}$ & 0 & 0 & 1 & 1 & 33.3 \\
\hline $\begin{array}{l}\text { Program Assessment } \\
\text { Committee }\end{array}$ & 0 & 1 & 0 & 1 & 33.3 \\
\hline Common Examinations & 0 & & & \\
\hline
\end{tabular}

Program administrators reported that annual assessment reports were submitted to central leaders at AU and GU. Additionally, the program administrators identified the senior project/capstone experience as a mechanism to maintain accountability to internal stakeholders ant BU and AU.

Ongoing assessment. Evidence from interviews and documents revealed that faculty representing each program included within this study conducted ongoing assessment activities. Faculty conducted assessment activities on a predictable schedule (see Table 178). Additionally, program faculty at BU reported that the senior project facilitated ongoing assessment while faculty at GU reported that common examination items facilitated ongoing assessment. 
Table 178

Ongoing assessment: Mathematics department

\begin{tabular}{|l|l|l|c|c|c|}
\hline & \multicolumn{1}{|l|}{$\begin{array}{l}\text { Beta } \\
\text { University } \\
\text { (BU) }\end{array}$} & $\begin{array}{l}\text { Alpha } \\
\text { University } \\
\text { (AU) }\end{array}$ & $\begin{array}{l}\text { Gamma } \\
\text { University } \\
\text { (GU) }\end{array}$ & \multicolumn{2}{|c|}{ Total } \\
\cline { 3 - 6 } & 1 & 1 & 1 & 3 & 100 \\
\hline Predictable Schedule & 1 & 0 & 0 & 1 & 33.3 \\
\hline $\begin{array}{l}\text { Senior } \\
\text { Project/Capstone } \\
\text { Experience }\end{array}$ & 0 & 0 & 1 & 1 & 33.3 \\
\hline $\begin{array}{l}\text { Common Examination } \\
\text { Items }\end{array}$ & 0 & & & & \\
\hline
\end{tabular}

Ongoing evaluation and improvement. No evidence suggested that program faculty from any of the mathematics programs practiced ongoing evaluation and improvement of the assessment plan itself (see Table 179).

Table 179

Ongoing evaluation and improvement: Mathematics

\begin{tabular}{|l|c|l|l|c|c|}
\hline Actions & \multicolumn{1}{|l|}{$\begin{array}{l}\text { Beta University } \\
(\mathrm{BU})\end{array}$} & $\begin{array}{l}\text { Alpha } \\
\text { University } \\
(\mathrm{AU})\end{array}$ & $\begin{array}{l}\text { Gamma } \\
\text { University } \\
(\mathrm{GU})\end{array}$ & \multicolumn{2}{|c|}{ Total } \\
\cline { 3 - 6 } & & 1 & $\mathrm{~N}$ & $\%$ \\
\hline $\begin{array}{l}\text { Plan Did Not } \\
\begin{array}{l}\text { Encompass this } \\
\text { Element }\end{array}\end{array}$ & 1 & 1 & 3 & 100 \\
\hline
\end{tabular}

\section{Institutional Commitments and Resources}

Commitments. Department chairs from BU and GU identified executive-level support as an important commitment for assessment (see Table 180). Both chairs reported that executive-level support was evident through financial resources for faculty working on assessment activities. The department chair representing BU also noted that executivelevel support was evident through the faculty development program while the department chair representing GU identified financial support for faculty to attend conferences. 
Table 180

Commitments: Mathematics department

\begin{tabular}{|c|c|c|c|c|}
\hline \multirow[t]{2}{*}{ Commitments } & \multirow{2}{*}{$\begin{array}{l}\text { Beta } \\
\text { University } \\
(\mathrm{BU})\end{array}$} & \multirow{2}{*}{$\begin{array}{l}\text { Gamma } \\
\text { University } \\
\text { (GU) }\end{array}$} & \multicolumn{2}{|c|}{ Total } \\
\hline & & & $\mathrm{N}$ & $\%$ \\
\hline Executive-Level Support & 1 & 1 & 2 & \\
\hline $\begin{array}{ll}\text { - Financial Resources for } \\
\text { Faculty Working on } \\
\text { Assessment Activities } \\
\end{array}$ & 1 & 1 & 2 & \\
\hline $\begin{array}{l}\text { - Financial Resources for } \\
\text { Faculty to Attend } \\
\text { Conferences }\end{array}$ & 0 & 1 & 1 & \\
\hline $\begin{array}{ll}\text { - } & \text { Faculty Development } \\
& \text { Program } \\
\end{array}$ & 1 & 0 & 1 & \\
\hline $\begin{array}{l}\text { Campus-Wide Assessment } \\
\text { Committee With Broad } \\
\text { Representation }\end{array}$ & 0 & 1 & 1 & \\
\hline Culture That Values Assessment & 1 & 0 & 1 & \\
\hline $\begin{array}{l}\text { Policies That Promote } \\
\text { Communication About } \\
\text { Assessment }\end{array}$ & 1 & 0 & 1 & \\
\hline - Assessment Committee & 1 & 0 & 1 & \\
\hline $\begin{array}{l}\text { Guiding Principles for } \\
\text { Assessment }\end{array}$ & 1 & 0 & 1 & \\
\hline $\begin{array}{l}\text { Assessment Data Considered in } \\
\text { Evaluating and Rewarding } \\
\text { Faculty }\end{array}$ & 1 & 0 & 1 & \\
\hline $\begin{array}{l}\text { Student Assessment Expertise } \\
\text { Considered in the Hiring } \\
\text { Process for New Faculty }\end{array}$ & 1 & 0 & 1 & \\
\hline Internal Consulting Services & 1 & 0 & 0 & \\
\hline $\begin{array}{ll}\text { - Institutional Assessment } \\
\text { Office }\end{array}$ & 1 & 0 & 0 & \\
\hline
\end{tabular}

Resources. Department chairs at BU and GU identified financial support for faculty

to attend assessment related conferences, professional development opportunities for

faculty, and internal consulting services as important resources for assessment (see Table

181). The department chair at AU also identified course releases for assessment 
purposes, professional development programming for academic administrators, and a permanent assessment office as important resources.

Table 181

Resources: Mathematics department

\begin{tabular}{|c|c|c|c|c|}
\hline \multirow[t]{2}{*}{ Resources } & \multirow{2}{*}{$\begin{array}{l}\text { Beta } \\
\text { University } \\
\text { (BU) }\end{array}$} & \multirow{2}{*}{$\begin{array}{l}\text { Gamma } \\
\text { University } \\
\text { (GU) }\end{array}$} & \multicolumn{2}{|c|}{ Total } \\
\hline & & & $\mathrm{N}$ & $\%$ \\
\hline Financial Support & 1 & 1 & 2 & 100 \\
\hline $\begin{array}{l}\text { - Support for Faculty to } \\
\text { Attend Assessment } \\
\text { Related Conferences }\end{array}$ & 1 & 1 & 2 & 100 \\
\hline $\begin{array}{l}\text { - Course Release for } \\
\text { Assessment Purposes }\end{array}$ & 0 & 1 & 1 & 50 \\
\hline $\begin{array}{l}\text { Professional Development } \\
\text { Opportunities }\end{array}$ & 1 & 1 & 2 & 100 \\
\hline $\begin{array}{ll}\text { - } & \text { Programming for } \\
& \text { Faculty } \\
\end{array}$ & 1 & 1 & 2 & 100 \\
\hline $\begin{array}{l}\text { - } \text { Programming for } \\
\text { Academic } \\
\text { Administrators }\end{array}$ & 0 & 1 & 1 & 50 \\
\hline Consulting Services & 1 & 1 & 2 & 100 \\
\hline $\begin{array}{l}\text { - Internal Consulting } \\
\text { Services }\end{array}$ & 1 & 1 & 2 & 100 \\
\hline Assessment Related Offices & 0 & 1 & 1 & 50 \\
\hline $\begin{array}{ll}\text { - } & \text { Permanent Assessment } \\
\text { Office (Institution) }\end{array}$ & 0 & 1 & 1 & 50 \\
\hline
\end{tabular}

Faculty Satisfaction with Assessment

Mathematics faculty across all institutions shared a diverse mix of strengths and challenges related to the assessment process. The researcher identified common themes pertaining to the strengths of the assessment methods, resources, institutional assessment office, faculty participation, the benefits of conducting assessment, and faculty ownership and challenges with the assessment plan. 
Mathematics program faculty reported that assessment methods were a strength of the assessment plan. Specifically, faculty were satisfied that the plan incorporated multiple challenging assessments (see Table 182).

Table 182

Assessment methods: Strengths

\begin{tabular}{|l|c|l|l|}
\hline Factors & $\begin{array}{l}\text { Beta University } \\
\text { (BU) }\end{array}$ & $\begin{array}{l}\text { Alpha } \\
\text { University } \\
\text { (AU) }\end{array}$ & $\begin{array}{l}\text { Gamma } \\
\text { University } \\
\text { (GU) }\end{array}$ \\
\hline $\begin{array}{l}\text { Multiple } \\
\text { Methods of } \\
\text { Assessment }\end{array}$ & $\mathrm{X}$ & \\
\hline $\begin{array}{l}\text { Challenging } \\
\text { Assessments }\end{array}$ & $\mathrm{X}$ & & \\
\hline $\begin{array}{l}\text { Senior } \\
\text { Assignment }\end{array}$ & $\mathrm{X}$ & & \\
\hline $\begin{array}{l}\text { Common } \\
\text { Examinations }\end{array}$ & & $\mathrm{X}$ & \\
\hline $\begin{array}{l}\text { Course- } \\
\text { Embedded } \\
\text { Assessment }\end{array}$ & & & $\mathrm{X}$ \\
\hline
\end{tabular}

Faculty across both programs reported that resources were allocated to the assessment process. They identified the expertise of institutional- and department-level leaders as well as fiscal resources (see Table 183).

Table 183

Resources: Strengths

\begin{tabular}{|l|l|l|l|}
\hline Factors & $\begin{array}{l}\text { Beta University } \\
\text { (BU) }\end{array}$ & $\begin{array}{l}\text { Alpha } \\
\text { University } \\
\text { (AU) }\end{array}$ & $\begin{array}{l}\text { Gamma } \\
\text { University } \\
\text { (GU) }\end{array}$ \\
\hline $\begin{array}{l}\text { Permanent } \\
\begin{array}{l}\text { Assessment } \\
\text { Office }\end{array}\end{array}$ & & X \\
\hline $\begin{array}{l}\text { Conference } \\
\text { Support }\end{array}$ & & & X \\
\hline
\end{tabular}


Table 183

Resources: Strengths continued

\begin{tabular}{|l|l|l|c|}
\hline Factors & $\begin{array}{l}\text { Beta University } \\
\text { (BU) }\end{array}$ & $\begin{array}{l}\text { Alpha } \\
\text { University } \\
\text { (AU) }\end{array}$ & $\begin{array}{l}\text { Gamma } \\
\text { University } \\
\text { (GU) }\end{array}$ \\
\hline $\begin{array}{l}\text { Faculty Release } \\
\text { Time }\end{array}$ & & & $\mathrm{X}$ \\
\hline $\begin{array}{l}\text { Assessment } \\
\text { Fellowships }\end{array}$ & & $\mathrm{X}$ & $\mathrm{X}$ \\
\hline $\begin{array}{l}\text { Department } \\
\text { Assessment } \\
\text { Leader }\end{array}$ & & $\mathrm{X}$ & \\
\hline $\begin{array}{l}\text { Institutional } \\
\text { Assessment } \\
\text { Leader }\end{array}$ & & $\mathrm{X}$ & \\
\hline $\begin{array}{l}\text { Availability of } \\
\text { Resources for } \\
\text { Assessment } \\
\text { Activities }\end{array}$ & & & \\
\hline $\begin{array}{l}\text { Financial } \\
\text { Support }\end{array}$ & & $\mathrm{X}$ & \\
\hline
\end{tabular}

Faculty representing two of the three mathematics programs reported that their institutional assessment offices provided important support and resources to the assessment process. These resources included assessment fellowships and support from the institutional assessment leader (see Table 184).

Table 184

Institutional assessment office: Strengths

\begin{tabular}{|l|l|l|l|}
\hline Factors & $\begin{array}{l}\text { Beta University } \\
\text { (BU) }\end{array}$ & $\begin{array}{l}\text { Alpha } \\
\text { University } \\
\text { (AU) }\end{array}$ & $\begin{array}{l}\text { Gamma } \\
\text { University } \\
\text { (GU) }\end{array}$ \\
\hline $\begin{array}{l}\text { Assessment } \\
\text { Fellowships }\end{array}$ & & & X \\
\hline $\begin{array}{l}\text { Institutional } \\
\begin{array}{l}\text { Assessment } \\
\text { Leader }\end{array}\end{array}$ & & $\mathrm{X}$ & \\
\hline
\end{tabular}


Faculty across the programs reported that service to various academic committees and participation in annual faculty meetings were important strengths related to faculty participation (see Table 185). Additionally, some faculty reported that their own contributions to the assessment plan ensured participation.

Table 185

Faculty participation: Strengths

\begin{tabular}{|l|c|l|l|}
\hline Factors & $\begin{array}{l}\text { Beta University } \\
\text { (BU) }\end{array}$ & $\begin{array}{l}\text { Alpha } \\
\text { University } \\
\text { (AU) }\end{array}$ & $\begin{array}{l}\text { Gamma } \\
\text { University } \\
\text { (GU) }\end{array}$ \\
\hline $\begin{array}{l}\text { Committee } \\
\text { Participation }\end{array}$ & $\mathrm{X}$ & & \\
\hline $\begin{array}{l}\text { Annual Faculty } \\
\text { Meeting }\end{array}$ & $\mathrm{X}$ & & \\
\hline $\begin{array}{l}\text { Personal } \\
\text { Contribution to } \\
\text { the Assessment } \\
\text { Plan }\end{array}$ & & & \\
\hline $\begin{array}{l}\text { Service to the } \\
\text { Departmental } \\
\text { Assessment } \\
\text { Committee }\end{array}$ & & & \\
\hline
\end{tabular}

Faculty across the programs reported that assessment provided many benefits. As a result of assessment activities, many faculty reported that improvements in retention and student achievement occurred. Additionally, faculty noted that assessment generated useful information (see Table 186).

Table 186

Benefits of assessment: Strengths

\begin{tabular}{|l|l|l|l|}
\hline Factors & $\begin{array}{l}\text { Beta University } \\
(\mathrm{BU})\end{array}$ & $\begin{array}{l}\text { Alpha } \\
\text { University } \\
\text { (AU) }\end{array}$ & $\begin{array}{l}\text { Gamma } \\
\text { University } \\
\text { (GU) }\end{array}$ \\
\hline $\begin{array}{l}\text { Improved } \\
\text { Retention }\end{array}$ & & \multicolumn{1}{|c|}{$\mathrm{X}$} & \\
\hline
\end{tabular}


Table 186

Benefits of assessment: Strengths continued

\begin{tabular}{|l|l|l|l|}
\hline Factors & $\begin{array}{l}\text { Beta University } \\
\text { (BU) }\end{array}$ & $\begin{array}{l}\text { Alpha } \\
\text { University } \\
\text { (AU) }\end{array}$ & $\begin{array}{l}\text { Gamma } \\
\text { University } \\
\text { (GU) }\end{array}$ \\
\hline $\begin{array}{l}\text { Improved } \\
\text { Student } \\
\text { Achievement }\end{array}$ & & \multicolumn{1}{|c|}{$\mathrm{X}$} & \\
\hline $\begin{array}{l}\text { Generation of } \\
\text { Useful } \\
\text { Information }\end{array}$ & & & $\mathrm{X}$ \\
\hline
\end{tabular}

Mathematics program faculty reported that their ownership of the assessment plan was an important strength. They noted that the plan minimally interfered with the process of teaching and learning (see Table 187).

Table 187

Faculty ownership: Strengths

\begin{tabular}{|l|l|l|l|}
\hline Factors & $\begin{array}{l}\text { Beta University } \\
\text { (BU) }\end{array}$ & $\begin{array}{l}\text { Alpha } \\
\text { University } \\
\text { (AU) }\end{array}$ & $\begin{array}{l}\text { Gamma } \\
\text { University } \\
\text { (GU) }\end{array}$ \\
\hline $\begin{array}{l}\text { Minimal } \\
\begin{array}{l}\text { Interference } \\
\text { with Teaching } \\
\text { and Learning }\end{array}\end{array}$ & & X \\
\hline $\begin{array}{l}\text { Ownership of } \\
\text { Assessment } \\
\text { Within the } \\
\text { Department }\end{array}$ & $\mathrm{X}$ & & \\
\hline
\end{tabular}

Mathematics program faculty identified several challenges with the assessment plan. Faculty members were disappointed that assessment data could not be compared to students at other campuses and that assessment activities increased the workload of 
students (see Table 188). Faculty also reported that the assessment plan was in a constant state of revision. Thus, utilizing assessment data was a challenge.

Table 188

Assessment plan: Challenges

\begin{tabular}{|l|c|l|c|}
\hline Factors & $\begin{array}{l}\text { Beta University } \\
\text { (BU) }\end{array}$ & $\begin{array}{l}\text { Alpha } \\
\text { University } \\
\text { (AU) }\end{array}$ & $\begin{array}{l}\text { Gamma } \\
\text { University } \\
\text { (GU) }\end{array}$ \\
\hline Nationally Comparable Data & $\mathrm{X}$ & & \\
\hline Increased Workload for Students & $\mathrm{X}$ & $\mathrm{X}$ & \\
\hline $\begin{array}{l}\text { Assessment Plan Was Under } \\
\text { Revision }\end{array}$ & & & $\mathrm{X}$ \\
\hline Use of Assessment Data & & & $\mathrm{X}$ \\
\hline Sharing of Assessment Data & & & \\
\hline Increased Workload for Faculty & $\mathrm{X}$ & & \\
\hline Increased Workload for Students & $\mathrm{X}$ & & \\
\hline
\end{tabular}

Undergraduate English Program

A total of five individuals from the undergraduate English programs at BU and AU participated in this study. The researcher interviewed one department chair, one assistant department chair, and three faculty members.

Characteristics of Effective Assessment Practice

The researcher analyzed interview data, annual assessment reports, and assessment plans to identify characteristics of effective practice.

Credible evidence of learning. The researcher was not given access to the intended learning outcomes from AU. Program administrators from BU and AU did not report any common assessment methods (see Table 189). Faculty from BU implemented a research project/paper while AU faculty implemented a self-reflection of program outcomes and goals. 
Table 189

Assessments: English

\begin{tabular}{|c|l|l|l|l|}
\hline Assessments & $\begin{array}{l}\text { Beta } \\
\text { University } \\
\text { (BU) }\end{array}$ & $\begin{array}{l}\text { Alpha } \\
\text { University } \\
\text { (AU) }\end{array}$ & \multicolumn{2}{|l|}{ Total } \\
\cline { 3 - 5 } & & & $\mathrm{N}$ & $\%$ \\
\hline Direct Assessments & 1 & 0 & 1 & 50 \\
\hline $\begin{array}{l}\text { Research } \\
\text { Project/Paper }\end{array}$ & 1 & 0 & 1 & 50 \\
\hline Portfolio & & 1 & 1 & 50 \\
\hline Indirect Assessments & 0 & & & \\
\hline $\begin{array}{l}\text { Self-Reflection of } \\
\text { Program Outcomes } \\
\text { and Goals }\end{array}$ & & & & \\
\hline
\end{tabular}

Continuously improve programs and services. Faculty from each institution reported that curricular revisions were informed with assessment data. Faculty at BU created a new required course (see Table 190). Additionally, program administrators at AU utilized assessment data to change faculty development opportunities.

Table 190

Continuously improve programs and services: English

\begin{tabular}{|c|c|c|}
\hline Actions & $\begin{array}{l}\text { Beta University } \\
(\mathrm{BU})\end{array}$ & $\begin{array}{l}\text { Alpha } \\
\text { University } \\
\text { (AU) }\end{array}$ \\
\hline Curricular Revisions & 1 & 1 \\
\hline $\begin{array}{l}\text { - Created New Required } \\
\text { Course }\end{array}$ & 1 & 0 \\
\hline $\begin{array}{l}\text { Changed Faculty Development } \\
\text { Opportunities }\end{array}$ & 0 & 1 \\
\hline
\end{tabular}

Accountability to internal stakeholders. Program administrators did not identify any common mechanisms to maintain accountability to internal stakeholders (see Table 191). Faculty at BU utilized to informal evidence to maintain accountability while faculty at AU utilized the school- and program-level assessment committees. 
Table 191

Accountability to internal stakeholders: English

\begin{tabular}{|l|c|c|c|c|}
\hline & \multicolumn{1}{|l|}{$\begin{array}{l}\text { Beta } \\
\text { University } \\
\text { (BU) }\end{array}$} & $\begin{array}{l}\text { Alpha } \\
\text { University } \\
\text { (AU) }\end{array}$ & \multicolumn{2}{|c|}{ Total } \\
\cline { 3 - 5 } & 0 & 1 & 1 & 50 \\
\hline $\begin{array}{l}\text { School Assessment } \\
\text { Committee }\end{array}$ & 0 & 1 & 1 & 50 \\
\hline $\begin{array}{l}\text { Program Assessment } \\
\text { Committee }\end{array}$ & 1 & 0 & 1 & 50 \\
\hline Informal Evidence & & & & \\
\hline
\end{tabular}

Ongoing assessment. Faculty at BU and AU conducted assessment activities on a predictable schedule (see Table 192). The program administrator at BU also revealed that faculty had continuous assessment discussions.

Table 192

Ongoing assessment: English

\begin{tabular}{|l|c|c|c|c|}
\hline & \multicolumn{1}{|c|}{$\begin{array}{l}\text { Beta } \\
\text { University } \\
\text { (BU) }\end{array}$} & $\begin{array}{l}\text { Alpha } \\
\text { University } \\
\text { (AU) }\end{array}$ & \multicolumn{2}{|c|}{ Total } \\
\cline { 3 - 5 } & 1 & 1 & 2 & 100 \\
\hline Predictable Schedule & 1 & 0 & 1 & 0 \\
\hline $\begin{array}{l}\text { Faculty Had } \\
\begin{array}{l}\text { Continuous Assessment } \\
\text { Discussions }\end{array}\end{array}$ & \multicolumn{2}{|c|}{0} \\
\hline
\end{tabular}

Ongoing evaluation and improvement. Program administrators did not identify any common methods to ensure that the assessment plan was continuously evaluated and improved (see Table 193). The assistant department chair at BU reported that the assessment plan did not contain a formal method for evaluation and improvement. However, he noted that sometimes faculty held informal discussions to evaluate the assessment plan. The department chair representing AU reported that the quantity of faculty involved in program assessment ensured that the assessment plan was continually evaluated and improved. 
Table 193

Ongoing evaluation and improvement: English

\begin{tabular}{|c|c|c|c|c|}
\hline \multirow[t]{2}{*}{ Actions } & \multirow{2}{*}{$\begin{array}{l}\text { Beta University } \\
(\mathrm{BU})\end{array}$} & \multirow{2}{*}{$\begin{array}{l}\text { Alpha } \\
\text { University } \\
\text { (AU) }\end{array}$} & \multicolumn{2}{|c|}{ Total } \\
\hline & & & $\mathrm{N}$ & $\%$ \\
\hline $\begin{array}{l}\text { Plan Did Not } \\
\text { Encompass this } \\
\text { Element }\end{array}$ & 1 & 0 & 1 & 50 \\
\hline "Anecdotally" & 1 & 0 & 1 & 50 \\
\hline $\begin{array}{l}\text { Quantity of } \\
\text { Faculty } \\
\text { Involved in } \\
\text { Program } \\
\text { Assessment }\end{array}$ & 0 & 1 & 1 & 50 \\
\hline
\end{tabular}

\section{Institutional Commitments and Resources}

Commitments. Program administrators from BU and AU identified executive-level support, a campus-wide assessment committee with broad representation, the incorporation of outcomes assessment in promotion and tenure guidelines, policies that promote communication about assessment, and guiding principles of assessment as important commitments (see Table 194).

Table 194

Commitments: English

\begin{tabular}{|c|c|c|c|c|}
\hline Commitments & \multirow{2}{*}{$\begin{array}{l}\text { Beta } \\
\text { University }\end{array}$} & $\begin{array}{l}\text { Alpha } \\
\text { University } \\
\text { (AU) }\end{array}$ & N & \multicolumn{2}{|c|}{ Total } \\
\hline Executive-Level Support & 1 & 1 & 2 & 100 \\
\hline $\begin{array}{l}\text { Financial Resources for Faculty } \\
\text { Working on Assessment Activities }\end{array}$ & 1 & 0 & 1 & 50 \\
\hline$\quad$ Permanent Assessment Office & 0 & 1 & 1 & 50 \\
\hline$\bullet \quad$ Assessment Committee & 1 & 0 & 1 & 50 \\
\hline $\begin{array}{l}\text { Campus-Wide Assessment Committee With } \\
\text { Broad Representation }\end{array}$ & 1 & 1 & 2 & 100 \\
\hline $\begin{array}{l}\text { Incorporation of Guiding Principles of } \\
\text { Assessment in Promotion and Tenure } \\
\text { Guidelines }\end{array}$ & 1 & 1 & 2 & 100 \\
\hline
\end{tabular}


Table 194

Commitments: English continued

\begin{tabular}{|l|l|l|c|c|}
\hline Commitments & \multirow{2}{*}{$\begin{array}{l}\text { Beta } \\
\text { University }\end{array}$} & $\begin{array}{l}\text { Alpha } \\
\text { University } \\
\text { (AU) }\end{array}$ & \multicolumn{2}{|c|}{ Total } \\
\cline { 5 - 6 } & N & $\%$ \\
\hline $\begin{array}{l}\text { Policies That Promote Communication About } \\
\text { Assessment }\end{array}$ & 1 & 1 & 2 & 100 \\
\hline • Assessment Committee & 1 & 1 & 2 & 100 \\
\hline Guiding Principles for Assessment & 1 & 1 & 2 & 100 \\
\hline Publications Count Towards Research & 1 & 0 & 1 & 50 \\
\hline
\end{tabular}

The assistant department chair representing BU reported that executive-level support was evident though financial resources for faculty working on assessment activities and the campus-wide assessment committee. The department chair representing AU reported that executive-level support was evident though the institution's permanent assessment office. Both program administrators reported that assessment committees were important to communication about assessment.

Resources. Program administrators at BU and AU identified financial support for faculty to attend assessment related conferences, professional development opportunities for faculty, and internal consulting services as important resources for assessment (see Table 195). The assistant dean representing BU also identified external consulting services, an assessment committee, and “people” that were helpful with data gathering initiatives. The assistant department chair at BU also identified course releases for assessment purposes, professional development programming for academic administrators, and a permanent assessment office as important resources. The department chair at AU identified assessment grants, the institutional research office, the 
institutional assessment office, and the Center for Teaching and Learning as important resources.

Table 195

Resources: English

\begin{tabular}{|c|c|c|c|c|}
\hline \multirow[t]{2}{*}{ Resources } & \multirow{2}{*}{$\begin{array}{l}\text { Beta } \\
\text { University } \\
\text { (BU) }\end{array}$} & \multirow{2}{*}{$\begin{array}{l}\text { Alpha } \\
\text { University } \\
\text { (AU) }\end{array}$} & \multicolumn{2}{|c|}{ Total } \\
\hline & & & $\mathrm{N}$ & $\%$ \\
\hline Financial Support & 1 & 1 & 2 & 100 \\
\hline - Support for Assessment & 1 & 0 & 1 & 50 \\
\hline $\begin{array}{l}\text { - Support for Faculty to } \\
\text { Attend Assessment } \\
\text { Related Conferences }\end{array}$ & 1 & 1 & 2 & 100 \\
\hline - Assessment Grants & 0 & 1 & 1 & 50 \\
\hline $\begin{array}{l}\text { Professional Development } \\
\text { Opportunities }\end{array}$ & 1 & 1 & 2 & 100 \\
\hline $\begin{array}{ll}\text { - } & \text { Programming for } \\
& \text { Faculty }\end{array}$ & 1 & 1 & 2 & 100 \\
\hline Consulting Services & 1 & 1 & 2 & 100 \\
\hline $\begin{array}{ll}\text { - } & \text { Internal Consulting } \\
\text { Services }\end{array}$ & 1 & 1 & 2 & 100 \\
\hline $\begin{array}{l}\text { - External Consulting } \\
\text { Services }\end{array}$ & 1 & 0 & 1 & 50 \\
\hline Assessment Related Offices & 0 & 1 & 1 & 50 \\
\hline $\begin{array}{ll}\text { - Institutional Research } \\
\text { Office }\end{array}$ & 0 & 1 & 1 & 50 \\
\hline 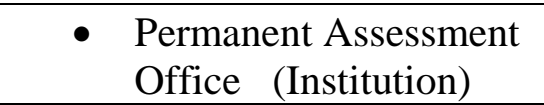 & 0 & 1 & 1 & 50 \\
\hline $\begin{array}{l}\text { Center for Teaching and } \\
\text { Learning }\end{array}$ & 0 & 1 & 1 & 50 \\
\hline Assessment Committee & 1 & 0 & 1 & 50 \\
\hline $\begin{array}{l}\text { "People” That Are Helpful } \\
\text { With Data Gathering Initiatives }\end{array}$ & 1 & 0 & 1 & 50 \\
\hline
\end{tabular}

Faculty Satisfaction with Assessment

English program faculty across both institutions shared a diverse mix of strengths and challenges related to the assessment process. The researcher identified common themes 
pertaining to strengths of faculty participation, and assessment leadership and challenges with assessment discussions and data.

English program faculty reported that they were interested in assessment and had access to venues to participate in assessment decisions (see Table 196). Faculty reported that they had participated in assessment activities by developing the program's assessment plan and that they had access to professional development workshops about student outcomes assessment and financial support to attend assessment related conferences.

Table 196

Faculty participation: Strengths

\begin{tabular}{|l|l|l|}
\hline Participation & $\begin{array}{l}\text { Beta University } \\
\text { (BU) }\end{array}$ & $\begin{array}{l}\text { Alpha } \\
\text { University } \\
\text { (AU) }\end{array}$ \\
\hline Faculty Interest & $\mathrm{X}$ & $\mathrm{X}$ \\
\hline $\begin{array}{l}\text { Faculty } \\
\text { Participation }\end{array}$ & & \\
\hline $\begin{array}{l}\text { Avenues to } \\
\text { Participate in } \\
\text { Assessment } \\
\text { Decisions }\end{array}$ & $\mathrm{X}$ & \\
\hline $\begin{array}{l}\text { Professional } \\
\text { Development } \\
\text { Workshops }\end{array}$ & & $\mathrm{X}$ \\
\hline $\begin{array}{l}\text { Faculty } \\
\text { Developed the } \\
\text { Assessment } \\
\text { Plan }\end{array}$ & & $\mathrm{X}$ \\
\hline $\begin{array}{l}\text { Financial } \\
\text { Support to } \\
\text { Attend }\end{array}$ & & \\
Conferences & & $\mathrm{X}$ \\
\hline $\begin{array}{l}\text { Center for } \\
\text { Teaching and } \\
\text { Learning }\end{array}$ & & \\
\hline
\end{tabular}


English program faculty reported that institutional- and program-level leaders valued and supported assessment activities. Additionally, some program faculty participated in assessment activities directly with the institutional assessment leader (see Table 197).

Table 197

Leadership: Strengths

\begin{tabular}{|l|l|l|}
\hline Participation & $\begin{array}{l}\text { Beta University } \\
\text { (BU) }\end{array}$ & $\begin{array}{l}\text { Alpha } \\
\text { University } \\
\text { (AU) }\end{array}$ \\
\hline $\begin{array}{l}\text { Director of } \\
\text { Assessment }\end{array}$ & $\mathrm{X}$ & \\
\hline $\begin{array}{l}\text { Central } \\
\text { Leadership } \\
\text { Support }\end{array}$ & $\mathrm{X}$ & \\
\hline $\begin{array}{l}\text { Department } \\
\text { Chair Valued } \\
\text { Assessment }\end{array}$ & & \\
\hline $\begin{array}{l}\text { Participation in } \\
\text { Assessment } \\
\text { Activities With } \\
\text { the Institutional }\end{array}$ & & \\
Assessment & & \\
Leader & & \\
\hline
\end{tabular}

Program faculty reported that challenges with the assessment plan existed. BU program faculty reported that the assessment plan needed to be revised (see Table 198). Additionally, they reported that assessment data were not used to inform academic decisions.

Some AU program faculty reported that an assessment plan did not exist while others reported that the plan was disorganized. Faculty who reported that an assessment plan did not exist also claimed that program-level assessment leaders were slowly developing a plan. Faculty reported that the disorganization of the assessment plan was a challenge to the collection of assessment data. 
Table 198

Assessment plan: Challenges

\begin{tabular}{|l|c|c|}
\hline & $\begin{array}{l}\text { Beta University } \\
\text { (BU) }\end{array}$ & $\begin{array}{l}\text { Alpha } \\
\text { University } \\
\text { (AU) }\end{array}$ \\
\hline $\begin{array}{l}\text { Assessment } \\
\text { Plan Needs } \\
\text { Revision }\end{array}$ & X \\
\hline $\begin{array}{l}\text { Assessment } \\
\text { Data Was Not } \\
\text { Used to Make } \\
\text { Academic } \\
\text { Decisions }\end{array}$ & $\quad \mathrm{X}$ & \\
\hline $\begin{array}{l}\text { Assessment } \\
\text { Plan Did Not } \\
\text { Exist }\end{array}$ & & \\
\hline $\begin{array}{l}\text { Direction From } \\
\text { Central Leaders }\end{array}$ & & \\
\hline $\begin{array}{l}\text { Lack of } \\
\text { Assessment }\end{array}$ & & \\
Data & & $\mathrm{X}$ \\
\hline $\begin{array}{l}\text { Assessment } \\
\text { Plan Was }\end{array}$ & & $\mathrm{X}$ \\
Disorganized & & $\mathrm{X}$ \\
\hline $\begin{array}{l}\text { Slow Progress } \\
\text { in Assessment } \\
\text { Plan }\end{array}$ & & \\
Development & & \\
\hline
\end{tabular}

Undergraduate Psychology Program

A total of eight individuals representing the undergraduate psychology programs at AU and GU participated in this study. Two participants were department chairs and six participants were faculty members.

\section{Characteristics of Effective Assessment Practice}

The researcher analyzed interview data, annual assessment reports, and assessment plans to identify characteristics of effective practice. 
Credible evidence of learning. Intended learning outcomes across the psychology programs spanned at least two cognitive domains included within Bloom’s Taxonomy (see Table 199). The majority of outcomes were in the understand domain. One-third of the outcomes represented the apply domain. Eight percent of the outcomes represented the analyze, evaluate, and create domains.

Table 199

Distribution of intended learning outcomes: Psychology

\begin{tabular}{|l|c|c|c|c|c|c|}
\hline $\begin{array}{l}\text { Cognitive } \\
\text { Domains }\end{array}$ & \multicolumn{2}{l|l}{$\begin{array}{l}\text { Alpha } \\
\text { University } \\
\text { (AU) }\end{array}$} & $\begin{array}{l}\text { Gamma } \\
\text { University } \\
\text { (GU) }\end{array}$ & \multicolumn{2}{|l|}{} \\
\cline { 2 - 7 } & $\mathrm{N}$ & $\%$ & $\mathrm{~N}$ & $\%$ & $\mathrm{~N}$ & $\%$ \\
\hline Remember & 0 & 0 & 3 & 9 & 3 & 6.0 \\
\hline Understand & 14 & 70 & 14 & 42 & 28 & 53.0 \\
\hline Apply & 6 & 30 & 12 & 36 & 18 & 34 \\
\hline Analyze & 0 & 0 & 1 & 3 & 1 & 2 \\
\hline Evaluate & 0 & 0 & 2 & 6 & 2 & 4 \\
\hline Create & 0 & 0 & 1 & 3 & 1 & 2 \\
\hline
\end{tabular}

Faculty from both institutions utilized multiple indirect assessments including the senior exit interviews/surveys and self-reflection papers pertaining to program outcomes and goals (see Table 200). Additionally, faculty utilized a mentoring faculty survey and an academic advisor survey at AU while faculty at GU utilized an academic skills inventory and a job readiness survey. The researcher did not identify any common direct assessment methods. 
Table 200

Assessments: Psychology

\begin{tabular}{|c|c|c|c|c|}
\hline \multirow[t]{2}{*}{ Assessments } & \multirow{2}{*}{\begin{tabular}{|l} 
Alpha \\
University \\
(AU)
\end{tabular}} & \multirow{2}{*}{$\begin{array}{l}\text { Gamma } \\
\text { University } \\
\text { (GU) }\end{array}$} & \multicolumn{2}{|c|}{ Total } \\
\hline & & & $\mathrm{N}$ & $\%$ \\
\hline \multicolumn{5}{|l|}{ Indirect Assessments } \\
\hline $\begin{array}{l}\text { Senior Exit } \\
\text { Interview/Survey }\end{array}$ & 1 & 1 & 2 & 100 \\
\hline $\begin{array}{l}\text { Self-Reflection of } \\
\text { Program Outcomes } \\
\text { and Goals }\end{array}$ & 1 & 1 & 2 & 100 \\
\hline $\begin{array}{l}\text { Academic Skills } \\
\text { Inventory }\end{array}$ & 0 & 1 & 1 & 50 \\
\hline $\begin{array}{l}\text { Job Readiness } \\
\text { Survey }\end{array}$ & 0 & 1 & 1 & 50 \\
\hline $\begin{array}{l}\text { Mentoring Faculty } \\
\text { Survey }\end{array}$ & 1 & 0 & 1 & 50 \\
\hline $\begin{array}{l}\text { Academic Advisor } \\
\text { Survey }\end{array}$ & 1 & 0 & 1 & 50 \\
\hline \multicolumn{5}{|l|}{ Direct Assessments } \\
\hline $\begin{array}{l}\text { Commercially } \\
\text { Available Content } \\
\text { Examination }\end{array}$ & 0 & 1 & 1 & 50 \\
\hline $\begin{array}{l}\text { Locally Developed } \\
\text { Information Literacy } \\
\text { Examination }\end{array}$ & 0 & 1 & 1 & 50 \\
\hline
\end{tabular}

Continuously improve programs and services. Faculty reported that curricular revisions were informed with assessment data. AU psychology faculty added an examination, required additional oral presentations, incorporated the use of data analysis software, and required students to use APA document formatting across all of the courses within the program (see Table 201). GU psychology faculty offered specific courses more frequently, provided students with more opportunities to practice writing, offered new elective courses, and increased the number of credit hours required for the major. 
Table 201

Continuously improve programs and services: Psychology

\begin{tabular}{|c|c|c|}
\hline Actions & $\begin{array}{l}\text { Alpha } \\
\text { University } \\
\text { (AU) }\end{array}$ & $\begin{array}{l}\text { Gamma } \\
\text { University (GU) }\end{array}$ \\
\hline Curricular Revisions & 1 & 1 \\
\hline $\begin{array}{ll}-\quad \begin{array}{l}\text { More Frequent Course } \\
\text { Offerings }\end{array} \\
\end{array}$ & 0 & 1 \\
\hline $\begin{array}{l}\text { - } \begin{array}{l}\text { More Frequent } \\
\text { Opportunities for Students } \\
\text { to Practice Writing }\end{array} \\
\end{array}$ & 0 & 1 \\
\hline - $\quad$ Offer New Electives & 0 & 1 \\
\hline - Added an Examination & 1 & 0 \\
\hline $\begin{array}{ll}\text { - } & \text { Required Additional Oral } \\
& \text { Presentations } \\
\end{array}$ & 1 & 0 \\
\hline $\begin{array}{l}\text { - Incorporate the Use of Data } \\
\text { Analysis Software }\end{array}$ & 1 & 0 \\
\hline $\begin{array}{l}\text { - Required APA Formatting } \\
\text { Across Program Courses }\end{array}$ & 1 & 0 \\
\hline $\begin{array}{l}\text { Increased the Number of } \\
\text { Credit Hours Required for } \\
\text { the Major }\end{array}$ & 0 & 1 \\
\hline $\begin{array}{l}\text { Faculty Became More Proactive } \\
\text { With Graduate School Application } \\
\text { Process of Students }\end{array}$ & 1 & 0 \\
\hline Improved Peer Advising & 0 & 1 \\
\hline Website Revisions & 0 & 1 \\
\hline $\begin{array}{l}\text { Increased the Number of } \\
\text { Opportunities for Students to } \\
\text { Conduct Research with Faculty }\end{array}$ & 0 & 1 \\
\hline $\begin{array}{l}\text { Revised New Student Orientation } \\
\text { Program }\end{array}$ & 0 & 1 \\
\hline Revised Weekly E-Mail Newsletter & 0 & 1 \\
\hline Improved Advising Services & 1 & 1 \\
\hline
\end{tabular}

Accountability to internal stakeholders. The researcher did not identify any common mechanisms utilized by program faculty to maintain accountability to internal stakeholders (see Table 202). Faculty at AU reported that program changes, assessment results, and discussions about assessment maintained internal accountability. Program 
faculty at GU utilized faculty meetings, an exit survey, and personalized assessment reports.

Table 202

Accountability to internal stakeholders: Psychology

\begin{tabular}{|l|c|c|c|c|}
\hline & \multicolumn{2}{|l|}{$\begin{array}{l}\text { Alpha } \\
\text { University } \\
\text { (AU) }\end{array}$} & $\begin{array}{l}\text { Gamma } \\
\text { University } \\
\text { (GU) }\end{array}$ & \multicolumn{2}{|c|}{ Total } \\
\cline { 3 - 5 } & 1 & 0 & 1 & 50 \\
\hline $\begin{array}{l}\text { Implemented Program } \\
\text { Changes }\end{array}$ & 0 & 1 & 1 & 50 \\
\hline Faculty Meetings & 1 & 0 & 1 & 50 \\
\hline $\begin{array}{l}\text { Availability of } \\
\text { Assessment Results to } \\
\text { the Faculty }\end{array}$ & 0 & 1 & 1 & 50 \\
\hline Exit Survey & 0 & 1 & 1 & 50 \\
\hline $\begin{array}{l}\text { Personalized } \\
\text { Assessment Reports to } \\
\text { Faculty }\end{array}$ & 1 & 0 & 1 & 50 \\
\hline $\begin{array}{l}\text { Discussions of } \\
\text { Assessment Results }\end{array}$ & & & & \\
\hline
\end{tabular}

Faculty representing each psychology program included within this study conducted ongoing assessment activities on a predictable schedule (see Table 203). However, the researcher did not identify any other methods that ensured assessment was ongoing and not episodic.

Table 203

Ongoing assessment: Psychology

\begin{tabular}{|l|l|l|c|c|}
\hline & $\begin{array}{l}\text { Alpha } \\
\text { University } \\
\text { (AU) }\end{array}$ & $\begin{array}{l}\text { Gamma } \\
\text { University } \\
\text { (GU) }\end{array}$ & \multicolumn{2}{|c|}{ Total } \\
\cline { 3 - 5 } & \multicolumn{1}{|c|}{1} & 1 & 2 & 100 \\
\hline Predictable Schedule & & \multicolumn{2}{|c|}{1} & 2 \\
\hline
\end{tabular}

Ongoing evaluation and improvement. Psychology faculty from both institutions did not conduct ongoing evaluation and improvement of the assessment plan. 


\section{Faculty Satisfaction with Assessment}

Psychology program faculty across both institutions shared a diverse mix of strengths and challenges related to the assessment process. The researcher identified common themes pertaining to strengths of faculty participation, a culture that valued assessment, and the institutional assessment office, and challenges with the assessment plan.

Program faculty reported that they participated in assessment activities. They reported that service to undergraduate committees, regular e-mail communications, personal contributions to the assessment plan, departmental meetings, faculty retreats, financial support to attend conferences, and the availability of developmental workshops about assessment were improving participation with assessment related activities (see Table 204). Faculty also reported that they participated with the assessment advisory committee and in the development of a motivation research institute.

Table 204

Faculty participation: Strengths

\begin{tabular}{|l|l|l|}
\hline Resources & $\begin{array}{l}\text { Alpha } \\
\text { University } \\
\text { (AU) }\end{array}$ & $\begin{array}{l}\text { Gamma } \\
\text { University } \\
\text { (GU) }\end{array}$ \\
\hline $\begin{array}{l}\text { Service to the } \\
\text { Undergraduate } \\
\text { Committee }\end{array}$ & $\mathrm{X}$ & \\
\hline $\begin{array}{l}\text { Improving } \\
\text { Faculty } \\
\text { Participation }\end{array}$ & $\mathrm{X}$ & \\
\hline $\begin{array}{l}\text { Personal } \\
\text { Contributions to } \\
\text { the Assessment } \\
\text { Plan }\end{array}$ & $\mathrm{X}$ & \\
\hline $\begin{array}{l}\text { Departmental } \\
\text { Meetings }\end{array}$ & $\mathrm{X}$ & \\
\hline
\end{tabular}


Table 204

Faculty participation: Strengths continued

\begin{tabular}{|l|l|l|}
\hline Resources & $\begin{array}{l}\text { Alpha } \\
\text { University } \\
\text { (AU) }\end{array}$ & $\begin{array}{l}\text { Gamma } \\
\text { University } \\
\text { (GU) }\end{array}$ \\
\hline Faculty Retreats & \multicolumn{1}{|c|}{$\mathrm{X}$} & \\
\hline $\begin{array}{l}\text { E-Mail } \\
\text { Communication }\end{array}$ & $\mathrm{X}$ & \\
\hline $\begin{array}{l}\text { Service to the } \\
\text { Assessment } \\
\text { Advisory } \\
\text { Committee }\end{array}$ & & $\mathrm{X}$ \\
\hline $\begin{array}{l}\text { Faculty } \\
\text { Participation }\end{array}$ & & \\
\hline $\begin{array}{l}\text { Participation in } \\
\text { the Development } \\
\text { of the } \\
\text { Motivational } \\
\text { Research } \\
\text { Institute }\end{array}$ & & $\mathrm{X}$ \\
\hline
\end{tabular}

Psychology program faculty reported that a culture that valued assessment existed.

They identified the expertise of administrators and their center's for teaching and learning as important assessment strengths (see Table 205).

Table 205

Culture that values assessment: Strengths

\begin{tabular}{|l|l|l|}
\hline $\begin{array}{l}\text { Assessment } \\
\text { Discussions }\end{array}$ & $\begin{array}{l}\text { Alpha } \\
\text { University } \\
\text { (AU) }\end{array}$ & $\begin{array}{l}\text { Gamma } \\
\text { University } \\
\text { (GU) }\end{array}$ \\
\hline $\begin{array}{l}\text { Culture that } \\
\text { Values } \\
\text { Assessment }\end{array}$ & $\mathrm{X}$ & $\mathrm{X}$ \\
\hline $\begin{array}{l}\text { Expertise of } \\
\text { Administrators }\end{array}$ & $\mathrm{X}$ & $\mathrm{X}$ \\
\hline
\end{tabular}


Table 205

Culture that values assessment: Strengths continued

\begin{tabular}{|l|l|l|}
\hline $\begin{array}{l}\text { Assessment } \\
\text { Discussions }\end{array}$ & $\begin{array}{l}\text { Alpha } \\
\text { University } \\
\text { (AU) }\end{array}$ & $\begin{array}{l}\text { Gamma } \\
\text { University } \\
\text { (GU) }\end{array}$ \\
\hline $\begin{array}{l}\text { Center for } \\
\text { Teaching and } \\
\text { Learning }\end{array}$ & \multicolumn{1}{|c|}{$\mathrm{X}$} & \multicolumn{1}{|c|}{$\mathrm{X}$} \\
\hline
\end{tabular}

Psychology program faculty revealed that the institutional assessment office was a strength. Faculty reported that the assessment office provided several resources including intellectual assistance, financial assistance, and fellowships (see Table 206). Faculty regularly utilized the expertise of assessment experts on-campus.

Table 206

Institutional assessment office: Strengths

\begin{tabular}{|l|l|c|}
\hline & $\begin{array}{l}\text { Alpha } \\
\text { University } \\
\text { (AU) }\end{array}$ & $\begin{array}{l}\text { Gamma } \\
\text { University } \\
\text { (GU) }\end{array}$ \\
\hline $\begin{array}{l}\text { Assessment } \\
\text { Experts on } \\
\text { Campus }\end{array}$ & $\mathrm{X}$ \\
\hline $\begin{array}{l}\text { Financial } \\
\text { Assistance }\end{array}$ & & $\mathrm{X}$ \\
\hline $\begin{array}{l}\text { Intellectual } \\
\text { Assistance }\end{array}$ & & $\mathrm{X}$ \\
\hline $\begin{array}{l}\text { Communication } \\
\text { with the } \\
\text { Assessment } \\
\text { Office }\end{array}$ & & $\mathrm{X}$ \\
\hline $\begin{array}{l}\text { Realistic } \\
\text { Directives }\end{array}$ & & $\mathrm{X}$ \\
\hline $\begin{array}{l}\text { Assessment } \\
\text { Fellowships }\end{array}$ & & $\mathrm{X}$ \\
\hline Liaison & & $\mathrm{X}$ \\
\hline
\end{tabular}


Faculty within both programs identified challenges with the assessment plan. They reported that keeping up with assessment data, lack of systematic implementation, and the minimal quantity of assessment measures were challenges to the assessment process. Additionally, program faculty reported that the overabundance of assessment data collected was a challenge because it was difficult to analyze all of the data. Faculty encountered challenges developing and improving specific assessment activities in order to avoid high-stakes testing (see Table 207).

Table 207

Assessment plan: Challenges

\begin{tabular}{|l|c|c|}
\hline Assessment Plan & $\begin{array}{l}\text { Alpha } \\
\text { University } \\
\text { (AU) }\end{array}$ & $\begin{array}{l}\text { Gamma } \\
\text { University } \\
\text { (GU) }\end{array}$ \\
\hline $\begin{array}{l}\text { Difficult to Keep } \\
\text { Up With Data }\end{array}$ & X & \\
\hline $\begin{array}{l}\text { Assessment Plan } \\
\text { Lacks Systematic } \\
\text { Implementation }\end{array}$ & $\mathrm{X}$ & \\
\hline $\begin{array}{l}\text { Minimal Quantity } \\
\text { of Assessments } \\
\text { Have Been } \\
\text { Implemented }\end{array}$ & $\mathrm{X}$ & \\
\hline $\begin{array}{l}\text { Quality } \\
\text { Assessment Data } \\
\text { Not Collected }\end{array}$ & $\mathrm{X}$ & \\
\hline $\begin{array}{l}\text { Overabundance of } \\
\text { Data }\end{array}$ & & $\mathrm{X}$ \\
\hline $\begin{array}{l}\text { Lack of Analysis } \\
\text { of Data }\end{array}$ & & $\mathrm{X}$ \\
\hline $\begin{array}{l}\text { Challenges } \\
\text { Developing } \\
\text { Writing } \\
\text { Assessments }\end{array}$ & & $\mathrm{X}$ \\
\hline
\end{tabular}


Table 207

Assessment plan: Challenges continued

\begin{tabular}{|l|l|c|}
\hline $\begin{array}{l}\text { Assessment } \\
\text { Plan }\end{array}$ & $\begin{array}{l}\text { Alpha } \\
\text { University } \\
\text { (AU) }\end{array}$ & $\begin{array}{l}\text { Gamma } \\
\text { University } \\
\text { (GU) }\end{array}$ \\
\hline $\begin{array}{l}\text { Need to } \\
\text { Improve } \\
\text { Assessment } \\
\text { Methods } \\
\text { Related to } \\
\text { Socio-Cultural } \\
\text { Awareness }\end{array}$ & & \\
\hline $\begin{array}{l}\text { High-Stakes } \\
\text { Testing }\end{array}$ & \\
\hline Credible & & \\
Measures of & & \\
Student & & \\
Achievement & & \\
\hline
\end{tabular}

\section{Undergraduate Secondary Education Program}

A total of seven individuals representing the secondary education programs from BU and AU participated in this study. The researcher interviewed a department chair, a program coordinator, an assistant dean, and four faculty members.

\section{Characteristics of Effective Assessment Practice}

The researcher analyzed interview data, annual assessment reports, and assessment plans to identify characteristics of effective practice.

Credible evidence of learning. Secondary education program faculty utilized direct and indirect assessments at both institutions. Common direct assessment included portfolios and clinical observations (see Table 208). The only common indirect assessment utilized by faculty was a senior exit interview/survey. Faculty at both institutions implemented multiple methods of assessment. 
Table 208

Assessments: Secondary education

\begin{tabular}{|c|c|c|c|c|}
\hline Assessments & \multicolumn{2}{|l|}{$\begin{array}{l}\text { Beta } \\
\text { University } \\
\text { (BU) }\end{array}$} & $\begin{array}{l}\text { Alpha } \\
\text { University } \\
\text { (AU) }\end{array}$ & \multicolumn{2}{l|}{ Total } \\
\cline { 3 - 5 } & 1 & 1 & 2 & 100 \\
\hline Direct Assessments & 1 & 1 & 2 & 100 \\
\hline Portfolio & 1 & 0 & 1 & 50 \\
\hline $\begin{array}{l}\text { Clinical } \\
\text { Observations }\end{array}$ & 1 & 0 & 1 & 50 \\
\hline $\begin{array}{l}\text { Commercially } \\
\text { Available Content } \\
\text { Examination }\end{array}$ & 1 & 1 & 2 & 100 \\
\hline $\begin{array}{l}\text { Licensure } \\
\text { Examination }\end{array}$ & 1 & 0 & 1 & 50 \\
\hline Indirect Assessments & 0 & 1 & 1 & 50 \\
\hline $\begin{array}{l}\text { Senior Exit } \\
\text { Interview/Survey }\end{array}$ & 0 & 1 & 1 & 50 \\
\hline Alumni Survey & 1 & & & \\
\hline Pre/Post Survey & 1 & & & \\
\hline $\begin{array}{l}\text { Faculty Focus } \\
\text { Groups }\end{array}$ & 1 & & & \\
\hline
\end{tabular}

Continuously improve programs and services. Faculty at AU revised their clinical evaluation rubrics and reflection prompts (see Table 209). The researcher did not identify any program changes at BU based on assessment data.

Table 209

Continuously improve programs and services: Secondary education

\begin{tabular}{|c|c|c|}
\hline Actions & $\begin{array}{l}\text { Beta University } \\
\text { (BU) }\end{array}$ & $\begin{array}{l}\text { Alpha } \\
\text { University } \\
\text { (AU) }\end{array}$ \\
\hline Curricular Revisions & 0 & 1 \\
\hline $\begin{array}{l}\text { Revised Clinical Evaluation } \\
\text { Rubrics }\end{array}$ & 0 & 1 \\
\hline$\bullet \quad$ Revised Reflection Prompts & 0 & 1 \\
\hline
\end{tabular}

Accountability to internal stakeholders. The researcher did not identify any common mechanisms utilized by faculty to maintain accountability to internal stakeholders. 
Secondary education program faculty at BU reported that a curriculum committee with broad representation maintained internal accountability while faculty at AU reported that annual assessment reports were submitted to central leadership and faculty meetings maintained internal accountability (see Table 210).

Table 210

Accountability to internal stakeholders: Secondary education

\begin{tabular}{|l|c|c|c|c|}
\hline & \multicolumn{1}{|l|}{$\begin{array}{l}\text { Beta } \\
\text { University } \\
\text { (BU) }\end{array}$} & $\begin{array}{l}\text { Alpha } \\
\text { University } \\
\text { (AU) }\end{array}$ & \multicolumn{2}{|c|}{ Total } \\
\cline { 3 - 5 } & 0 & 1 & 1 & 50 \\
\hline $\begin{array}{l}\text { Annual Assessment } \\
\text { Reports Submitted to } \\
\text { Central Leadership }\end{array}$ & 0 & 1 & 1 & 50 \\
\hline Faculty Meetings & 1 & 0 & 1 & 50 \\
\hline $\begin{array}{l}\text { Curriculum Committee } \\
\begin{array}{l}\text { With Broad } \\
\text { Representation }\end{array}\end{array}$ & & & & \\
\hline
\end{tabular}

Ongoing assessment. Secondary education program faculty conducted ongoing assessment activities on a predictable schedule (see Table 211). Additionally, BU faculty aggregated assessment data annually and indirect assessments implemented at AU ensured that assessment was ongoing.

Table 211

Ongoing assessment: Secondary education

\begin{tabular}{|l|c|c|c|c|}
\hline & \multicolumn{2}{|l|}{$\begin{array}{l}\text { Beta } \\
\text { University } \\
\text { (BU) }\end{array}$} & $\begin{array}{l}\text { Alpha } \\
\text { University } \\
\text { (AU) }\end{array}$ & \multicolumn{2}{|c|}{ Total } \\
\cline { 3 - 5 } & 1 & 1 & $\mathrm{~N}$ & $\%$ \\
\hline Predictable Schedule & 1 & 0 & 1 & 50 \\
\hline $\begin{array}{l}\text { Faculty Aggregate } \\
\begin{array}{l}\text { Assessment Data } \\
\text { Annually }\end{array}\end{array}$ & 1 & 1 & 50 \\
\hline Indirect Assessments & 0 & 1 & & \\
\hline
\end{tabular}


Ongoing evaluation and improvement. The researcher did not identify any common activities utilized to evaluate and improve the assessment plan. BU faculty constantly collected and reviewed assessment data while AU faculty held frequent assessment discussions (see Table 212).

Table 212

Ongoing evaluation and improvement: Secondary education

\begin{tabular}{|c|c|c|c|c|}
\hline \multirow[t]{2}{*}{ Actions } & \multirow{2}{*}{$\begin{array}{l}\text { Beta University } \\
\text { (BU) }\end{array}$} & \multirow{2}{*}{$\begin{array}{l}\text { Alpha } \\
\text { University } \\
\text { (AU) }\end{array}$} & \multicolumn{2}{|c|}{ Total } \\
\hline & & & $\mathrm{N}$ & $\%$ \\
\hline $\begin{array}{l}\text { Faculty } \\
\text { Constantly } \\
\text { Collected and } \\
\text { Reviewed } \\
\text { Assessment } \\
\text { Data }\end{array}$ & 1 & 0 & 1 & 50 \\
\hline \begin{tabular}{|l|} 
Faculty \\
Discussions \\
\end{tabular} & 0 & 1 & 1 & 50 \\
\hline
\end{tabular}

Commitments and Resources

Commitments. Program administrators most frequently identified the following assessment commitments:

- $\quad$ executive-level support,

- campus-wide assessment committee with broad representation,

- incorporation of the scholarship of teaching in promotion and tenure guidelines,

- culture that valued assessment, and

- consideration of assessment data in evaluating and rewarding faculty (see Table 213). 
Executive-level support was evident across both secondary education programs. The most frequently identified examples of executive-level support included a permanent assessment office and the creation of new assessment based positions.

Table 213

Commitments: Secondary education

\begin{tabular}{|c|c|c|c|c|}
\hline \multirow[t]{2}{*}{ Commitments } & \multirow{2}{*}{$\begin{array}{l}\text { Beta } \\
\text { University } \\
\text { (BU) }\end{array}$} & \multirow{2}{*}{$\begin{array}{l}\text { Alpha } \\
\text { University } \\
\text { (AU) }\end{array}$} & \multicolumn{2}{|c|}{ Total } \\
\hline & & & $\mathrm{N}$ & $\%$ \\
\hline Executive-Level Support & 1 & 1 & 2 & 100 \\
\hline $\begin{array}{l}\text { - Permanent Assessment } \\
\text { Office }\end{array}$ & 1 & 0 & 1 & 50 \\
\hline $\begin{array}{l}\text { - Creation of New } \\
\text { Assessment Positions }\end{array}$ & 0 & 1 & 1 & 50 \\
\hline $\begin{array}{l}\text { Campus-Wide Assessment } \\
\text { Committee With Broad } \\
\text { Representation }\end{array}$ & 1 & 1 & 2 & 100 \\
\hline $\begin{array}{l}\text { Incorporation of Guiding } \\
\text { Principles of Assessment in } \\
\text { Promotion and Tenure } \\
\text { Guidelines }\end{array}$ & 1 & 1 & 2 & 100 \\
\hline Culture That Values Assessment & 1 & 1 & 2 & 100 \\
\hline $\begin{array}{l}\text { Assessment Data Considered in } \\
\text { Evaluating and Rewarding } \\
\text { Faculty }\end{array}$ & 1 & 1 & 2 & 100 \\
\hline $\begin{array}{l}\text { Policies That Promote } \\
\text { Communication About } \\
\text { Assessment }\end{array}$ & 0 & 1 & 1 & 50 \\
\hline - New Student Orientation & 0 & 1 & 1 & 50 \\
\hline $\begin{array}{l}\text { Student Assessment Expertise } \\
\text { Considered in the Hiring } \\
\text { Process for New Faculty }\end{array}$ & 1 & 0 & 1 & 50 \\
\hline $\begin{array}{l}\text { Policies to Promote the } \\
\text { Involvement of Student Affairs } \\
\text { Personnel and Students in } \\
\text { Assessment Efforts }\end{array}$ & 0 & 1 & 1 & 50 \\
\hline Internal Consulting Services & 1 & 0 & 1 & 50 \\
\hline $\begin{array}{ll}\text { - Institutional Assessment } \\
\text { Office }\end{array}$ & 1 & 0 & 1 & 50 \\
\hline
\end{tabular}


Resources. Program administrators most frequently identified the following assessment resources:

- financial support for assessment,

- professional development opportunities for faculty, and

- $\quad$ assessment related offices (see Table 214).

Financial support for assessment was evident across both secondary education programs. Program administrators reported that faculty were supported to attend assessment-related conferences. Additionally, program administrators at both institutions reported that an office charged with coordinating data gathering initiatives was available.

Table 214

Resources: Secondary education

\begin{tabular}{|c|c|c|c|c|}
\hline \multirow[t]{2}{*}{ Resources } & \multirow{2}{*}{$\begin{array}{l}\text { Beta } \\
\text { University } \\
\text { (BU) }\end{array}$} & \multirow{2}{*}{$\begin{array}{l}\text { Alpha } \\
\text { University } \\
\text { (AU) }\end{array}$} & \multicolumn{2}{|c|}{ Total } \\
\hline & & & $\mathrm{N}$ & $\%$ \\
\hline Financial Support & 1 & 1 & 2 & 100 \\
\hline $\begin{array}{l}\text { Support for Faculty to } \\
\text { Attend Assessment } \\
\text { Related Conferences }\end{array}$ & 1 & 1 & 2 & 100 \\
\hline $\begin{array}{ll}\text { - } & \text { Course Release for } \\
\text { Assessment Purposes }\end{array}$ & 1 & 0 & 1 & 50 \\
\hline - Assessment Grants & 0 & 1 & 1 & 50 \\
\hline - $\quad$ Personnel Time & 0 & 1 & 1 & 50 \\
\hline $\begin{array}{l}\text { Professional Development } \\
\text { Opportunities }\end{array}$ & 1 & 1 & 2 & 100 \\
\hline $\begin{array}{l}\text { - Programming for } \\
\text { Faculty }\end{array}$ & 1 & 1 & 2 & 100 \\
\hline Assessment Related Offices & 1 & 1 & 2 & 100 \\
\hline $\begin{array}{l}\text { - Office Charged With } \\
\text { Coordinating Data- } \\
\text { Gathering Initiatives } \\
\end{array}$ & 1 & 1 & 2 & 100 \\
\hline $\begin{array}{l}\text { - Permanent Assessment } \\
\text { Office (Institution) }\end{array}$ & 0 & 1 & 1 & 50 \\
\hline $\begin{array}{l}\text { - Program-Level/School } \\
\text { Assessment Office }\end{array}$ & 0 & 1 & 1 & 50 \\
\hline
\end{tabular}


Table 214

Resources: Secondary education continued

\begin{tabular}{|c|c|c|c|c|}
\hline Resources & \multicolumn{2}{|l|}{$\begin{array}{l}\text { Beta } \\
\text { University } \\
\text { (BU) }\end{array}$} & $\begin{array}{l}\text { Alpha } \\
\text { University } \\
\text { (AU) }\end{array}$ & \multicolumn{2}{|c|}{ Total } \\
\cline { 3 - 5 } & 1 & 0 & 1 & 50 \\
\hline Assessment Related Databases & 1 & 0 & 1 & 50 \\
\hline $\begin{array}{l}\text { Comprehensive } \\
\text { Assessment Database }\end{array}$ & 0 & 1 & 1 & 50 \\
\hline $\begin{array}{l}\text { Consulting Services } \\
\text { Internal Consulting }\end{array}$ & 0 & 1 & 1 & 50 \\
\hline $\begin{array}{l}\text { Center for Teaching and } \\
\text { Learning }\end{array}$ & 0 & 1 & 1 & 50 \\
\hline Technology Department & 0 & 1 & 1 & 50 \\
\hline
\end{tabular}

Faculty Satisfaction with Assessment

Secondary education program faculty across both institutions shared a diverse mix of strengths and challenges related to the assessment process. The researcher identified common themes pertaining to strengths of assessment related resources, faculty participation, and the benefits of assessment. However, faculty identified challenges with assessment related discussions and assessment data.

Secondary education program faculty reported that resources to support the assessment endeavor were available and that professional development workshops pertaining to assessment were offered regularly. Additionally, faculty reported that assessment grants were available to faculty working on assessment related projects (see Table 215).

Secondary education program faculty participated in assessment decision making. Faculty identified meetings and committees as their main venues to discuss assessment. They also reported that they discussed assessment topics informally. Program faculty 
also reported that they participated in professional development workshops and brown bag lunches about assessment (see Table 216).

Table 215

Resources: Strengths

\begin{tabular}{|l|l|l|}
\hline Resources & $\begin{array}{l}\text { Beta University } \\
\text { (BU) }\end{array}$ & $\begin{array}{l}\text { Alpha } \\
\text { University } \\
\text { (AU) }\end{array}$ \\
\hline $\begin{array}{l}\text { Resources } \\
\text { Were Available }\end{array}$ & $\mathrm{X}$ & \\
\hline $\begin{array}{l}\text { Access to } \\
\text { Professional } \\
\text { Development } \\
\text { Workshops }\end{array}$ & $\mathrm{X}$ & \\
\hline $\begin{array}{l}\text { Assessment } \\
\text { Grants }\end{array}$ & & $\mathrm{X}$ \\
\hline
\end{tabular}

Table 216

Faculty participation: Strengths

\begin{tabular}{|l|l|l|}
\hline $\begin{array}{l}\text { Faculty } \\
\text { Participation }\end{array}$ & $\begin{array}{l}\text { Beta University } \\
\text { (BU) }\end{array}$ & $\begin{array}{l}\text { Alpha } \\
\text { University } \\
\text { (AU) }\end{array}$ \\
\hline $\begin{array}{l}\text { Program } \\
\text { Meetings }\end{array}$ & $\mathrm{X}$ & \\
\hline $\begin{array}{l}\text { Joint } \\
\text { Committee on } \\
\text { Teacher } \\
\text { Education }\end{array}$ & $\mathrm{X}$ & \\
\hline $\begin{array}{l}\text { Informal } \\
\text { Discussions }\end{array}$ & $\mathrm{X}$ & $\mathrm{X}$ \\
\hline $\begin{array}{l}\text { Access to } \\
\text { Professional } \\
\text { Development } \\
\text { Opportunities }\end{array}$ & $\mathrm{X}$ & \\
\hline $\begin{array}{l}\text { Communication } \\
\text { of Assessment } \\
\text { Results }\end{array}$ & & $\mathrm{X}$ \\
\hline
\end{tabular}


Table 216

Faculty participation: Strengths continued

\begin{tabular}{|l|l|l|}
\hline $\begin{array}{l}\text { Faculty } \\
\text { Participation }\end{array}$ & $\begin{array}{l}\text { Beta University } \\
\text { (BU) }\end{array}$ & $\begin{array}{l}\text { Alpha } \\
\text { University } \\
\text { (AU) }\end{array}$ \\
\hline $\begin{array}{l}\text { Brown Bag } \\
\text { Lunches About } \\
\text { Assessment }\end{array}$ & & $\mathrm{X}$ \\
\hline
\end{tabular}

Program faculty identified various benefits of assessment. Some program faculty reported that the assessment of student learning assisted in the identification of areas for teacher candidates to improve while others reported that the collection of retention data and the measurement of higher-order cognitive abilities were important strengths of the assessment process (see Table 217).

Table 217

Benefits of assessment: Strengths

\begin{tabular}{|l|l|l|}
\hline $\begin{array}{l}\text { Benefits of } \\
\text { Assessment }\end{array}$ & $\begin{array}{l}\text { Beta University } \\
\text { (BU) }\end{array}$ & $\begin{array}{l}\text { Alpha } \\
\text { University } \\
\text { (AU) }\end{array}$ \\
\hline $\begin{array}{l}\text { Identification of } \\
\text { Areas for } \\
\text { Teacher } \\
\text { Candidates to } \\
\text { Improve }\end{array}$ & $\mathrm{X}$ & \\
\hline $\begin{array}{l}\text { Collection of } \\
\text { Retention Data }\end{array}$ & & $\mathrm{X}$ \\
\hline $\begin{array}{l}\text { Measures } \\
\text { Higher Order } \\
\text { Thinking }\end{array}$ & & $\mathrm{X}$ \\
\hline
\end{tabular}

Program faculty reported that challenges existed within assessment discussions and assessment data. BU program faculty reported that assessment discussions were confining while AU program faculty reported that faculty lacked a voice in assessment 
decisions, assessment discussions did not lead to actions, and that there were too many voices in the assessment decision making process (see Table 218).

Table 218

Assessment discussions: Challenges

\begin{tabular}{|l|l|l|}
\hline $\begin{array}{l}\text { Assessment } \\
\text { Discussions }\end{array}$ & $\begin{array}{l}\text { Beta University } \\
\text { (BU) }\end{array}$ & $\begin{array}{l}\text { Alpha } \\
\text { University } \\
\text { (AU) }\end{array}$ \\
\hline $\begin{array}{l}\text { Confining } \\
\text { Discussions } \\
\text { About } \\
\text { Assessment }\end{array}$ & $\mathrm{X}$ & \\
\hline $\begin{array}{l}\text { Faculty Lacked } \\
\text { a Voice in } \\
\text { Assessment } \\
\text { Decisions }\end{array}$ & & \\
\hline Too Many & & $\mathrm{X}$ \\
Voices in & & \\
Assessment & & \\
Decision & & \\
Making & & \\
\hline
\end{tabular}

Secondary education program faculty identified various challenges with assessment data. BU program faculty reported that the assumption that assessment activities were perfect, the lack of nationally comparable data, and difficulties aligning assessment methods with other schools on-campus were challenges to the assessment process. AU program faculty reported that assessment data was not utilized in assessment decision making and that they lacked confidence in the implemented assessment instruments.

\section{Biology Program Study Participants}

A total of six individuals representing the undergraduate biology programs at AU and GU participated in this study. Two participants were department chairs and four participants were faculty members. 


\section{Characteristics of Effective Assessment Practice}

The researcher analyzed interview data, annual assessment reports, and assessment plans to identify characteristics of effective practice.

Credible evidence of learning. Intended learning outcomes across both of the institutions spanned two of the six cognitive domains included within Bloom's Taxonomy (see Table 219). The outcomes were sharply skewed to the lower-level domains. Fifty-nine percent of the outcomes represented the understand domain. Fortyone percent of the outcomes represented the apply domain. GU's biology outcomes were representative of only the apply domain. The greatest percentage of outcomes at AU represented the understand domain.

Table 219

Distribution of intended learning outcomes: Biology

\begin{tabular}{|l|c|c|c|c|c|c|}
\hline $\begin{array}{l}\text { Cognitive } \\
\text { Domains }\end{array}$ & \multicolumn{2}{l|l}{$\begin{array}{l}\text { Alpha } \\
\text { University } \\
\text { (AU) }\end{array}$} & $\begin{array}{l}\text { Gamma } \\
\text { University } \\
\text { (GU) }\end{array}$ & \multicolumn{2}{|l|}{} \\
\cline { 2 - 7 } & $\mathrm{N}$ & $\%$ & $\mathrm{~N}$ & $\%$ & $\mathrm{~N}$ & $\%$ \\
\hline Remember & 0 & 0 & 0 & 0 & 0 & 0 \\
\hline Understand & 13 & 81.3 & 0 & 0 & 13 & 59.1 \\
\hline Apply & 3 & 18.8 & 6 & 100 & 9 & 41.0 \\
\hline Analyze & 0 & 0 & 0 & 0 & 0 & 0 \\
\hline Evaluate & 0 & 0 & 0 & 0 & 0 & 0 \\
\hline Create & 0 & 0 & 0 & 0 & 0 & 0 \\
\hline
\end{tabular}

Program faculty at both institutions utilized locally- developed embedded examination items (see Table 220). Biology faculty at AU implemented multiple methods of direct assessments (only common examinations) while faculty at GU implemented multiple methods of direct and indirect assessment. However, biology program faculty at both institutions did not utilize assessment data for continuous improvement. 
Table 220

Assessments: Biology

\begin{tabular}{|c|c|c|c|c|}
\hline \multirow[t]{2}{*}{ Assessments } & \multirow{2}{*}{$\begin{array}{l}\text { Alpha } \\
\text { University } \\
\text { (AU) }\end{array}$} & \multirow{2}{*}{$\begin{array}{l}\text { Gamma } \\
\text { University } \\
\text { (GU) }\end{array}$} & \multicolumn{2}{|c|}{ Total } \\
\hline & & & $\mathrm{N}$ & $\%$ \\
\hline \multicolumn{5}{|l|}{ Direct Assessments } \\
\hline $\begin{array}{l}\text { Locally Developed } \\
\text { Embedded } \\
\text { Examination } \\
\text { Items }\end{array}$ & 1 & 1 & 2 & 100 \\
\hline $\begin{array}{l}\text { Commercially } \\
\text { Available Content } \\
\text { Examination }\end{array}$ & 0 & 1 & 1 & 50 \\
\hline Class Activities & 1 & 0 & 1 & 50 \\
\hline Class Presentations & 1 & 0 & 1 & 50 \\
\hline $\begin{array}{l}\text { Laboratory } \\
\text { Exercises }\end{array}$ & 1 & 0 & 1 & 50 \\
\hline $\begin{array}{l}\text { Essay/Short Answer } \\
\text { Questions }\end{array}$ & 1 & 0 & 1 & 50 \\
\hline Quizzes & 1 & 0 & 1 & 50 \\
\hline $\begin{array}{l}\text { Writing } \\
\text { Assignments }\end{array}$ & 1 & 0 & 1 & 50 \\
\hline \multicolumn{5}{|l|}{ Indirect Assessments } \\
\hline $\begin{array}{l}\text { Academic Skills } \\
\text { Inventory }\end{array}$ & 0 & 1 & 1 & 50 \\
\hline Focus Groups & 0 & 1 & 1 & 50 \\
\hline
\end{tabular}

Accountability to internal stakeholders. The researcher did not identify any common mechanisms utilized by faculty to maintain accountability to internal stakeholders.

Faculty at AU utilized an annual assessment report that was submitted to central leaders and a school-level assessment committee to maintain internal accountability (see Table 221). Assessment results were readily available to faculty at GU. 
Table 221

Accountability to internal stakeholders: Across institutions

\begin{tabular}{|l|c|c|c|c|}
\hline & \multicolumn{1}{|l|}{$\begin{array}{l}\text { Alpha } \\
\text { University } \\
\text { (AU) }\end{array}$} & $\begin{array}{l}\text { Gamma } \\
\text { University } \\
\text { (GU) }\end{array}$ & \multicolumn{2}{|c|}{ Total } \\
\cline { 3 - 5 } & 1 & 0 & 1 & 50 \\
\hline $\begin{array}{l}\text { Annual Assessment } \\
\text { Reports Submitted to } \\
\text { Central Leadership }\end{array}$ & 1 & 0 & 1 & 50 \\
\hline $\begin{array}{l}\text { School Assessment } \\
\text { Committee }\end{array}$ & 0 & 1 & 1 & 50 \\
\hline $\begin{array}{l}\text { Availability of } \\
\text { Assessment Results to } \\
\text { the Faculty }\end{array}$ & 0 & & & \\
\hline
\end{tabular}

Ongoing assessment. Each program included within this study conducted ongoing assessment activities on a predictable schedule. However, additional methods of maintaining ongoing assessment activities were diverse across the biology programs (see Table 222).

Table 222

Ongoing assessment: Biology

\begin{tabular}{|l|c|c|c|c|}
\hline & \multicolumn{1}{|l|}{$\begin{array}{l}\text { Alpha } \\
\text { University } \\
\text { (AU) }\end{array}$} & $\begin{array}{l}\text { Gamma } \\
\text { University } \\
\text { (GU) }\end{array}$ & \multicolumn{2}{|c|}{ Total } \\
\cline { 3 - 5 } & 1 & 1 & 2 & 100 \\
\hline Predictable Schedule & 0 & 1 & 1 & 50 \\
\hline $\begin{array}{l}\text { Institution Offers } \\
\begin{array}{l}\text { Graduate Programs in } \\
\text { Assessment and } \\
\text { Measurement }\end{array}\end{array}$ & 1 & 0 & 1 & 50 \\
\hline $\begin{array}{l}\text { Regional Accreditation } \\
\text { Reports }\end{array}$ & 0 & 1 & 1 & 50 \\
\hline Assessment Day & 1 & & & \\
\hline
\end{tabular}

Ongoing evaluation and improvement. Faculty from both institutions did not conduct ongoing evaluation and improvement of the assessment plan (see Table 223). 
Table 223

Ongoing evaluation and improvement: Biology

\begin{tabular}{|l|l|l|c|c|}
\hline Actions & $\begin{array}{l}\text { Alpha } \\
\text { University } \\
\text { (AU) }\end{array}$ & $\begin{array}{l}\text { Gamma } \\
\text { University } \\
\text { (GU) }\end{array}$ & \multicolumn{2}{|c|}{ Total } \\
\cline { 3 - 5 } & \multicolumn{1}{|c|}{1} & 1 & 2 & 100 \\
\hline $\begin{array}{l}\text { Plan Did Not } \\
\text { Encompass this } \\
\text { Element }\end{array}$ & & & $\mathrm{N}$ & $\%$ \\
\hline
\end{tabular}

\section{Institutional Commitments and Resources}

Commitments. The department chairs most frequently identified executive-level support and a campus-wide assessment committee with broad representation as important commitments (see Table 224). The AU department chair reported that financial resources available to faculty to attend assessment-related conferences provided evidence of executive-level support while the GU chair reported that the faculty development program provided evidence of support. Both participants reported that a campus-wide assessment committee with broad representation existed.

Table 224

Commitments: Biology

\begin{tabular}{|c|c|c|c|c|}
\hline Commitments & \multirow{2}{*}{$\begin{array}{l}\text { Alpha } \\
\text { University } \\
\text { (AU) }\end{array}$} & $\begin{array}{l}\text { Gamma } \\
\text { University } \\
(\mathrm{GU})\end{array}$ & $\mathrm{2}$ & Total \\
\cline { 3 - 5 } & 1 & 1 & 2 & 100 \\
\hline Executive-Level Support & 1 & 0 & 1 & 50 \\
\hline $\begin{array}{l}\text { Financial Resources for } \\
\text { Faculty to Attend } \\
\text { Conferences }\end{array}$ & 0 & 1 & 1 & 50 \\
\hline $\begin{array}{l}\text { Faculty Development } \\
\text { Program }\end{array}$ & 1 & 1 & 2 & 100 \\
\hline $\begin{array}{l}\text { Campus-Wide Assessment } \\
\text { Committee With Broad } \\
\text { Representation }\end{array}$ & & & & \\
\hline
\end{tabular}


Table 224

Commitments: Biology continued

\begin{tabular}{|l|c|c|c|c|}
\hline Commitments & \multirow{2}{*}{$\begin{array}{l}\text { Alpha } \\
\text { University } \\
\text { (AU) }\end{array}$} & $\begin{array}{l}\text { Gamma } \\
\text { University } \\
\text { (GU) }\end{array}$ & \multicolumn{2}{|c|}{ Total } \\
\cline { 4 - 5 } & & & & $\%$ \\
\hline $\begin{array}{l}\text { Incorporation of Guiding } \\
\text { Principles of Assessment in } \\
\begin{array}{l}\text { Promotion and Tenure } \\
\text { Guidelines }\end{array}\end{array}$ & 0 & 1 & 1 & 50 \\
\hline Culture That Values Assessment & 0 & 1 & 1 & 50 \\
\hline
\end{tabular}

Resources. The department chairs most frequently identified the following assessment resources:

- financial support,

- professional development opportunities,

- consulting services, and

- $\quad$ assessment related offices (see Table 225).

Financial support for assessment was evident within both programs. Both department chairs reported that support for faculty to attend assessment related conferences was available. Additionally, the GU department chair reported that faculty may receive course releases for assessment purposes. Both department chairs reported that faculty development programming, internal consulting services were available, and that a permanent assessment office existed.

Table 225

Resources: Biology

\begin{tabular}{|l|l|l|c|c|}
\hline Resources & Alpha & Gamma & \multicolumn{2}{|c|}{ Total } \\
\cline { 3 - 6 } & $\begin{array}{l}\text { University } \\
\text { (AU) }\end{array}$ & $\begin{array}{l}\text { University } \\
\text { (GU) }\end{array}$ & $\mathrm{N}$ & $\%$ \\
\hline Financial Support & 1 & 1 & 2 & 100 \\
\hline
\end{tabular}


Table 225

Resources: Biology continued

\begin{tabular}{|c|c|c|c|c|}
\hline \multirow[t]{2}{*}{ Resources } & \multirow{2}{*}{$\begin{array}{l}\text { Alpha } \\
\text { University } \\
\text { (AU) }\end{array}$} & \multirow{2}{*}{$\begin{array}{l}\text { Gamma } \\
\text { University } \\
(\mathrm{GU})\end{array}$} & \multicolumn{2}{|c|}{ Total } \\
\hline & & & $\mathrm{N}$ & $\%$ \\
\hline $\begin{array}{l}\text { Support for Faculty to } \\
\text { Attend Assessment } \\
\text { Related Conferences }\end{array}$ & 1 & 1 & 2 & 100 \\
\hline $\begin{array}{ll}- & \text { Course Release for } \\
& \text { Assessment Purposes } \\
\end{array}$ & 0 & 1 & 1 & 50 \\
\hline $\begin{array}{l}\text { Professional Development } \\
\text { Opportunities }\end{array}$ & 1 & 1 & 2 & 100 \\
\hline $\begin{array}{ll}- & \text { Programming for } \\
& \text { Faculty } \\
\end{array}$ & 1 & 1 & 2 & 100 \\
\hline Consulting Services & 1 & 1 & 2 & 100 \\
\hline $\begin{array}{ll}\text { - } & \text { Internal Consulting } \\
& \text { Services } \\
\end{array}$ & 1 & 1 & 2 & 100 \\
\hline $\begin{array}{ll}\text { - } & \text { External Consulting } \\
& \text { Services } \\
\end{array}$ & 0 & 1 & 1 & 50 \\
\hline Assessment Related Offices & 1 & 1 & 2 & 100 \\
\hline $\begin{array}{l}\text { - Office Charged With } \\
\text { Coordinating Data- } \\
\text { Gathering Initiatives }\end{array}$ & 0 & 1 & 1 & 50 \\
\hline $\begin{array}{ll}\text { - Institutional Research } \\
\text { Office }\end{array}$ & 1 & 0 & 1 & 50 \\
\hline $\begin{array}{ll}\text { - } & \text { Permanent Assessment } \\
\text { Office (Institution) }\end{array}$ & 1 & 1 & 2 & 100 \\
\hline $\begin{array}{l}\text { Access to On-Line Survey } \\
\text { Software }\end{array}$ & 0 & 1 & 1 & 50 \\
\hline
\end{tabular}

Faculty Satisfaction with Assessment

Biology program faculty across both institutions shared a diverse mix of strengths and challenges related to the assessment process. The researcher identified common themes pertaining to the strengths of resources allocated to the assessment endeavor and faculty participation and challenges with the assessment plan.

Biology program faculty reported that they had access to developmental workshops about assessment and financial support to attend national conferences. Faculty reported 
that they had access to readily available assistance in the forms of internal consulting services and assessment fellowships (see Table 226). Additionally, program faculty participated in the development of the assessment plan and had input into its implementation.

Table 226

Resources: Strengths

\begin{tabular}{|l|l|c|}
\hline Resources & $\begin{array}{l}\text { Alpha } \\
\text { University } \\
\text { (AU) }\end{array}$ & $\begin{array}{l}\text { Gamma } \\
\text { University } \\
\text { (GU) }\end{array}$ \\
\hline $\begin{array}{l}\text { Developmental } \\
\text { Workshops }\end{array}$ & $\mathrm{X}$ & \\
\hline Financial & & \\
Support to \\
$\begin{array}{l}\text { Attend National } \\
\text { Assessment } \\
\text { Conferences }\end{array}$ & $\mathrm{X}$ & \\
\hline $\begin{array}{l}\text { Internal } \\
\text { Consulting }\end{array}$ & & \\
Services & & $\mathrm{X}$ \\
\hline $\begin{array}{l}\text { Assistance with } \\
\text { Assessment }\end{array}$ & & \\
Endeavors & & $\mathrm{X}$ \\
Immediately & & \\
Available & & $\mathrm{X}$ \\
\hline Assessment & & \\
Fellowships & & \\
\hline
\end{tabular}

Biology program faculty across both institutions identified challenges with the assessment plan. They reported that learning outcomes needed revision, faculty needed to be updated about the assessment process, and that assessment data needed to be fully analyzed. Additionally, they reported that the lack of common assessment measures across courses and the lack of longitudinal assessment data were challenges to the assessment plan. Furthermore, program faculty reported that the implementation of a 
new curriculum, underutilized assessment data, and the lack of alignment between implemented commercially available examinations and program outcomes were challenges to the collection of good assessment data (see Table 227).

Table 227

Assessment plan: Challenges

\begin{tabular}{|c|c|c|}
\hline Assessment Plan & $\begin{array}{l}\text { Alpha } \\
\text { University } \\
\text { (AU) }\end{array}$ & $\begin{array}{l}\text { Gamma } \\
\text { University } \\
\text { (GU) }\end{array}$ \\
\hline $\begin{array}{l}\text { Learning } \\
\text { Outcomes Need } \\
\text { Revised }\end{array}$ & $X$ & \\
\hline $\begin{array}{l}\text { Faculty Need to } \\
\text { be Refreshed } \\
\text { About the } \\
\text { Assessment } \\
\text { Process }\end{array}$ & X & \\
\hline $\begin{array}{l}\text { Assessment } \\
\text { Data Had Not } \\
\text { Been Fully } \\
\text { Analyzed }\end{array}$ & $\mathrm{X}$ & \\
\hline $\begin{array}{l}\text { Lack of } \\
\text { Common } \\
\text { Assessment } \\
\text { Measures } \\
\text { Across Courses }\end{array}$ & $\mathrm{X}$ & \\
\hline $\begin{array}{l}\text { No Longitudinal } \\
\text { Assessment } \\
\text { Data }\end{array}$ & $X$ & \\
\hline $\begin{array}{l}\text { Implementation } \\
\text { of a New } \\
\text { Curriculum }\end{array}$ & & X \\
\hline $\begin{array}{l}\text { Under Utilized } \\
\text { Assessment } \\
\text { Data }\end{array}$ & & X \\
\hline
\end{tabular}


Table 228

Assessment plan: Challenges

\begin{tabular}{|l|l|l|}
\hline Assessment Plan & $\begin{array}{l}\text { Alpha } \\
\text { University } \\
\text { (AU) }\end{array}$ & $\begin{array}{l}\text { Gamma } \\
\text { University } \\
\text { (GU) }\end{array}$ \\
\hline $\begin{array}{l}\text { Alignment of } \\
\text { Items Included } \\
\text { in Commercially } \\
\text { Developed } \\
\text { Assessment to } \\
\text { Program }\end{array}$ & \\
Outcomes & & \\
\hline
\end{tabular}

Undergraduate Nursing Program

A total of seven individuals representing the undergraduate nursing program from AU and GU participated in this study. The researcher interviewed a department chair, an associate dean and four faculty members.

Characteristics of Effective Assessment Practice

The researcher analyzed interview data, annual assessment reports, and assessment plans to identify characteristics of effective practice.

Credible evidence of learning. Intended learning outcomes across the nursing programs spanned all six cognitive domains included within Bloom’s Taxonomy (see Table 229). The outcomes were skewed to the mid-level domains. Fifty-seven percent of the outcomes represented the apply domain. Twenty-six percent of the outcomes represented the create domain. The greatest percentage of outcomes at AU and GU represented the apply domain. 
Table 229

Distribution of intended learning outcomes: Nursing

\begin{tabular}{|l|c|c|l|c|c|c|}
\hline $\begin{array}{l}\text { Cognitive } \\
\text { Domains }\end{array}$ & \multicolumn{2}{l|}{$\begin{array}{l}\text { Alpha } \\
\text { University } \\
\text { (AU) }\end{array}$} & $\begin{array}{l}\text { Gamma } \\
\text { University } \\
\text { (GU) }\end{array}$ & \multicolumn{2}{|l|}{} \\
\cline { 2 - 7 } & $\mathrm{N}$ & $\%$ & $\mathrm{~N}$ & $\%$ & $\mathrm{~N}$ & $\%$ \\
\hline Remember & 2 & 9.1 & 0 & 0 & 2 & 4.1 \\
\hline Understand & 2 & 9.1 & 0 & 0 & 2 & 4.1 \\
\hline Apply & 13 & 59.1 & 15 & 55.6 & 28 & 57.1 \\
\hline Analyze & 1 & 4.5 & 0 & 0 & 1 & 2.0 \\
\hline Evaluate & 3 & 13.6 & 0 & 0 & 3 & 6.1 \\
\hline Create & 1 & 4.5 & 12 & 44.4 & 13 & 26.6 \\
\hline
\end{tabular}

Credible evidence of learning. Nursing program faculty at AU and GU utilized multiple methods of direct and indirect assessments. Program faculty from both institutions utilized direct assessments that included commercially available content examinations and licensure examinations and indirect assessments that included a senior exit survey/interview and an alumni survey (see Table 230).

Table 230

Assessments: Nursing

\begin{tabular}{|l|l|l|l|l|}
\hline Assessments & \multicolumn{2}{|l|}{$\begin{array}{l}\text { Alpha } \\
\text { University } \\
(\mathrm{AU})\end{array}$} & $\begin{array}{l}\text { Gamma } \\
\text { University } \\
(\mathrm{GU})\end{array}$ & \multicolumn{2}{|l|}{ Total } \\
\cline { 3 - 5 } & & $\mathrm{N}$ & $\%$ \\
\hline Direct Assessments & 1 & 1 & 2 & 100 \\
\hline $\begin{array}{l}\text { Commercially } \\
\text { Available Content } \\
\text { Examination }\end{array}$ & 1 & 1 & 2 & 100 \\
\hline $\begin{array}{l}\text { Licensure } \\
\text { Examination }\end{array}$ & 1 & 0 & 1 & 50 \\
\hline $\begin{array}{l}\text { Research } \\
\text { Project/Paper }\end{array}$ & 0 & 1 & 1 & 50 \\
\hline Portfolio & 0 & 1 & 1 & 50 \\
\hline $\begin{array}{l}\text { Clinical } \\
\text { Observations }\end{array}$ & & & & \\
\hline
\end{tabular}


Table 230

Assessments: Nursing continued

\begin{tabular}{|l|l|l|l|l|}
\hline Assessments & $\begin{array}{l}\text { Alpha } \\
\text { University } \\
\text { (AU) }\end{array}$ & $\begin{array}{l}\text { Gamma } \\
\text { University } \\
\text { (GU) }\end{array}$ & \multicolumn{2}{|l|}{ Total } \\
\cline { 3 - 5 } & 0 & 1 & 1 & 50 \\
\hline $\begin{array}{l}\text { Commercially } \\
\text { Developed } \\
\text { Pre/Post Test } \\
\text { Critical Thinking }\end{array}$ & 1 & 1 & 2 & 100 \\
\hline Indirect Assessments & 1 & 1 & 2 & 100 \\
\hline $\begin{array}{l}\text { Senior Exit } \\
\text { Interview/Survey }\end{array}$ & 0 & 1 & 1 & 50 \\
\hline Alumni Survey & 1 & 0 & 1 & 50 \\
\hline $\begin{array}{l}\text { Self-Reflection of } \\
\text { Program Outcomes } \\
\text { and Goals }\end{array}$ & & & & \\
\hline $\begin{array}{l}\text { Employer Focus } \\
\text { Groups }\end{array}$ & 1 & & & \\
\hline
\end{tabular}

Continuously improve programs and services. Multiple curricular revisions were informed with assessment data within the nursing programs at AU and GU. AU nursing faculty created new learning experiences pertinent to diversity, increased the number of opportunities for students to practice critical thinking skills as members of interdisciplinary teams, and increased the number of opportunities for students to practice communication skills as members of interdisciplinary teams (see Table 231). Curricular changes at GU included the implementation of new simulation case scenarios and increased opportunities for students to practice newly acquired professional skills. 
Table 231

Continuously improve programs and services: Nursing

\begin{tabular}{|c|c|c|}
\hline Actions & $\begin{array}{l}\text { Alpha } \\
\text { University } \\
\text { (AU) }\end{array}$ & $\begin{array}{l}\text { Gamma } \\
\text { University (GU) }\end{array}$ \\
\hline \multicolumn{3}{|l|}{ Curricular Revisions } \\
\hline $\begin{array}{l}\text { - Created New Learning } \\
\text { Experiences Pertaining } \\
\text { to Diversity }\end{array}$ & 1 & 0 \\
\hline $\begin{array}{l}\text { Increased the Opportunities } \\
\text { for Students to Practice } \\
\text { Critical Thinking Skills as } \\
\text { Members of } \\
\text { Interdisciplinary Teams }\end{array}$ & 1 & 0 \\
\hline $\begin{array}{l}\text { Increased the Opportunities } \\
\text { for Students to Practice } \\
\text { Critical Communication } \\
\text { Skills as Members of } \\
\text { Interdisciplinary Teams }\end{array}$ & 1 & 0 \\
\hline $\begin{array}{l}\text { - Developed New Simulation } \\
\text { Case Scenarios }\end{array}$ & 0 & 1 \\
\hline $\begin{array}{l}\text { Increased Opportunities for } \\
\text { Student to Practice Newly } \\
\text { Acquired Skills }\end{array}$ & 0 & 1 \\
\hline $\begin{array}{l}\text { Changed Commercial Testing } \\
\text { Companies }\end{array}$ & 0 & 1 \\
\hline
\end{tabular}

Ongoing assessment. Each program included within this study conducted ongoing assessment activities on a predictable schedule. However, additional methods of maintaining ongoing assessment activities were very diverse across the institutions (see Table 232).

Table 232

Ongoing Assessment: Nursing

\begin{tabular}{|l|l|l|c|c|}
\hline & Alpha & Gamma & \multicolumn{2}{|c|}{ Total } \\
\cline { 3 - 5 } & $\begin{array}{l}\text { University } \\
\text { (AU) }\end{array}$ & $\begin{array}{l}\text { University } \\
(\text { GU) }\end{array}$ & $\mathrm{N}$ & $\%$ \\
\hline Predictable Schedule & \multicolumn{1}{|c|}{1} & 1 & 2 & 100 \\
\hline
\end{tabular}


Table 232

Ongoing Assessment: Nursing continued

\begin{tabular}{|l|c|c|c|c|}
\hline & \multicolumn{1}{|l|}{$\begin{array}{l}\text { Alpha } \\
\text { University } \\
\text { (AU) }\end{array}$} & $\begin{array}{l}\text { Gamma } \\
\text { University } \\
\text { (GU) }\end{array}$ & \multicolumn{2}{|c|}{ Total } \\
\cline { 3 - 5 } & 1 & 0 & 1 & 50 \\
\hline $\begin{array}{l}\text { Commitment of School } \\
\text { or College to } \\
\text { Assessment }\end{array}$ & 1 & 0 & 1 & 50 \\
\hline $\begin{array}{l}\text { Professional } \\
\text { Accreditation Reports }\end{array}$ & 0 & 1 & 1 & 50 \\
\hline $\begin{array}{l}\text { Annual Report } \\
\text { Submitted to Central } \\
\text { Leadership }\end{array}$ & 0 & & & \\
\hline
\end{tabular}

Ongoing evaluation and improvement. Administrators revealed that the assessment plan for the undergraduate nursing program at AU did not include ongoing evaluation and improvement while the accreditation review self-study at GU ensured that evaluation and improvement occurred (see Table 233).

Table 233

Ongoing evaluation and improvement: Nursing

\begin{tabular}{|l|c|c|c|c|}
\hline Actions & $\begin{array}{l}\text { Alpha } \\
\text { University } \\
\text { (AU) }\end{array}$ & $\begin{array}{l}\text { Gamma } \\
\text { University } \\
\text { (GU) }\end{array}$ & \multicolumn{2}{|c|}{ Total } \\
\cline { 3 - 5 } & 1 & 0 & 1 & 50 \\
\hline $\begin{array}{l}\text { Plan Did Not } \\
\begin{array}{l}\text { Encompass this } \\
\text { Element }\end{array}\end{array}$ & 1 & 1 & 50 \\
\hline $\begin{array}{l}\text { Accreditation } \\
\text { Review Self- } \\
\text { Study }\end{array}$ & 0 & 1 & & N \\
\hline
\end{tabular}

\section{Institutional Commitments and Resources}

Commitments. Program administrators most frequently identified executive-level support and a campus-wide assessment committee as important commitments (see Table 
234). Executive-level support was evident across both programs. However, the program administrator at GU did not identify any evidence to support her claim.

Table 234

Commitments: Nursing

\begin{tabular}{|c|c|c|c|c|}
\hline \multirow[t]{2}{*}{ Commitments } & \multirow{2}{*}{$\begin{array}{l}\text { Alpha } \\
\text { University } \\
\text { (AU) }\end{array}$} & \multirow{2}{*}{$\begin{array}{l}\text { Gamma } \\
\text { University } \\
\text { (GU) }\end{array}$} & \multicolumn{2}{|c|}{ Total } \\
\hline & & & $\mathrm{N}$ & $\%$ \\
\hline Executive-Level Support & 1 & 1 & 2 & 100 \\
\hline $\begin{array}{l}\text { - Permanent Assessment } \\
\text { Office }\end{array}$ & 1 & 0 & 1 & 50 \\
\hline $\begin{array}{l}\text { Campus-Wide Assessment } \\
\text { Committee With Broad } \\
\text { Representation }\end{array}$ & 1 & 1 & 2 & 100 \\
\hline $\begin{array}{l}\text { Incorporation of Guiding } \\
\text { Principles of Assessment in } \\
\text { Promotion and Tenure } \\
\text { Guidelines }\end{array}$ & 1 & 0 & 1 & 50 \\
\hline Culture That Values Assessment & 0 & 1 & 1 & 50 \\
\hline $\begin{array}{l}\text { Policies That Promote } \\
\text { Communication About } \\
\text { Assessment }\end{array}$ & 0 & 1 & 1 & 50 \\
\hline $\begin{array}{l}\text { - Communication } \\
\text { Occurred in Class }\end{array}$ & 0 & 1 & 1 & 50 \\
\hline $\begin{array}{l}\text { Guiding Principles for } \\
\text { Assessment }\end{array}$ & 1 & 0 & 1 & 50 \\
\hline $\begin{array}{l}\text { Policies to Promote the } \\
\text { Involvement of Student Affairs } \\
\text { Personnel and Students in } \\
\text { Assessment Efforts }\end{array}$ & 0 & 1 & 1 & 50 \\
\hline Program Coordinator & 0 & 1 & 1 & 50 \\
\hline
\end{tabular}

Resources. Program administrators most frequently identified the following assessment resources:

- financial support,

- professional development opportunities,

- $\quad$ assessment related databases,

- consulting services, and 
- $\quad$ assessment related offices (see Table 235).

Financial support for faculty to attend assessment related conferences was evident.

Program administrators from both institutions reported that professional development programming was available for faculty while the AU administrator also reported that assessment-related programming was available to academic administrators and student affairs personnel. Additionally, both program administrators reported that external consulting services and a permanent assessment office were important resources.

Table 235

Resources: Nursing

\begin{tabular}{|c|c|c|c|c|}
\hline \multirow[t]{2}{*}{ Resources } & \multirow{2}{*}{$\begin{array}{l}\text { Alpha } \\
\text { University } \\
\text { (AU) }\end{array}$} & \multirow{2}{*}{$\begin{array}{l}\text { Gamma } \\
\text { University } \\
(\mathrm{GU})\end{array}$} & \multicolumn{2}{|c|}{ Total } \\
\hline & & & $\mathrm{N}$ & $\%$ \\
\hline Financial Support & 1 & 1 & 2 & 100 \\
\hline $\begin{array}{l}\text { Support for Faculty to } \\
\text { Attend Assessment } \\
\text { Related Conferences } \\
\end{array}$ & 1 & 1 & 2 & 100 \\
\hline - Assessment Grants & 1 & 0 & 1 & 50 \\
\hline $\begin{array}{l}\text { - Assistance to Purchase } \\
\text { Commercial } \\
\text { Examinations } \\
\end{array}$ & 0 & 1 & 1 & 50 \\
\hline $\begin{array}{l}\text { Professional Development } \\
\text { Opportunities }\end{array}$ & 1 & 1 & 2 & 100 \\
\hline $\begin{array}{ll}\text { - } & \text { Programming for } \\
& \text { Faculty } \\
\end{array}$ & 1 & 1 & 2 & 100 \\
\hline 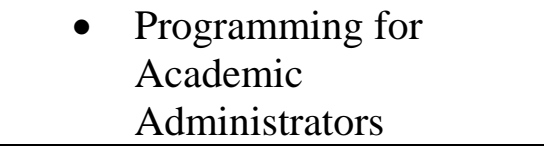 & 1 & 0 & 1 & 50 \\
\hline $\begin{array}{ll}\text { - } & \text { Programming for } \\
\text { Student Affairs } \\
\text { Personnel }\end{array}$ & 1 & 0 & 1 & 50 \\
\hline Assessment Related Databases & 1 & 1 & 2 & 100 \\
\hline $\begin{array}{l}\text { - Comprehensive } \\
\text { Assessment Database }\end{array}$ & 1 & 0 & 1 & 50 \\
\hline $\begin{array}{l}\text { - Assessment Related } \\
\text { Database }\end{array}$ & 0 & 1 & 1 & 50 \\
\hline
\end{tabular}


Table 235

Resources: Nursing continued

\begin{tabular}{|c|c|c|c|c|}
\hline Resources & $\begin{array}{l}\text { Alpha } \\
\text { University } \\
\text { (AU) }\end{array}$ & $\begin{array}{l}\text { Gamma } \\
\text { University } \\
(\mathrm{GU})\end{array}$ & \multicolumn{2}{|c|}{ Total } \\
\cline { 3 - 5 } & 1 & 1 & 2 & 100 \\
\hline Consulting Services & 1 & 1 & 2 & 100 \\
\hline $\begin{array}{l}\text { External Consulting } \\
\text { Services }\end{array}$ & 1 & 0 & 1 & 50 \\
\hline $\begin{array}{l}\text { Internal Consulting } \\
\text { Services }\end{array}$ & 1 & 1 & 2 & 100 \\
\hline Assessment Related Offices & 1 & 1 & 2 & 100 \\
\hline $\begin{array}{l}\text { Permanent Assessment } \\
\text { Office (Institution) }\end{array}$ & 1 & 0 & 1 & 50 \\
\hline $\begin{array}{l}\text { Institutional Research } \\
\text { Office }\end{array}$ & & &
\end{tabular}

Faculty Satisfaction with Assessment

Nursing program faculty across both programs shared a diverse mix of strengths and challenges related to the assessment process. The researcher identified common themes pertaining to strengths of faculty participation, the assessment plan, and assessment methods. However, faculty also identified challenges with the assessment plan.

Program faculty reported that they participated in assessment activities. Faculty reported that they shared assessment data during informal discussions, faculty meetings, and committee meetings. Additionally, faculty reported that they participated in assessment during professional development workshops and assessment related conferences held off-campus (see Table 236).

Program faculty within both programs identified strengths with the assessment plan. AU program faculty reported that assessment data was utilized to inform academic decisions and strategic planning. Additionally, they reported that multiple measures of assessment that included commercial assessment instruments were strengths of an 
improving assessment plan. GU program faculty reported that multiple measures of assessment had been implemented and that programmatic changes were supported by assessment data (see Table 237).

Table 236

Faculty participation: Strengths

\begin{tabular}{|l|c|c|}
\hline Resources & $\begin{array}{l}\text { Alpha } \\
\text { University } \\
\text { (AU) }\end{array}$ & $\begin{array}{l}\text { Gamma } \\
\text { University } \\
\text { (GU) }\end{array}$ \\
\hline $\begin{array}{l}\text { Faculty } \\
\text { Participation }\end{array}$ & $\mathrm{X}$ & $\mathrm{X}$ \\
\hline $\begin{array}{l}\text { Financial } \\
\text { Support to } \\
\text { Attend } \\
\text { Conferences }\end{array}$ & $\mathrm{X}$ & \\
\hline $\begin{array}{l}\text { Availability of } \\
\text { Professional } \\
\text { Development } \\
\text { Workshops }\end{array}$ & $\mathrm{X}$ & \\
\hline $\begin{array}{l}\text { Informal Faculty } \\
\text { Discussions }\end{array}$ & $\mathrm{X}$ & \\
\hline $\begin{array}{l}\text { Faculty } \\
\text { Meetings }\end{array}$ & $\mathrm{X}$ & $\mathrm{X}$ \\
\hline $\begin{array}{l}\text { Committee } \\
\text { Participation }\end{array}$ & & $\mathrm{X}$ \\
\hline $\begin{array}{l}\text { Informal } \\
\text { Communication }\end{array}$ & & $\mathrm{X}$ \\
\hline $\begin{array}{l}\text { Curriculum } \\
\text { Committee }\end{array}$ & & $\mathrm{X}$ \\
\hline $\begin{array}{l}\text { Sharing of } \\
\text { Assessment Data }\end{array}$ & & \\
\hline $\begin{array}{l}\text { Support for Off- } \\
\text { Campus Faculty } \\
\text { Development }\end{array}$ & & \\
\hline
\end{tabular}


Table 237

Assessment plan: Strengths

\begin{tabular}{|l|l|l|}
\hline Assessment Plan & $\begin{array}{l}\text { Alpha } \\
\text { University } \\
\text { (AU) }\end{array}$ & $\begin{array}{l}\text { Gamma } \\
\text { University } \\
\text { (GU) }\end{array}$ \\
\hline $\begin{array}{l}\text { Assessment } \\
\text { Data Was } \\
\text { Utilized to } \\
\text { Inform } \\
\text { Academic } \\
\text { Decisions }\end{array}$ & & \\
\hline $\begin{array}{l}\text { Assessment Plan } \\
\text { Was Improving }\end{array}$ & $\mathrm{X}$ & \\
\hline $\begin{array}{l}\text { Commercial } \\
\text { Assessment } \\
\text { Instruments }\end{array}$ & & \\
\hline $\begin{array}{l}\text { Multiple } \\
\text { Methods of } \\
\text { Assessment }\end{array}$ & & \\
\hline $\begin{array}{l}\text { Use of Student } \\
\text { Assessment } \\
\text { Data to Inform } \\
\text { Strategic } \\
\text { Planning }\end{array}$ & & \\
\hline $\begin{array}{l}\text { Use of Student } \\
\text { Assessment } \\
\text { Data to Inform } \\
\text { Programmatic } \\
\text { Changes }\end{array}$ & & \\
\hline
\end{tabular}

Faculty reported that multiple methods of assessment were a strength of the assessment plan. They identified commercial assessment instruments, on-line examinations, and portfolios as strengths of their multiple methods of assessments (see Table 238).

Program faculty also identified challenges with the assessment plan. AU program faculty reported that a formalized assessment plan had not been implemented and that decisions based on assessment data were often "rushed.” GU program faculty reported 
that the inability of the assessment plan to generate data pertinent to student achievement within sophisticated cognitive domains, a focus on individual assessments, and the implementation of on-line examinations were challenges to the assessment plan (see Table 239).

Table 238

Assessment methods: Strengths

\begin{tabular}{|l|l|c|}
\hline Assessment Plan & $\begin{array}{l}\text { Alpha } \\
\text { University } \\
\text { (AU) }\end{array}$ & $\begin{array}{l}\text { Gamma } \\
\text { University } \\
\text { (GU) }\end{array}$ \\
\hline $\begin{array}{l}\text { Multiple } \\
\text { Methods of } \\
\text { Assessment }\end{array}$ & $\mathrm{X}$ & $\mathrm{X}$ \\
\hline $\begin{array}{l}\text { Commercial } \\
\text { Assessment } \\
\text { Instruments }\end{array}$ & $\mathrm{X}$ & \\
\hline $\begin{array}{l}\text { On-Line } \\
\text { Examinations }\end{array}$ & & $\mathrm{X}$ \\
\hline Portfolio & & $\mathrm{X}$ \\
\hline
\end{tabular}

Table 239

Assessment plan: Challenges

\begin{tabular}{|l|l|l|}
\hline Assessment Plan & $\begin{array}{l}\text { Alpha } \\
\text { University } \\
\text { (AU) }\end{array}$ & $\begin{array}{l}\text { Gamma } \\
\text { University } \\
\text { (GU) }\end{array}$ \\
\hline $\begin{array}{l}\text { No Formalized } \\
\text { Assessment Plan }\end{array}$ & $\mathrm{X}$ & \\
\hline $\begin{array}{l}\text { Academic } \\
\text { Decisions Based } \\
\text { on Student }\end{array}$ & & \\
$\begin{array}{l}\text { Assessment } \\
\text { Data Was }\end{array}$ & $\mathrm{X}$ & \\
$\begin{array}{l}\text { Frequently } \\
\text { "Rushed" }\end{array}$ & & \\
\hline $\begin{array}{l}\text { Elevate } \\
\text { Cognitive }\end{array}$ & & \\
Measures & & $\mathrm{X}$ \\
\hline
\end{tabular}


Table 239

Assessment plan: Challenges

\begin{tabular}{|l|l|c|}
\hline Assessment Plan & $\begin{array}{l}\text { Alpha } \\
\text { University } \\
\text { (AU) }\end{array}$ & $\begin{array}{l}\text { Gamma } \\
\text { University } \\
\text { (GU) }\end{array}$ \\
\hline $\begin{array}{l}\text { Focus on } \\
\text { Individual } \\
\text { Assessments }\end{array}$ & & $\mathrm{X}$ \\
\hline $\begin{array}{l}\text { Implementation } \\
\text { of On-Line } \\
\text { Examinations }\end{array}$ & & $\mathrm{X}$ \\
\hline
\end{tabular}




\section{Chapter 8}

\section{Conclusions and Recommendations}

The purpose of this study was to investigate current assessment practices at the undergraduate level to determine the effectiveness of assessment plans within specific disciplines that implemented and sustained their assessment plans (Banta, 2002). The researcher examined institutions that national assessment scholars reported demonstrated these characteristics. Overall, the three selected institutions appeared to be more advanced with their assessment progress. However, as the researcher investigated assessment within individual programs, a different trend emerged. Participating program faculty at each institution were in very different stages of assessment plan implementation. For example, program faculty in the Department of Mathematics and Statistics at AU and in the secondary education program at BU did not utilize assessment data to continuously improve the program and services while psychology program faculty at GU implemented 10 improvements and nursing program faculty at AU and GU implemented three improvements each informed by assessment data.

Overall, professional accreditation requirements had little effect on the assessment plans. Program faculty from both nursing programs implemented a robust collection of assessment methods. However, the secondary education program at AU relied heavily on a few assessment measures. Therefore, the researcher found great variability among individual programs regarding their levels of assessment implementation regardless of their accreditation associations. Thus, it is possible that the perceptions held by assessment scholars who nominated case study institutions were based on their experience with one specific program and/or their external reputations. 
Credible evidence of learning. The majority of faculty across programs had developed intended learning outcomes. The majority of these intended learning outcomes were learner-centered, clear, measurable, and linked directly to the program's mission. Typically, these outcomes were reflective of the characteristics of effective statements described by Huba and Freed (2000). This practice is reflective of programs engaged in strong practice as faculty collected data that was "directly linked with the goals of the learning experience” (Jones \& Voorhees, 2002, p. 28).

The researcher did not analyze intended learning statements that were not clear. Program faculty from several programs across the institutions included such outcomes in their assessment plans. Furthermore, program faculty primarily assessed cognitive abilities. However, eighty-three percent of the outcomes represented the remember, understand, and apply domains. While faculty valued student achievement within certain cognitive domains, critical thinking skills were rarely considered within the intended learning outcomes. Only the secondary education program at AU and the psychology and nursing programs at GU included outcomes representative of the affective domain within their assessment plans. Affective outcomes represented a small number of the total outcomes included within the program assessment plans.

Accountability to internal stakeholders. Even though the researcher did not ask questions to specifically elicit the purposes of student outcomes assessment within the programs, participants and documents rarely indicated that assessment data were utilized for external accountability. Only the nursing and secondary education programs were affiliated with professional accreditation agencies. Internal stakeholders were the overwhelming users of assessment data. Program administrators and documents revealed 
that annual assessment reports submitted to central leaders were the most frequently utilized mechanism to ensure internal accountability. All three of the institutions required program faculty to submit such reports to a permanent institutional-level assessment office and/or a campus-wide assessment committee with broad representation. Faculty representing the majority of programs utilized assessment data to inform curricular revisions. Only one program did not utilize assessment data to inform program decisions.

Ongoing assessment. Across programs, faculty reported that ongoing assessment occurred on a predictable schedule. Faculty within each program utilized multiple methods of assessment at specific points of time within the curriculum. Thus, program faculty adhered to the recommendation within the Principles of Good Practice for Assessing Student Learning by recording assessment data at various points throughout the curriculum (AAHE, In Huba and Freed, 2000). However, many program representatives had challenges describing additional methods to ensure that assessment did not occur episodically.

Ongoing evaluation and improvement. Jones and Voorhees (2002) revealed that institutions engaged in strong practices of assessment "experiment with new ways to document students' mastery of competencies that supplement the traditional manuscript” (p.25). However, very few program faculty utilized any methods to ensure that the assessment plan was continuously evaluated and improved. None of the methods utilized by program faculty to evaluate and improve the assessment plan were intentional. Rather, the processes utilized by faculty within the few programs that reported conducting ongoing evaluation and improvement occurred as a result of accreditation 
review self-studies, informal faculty discussions, the collection and review of assessment data, the quantity of faculty involved in program assessment, and faculty discussions.

\section{Institutional Commitments and Resources}

Peterson, et al. (1999) reported that commitments and resources provided to faculty were important to facilitating student outcomes assessment. Central leaders at all participating institutions valued student outcomes assessment. At each institution, central leaders provided an array of resources to support the assessment initiatives. These commitments and resources typically included the items identified by Peterson, et al. (1999), Shipman (2004), Banta (2004). All three of the institutions maintained a permanent assessment office and a campus-wide assessment committee with broad representation. However, the scope of resources available from each assessment office varied. Faculty at GU had access to a much more robust and diverse pool of resources than those available at BU and AU. These resources included internal consulting services, assessment fellowships, assistance to purchase commercially available examinations, and stipends for assessment related activities. However, AU’s institutional assessment office provided unique resources such as assessment grants for faculty working on related projects. Furthermore, one department chair from GU revealed that direct presidential involvement illustrated the value of assessment held by central leaders. Thus, supporting a claim by Banta that "for outcomes assessment to succeed, the president or the provost must say it is important and provide essential support mechanisms” (p. 41).

According to Banta, assessment plan implementation requires "knowledgeable and effective leadership” (2002, p. 262). Thus, leadership characteristics of program 
assessment leaders may reveal some of the challenges facing assessment plan implementation when adequate commitments and resources are not provided to support assessment.

\section{Faculty Satisfaction}

Factors pertaining to faculty satisfaction with assessment varied across programs. Due to the differing stages of assessment plan implementation, faculty representing each program encountered their own unique strengths and challenges with assessment. However, strengths pertaining to assessment methods, resources, institutional assessment office, faculty participation, benefits of assessment, and assessment leadership emerged across multiple programs and institutions.

Faculty across the institutions reported that multiple challenging assessments in the forms of common examinations across courses and capstone/senior projects were strengths of the assessment plan. The Middle States Commission on Higher Education (2003) supports the use of multiple methods of assessment as individual evaluations that gather perfect data are rare. However, faculty also identified challenges within the assessment plan. They expressed interest in comparing their assessment data to that of peer institutions. Additionally, they reported that assessment activities increased their workload and the workload of their students. They also claimed that the assessment plan was in a constant state of flux and changes occurred too rapidly.

Faculty across the institutions identified a diverse array of resources was available to them to conduct various assessment activities. They reported that resources such as support to attend assessment related conferences and financial support to purchase commercially available examinations strengthen the assessment plan. 
Faculty across the institutions often referred to their institutional assessment office as an important source of intellectual capital. Faculty reported that they frequently utilized internal assessment consulting services to improve the assessment process. Additionally, many of the campus-wide assessment committees included representative from the institutional assessment office. Furthermore, many of the institutional assessment leaders and their staff directly assisted in the development of assessment activities or in the analysis of assessment data.

Faculty participation in assessment activities was also considered a strength of the assessment process by faculty across the institutions. Faculty identified various venues in which they were able to participate in assessment discussions. Faculty identified formal meetings and faculty retreats as important venues. However, they also noted that professional development workshops helped facilitate participation. Thus, faculty were engaged in learning about assessment as well as assessment decision making. According to the Middle States Commission on Higher Education, "the purpose of assessment is to engage a campus community collectively in a systematic and continuing process to create shared learning goals and to enhance learning” (2003, p.5).

Faculty identified various benefits of assessment across the institutions. They reported that student outcomes assessment improve retention and student achievement. Faculty also reported that data generated by assessment activities was useful in making academic decisions.

Faculty across the institutions also reported that the leadership of assessment experts strengthened the assessment process. According to Diamond (2002), "we can think of leadership in evaluation and assessment as an effort by all concerned to create sustain, 
and improve the systems we use to determine merit and worth” (p. 233). Faculty identified institutional leaders and program leaders as important to the assessment process. One faculty member appreciated her opportunities to participate in assessment activities with the institutional assessment leader.

Palomba and Banta (1999) maintained that responsibility, resources, and rewards are required to overcome faculty resistance with assessment. Overall, institutional- and program-level leaders enabled faculty to participate in assessment and provided the necessary resources to facilitate effective assessment. Faculty members from all of the programs included within this study had access to a plethora of resources and had ample opportunities to take ownership of the assessment process.

\section{Recommendations for Practice}

Some program outcomes were not clear or measurable. Additionally, many program faculty did not value critical thinking skills highly enough to regularly incorporate outcomes within the analyze, evaluate, and create domains into their assessment plans. Program faculty may have avoided the incorporation of such measures due to large class sizes and the perception held by many that such assessments required extensive time and were complicated to create. Thus, academic administrators should provide more opportunities for faculty to participate in professional development activities pertaining to articulating intended student learning outcomes and how to foster critical thinking outcomes.

Many program administrators did not identify all of the commitments and/or resources that were available. For example, only one of three program administrators reported that an institutional assessment office existed. Central leaders need to more effectively 
communicate the array of resources and commitments available. Institutional leaders should utilize diverse channels of communication in order to reach all of the faculty.

The researcher revealed that faculty had different perceptions of assessment plan implementation. In order to coordinate faculty activities related to assessment, program leaders and/or department chairs should clearly communicate information about the assessment process and facilitate more discussions about the status of their assessment plans in formal meetings. Program leaders and/or program administrators should also incorporate discussions about faculty rewards for engaging in assessment activities and information about the commitments and resources available to them to encourage participation.

Program faculty from across the intuitions reported that assessment activities required extensive amounts of time to complete. Thus, academic leaders should provide graduate assistants or students skilled in statistics to assist in data analysis and report writing.

Recommendations for future studies. Many program faculty did not incorporate ongoing evaluation and improvement into the assessment plan. Future studies should examine the reasons that faculty so frequently overlooked this attribute of the assessment plan within the sustainment and improvement phase (Banta, 2002). Findings from such studies may assist assessment leaders with ongoing evaluation and improvement of the plan.

This research study identified specific commitments and resources provided to the assessment endeavor. However, the study did not consider the perceived value of the commitments and resources to program faculty and administrators. Further research should be conducted to determine which resources faculty found most useful to furthering 
the assessment effort. This information should be utilized to guide strategic planning activities related to assessment. Additionally, an analysis of programs within the three stages of assessment as defined by Banta (2002) would assist central leaders in allocating resources that program faculty and administrators might find most helpful in sustaining the assessment plan.

Across the institutions, many faculty and administrators reported that rewarding and evaluating faculty performance based on student assessment data or involvement was a challenge. Many participants reported that rewards for assessment activities were embedded in promotion and tenure guidelines. Additionally, methods to reward faculty should be implemented to encourage participation. Future studies should investigate practices or incentives utilized to reward faculty for participating in assessment activities. 


\section{References}

Angelo, T. A. (1999). Doing assessment as if learning matters most. Retrieved January 20, 2006 from the Association of to Advance Schools of Business Website: http://www.aacsb.edu/resource_centers/assessment/Angelo-TAReprint.asp

Aloi, S. L. (2004). The use of assessment data in academic strategic planning. Unpublished doctoral dissertation, West Virginia University, Morgantown.

Banta, T. W. (2002). Building a scholarship of assessment. San Francisco: Jossey Bass.

Banta, T. W. \& Associates (2004). That second look at student work: A strategy for engaging faculty in outcome assessment. In Banta, T. W. (Ed.), Hallmarks of effective outcomes assessment. (pp. 37 - 42). San Francisco: Jossey-Bass.

Banta, T. W., Rudolph, L. B., Van Dyke, J., \& Fisher, H. S. (1996). Performance funding comes of age in Tennessee. The Journal of Higher Education, (67)1, 23-45.

Biglan, A. (1973). Relationships between subject matter in difference academic areas. Journal of Applied Psychology, (57)3, 204-213.

Burke, J. C. (2005a). The many faces of accountability. In Burke, J. C. (Ed.), Achieving accountability in higher education: Balancing public, academic, and market demands. (pp. 1-24). San Francisco: Jossey-Bass.

Burke, J. C. (2005b). Reinventing accountability: From bureaucratic rules to performance results. In Burke, J. C. (Ed.), Achieving accountability in higher education: Balancing public, academic, and market demands. (pp. 216-245). San Francisco: Jossey-Bass. 
Burke, J. C. \& Minassians, H. (2002). Performance reporting: The preferred "no cost" accountability program. Albany, NY: The Nelson A. Rockefeller Institute of Government, State University of New York.

Callan, P. M. \& Finney, J. E. (2005). State-by-state report cards for a new century. In Burke, J. C. (Ed.), Achieving accountability in higher education: Balancing public, academic, and market demands (pp. 198-215). San Francisco: Jossey-Bass.

Carnegie Foundation for the Advancement of Teaching. (2006). Classifications. Retrieved July 20, 2006 from http://www.carnegiefoundation.org/classifications/index.asp?key=782

Cashin W. E. \& Downey R. G. (1995). Disciplinary differences in what is taught and in student's perceptions of what they learn and of how they are taught. New Direction for Teaching and Learning, 64, pp. 81-91.

Coffey, A. J. \& Atkinson, P. A. (1996). Making sense of qualitative data: Complementary research strategies. Thousand Oaks, CA: Sage Publications, Inc.

Creswell, J. W. (2003). Research design: Qualitative, quantitative, and mixed methods approaches $\left(2^{\text {nd }}\right.$ ed.). Thousand Oaks, CA: Sage Publications, Inc.

Cross, K. P. \& Steadman, M. H. (1996). Classroom research: Implementing the scholarship of teaching. San Francisco: Jossey-Bass.

Diamond, R. M. (2002). A field guide to academic leadership. San Francisco: Jossey-Bass. 
Ewell, P. T. (2002). An emerging scholarship: A brief history of assessment. In Banta, T. W., Building a scholarship of assessment (pp. 3-25). San Francisco: Jossey Bass.

Gilbert, S. (1995). An online experience, Change. 27(2), 28-35.

Glesne, C. \& Peshkin, A. (1992). Becoming qualitative researchers: An introduction. White Plains, NY: Longman.

Grunwald, H. \& Peterson, M. W. (2003). Factors that promote faculty involvement in and satisfaction with institutional and classroom student assessment. Research in Higher Education, 44(2), 173-204.

Gravetter, F. J. \& Wallnau, L. B. (2004). Statistics for the behavioral sciences. Belmont, CA: Wadsworth.

Grunwald, H. \& Peterson, M. W. (2003). Factors that promote faculty involvement in and satisfaction with institutional and classroom student assessment. Research in Higher Education, (44)2, 173-205.

Huba, M. E. \& Freed, J. E. (2000). Learner centered assessment on college campuses: Shifting the focus from learning to teaching. Boston: Allyn and Bacon.

Jones, E. A. (2005). Undergraduate program-level assessment checklist. Unpublished manuscript.

Jones, E. A. \& Voorhees, R. A. (2002). Defining and assessing learning: Exploring competency-based initiatives. National Postsecondary Education Cooperative: Washington, D. C. 
Kuh, G. D. (2005). Imagine asking the client: Using student and alumni surveys for accountability in higher education. In Burke, J. C. (Ed.), Achieving accountability in higher education: Balancing public, academic, and market demands (pp.148172). San Francisco: Jossey Bass.

Lazerson, M., Wagenar, U., \& Shumanis, N. (2000). What makes a revolution? Change, 32(3), 12-20.

Maki, P. L., (2004). Assessing for learning: Building a sustainable commitment across the institution. Sterling, VA: Stylus Publishing.

Merriam, S. B. (2001). Qualitative research and case study applications in education. San Francisco: Jossey Bass.

Middle States Commission on Higher Education. (2002). Characteristics of excellence in higher education: Eligibility requirements and standards for accreditation (11 ${ }^{\text {th }}$ ed.). Philadelphia, PA: Middle States Commission on Higher Education. Middle States Commission on Higher Education. (2003). Student learning assessment: Options and resources. Philadelphia, PA: Middle States Commission on Higher Education.

Miller, M. T., McCormack, T. F., and Pope, M. L. (2000). Sharing authority in higher education: Faculty involvement in governance. San Jose State University, San Jose, CA. 
National Center for Higher Education Management Systems. (2002a).

Finance: State and local public higher education support per full-time equivalent student. Retrieved June 1, 2005 from

http://www.higheredinfo.org/dbrowser/index.php?submeasure=67\&year=2001\&l

evel $=$ nation $\&$ mode $=$ data $\&$ state $=0$

National Center for Higher Education Management Systems. (2002b).

Finance: Federal Pell Grants. Retrieved August 1, 2004 from

http://www.higheredinfo.org/dbrowser/index.php?submeasure=196\&year=2001\&

level $=\&$ mode $=$ policy $\&$ state $=0$

National Center for Higher Education Management Systems. (2002c).

Affordability: State grant aid targeted to low-income families as a percent fo

federal Pell grant aid. Retrieved June 1, 2005 from

http://www.higheredinfo.org/dbrowser/index.php?year=2001\&level=nation\&mod $\mathrm{e}=$ data $\&$ state $=0 \&$ submeasure $=124$

Patton, M. Q. (2002). Qualitative research and evaluation methods. Thousand Oaks, CA: Sage Publications, Inc.

Peterson, M. W. \& Einarson, M. K. (2001). What are colleges doing about student assessment? Does it make a difference? Journal of Higher Education, 72 (6), 629-669.

Peterson, M. W., Einarson, M. L., Augustine, C. H., \& Vaughn, D. S. (1999). Institutional support for student assessment: Methodology and results of a national survey. Stanford, CA: National Center for Postsecondary Improvement. 
Peterson, M. W. \& Vaughan, D. S. (2002). Promoting academic improvement: organizational and administrative dynamics that support student assessment. In Banta, T. W. Building a scholarship of assessment (pp. 26-46). San Francisco: Jossey-Bass.

Palomba, C. A. \& Banta, T. W. (1999). Assessment essentials: Planning, implementing, and improving assessment in higher education ( $1^{\text {st }}$ ed.). San Francisco: Jossey - Bass.

Profit, J. R. (1979). The federal connection for accreditation. The Journal of Higher Education, (50)2, 145-157.

Ratliff, J. L., Lubinescu, E. S. \& Gaffney, M. A. (Eds.). (2001). How accreditation influences assessment. San Francisco: Jossey-Bass.

Ruppert, S. S. (1996). The politics of remedy: State legislative views on higher education. Washington D. C.: National Education Association.

Shipman, D. G. (2004). Examining internal programmatic assessments implemented by physician assistant educators. Unpublished doctoral dissertation, West Virginia University, Morgantown.

Smart, J. C. \& Elton, C. F. (1982). Validation of the Biglan model. Research in Higher Education, (17)3, 213-226.

Suskie, L. (2004). Assessing student learning: A common sense guide. Boston: Anker Publishing Company, Inc.

Terenzini, P. T. (1989). Assessment with open eyes: Pitfalls in studying student outcomes. The Journal of Higher Education (60)6, 644-664. 
United States Department of Education. (n.d.) Financial aid for postsecondary students: Accreditation in the United States. Retrieved August 1, 2004 from http://www.ed.gov/admins/finaid/accred/accreditation_pg2.html\#U.S.

van Vught, F. A. (1994). Intrinsic and extrinsic aspects of quality assessment in higher education. In Westerheijden, D. F., Brennan, J., and Massen, P. A. M. (eds.), Changing contexts of quality assessment: Recent trends in Western European higher education. Utrecht: Lemma.

Zumeta, W. M. (2005). Accountability and the private sector: State and federal perspectives. In Burke, J. C. (Ed.), Achieving accountability in higher education: Balancing public, academic, and market demands (pp. 25-54). San Francisco: Jossey-Bass. 


\section{Appendix A}

Letter Requesting Nominations for Institutions that Have Assessment Plans Within the Sustainment and Improvement Phase

Christopher A. McCullough

College of Human Resources and Education

Department of Educational Leadership Studies

P. O. Box 6122

Morgantown, WV 26505-6122

[Recipient's Name]

[Recipent's Institution]

[Recipient's Address]

Dear XXXX,

I am currently a doctoral student studying higher education administration at West Virginia University. My doctoral dissertation advisor is Dr. Elizabeth Jones. I am seeking your assistance in selecting institutions for case study analyses. The purpose of this study is to investigate current assessment practices at the undergraduate program level. The study will determine the effectiveness of assessment plans within specific disciplines (Mathematics, Biology, English, Psychology, Civil Engineering, Nursing, Accounting, and Secondary Education) at institutions that have implemented and sustained their assessment plans. The study will also identify the degree to which related institutional commitments and resources are provided to support the assessment process. Faculty satisfaction with the assessment plan will also be examined. Dr. Trudy Banta (2002) has identified characteristics of effective practice for colleges and universities who are in the sustainment and improvement phase of their assessment plans. I am requesting your assistance to identify a sample of institutions of higher education, excluding community colleges, whose assessment plans demonstrate Banta’s characteristics:

produces credible evidence of learning, ensures that assessment data are used continuously to improve programs and services, provides a vehicle for demonstrating accountability to stakeholders within and outside the institution,

encompasses the expectation that outcomes assessment will be ongoing, not episodic, and incorporates ongoing evaluation and improvement of the assessment process itself (Banta, 2002, p. Building a Scholarship of Assessment. San Francisco: Jossey Bass). 
Please consider these attributes of assessment and nominate ten colleges or universities (excluding community colleges) in the United States that you believe exemplify these characteristics. Your nominations will assist me in identifying potential case studies. The research I will be conducting, based on your input, is for the fulfillment of my dissertation requirement. Your responses will be kept confidential. When the lists of institutions are returned via e-mail all names and indicators will be removed and only the commonly identified institutions will be studied. If you would like, I will send you an executive summary of the research findings.

Thank you,

Christopher A. McCullough

Doctoral Student

West Virginia University 


\section{Appendix B}

Nomination Form for National Assessment Leaders

Nominations of Colleges and Universities in the Sustainment and Improvement Phase (excluding community colleges)

1.

2.

3.

4.

5.

6.

7.

8.

9.

10.

Yes, I would like an executive summary of the research findings.

No, I would not like an executive summary of the research findings.

Please return to Christopher A. McCullough by August 20, 2006. If you have questions, please contact me at CAMcCullough@mail.wvu.edu.

Thank you for your participation! 


\section{Appendix C}

Letter to Request Institutional Site Approval

(on WVU letterhead)

Date

Address

Dear Dr. XXXX,

Thank you for your assistance in securing permission for me to visit your institution as part of my dissertation study on student outcomes assessment. This letter will describe the purposes of my visit and requirements to attain written approval to conduct this research on your campus.

I am requesting your permission to interview approximately \#\# individuals on your campus who are assessment leaders, department chairs/program coordinators, and faculty members. I will also be collecting pertinent documents. These documents will include assessment plans, reports of assessment results, and minutes from assessment meetings. I would like to visit your institution sometime during the Fall 2006 semester.

The purpose of my research project is to investigate current assessment practices at the undergraduate program level. This study will determine the effectiveness of assessment plans within specific disciplines at institutions that have implemented and sustained their assessment plans. The study will also identify the degree to which related institutional commitments and resources are provided to support assessment the assessment process. Faculty satisfaction with the assessment plan will examined.

I would appreciate your approval for me to conduct my research at your university and interview faculty. If you approve, I am required to submit a letter from you indicating your willingness to participate in this research study in order to request Human Subjects Exemption Review from West Virginia University’s Institutional Review Board. Please find a letter template attached that you may alter as you find fit. This letter must appear on your institutional letterhead. Please send this letter to me by (date) so that I may continue with my study. Interviews will be scheduled on your campus immediately following IRB approval.

The data collected in this study will be used for the dissertation requirement of doctoral degree program. The data collected will be confidential and the participants will remain anonymous. All participants will be informed that their participation is completely voluntary. Participants do not have to respond to every question. 
I will be happy to share an executive study of the research findings with you or any participants. If you have any questions please contact me at 304-685-3530 or by e-mail at CAMcCullough@mail.wvu.edu.

Thank you,

Christopher A. McCullough

Doctoral Student

West Virginia University 


\section{Appendix D}

Letter Granting Institutional Agreement to Participate

(on letterhead from case institution)

Date

Mr. Christopher A. McCullough

West Virginia University

P. O. Box 6122

Morgantown, WV 26505

Dear Chris,

I approve of your doctoral dissertation research at (name of institution). I will be happy to assist you in contacting department chairs/program coordinators of the programs that pertain to your study. Additionally, I will assist you in collecting documents pertinent to assessment meeting minutes, assessment plans, and assessment results.

You can schedule interviews with myself, department chairs/program coordinators included within the scope of your research, and faculty members from the relevant academic programs. I understand that interviews will last approximately 60 minutes and will occur in the Fall semester of 2006.

We look forward to seeing you on campus.

Thank you,

Dr. XXXX

Title 


\section{Appendix E}

Letter Requesting Department Chair/Program Coordinator Information

(on WVU letterhead)

Date

Address

Dear Dr. XXXX,

Thank you for agreeing to participate in this study. I am requesting that you identify the department chairs and/or program coordinators of the \{Mathematics, Civil Engineering, Biology, Nursing, English, Accounting, Psychology, Secondary Education \} programs. Interviews will be conducted to gather information pertaining to the undergraduate program assessment plans. Interviews will require approximately 60 minutes. Interviews will be scheduled during the months of September and October of 2006.

I also would like to invite you to participate in this study. I am interviewing the institutional assessment leader and department chairs/program coordinators to ascertain information about the undergraduate assessment plan of the pertinent program. Und ergraduate programs under study include \{Mathematics, Civil Engineering, Biology, Nursing, English, Accounting, Psychology, Secondary Education\}. Interviews will last approximately 60 minutes. Your participation will be greatly appreciated.

The data collected in this study will be used for the dissertation requirement of doctoral degree program. The data collected will be confidential and the participants will remain anonymous. All participants will be informed that their participation is completely voluntary. Participants do not have to respond to every question. Please provide the names of the department chairs/program coordinators on the enclosed form and return it to me by September 1, 2006.

Thank you,

Christopher A. McCullough

Doctoral Student

West Virginia University 


\section{Appendix F}

Institutional Assessment Leader Disclosure of Department Chairs/Program Coordinators Form

(on letterhead from case institution)

Date

Mr. Christopher A. McCullough

West Virginia University

P. O. Box 6122

Morgantown, WV 26505

\section{Dear Chris,}

The following department chairs and/or program coordinators represent the programs we offer that are pertinent to your study.

Program Coordinator/ Department

Department Chair 


\section{Appendix G}

Department Chair/Program Coordinator Participation Letter Requesting Faculty Nominations

(on WVU letterhead)

Date

Address

\section{Dear Dr. XXXX,}

Dr. XXXX at (name of institution) has agreed to participate in a study that will investigate current assessment practices at the program level. Additionally, this study will determine the effectiveness of assessment plans within specific disciplines at institutions that have implemented and sustained their assessment plans. The study will also identify the degree to which related institutional commitments and resources are provided to support assessment the assessment process. Faculty satisfaction with the assessment plan will examined.

I am requesting that you nominate three faculty members within (program) to participate in this study. The participants will be interviewed so that I may gather faculty satisfaction information with the undergraduate program assessment plan. Interviews will require approximately 60 minutes. Interviews will be scheduled during the months of September and October of 2006.

I also would like to invite you to participate in this study. I am interviewing the institutional assessment leader and department chairs/program coordinators to ascertain information about the undergraduate assessment plan of the pertinent program. Interviews will last approximately 60 minutes. Your participation will be greatly appreciated.

During the onsite visit, I will also be collecting documents. These documents will include the assessment plan, assessment meeting minutes, and assessment reports. Your assistance in ascertaining these documents is greatly appreciated.

The data collected in this study will be used for the dissertation requirement of doctoral degree program. The data collected will be confidential and the participants will remain anonymous. All participants will be informed that their participation is completely voluntary. Participants do not have to respond to every question.

I will be happy to share an executive study of the research findings with you or any participants. If you have any questions please contact me at 304-685-3530 or by e-mail 
at CAMcCullough@mail.wvu.edu. Please return the included nomination form to me by September 10, 2006.

Thank you,

Christopher A. McCullough

Doctoral Student

West Virginia University 


\section{Appendix $\mathbf{H}$}

\section{Department Chair/Program Coordinator Form for Faculty Nominations}

(on letterhead from case institution)

Date

Mr. Christopher A. McCullough

West Virginia University

P. O. Box 6122

Morgantown, WV 26505

Dear Chris,

I nominate the following faculty members to participate in your study.

Faculty Member Name Department

Thank you,

Dr. XXXX

Title 


\section{Appendix I}

\section{Letter Requesting Faculty Participation}

(on WVU letterhead)

Date

Address

Dear Dr. XXXX,

Dr. (name of contact) at (name of institution) has agreed to participate in a study that will investigate current assessment practices at the program level. Additionally, this study will determine the effectiveness of assessment plans within specific disciplines at institutions that have implemented and sustained their assessment plans. The study will also identify the degree to which related institutional commitments and resources are provided to support assessment the assessment process. Faculty satisfaction with the assessment plan will examined.

You have been nominated by your \{department chair/program coordinator to participate in this study and would like to interview you. The purpose of the interview is to determine your satisfaction information with the undergraduate program assessment plan and its implementation. Interviews will take approximately 60 minutes and will be scheduled during the months of September and October of 2006.

The data collected in this study will be used for the dissertation requirement of doctoral degree program. The data collected will be confidential and the participants will remain anonymous. All participants will be informed that their participation is completely voluntary. You do not have to respond to each question.

I will be happy to share an executive study of the research findings with you or any participants. If you have any questions please contact me at 304-685-3530 or by e-mail at CAMcCullough@mail.wvu.edu. Please contact me by September 10, 2006. Your participation in this study is greatly appreciated.

Thank you,

Christopher A. McCullough

Doctoral Student

West Virginia University 


\section{Appendix $\mathbf{J}$}

Institutional Assessment Leaders/Department Chairs/Program Coordinators Interview Protocol

Assessment Plan Effectiveness at the Sustainment and Improvement Phase

Good morning, (afternoon, evening). Thank you for agreeing to participate in my study. The goal of my research is to investigate current assessment practices at the undergraduate program level. This study will determine the effectiveness of assessment plans within specific disciplines at institutions that have implemented and sustained their assessment plans. The study will also identify the degree to which related institutional commitments and resources are provided to support assessment the assessment process. Faculty satisfaction with the assessment plan will examined. Today I would like to ask you a series of questions regarding \{Mathematics, Biology, English, Psychology, Civil Engineering, Nursing, Accounting, or Secondary Education\}.

The information gathered here will be used for my doctoral dissertation. I want to point out several things to you before we start:

Your participation is entirely voluntary and you do not have to respond to every item or question;

Your responses will remain anonymous and confidentiality will be maintained; and Your job status will not be affected by refusing to participate or by withdrawing from this study.

Thank you for agreeing to participate in this study.

Subject's Role

Undergraduate Program

\section{Demographic Items}

What is your rank?

How long have been in your current position?

Do you currently hold tenure?

How long have you worked in higher education?

How knowledgeable do you feel about student assessment?

How many full-time faculty are teaching in your program?

How many part-time faculty are teaching in your program? Are your students primarily enrolled full-time or part-time? 
What is your average class size for individual courses?

Are any of your degrees in education or a related field?

How many assessment conferences have you attended in the past two years?

How many publications pertaining to student assessment have you authored in the past two years?

How many conferences have you presented your assessment results?

When (year) did you begin your assessment initative for your program?

\section{Assessment Plan Effectiveness Items}

What are your learning outcomes for the Mathematics, Biology, English, Psychology, Civil Engineering, Nursing, Accounting, or Secondary Education $\}$ program?

What assessment methods do you use to measure student achievement of the program learning outcomes?

How does the assessment plan produce credible evidence of student learning?

Where and how often do your program faculty discuss assessment results for your undergraduate students?

How is assessment data used to continuously improve programs and services?

How does the assessment plan provide a vehicle for demonstrating accountability to internal stakeholders?

How does the assessment plan encompass the expectation that outcomes assessment will be ongoing and not episodic?

How does the assessment plan incorporate ongoing evaluation and improvement of the assessment process itself?

\section{Resources}

What types of resources are allocated to your department from the institution for assessment activities?

Is a comprehensive student assessment information database available?

Are faculty workshops on student assessment offered? If yes, how frequently? 
Is there support for faculty to attend professional conferences on student assessment? If yes, what types and quantities of support are available?

Are there internal or external consultant services for faculty on the use of student assessment in course design or instruction? If yes, how accessible are the consultants?

Is there assistance for faculty (paid leaves, stipends, mini grants or course reduction? If yes, what types of assistance and what quantities?

Are there student assessment workshops for deans, department chairs, and other academic administrators? If yes, how frequently?

Are there student assessment workshops for student affairs staff and administrators? If yes, how frequently?

Is there an annual budget allocated to academic units to support student assessment? If yes, how large is the budget for each program?

Is there an institutional assessment office? Who oversees this office?

Is there a program assessment office? Who oversees this office?

Is there an office charged with coordinating data-gathering initiatives such as surveys and standardized tests?

\section{Commitments}

Is the evidence of student assessment data utilized in the evaluation and rewarding of faculty currently employed? If yes, how is student assessment data utilized in the evaluation and rewarding of currently employed faculty?

Is student assessment expertise considered in the hiring process for new faculty? If yes, how is student expertise in the hiring process considered?

Are there policies and/or practices that facilitate the communication of student assessment purposes?

Are there policies that promote the involvement of student affairs personnel and students in assessment efforts?

Is there executive level support for student assessment?

How would you describe the culture of assessment within your \{institution, program\}?

Have guiding principles for assessment been articulated? (Request a copy) 
Is there a campus wide assessment committee with broad representation?

Has outcomes assessment been incorporated into the scholarship of teaching in promotion and tenure guidelines?

\section{Satisfaction Items}

How would you describe your satisfaction with your department's/program's approach to student assessment (content and methods)?

Why are you satisfied or unsatisfied with your department's/program's approach to student assessment?

How would you describe your satisfaction with your department's/program’s plan?

Why are you satisfied or unsatisfied with your department's/program's plan or policy on student assessment?

How would you describe your satisfaction with the implementation of your current assessment plan?

Why are you satisfied or unsatisfied with the implementation of your current assessment plan?

How would you describe your satisfaction with the opportunities you have to participate in policy making about student assessment?

Why are you satisfied or unsatisfied with the opportunities you have to participate in policy making about student assessment?

How would you describe your satisfaction with the administrative leadership support for student assessment?

Why are you satisfied or unsatisfied with the administrative leadership support for student assessment? 


\title{
Appendix K
}

\author{
Faculty Protocol
}

\section{Faculty Satisfaction Interview Protocol}

Good morning, (afternoon, evening). Thank you for agreeing to participate in my study. The goal of my research is to investigate current assessment practices at the institutional and programmatic levels. This study will determine the effectiveness of assessment plans within specific disciplines at institutions that have implemented and susta ined their assessment plans. The study will also identify the degree to which related institutional commitments and resources are provided to support assessment the assessment process. Faculty satisfaction with the assessment plan will examined.

The information gathered here will be used for my doctoral dissertation. I want to point out several things to you before we start:

Your participation is entirely voluntary and you do not have to respond to every item or question;

Your responses will remain anonymous and confidentiality will be maintained; and Your job status will not be affected by refusing to participate or by withdrawing from this study.

Thank you for agreeing to participate in this study.

\section{Demographic Items}

How long have been in your current position?

Do you currently hold tenure?

How long have you worked in higher education?

How knowledgeable do you feel about student assessment?

How many full-time faculty are teaching in your program?

How many part-time faculty are teaching in your program?

Are your students primarily enrolled full-time or part-time?

What is your average class size for individual courses?

Are any of your degrees in education or a related field?

How many assessment conferences have you attended in the past two years? 
How many publications pertaining to student assessment have you authored in the past two years?

How many conferences have you presented your assessment results?

\section{Faculty Satisfaction Items}

How would you describe your satisfaction with your department's/program's approach to student assessment (content and methods)?

Why are you satisfied or unsatisfied with your department's/program's approach to student assessment?

How would you describe your satisfaction with your department's/program's plan or policy on student assessment?

Why are you satisfied or unsatisfied with your department's/program's plan for student assessment?

How would you describe your satisfaction with the implementation of your current assessment plan?

Why are you satisfied or unsatisfied with the implementation of your current assessment plan?

How would you describe your satisfaction with the opportunities you have to participate in policy making about student assessment?

Why are you satisfied or unsatisfied with the opportunities you have to participate in policy making about student assessment?

How would you describe your satisfaction with the central leadership support for student assessment?

Why are you satisfied or unsatisfied with the administrative leadership support for student assessment?

How would you describe your satisfaction with program faculty leadership support for student assessment?

Why are you satisfied or unsatisfied with the faculty leadership support of student assessment?

How would you describe your satisfaction with professional development for student assessment? 
Why are you satisfied or unsatisfied with professional development for student assessment?

How would you describe your satisfaction with evaluations and rewards based on student assessment data or involvement?

Why are you satisfied or unsatisfied with evaluations and rewards based on student assessment data or involvement?

How would you describe your satisfaction with the use of student assessment data in making academic decisions?

Why are you satisfied or unsatisfied with the use of student assessment data in making academic decisions?

How would you describe your satisfaction with the impact student assessment has had on your program?

Why are you satisfied or unsatisfied with the impact student assessment has had on your program? 


\section{Appendix L}

Assessment Plan Effectiveness at the Sustainment and Improvement Phase Document Analysis Protocol

Please check the appropriate yes/no response. For any question you select 'yes' as an appropriate response, please provide evidence of the means by which the goal of the assessment plan is accomplished (see the follow-up question for appropriate items).

Are the intended learning outcomes articulated effectively?

a. Are learning outcomes are identified for the program? Yes _ No

Are the learning outcomes are clear? Yes No

Are the learning outcomes are measurable? Yes No

Are the learning outcomes span multiple learning domains? Yes No

Are the learning outcomes are student-focused rather than professor-focused? Yes No

Do the learning outcomes clearly link to the program's mission statement? Yes No

Does the assessment plan produce credible evidence of student learning? Yes No

If yes, how does the assessment plan produce credible evidence of student learning?

Identify the assessment measures utilized to collect credible evidence of student learning.

Is assessment data being used continuously to improve programs and services? Yes No

If yes, how is assessment data used to continuously improve programs and services? 
Does the assessment plan provide a vehicle for demonstrating accountability to internal stakeholders?

Yes $\quad$ No

If yes, how does the assessment plan provide a vehicle for demonstrating accountability to internal stakeholders?

Does the assessment plan encompass the expectation that outcomes assessment will be ongoing and not episodic?

Yes $\quad$ No

If yes, how does the assessment plan encompass the expectation that outcomes assessment will be ongoing and not episodic?

Does the assessment plan incorporate ongoing evaluation and improvement of the assessment process itself?

Yes $\quad$ No

If yes, how does the assessment plan incorporate ongoing evaluation and improvement of the assessment process itself?

Are any institutional commitments and resources provided to the assessment endeavor? Yes No

If yes, what type and what quantity (when appropriate) of institutional commitme nts and resources are provided to the assessment endeavor? 


\section{Appendix M}

Assessment Results

Document Analysis Protocol

Please check the appropriate yes/no response. For any question you select 'yes' as an appropriate response, please provide evidence of the means by which the goal of the assessment plan is accomplished (see the follow-up question for appropriate items).

1. Are major assessment results reported that relate to programmatic student learning outcomes? Yes No

2. Are the assessment results are clear? Yes No

a. If yes, what assessment methods were used?

3. The analysis of data is appropriate given the types of assessment methods utilized? Yes No

a. If yes, how was data analyzed?

4. Information from the assessment results is shared with multiple constituents? Yes No

a. If yes, with what audiences is assessment data shared?

5. The assessment results indicate the extent to which learning outcomes have been achieved? Yes No

a. If yes, how do the assessment results indicate the extent to which learning outcomes have been achieved?

6. A discussion regarding how the assessment results are used is reported? Yes No

a. If yes, what evidence is cited that suggests how the assessment results are used?

b. If yes, where are the assessment results discussed?

c. Provide some examples of the discussions.

7. The intended learning outcomes are changed or revised based upon assessment results? Yes No

a. If yes, how are the intended learning outcomes changed or revised? 
8. Is there evidence that suggests the assessment results are used by faculty to improve student learning? Yes No

a. If yes, what evidence is cited that suggests faculty use the assessment results to improve student learning?

9. Is there evidence that suggests faculty report making changes in their courses, services, or curriculum based upon the results? Yes No

a. If yes, what changes are being made to courses, services, and/or curriculum based on assessment results?

10. Is there evidence that suggests faculty use the assessment results in strategic planning? Yes No

a. If yes, what evidence is cited that suggests faculty use the assessment results in strategic planning?

11. Is there evidence that supports that assessment will be ongoing and continuous over time?

a. If yes, what evidence is cited that supports that assessment will be ongoing and continuous over time?

12. Is there evidence that suggests that the assessment plan incorporates ongoing evaluation and improvement of the assessment process itself?

a. If yes, what evidence is cited that suggests that the assessment plan incorporates ongoing evaluation and improvement of the assessment process itself? 


\section{Appendix N}

\section{Assessment Meeting Minutes Document Analysis Protocol}

Please check the appropriate yes/no response. For any question you select 'yes' as an appropriate response, please provide evidence of the means by which the goal of the assessment plan is accomplished (see the follow-up question).

Are intended learning outcomes addressed? Yes No

If yes, what are the major themes of the discussion about intended learning outcomes?

Is there evidence that suggests the assessment plan produces credible evidence of student learning? Yes No

a. If yes, what evidence is cited to support the ability of the assessment plan to produce credible evidence of learning?

b. If yes, is there evidence to support the continuous use of assessment data to improve programs and services?

Is there evidence that suggests that assessment data is used continuously to improve programs and services?

If yes, what evidence is cited to support the continuous use of assessment data to improve programs and services?

Is there evidence that suggests the assessment plan provides a vehicle for demonstrating accountability to internal and external stakeholders?

If yes, what evidence is cited to support the ability of the assessment plan to provide a vehicle for demonstrating accountability to internal stakeholders?

b. If yes, what evidence is cited to support the ability of the assessment plan to provide a vehicle for demonstrating accountability to external stakeholders?

Is there evidence that suggests that the assessment plan will be ongoing and not episodic? If yes, what evidence is cited to support the ability of the assessment plan to be ongoing and not episodic?

Is there evidence that suggests the assessment plan incorporates ongoing evaluation and improvement of the assessment process itself? 
If yes, what evidence is cited that suggests that the assessment plan incorporates ongoing evaluation and improvement of the assessment process itself?

Is there evidence that suggests that institutional commitments and resources are provided to the assessment endeavor?

If yes, what evidence is cited that suggests that institutional commitments and resources are provided to the assessment endeavor?

Are major assessment results discussed? Yes _ No

If yes, what are the major themes of the discussion about assessment results?

What stakeholders are addressed in the discussions?

Is there evidence that suggests faculty use the results of strategic planning? Yes No

If yes, what evidence that suggests faculty use the results of strategic planning is cited? 
Letter to Request Institutional Site Approval for Pilot Study

(on WVU letterhead)

Date

Address

Dear Dr. XXXX,

Thank you for your assistance in securing permission for me to visit your institution as part of my dissertation study on student outcomes assessment. This letter will describe the purposes of my visit and requirements to attain written approval to conduct this research on your campus.

I am requesting your permission to interview approximately four individuals on your campus who are assessment leaders, department chairs/program coordinators, and faculty members. I will also be collecting pertinent documents including assessment plans, reports of assessment results, and minutes from assessment meetings.

The purpose of my research project is to investigate current assessment practices at the program level. This study will determine the effectiveness of assessment plans within specific disciplines at institutions that have implemented and sustained their assessment plans. The study will also identify the degree to which related institutional commitments and resources are provided to support assessment the assessment process. Faculty satisfaction with the assessment plan and its implementation will examined. Your institution will provide the setting necessary to conduct an effective pilot study. During the interview, I will be soliciting your feedback about the clarity of questions and ask you to critique the cover letter.

I am required to submit a letter from you indicating your willingness to participate in this research study in order to request Human Subjects Exemption Review from West Virginia University's Institutional Review Board. Please find a letter template attached that you may alter as you find fit. This letter must appear on your institutional letterhead. Please send this letter to me by (date) so that I may continue with my study. Interviews will be scheduled on your campus immediately following IRB approval.

The data collected in this study will be used for the dissertation requirement of doctoral degree program. The data collected will be confidential and the participants will remain anonymous. All participants will be informed that their participation is completely voluntary. Participants do not have to answer every question. 


\section{Appendix 0}

Letter to Request Institutional Site Approval for Pilot Study

(on WVU letterhead)

Date

Address

\section{Dear Dr. XXXX,}

Thank you for your assistance in securing permission for me to visit your institution as part of my dissertation study on student outcomes assessment. This letter will describe the purposes of my visit and requirements to attain written approval to conduct this research on your campus.

I am requesting your permission to interview approximately four individuals on your campus who are assessment leaders, department chairs/program coordinators, and faculty members. I will also be collecting pertinent documents including assessment plans, reports of assessment results, and minutes from assessment meetings.

The purpose of my research project is to investigate current assessment practices at the program level. This study will determine the effectiveness of assessment plans within specific disciplines at institutions that have implemented and sustained their assessment plans. The study will also identify the degree to which related institutional commitments and resources are provided to support assessment the assessment process. Faculty satisfaction with the assessment plan and its implementation will examined. Your institution will provide the setting necessary to conduct an effective pilot study. During the interview, I will be soliciting your feedback about the clarity of questions and ask you to critique the cover letter.

I am required to submit a letter from you indicating your willingness to participate in this research study in order to request Human Subjects Exemption Review from West Virginia University's Institutional Review Board. Please find a letter template attached that you may alter as you find fit. This letter must appear on your institutional letterhead. Please send this letter to me by (date) so that I may continue with my study. Interviews will be scheduled on your campus immediately following IRB approval.

The data collected in this study will be used for the dissertation requirement of doctoral degree program. The data collected will be confidential and the participants will remain anonymous. All participants will be informed that their participation is completely voluntary. Participants do not have to answer every question. 
I will be happy to share an executive study of the research findings with you or any participants. If you have any questions please contact me at 304-685-3530 or by e-mail at CAMcCullough@mail.wvu.edu.

Thank you,

Christopher A. McCullough

Doctoral Student

West Virginia University 


\section{Appendix P}

\section{Pilot Study Interview Protocol}

Good morning, (afternoon, evening). Thank you for agreeing to participate in my study. The goal of my research is to investigate current assessment practices at the institutional and programmatic levels. This study will determine the effectiveness of assessment plans within specific disciplines at institutions that have implemented and sustained their assessment plans for a minimum of five years. The study will also identify the degree to which related institutional commitments and resources are provided to support assessment the assessment process. Faculty satisfaction with the assessment plan will examined.

The information gathered here will be used for my doctoral dissertation. I want to point out several things to you before we start:

your participation is entirely voluntary and you do not have to respond to every item or question;

your responses will remain anonymous and confidentiality will be maintained; and your job status will not be affected by refusing to participate or by withdrawing from this study.

Thank you for agreeing to participate in this study.

Time Required

1. What is your role \{institutional assessment leader, department chair/program coordinator, faculty\}?

2. What is your rank?

3. Do you currently hold tenure?

How long have you been at this institution?

At what capacity do you work with the assessment endeavor on campus?

Did any of the interview questions seem unclear?

If yes, what impeded the clarity of the question?

Did you find it difficult to respond to any of the items?

Do you have any comments about the organization of the items?

Do you think there are any important questions missing? 
At what capacity do you work with the assessment endeavor on campus?

Do you have any suggestions to improve this study?

Is the cover letter clear and concise?

Does the cover letter clearly explain the purpose of the interviews? 